NADJA KAROLINA LEONEL WIZIACK

\title{
DESENVOLVIMENTO DE SISTEMAS MULTISSENSORIAIS HIIBRIDOS, LÍNGUA E NARIZES ELETRÔNICOS PARA A AVALIAÇÃO DE COMBUSTÍVEIS
}

Tese de Doutorado apresentada à Escola

Politécnica da Universidade de São Paulo para a obtenção do Título de Doutor em Engenharia Elétrica. 


\section{DESENVOLVIMENTO DE SISTEMAS MULTISSENSORIAIS HÍBRIDOS, LÍNGUA E NARIZES ELETRÔNICOS PARA A AVALIAÇÃO DE COMBUSTÍVEIS}

Tese de Doutorado apresentada à Escola Politécnica da Universidade de São Paulo para a obtenção do Título de Doutor em Engenharia Elétrica.

Área de Concentração:

Engenharia Elétrica

Orientador:

Prof. Livre - Docente

Fernando Josepetti Fonseca 
Este exemplar foi revisado e alterado em relação à versão original, sob
responsabilidade única do autor e com a anuência de seu orientador.

São Paulo, de setembro de 2010.

Assinatura do autor

Assinatura do orientador

FICHA CATALOGRÁFICA

Wiziack, Nadja Karolina Leonel

Desenvolvimento de sistemas multissensoriais híbridos, língua e narizes eletrônicos para a avaliação de combustíveis / N.K.L. Wiziack. -- ed.rev. --São Paulo, 2010.

$159 \mathrm{p}$.

Tese (Doutorado) - Escola Politécnica da Universidade de São Paulo. Departamento de Engenharia de Sistemas Eletrônicos.

1. Sistemas híbridos 2 . Sensores químicos 3 . Combustíveis (Avaliação) 4. Língua eletrônica 5 Narizes eletrônicos I. Universidade de São Paulo. Escola Politécnica. Departamento de Engenharia de Sistemas Eletrônicos II. t. 
Dedico este trabalho aos meus queridos pais Edson e lolanda e aos meus avós Mercedes, Estanislau, Anaide e Nestor. 


\section{AGRADECIMENTOS}

Primeiramente agradeço aos meus pais Edson Wiziack e lolanda Leonel Wiziack pelo apoio, amor e compreensão em todos os momentos da minha vida.

Ao orientador Prof. Dr. Fernando Josepetti Fonseca meus sinceros agradecimentos pela oportunidade, confiança e incentivo.

Aos meus irmãos Edson Jr., Erika e Stella pela amizade e companheirismo.

A todos os meus familiares, em especial ao meu tio Adilson Leonel dos Santos pelo apoio sempre.

Ao meu companheiro Tommaso Novellino pelo grande carinho, compreensão e incentivo durante grande parte desta caminhada.

Ao Prof. Dr. Luiz Henrique Caparelli Mattoso pelo apoio e suporte através de equipamentos indispensáveis para a concretização do trabalho.

Ao Prof. Corrado Di Natale pelos ensinamentos, disponibilização de materiais e dispositivos, imensa contribuição ao trabalho e oportunidade de desenvolvimento de parte da pesquisa no Laboratorio di Sensori - Departamento de engenharia da Università Degli Studi di Roma - Tor Vergata.

Ao Prof. Eugenio Martinelli pelos ensinamentos e contribuição ao trabalho.

Aos Professores Arnaldo D'Amico e Roberto Paolesse pelo suporte através da disponibilização de equipamentos do laboratório de sensores e de química da Università di Roma - Tor Vergata.

Aos professores do grupo GEM: Adnei M. de Andrade e Ely Antônio Dirani pela dedicação e contribuição para o fortalecimento do grupo. 
Aos colegas do grupo di Sensori, Alex Catini, Francesca Dini, Giulia Mantini e Marco Santonico pela contribuição ao trabalho, transmissão de conhecimento e paciência durante o início do meu período em Roma.

Aos amigos Prof. Jadis de Santis Junior e Prof. Dr. João de Mendonça Naime pelos ensinamentos, contribuição e incentivo desde o período inicial dos meus estudos acadêmicos.

À Dra. Alessandra Alves Correia Forner pela elaboração de filmes eletrodepositados.

Aos amigos e aos colegas do grupo GEM e da Universidade de Roma: Alexandre, Camila, Davide, Emerson, Federica, Francesco, Giuseppe, Gerson, Guilherme, Helena, John, Larisa, Lorenzo, Luca, Manuela, Marco, Marco, Rose, e Sara pela contribuição ao trabalho e por todos os momentos que tornaram o dia a dia mais alegre durante a realização desta pesquisa.

À Francesca Dini e seus pais pelo apoio no período inicial em Roma.

Aos amigos Dunia, Emanuela, Erica, Fabio, Helen, Humberto, Jean Marcel, Laura, Ludmila, Marcelo, Nadja, Natalina, Priscila, Renata, Rita, Sara e Vicenzo pelos inúmeros momentos felizes.

Aos amigos Jair, Marcio, Prof. Marco Túlio, Epaminondas, Sr. Latife, Mauricio Perez, Mara, Cristina e a todos os outros funcionários do LME que contribuíram com o trabalho.

À Embrapa Instrumentação Agropecuária - São Carlos pelo suporte ao trabalho.

À Capes e ao CNPq pelo apoio financeiro.

E a todos que contribuíram direta e indiretamente para a realização deste trabalho. 


\section{RESUMO}

A utilização simultânea de diferentes tecnologias de sensores é um método eficiente para aumentar o desempenho de sistemas sensoriais. Com o intuito de contribuir para um melhor controle da qualidade de combustíveis brasileiros, foram desenvolvidos neste trabalho sensores para serem utilizados em Língua e Narizes Eletrônicos. Estes sistemas multissensoriais foram utilizados separadamente, bem como simultaneamente, integrando-os para a avaliação da qualidade de gasolina e etanol. Desse modo, foram fabricados dois tipos de sistemas multissensoriais híbridos. O primeiro sistema foi composto pela integração de uma Língua Eletrônica (LE) e de um Nariz Eletrônico (NE), denominado SH-1. Neste sistema multissensorial, a impedância elétrica do conjunto dos diferentes sensores, baseados em filmes nanoestruturados de diferentes polímeros condutores depositados sobre diferentes microeletrodos de ouro, foi medida simultaneamente no líquido e no vapor de amostras de combustíveis. Já o segundo sistema multissensorial híbrido, $\mathrm{SH}-2$, foi composto pela união de dois tipos de NEs e foi fabricado integrando sensores produzidos a partir de microbalanças de quartzo e de uma matriz de capacitores, ambos funcionalizados com os mesmos materiais sensoativos, polímeros condutores e metaloporfirinas. A frequência de oscilação do cristal de quartzo, bem como a capacitância da matriz de capacitores foram medidas no vapor de combustíveis. Estes sistemas híbridos são de fácil fabricação, simples operação e sensíveis a uma grande variedade de substâncias químicas de interesse. Foram empregadas ferramentas de análise multivariada de dados para a calibração e validação dos sensores, bem como para a interpretação dos resultados obtidos.

Palavras-chave: Sistemas híbridos, sensores químicos, avaliação de combustíveis, língua eletrônica, nariz eletrônico. 


\begin{abstract}
The simultaneous use of different sensor technologies is an efficient method to increase the performance of sensor systems. Aiming to contribute to a better quality control of Brazilian fuels, sensors were developed in this work to be used in electronic tongue and electronic noses. These multisensor systems were used separately and simultaneously integrating them to evaluation the quality of gasoline and ethanol. Thus, two types of multisensor hybrid systems were manufactured. The first system was composed by the integration of an Electronic Tongue (LE) and an Electronic Nose (NE), called $\mathrm{SH}-1$. In this multisensor system, the electrical impedance of all the different sensors, based on nanostructured films of conducting polymers deposited on different gold microelectrodes, was measured simultaneously in both liquid and vapor fuel samples. The second multisensor hybrid system, $\mathrm{SH}-2$, was composed by the union of two types of NEs and was fabricated by integrating sensors made from quartz microbalance and an array of capacitors, both functionalized with the same sensitive materials, conducting polymers and metalloporphyrins. The oscillation frequency of quartz crystal, and the capacitance of the array of capacitors were measured in the fuel vapor. These hybrid systems are easy to fabricate, simple to operate and sensitive to a wide variety of chemicals of interest. Tools for multivariate analysis were used for calibration and validation of the sensors, as well as for the interpretation of results.
\end{abstract}

Keywords: Hybrid systems, chemical sensors, fuel evaluation, electronic tongue, electronic nose. 


\section{LISTA DE FIGURAS}

Figura 1 - Comparação entre o sistema sensorial biológico e o sistema sensorial artificial a partir da recepção de um estímulo, seguido de reação a este [20]. 29

Figura 2 - Estrutura química de uma porfirina. 36

Figura 3 - Estrutura química da polianilina. 38

Figura 4 - Dopagem da polianilina no estado esmeraldina. EB=base esmeraldina; ES=forma dopada de sal de esmeraldina. 39

Figura 5 - Representação esquemática do processo de deposição automontagem: (a) Suporte sólido com superfície carregada negativamente. (b) Adsorção de um policátion. (c) Adsorção de um poliânion e formação de uma bicamada.

Figura 6 - Circuito equivalente para um sistema representando um eletrodo metálico coberto com um filme semicondutor, imerso em uma solução eletrolítica. 42

Figura 7 - Curvas teóricas de capacitância (o) e perda dielétrica $\left(\varepsilon^{*}\right)$ para 0 circuito equivalente descrito na figura 6 . Os valores utilizados para gerar as curvas de capacitância e perda dielétrica foram: $\mathrm{Cg}=20 \mathrm{pF} ; \mathrm{Cb}=2 \mathrm{nF} ; \mathrm{Cd}=100 \mathrm{nF} ; \mathrm{Gt}=10^{-8}$ $\mathrm{S} ; \mathrm{Gb}=10^{-7} \mathrm{~S} ; \mathrm{Gd}=10^{-5} \mathrm{~S}$.

Figura 8 - Cortes do cristal de quartzo. 46

Figura 9 - a) Orientação do corte AT do cristal de quartzo. b) Relação da frequência relativa do cristal da microbalança de quartzo em relação a temperatura. 46

Figura 10 - Microbalança de quartzo. 47

Figura 11 - Detalhe de uma microbalança de quartzo. Cristal de quartzo, eletrodos e camada sensoativa.

Figura 12 - llustração de um microeletrodo interdigitado e suas dimensões. 56

Figura 13 - Microeletrodos de diferentes geometrias. 57

Figura 14 - Microeletrodos com geometrias do tipo NF 57

Figura 15 - Microbalança de Quartzo. 58

Figura 16 - Matriz capacitiva, conjunto de 256 × 300 capacitores, Fujitsu [43]. 59 
Figura 17 - Célula capacitiva.

Figura 18 - Ilustração da fabricação de uma bicamada de Policátion/Poliânion pela técnica de automontagem.

Figura 19 - llustração da deposição de filmes de metaloporfirinas sobre MBQ pela técnica de spray casting [107] 64

Figura 20 - Língua Eletrônica baseada em microeletrodos. 66

Figura 21 - Microeletrodo de ouro 66

Figura 22 - Cabeça sensora -Terminais de entrada dos sensores. 67

Figura 23 - Cabeça sensora - Terminais de saída dos sensores. 67

Figura 24 - Sistema de derivação de um banho termostático. 67

Figura 25 - Nariz Eletrônico baseado em microeletrodos. 68

Figura 26 - Foto do sistema de medida para LE-NE, SH-1.... 69

Figura 27 - Esquema do sistema de medida para LE-NE, SH-1. 69

Figura 28 - Nariz eletrônico baseado em microbalança de quartzo. 70

Figura 29 - Sistema de medidas para MBQ. 71

Figura 30 - Detector da matriz capacitiva recoberto com diferentes materiais sensoativos. .72

Figura 31 - Sistema de medidas nariz eletrônico baseado em matriz capacitiva......73 Figura 32 - Placa com o detector contendo as regiões sensoativas do nariz eletrônico baseado em matriz capacitiva............................................................ 74

Figura 33 - Organograma detalhando os sistemas híbridos................................. 75

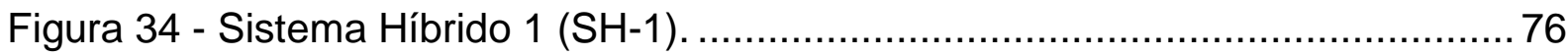

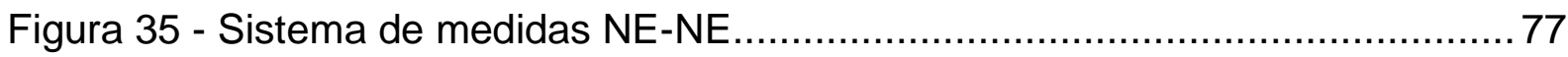

Figura 36 - Resposta de diferentes geometrias de microeletrodos no AEAC e na gasolina em $100 \mathrm{kHz}$ 80

Figura 37 - Reprodutibilidade da resposta de microeletrodos de diferentes geometrias no álcool etílico e na gasolina em $100 \mathrm{kHz}$. 
Figura 38 - Visualização para comparação de perda de filme sobre substrato de vidro, antes e após 14 imersões em álcool etílico anidro combustível.

Figura 39 - Absorbância de diferentes filmes poliméricos em função do número de imersões em álcool etílico anidro combustível.

Figura 40 - (a) e (b) Medidas da capacitância de sensores com filmes poliméricos expostos ao ar e ao vapor de álcool etílico anidro combustível durante 5 ciclos em $1 \mathrm{kHz}$; (c) e (d) variação da capacitância de sensores com filmes poliméricos expostos ao ar e ao vapor de gasolina A durante 5 ciclos em $1 \mathrm{kHz}$.

Figura 41 - Avaliação do desempenho de sensores contendo filmes de PMTh em álcool etílico anidro combustível.

Figura 42 - Gráfico PCA comparando combustíveis comerciais da cidade de São Paulo com gasolina A e gasolina com 20\% de AEAC preparada em laboratório...... 91

Figura 43 - PCA de combustíveis e solventes com diferentes constantes dielétricas.92 Figura 44 - Gráfico PCA comparando AEHC e gasolina comerciais com álcool etílico PA, gasolina A e gasolina com $20 \%$ de AEAC. .95

Figura 45 - Gráfico PCA comparando combustíveis comerciais da cidade de São Paulo com solventes, gasolina A e gasolina com $20 \%$ de AEAC, medidos com o sistema híbrido LE-NE.

Figura 46 - Gráficos biplot e scores da PCA obtidos em medidas diferentes solventes e combustíveis com a LE, NE e SH, na frequência de $100 \mathrm{~Hz}$.

Figura 47 - Gráficos biplot e scores da PCA obtidos em medidas diferentes solventes e combustíveis com a LE, NE e SH, na frequência de $1 \mathrm{kHz}$. 100

Figura 48 - Variação de frequência com a deposição de material sensoativo. 104

Figura 49 - Gráfico biplot da PCA dos dados do conjunto de sensores de MBQ. Scores são mostrados como círculos numerados. 106

Figura 50 - Representação da matriz em contato com gases de análise 108

Figura 51 - Gráfico biplot da PCA dos dados do conjunto de sensores capacitivos. Scores e loadings são mostrados como círculos e cruzes numerados respectivamente. Os scores são agrupados e denominados na figura de acordo com a amostra medida. Os loadings estão detalhados na tabela 10. 
Figura 52 - Gráfico biplot da PCA do conjunto de dados do SH-2. Scores são mostrados como círculos e loadings como símbolos (+) numerados. Os scores são agrupados e denominados na figura de acordo com a amostra medida. Loadings de 1 a 8 representam o conjunto de sensores capacitores e de 9 a 16 o os sensores da $M B Q$, listados na tabela 11

Figura 53- Modelo PLS para concentrações de etanol em gasolina, figura a, b e c são relativas aos dados de gasolinas individuais enquanto a figura $d$ representa os dados de todas as gasolinas 116

Figura 54 - Cromatogramas de uma gasolina: (a) gasolina A, (b) gasolina com 23\% de etanol.

Figura 55 - Gráfico biplot da PLS dos dados do SH-2 para concentrações de etanol em gasolinas durante três dias consecutivos. Scores e loadings são mostrados como círculos e cruzes numerados respectivamente.

Figura 56 - Modelo PLS para concentrações de 0 a 100\% de etanol em diferentes gasolinas comerciais italianas durante três dias 119

Figura 57 - Exemplo do processo de adsorção e dessorção durante a exposição de um sensor químico de microbalança de quartzo a um gás de amostra e sequencialmente a um gás de limpeza. (1) adsorção, (2) dessorção 121

Figura 58 - Exemplo de três sequências de pulsos aplicadas a um sensor 122

Figura 59 - Modelo PLS para medidas pulsadas em dois dias. Onde: (a) Primeiro pulso, (b) segundo pulso e (c) terceiro pulso. 124 


\section{LISTA DE TABELAS}

Tabela 1- Fórmula estrutural dos materiais sensoativos utilizados na fabricação dos sensores.

Tabela 2 - Tipos de geometrias de microeletrodos e suas dimensões 57

Tabela 3 - Constantes dielétricas de solventes 60

Tabela 4 - Descrição das soluções poliméricas 62

Tabela 5 - Perda de massa de filmes após 14 imersões em Álcool etílico anidro combustível.

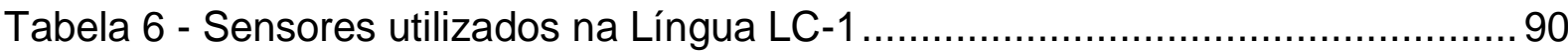

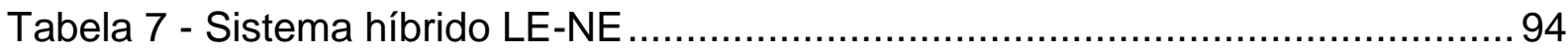

Tabela 8 - Avaliação da deposição de filmes em MBQ. ........................................ 103

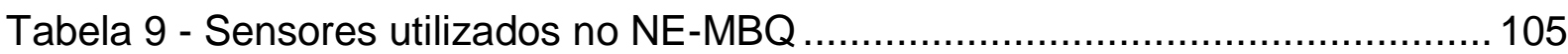

Tabela 10 - Sensores utilizados no NE - Matriz Capacitiva .................................. 109

Tabela 11 - Sensores utilizados no SH-2 ……………...................................111

Tabela 12 - Erro quadrático médio de calibração (RMSEC) e de validação (RMSECV) obtidos para os quatro modelos de regressão PLS. Cada modelo pertence a uma única formulação de gasolina, exceto o último modelo, onde os dados são relativos as medidas de todas gasolina.

Tabela 13 - Erro quadrático médio de calibração (RMSEC) e de validação (RMSECV) obtidos para os quatro modelos de regressão PLS. O primeiro modelo pertence a três formulações de gasolina, contendo de $0-100 \%$ de etanol, medidas em um único dia. No último modelo, os dados são relativos às três formulações de gasolina medidas em três diferentes dias.

Tabela 14 - Quantidade de erros obtidos a partir dos modelos PLS baseados nos sinais relacionados ao primeiro, segundo e terceiro pulso para medidas de gasolina contendo concentração de $0-100 \%$ de etanol. RMSEC e RMSECV são os erros de treinamento e validação cruzada respectivamente. As quantidades dos erros são relatadas no percentual total de unidades. 


\section{LISTA DE ABREVIATURAS E SÍMBOLOS}

A - Absorbância;

AC - Corrente alternada;

AEAC - Álcool etílico anidro combustível;

AEHC - Álcool etílico hidratado combustível;

AFM - Microscopia de força atômica;

Água DI - Água deionizada;

AM - Automontagem;

ANP - Agência Nacional do Petróleo, Gás Natural e Biocombustíveis;

C - Capacitância;

CIDE - Contribuição de intervenção no domínio econômico;

COFINS - Contribuição para financiamento da seguridade social;

EB - Base esmeraldina;

ES - Sal de esmeraldina;

FTIR - Espectroscopia no Infravermelho por transformada de Fourier;

FtTsNi - Ftalocianina tetrasulfonada de níquel;

G - Condutância;

GC-MS - Cromatografia gasosa acoplada à espectrometria de massas;

IA - Inteligência Artificial;

ISA - International society of automation;

LB - Langmuir-Blodgett;

LE - Língua eletrônica;

LE-NE - Sistema híbrido língua eletrônica e nariz eletrônico;

LC-1 - Língua eletrônica para combustíveis;

LS - Lignina sulfonada;

LV - Variável latente;

$\mathrm{M}$ - Molar, $\mathrm{mol} / \mathrm{L}$;

$\mathrm{MBQ}$ - Microbalança de quartzo;

Me - Metal;

ME - Microeletrodo interdigitado;

MOM - Número de octano motor;

NE - Nariz eletrônico; 
NE-NE - Sistema intergrado de narizes eletrônicos;

NIR - Espectroscopia por infravermelho próximo;

PANI - Polianilina;

PC - Componente principal;

PCA - Análise de componentes principais;

PLS - Mínimos quadrados parciais;

PEDOT - poli(3,4-etilenodioxitiofeno)-PEDOT (Baytron P);

PIS - Programa de integração social;

PMQC - Programa de monitoramento da qualidade de combustíveis;

PMTh - Poli(metiltiofeno);

POEA - Poli(o-etoxianilina);

POMA - poli(o-metoxianilina);

PPY - Polipirrol;

ppb - Partes por bilhão;

PSS - Poliestireno sulfonato de sódio;

RMSEC- Erro quadratico médio de calibração;

RMSECV - Erro quadratico médio de validação cruzada;

RNA - Redes neurais artificiais;

ROM - Número de octano pesquisa;

$\mathrm{SH}-1$ - Sistema híbrido 1;

SH-2 - Sistema híbrido 2;

SM - Sistema multissensorial;

$\mathrm{t}$ - tempo;

THF - Tetrahidrofurano;

TPP - Tetrafenilporfirina;

UV-Vis - Espectroscopia no ultravioleta e no visível;

$\mu$ - Mobilidade de portadores de carga;

$\sigma-$ Condutividade elétrica do material. 


\section{SUMÁRIO}

RESUMO

ABSTRACT

LISTAS DE FIGURAS

LISTA DE TABELAS

LISTA DE ABREVIATURAS

LISTA DE SÍMBOLOS

1 - INTRODUÇÃO

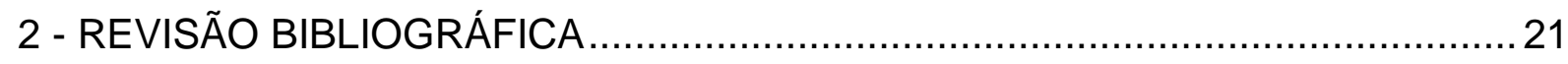

2.1 - COMBUSTÍVEIS COMERCIAIS BRASILEIROS .......................................21

2.1.1 - Etanol combustível ou álcool etílico combustível................................23

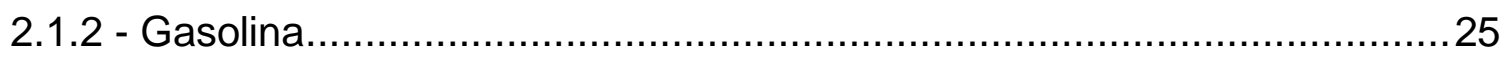

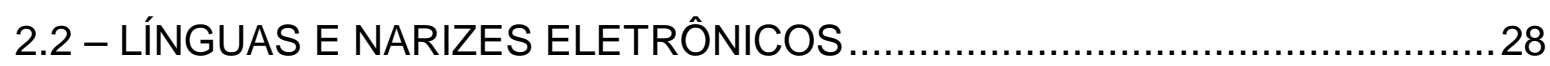

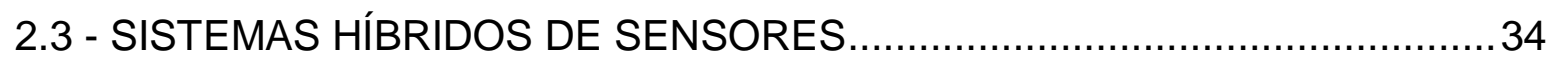

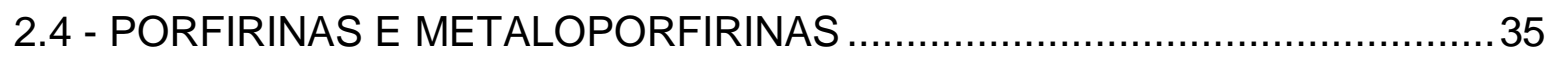

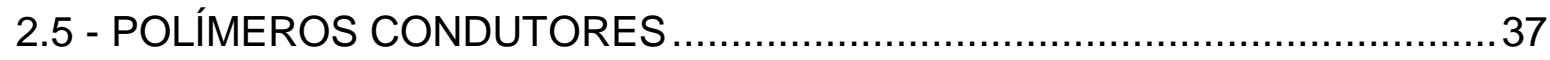

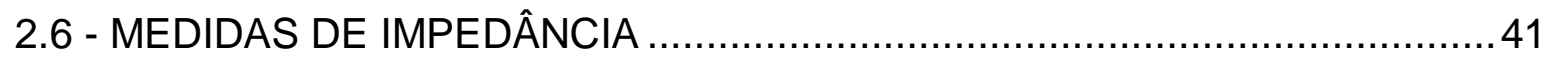

2.6.1 - Teoria envolvida na análise por espectroscopia de impedância ..............42

2.7 - MEDIDAS PIEZOELÉTRICAS E TRANSDUTORES DE MASSA .................. 44

2.8 - MÉTODOS DE ANÁLISE DE DADOS ………........................................ 49

2.8.1 - PCA (Principal component analysis - Análise da componente principal)49

2.8.2 - PLS ( Partial Least Square - Mínimos Quadrados Parciais) ...................50

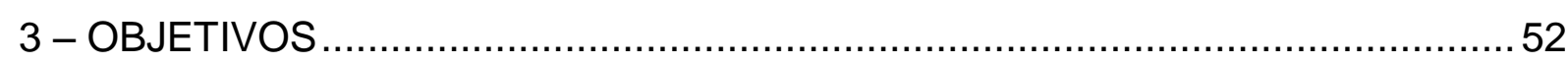

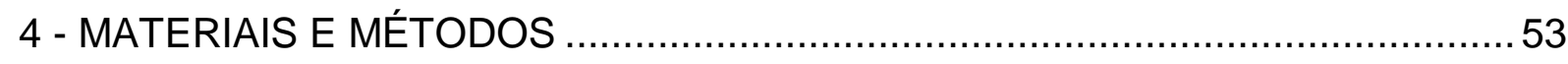

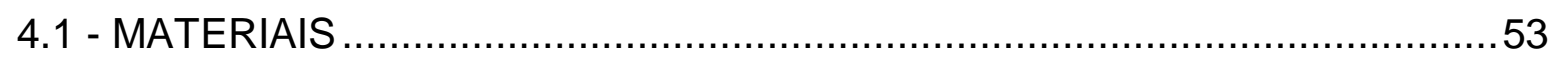

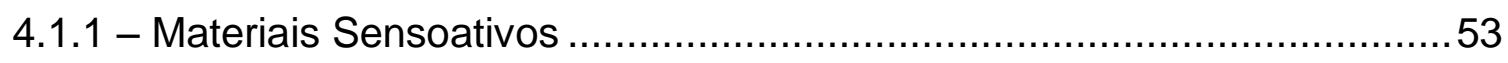

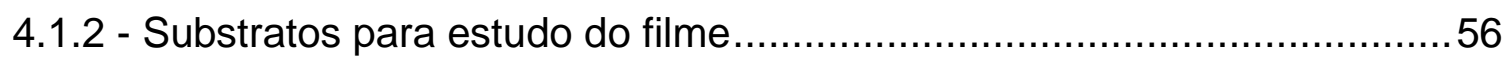


4.1.4 - Microbalança de quartzo ............................................................... 58

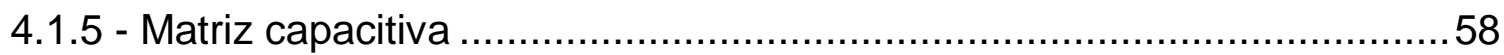

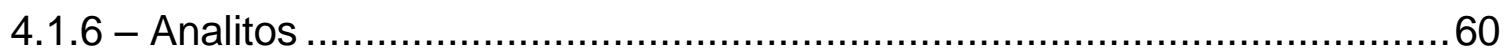

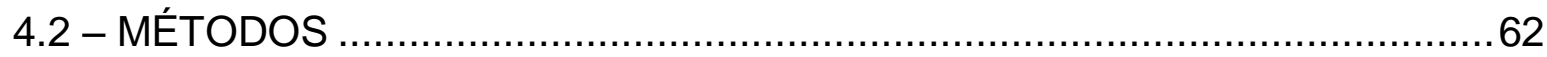

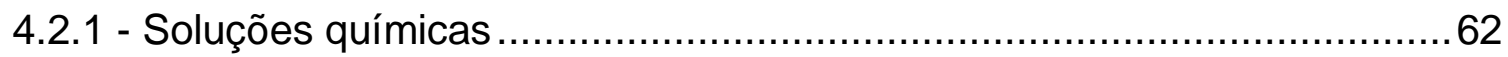

4.2 .2 - Fabricação das unidades sensoriais ........................................... 62

4.2.3 - Espectroscopia no ultravioleta e no visível (UV-Vis) ..........................65

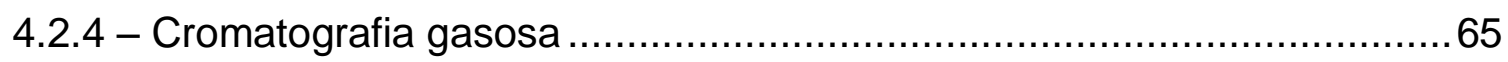

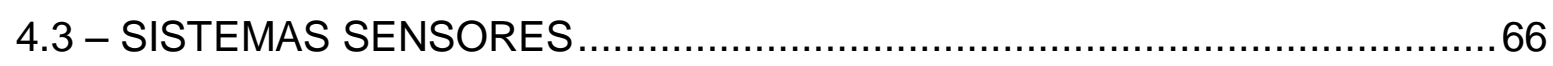

4.3.1 - Sistemas sensores Língua eletrônica e nariz eletrônico baseados em microeletrodos

4.3.2 - Sistema sensor nariz eletrônico baseado em microbalanças de quartzo 70

4.3.3 - Sistema sensor nariz eletrônico baseado em matriz de capacitores ......72

4. 4 - SISTEMAS HÍBRIDOS DE SENSORES. 74

4.4.1 - Sistema híbrido nariz eletrônico e língua eletrônica baseados em ME $(\mathrm{SH}-1)$

4.4.2 - Sistema híbrido de narizes eletrônico baseados em MBQ e matriz de

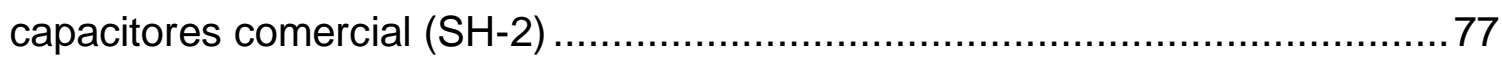

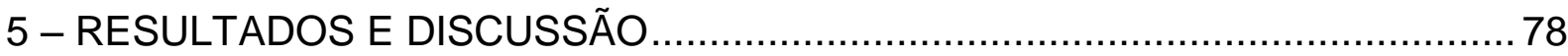

5.1 - DESENVOLVIMENTO E AVALIAÇÃO DO DESEMPENHO DOS SISTEMAS SENSORES BASEADOS EM MICROELETRODOS .................................. 79

5.1.1 - Estudo da sensibilidade de diferentes microeletrodos na análise de combustíveis comerciais 79

5.1.2 - Avaliação da estabilidade de filmes poliméricos para a análise de combustíveis em meio líquido

5.1.3 - Avaliação do desempenho de filmes poliméricos depositados sobre microeletrodos na análise de vapor de combustíveis comerciais 
5.1.4 - Desenvolvimento dos sistemas multissensores baseados em ME 89

5.1.5 - Desenvolvimento da LE baseada em ME e avaliação da sua capacidade de discriminação de solventes e combustíveis .90

5.2 - DESENVOLVIMENTO E AVALIAÇÃO DO DESEMPENHO DO SISTEMA HÍBRIDO 1 (SH-1) PARA SOLVENTES E COMBUSTÍVEIS .93

5.3 - DESENVOLVIMENTO E AVALIAÇÃO DO DESEMPENHO DOS SISTEMAS SENSORES BASEADOS EM MICROBALANÇAS DE QUARTZO 102

5.3.1 - Desenvolvimento dos sistemas multissensoriais baseados em MBQ..104 5.3.2 - Avaliação da capacidade de discriminação de solventes e combustíveis com o NE-MBQ. 105

5.4 - DESENVOLVIMENTO E AVALIAÇÃO DO DESEMPENHO DOS SISTEMAS SENSORES BASEADOS EM MATRIZ CAPACITIVA

5.4.1 - Avaliação da capacidade de discriminação de solventes e combustíveis com a Matriz capacitiva. 109

5.5 - DESENVOLVIMENTO E AVALIAÇÃO DA CAPACIDADE DE DISCRIMINAÇÃO DE SOLVENTES COM O SISTEMA HÍBRIDO 2

5.5.1 - Avaliação da capacidade de discriminação de concentrações de etanol em gasolina com o $\mathrm{SH}-2$ 113

5.6 - MEDIDAS PULSADAS 120

6 - CONCLUSÕES 125

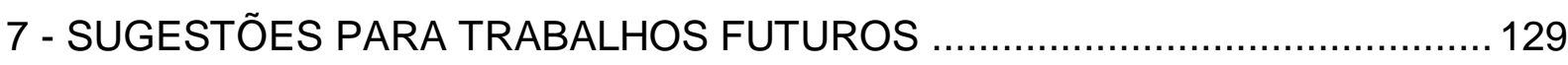

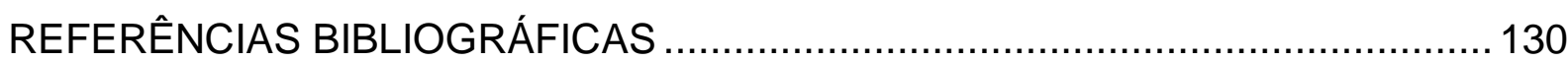

APÊNDICE A - Confecção dos microeletrodos ....................................................143

APÊNDICE B - Publicações e participações em congressos científicos.

ANEXO A - Regulamento técnico ANP oㅜ 7/2005 146

ANEXO B - Regulamento técnico ANP no 2/2009. .152 


\section{1 - INTRODUÇÃO}

Combustíveis adulterados podem danificar os motores dos automóveis e sua combustão liberar substâncias prejudiciais ao meio-ambiente e a saúde. A adulteração também causa prejuízos ao Estado, uma vez que os impostos referentes ao aumento de volume devido à adição de adulterantes normalmente não são recolhidos. [1,2,3].

Diante destes problemas, torna-se necessário o desenvolvimento de tecnologias dedicadas ao controle da qualidade do combustível comercializado no Brasil. Algumas tecnologias já existentes, como por exemplo, a cromatografia gasosa acoplada à espectrometria de massas (GC-MS), a espectroscopia por infravermelho próximo (NIR) e curvas de destilação tem sido utilizadas para esse fim $[4,5,6,7,8,9,10,11,12,13,14]$. Entretanto, estas técnicas exigem que a análise seja realizada em laboratório, por pessoal altamente especializado tanto na execução como na interpretação dos dados, são dispendiosas e levam um tempo excessivo para serem realizadas (em torno de duas horas por amostra no caso da GC). Uma tecnologia mais simples e econômica, que pudesse ser realizada por pessoal não especializado e no local da coleta da amostra, seria amplamente desejável para um controle mais rigoroso e feito diretamente nos pontos de distribuição e venda de combustíveis.

Vem sendo desenvolvidos por centros de pesquisa brasileiros e internacionais, sensores capazes de discriminar líquidos e gases pela diferença de sabor e odor [15,16,17,18,19,20,21,22,23,24,25,26]. Estes sensores atuam de maneira similar aos sistemas gustativo e olfativo humano e desta maneira são denominados língua eletrônica (LE) e nariz eletrônico (NE) [27,28]. Tanto em LE quanto em NE, cada unidade sensorial responde de maneira individual à presença da substância de interesse, gerando uma impressão digital característica, a qual pode ser interpretada com o auxílio de ferramentas computacionais.

O uso de polímeros condutores em camadas sensoativas de sensores químicos, usados em LEs e NEs, tem sido bastante considerado nos últimos anos devido principalmente à capacidade desses materiais em mudar, de forma reversível, seus valores de condutividade elétrica em função da exposição a 
diferentes substâncias químicas e diferentes ambientes [29,30,31,32]. A Embrapa Instrumentação Agropecuária de São Carlos, em parceria com a Escola Politécnica da USP de São Paulo e outros centros de pesquisa, desenvolveu uma "língua eletrônica" com polímeros condutores, a qual tem se mostrado extremamente eficiente na certificação de bebidas, como café, vinho e água, por meio da análise de sabores. Além da certificação, este sistema é capaz de detectar quantidades ínfimas de contaminantes em água, tais como metais pesados e pesticidas [33,34,35,36]. Esta LE é constituída por um conjunto de filmes nanoestruturados de polímeros condutores, depositados sobre microeletrodos interdigitados, cuja impedância elétrica é medida quando imersos na amostra avaliada [37,36,38]

NEs baseados em filmes nanoestruturados de polímeros condutores e microeletrodos interdigitados também já foram estudados no passado [39,40,41] e da mesma forma que a LE de polímeros condutores, a impedância das unidades sensoriais é medida quando estas são expostas à substância de interesse, que neste caso é um gás ou aroma em análise.

Recentemente, sensores baseados em capacitores ganharam vantagens a partir da introdução no mercado de dispositivos híbridos destinados a biometria para detectar impressões digitais. Estes dispositivos são matrizes de centenas de capacitores e seu uso como sensores foi introduzido há poucos anos atrás para detecção química [42,43] e para a identificação de DNA [44].

Narizes eletrônicos contendo sensores fabricados a partir de microbalanças de quartzo e metaloporfirina estão entre os dispositivos não seletivos mais encontrados na literatura $[45,46,47,48]$, onde a frequência de oscilação do cristal piezoelétrico de quartzo, recoberto com a camada sensitiva orgânica, varia linearmente a partir da interação com moléculas voláteis quando expostos a determinadas substâncias.

A utilização simultânea de diferentes tecnologias de sensores tem sido demonstrada no passado [49,50] e é um método eficiente para aumentar o desempenho dos sistemas de sensores químicos. Entre as tecnologias disponíveis, transdutores de massa e capacitância são particularmente interessantes porque podem ser vantajosos também a partir de camadas sensoativas não condutivas, tais como a maioria dos mais interessantes sistemas de reconhecimento molecular [51].

Desse modo, o objetivo deste trabalho foi desenvolver e integrar sistemas sensores, LEs e NEs, a fim de se obter um sistema de extrema sensibilidade e 
capaz de determinar adulteração em combustíveis comercializados no Brasil, como a gasolina e o etanol combustível.

Para tanto, filmes nanoestruturados de materiais poliméricos e de metaloporfirinas foram desenvolvidos e utilizados como camadas sensoativas depositadas sobre microeletrodos interdigitados, microbalanças de quartzo e também sobre uma matriz capacitiva comercial, formando as unidades sensoriais.

A transdução elétrica destas unidades foi medida em função da exposição às amostras de combustíveis a partir de dois tipos de sistemas híbridos de LEs e NEs desenvolvidos. O primeiro sistema foi composto pela integração de uma LE e de um NE, denominado LE-NE, onde a impedância elétrica do conjunto de diferentes sensores, baseados em filmes nanoestruturados de diferentes polímeros condutores e diferentes microeletrodos interdigitados de ouro, foi medida simultaneamente no líquido e no vapor de amostras de combustíveis.

Já no segundo sistema, composto pela integração de dois tipos de NEs, denominado NE-NE, um conjunto de sensores de microbalanças é complementado por uma matriz de sensores capacitivos, obtida a partir de um detector biométrico comercial de impressões digitais. Os dois conjuntos de transdutores foram devidamente funcionalizados por metaloporfirinas e filmes poliméricos e a frequência de oscilação do quartzo, bem como a capacitância da matriz de capacitores foram medidas simultaneamente no vapor de combustíveis.

Ferramentas estatísticas de análise multivariada de dados, como a PCA [52,53] e PLS [54,55] foram empregadas para a calibração e validação dos sensores, bem como para a interpretação dos resultados obtidos. 


\section{2 - REVISÃO BIBLIOGRÁFICA}

\section{1 - COMBUSTÍVEIS COMERCIAIS BRASILEIROS}

Os combustíveis são classificados como de origens minerais ou não minerais. Os combustíveis minerais são obtidos pela refinação do petróleo, destilação do xisto betuminoso ou hidrogenação do carvão. Os mais usados são a gasolina, o óleo diesel e o óleo combustível. Estes combustíveis são formados de hidrocarbonetos [56,57]. Os combustíveis líquidos não minerais mais comuns são os alcoóis e os óleos vegetais. Entre os alcoóis, temos o álcool metílico e o etílico.

O mercado de combustíveis no Brasil está configurado, genericamente, pela presença de três agentes principais: O produtor/importador, as distribuidoras e a rede de postos de revenda a varejo [58]. O produtor/importador, no caso da gasolina A (detalhada no item posterior) e óleo diesel, é representado pelas refinarias e centrais petroquímicas e, no caso do álcool etílico anidro e hidratado, pelas usinas de processamento de cana-de-açúcar.

Vale destacar que a PETROBRAS S/A, por meio das refinarias REMAN (Refinaria Issac Sabbá - Manaus/AM), LUBNOR (Lubrificantes e Derivados de Petróleo do Nordeste - Mucuripe-Fortaleza/CE), RLAM (Refinaria Landulpho Alves São Francisco do Conde/BA), REGAP (Refinaria Gabriel Passos - Betim/MG), REDUC (Refinaria Duque de Caixas Duque de Caixas/RJ), REVAP (Refinaria Henrique Lage - São José dos Campos/SP), RPBC (Refinaria Presidente Bernardes - Cubatão/SP), RECAP (Refinaria de Capuava - Capuava-Mauá/SP), REPLAN (Refinaria de Paulínia - Paulínia/SP), REPAR (Refinaria Pres. Getúlio Vargas Araucária/PR), REFAP (Refinaria Alberto Pasqualini - Canoas/RS) é responsável, aproximadamente, pela produção de mais de $90 \%$ da gasolina A no Brasil.

As refinarias, centrais petroquímicas e usinas de processamento de cana-deaçúcar comercializam a produção para as distribuidoras de combustíveis que, por sua vez, fornecem para a extensa e diversificada rede de postos de revenda a varejo existentes em todos os rincões do País, encarregados de comercializar os produtos 
para o consumidor final. Somente na Grande São Paulo existem em torno de 5.000 postos de combustíveis.

A regulação e a fiscalização dessa estrutura de mercado são, atualmente, exercidas, com exclusividade, pela Agência Nacional do Petróleo, Gás Natural e Biocombustíveis - ANP [58], autarquia federal vinculada ao Ministério das Minas e Energia. É função da ANP regular a qualidade dos produtos derivados de petróleo por meio de regras estabelecidas em portarias, instruções normativas e resoluções, em conformidade com a legislação e com a Política Energética Nacional. O objetivo destas atividades é proteger a sociedade quanto à adequação dos combustíveis ao uso e ao meio ambiente, considerando a realidade nacional

A qualidade dos combustíveis é definida por um conjunto de características físicas e químicas previstas nas Normas Brasileiras (NBR) e Métodos Brasileiros (MB) da Associação Brasileira de Normas Técnicas (ABNT) e de normas da American Society for Testing and Materials (ASTM). A especificação estabelecida pela ANP, conforme a Lei no 9.478/1997, determina valores limites para essas características, de modo a assegurar o desempenho adequado dos combustíveis.

Visando garantir a qualidade e o suprimento de combustíveis ao mercado nacional foi instituído pela ANP o Programa de Monitoramento da Qualidade dos Combustíveis (PMQC), que atinge 23 estados da federação por meio de contratos com laboratórios de universidades e institutos de pesquisa. Os principais objetivos do PMQC são o levantamento dos indicadores gerais da qualidade dos combustíveis comercializados no País e a identificação de focos de não conformidade. Para identificar eventuais adulterações na gasolina, a ANP também instituiu, por meio das Portarias 274/2001 e 231/2002, o Programa de Marcação de Solventes, que torna obrigatória a adição de corantes a solventes com objetivo de acusar a presença ilegal destes produtos na gasolina

Feitas essas breves considerações sobre o mercado de combustíveis, passemos à análise do álcool etílico combustível e da gasolina, espécies tratadas neste trabalho. 


\subsection{1 - Etanol combustível ou álcool etílico combustível}

O etanol ou álcool etílico pode ser produzido a partir de diversas fontes vegetais, mas a cana de açúcar é a que oferece mais vantagens energéticas e econômicas ao Brasil. De acordo com a Resolução ANP n.. 36, de 06 de dezembro de 2005, são produzidos dois tipos de etanóis para serem utilizados como combustíveis nos veículos brasileiros:

- Etanol Hidratado Combustível ou Álcool Etílico Hidratado Combustível (AEHC) - É utilizado nos carros a "álcool", e como o próprio nome diz é hidratado, ou seja, possui água. Esse teor de água é, em média, de 7\%, sendo o teor alcoólico na faixa de $92,6^{\circ}$ a 93,8 INPM. Este produto não é utilizado como aditivo à gasolina. O etanol combustível é um produto renovável e limpo e que contribui para a redução do efeito estufa e diminui substancialmente a poluição do ar.

\section{- Etanol Anidro Combustível ou Álcool Etílico Anidro Combustível (AEAC)} É obtido a partir da fermentação do caldo da cana-de-açúcar e possui teor alcoólico mínimo de 99,3 INPM. Por lei federal, é destinado aos distribuidores para mistura com a gasolina $\mathrm{A}$.

O álcool etílico hidratado é utilizado diretamente nos veículos movidos a "álcool" ou bicombustíveis. Já o álcool etílico anidro não pode ser usado diretamente como combustível nos veículos, sendo produzido para ser adicionado à gasolina "A" para dar origem à gasolina " $C$ ".

A utilização do etanol como aditivo à gasolina teve início nos anos 30. A medida foi regulamentada pelo decreto 19.717 , de 20 de fevereiro de 1931, que estabeleceu a aquisição obrigatória de etanol anidro de procedência nacional, na proporção de $5 \%$ da gasolina importada, e dava outras providências $[59,60]$.

Com a implantação do Programa Nacional do Álcool (Proálcool), criado pelo decreto de lei 76.593 de 14 de novembro de 1975, o etanol combustível teve um impulso $[58,61,62]$. Lançado no Brasil durante o governo do Presidente Ernesto 
Geisel o Proálcool foi uma iniciativa governamental para fazer frente aos sucessivos aumentos do preço do petróleo devido à crise da OPEP. O Proálcool tinha como objetivo conter os gastos com a importação de petróleo garantindo o suprimento de etanol no processo de substituição da gasolina. Tinha também como meta apoiar o desenvolvimento tecnológico da indústria sucroalcooleira. Na primeira fase do programa, até 1979, a ênfase foi a produção de etanol anidro para ser misturado à gasolina. Na segunda fase, a ênfase passou a ser o etanol hidratado, usado puro em motores adaptados para o combustível.

Os primeiros carros movidos a etanol combustível foram produzidos em 1979, mas em pequena escala. De $98 \%$ dos carros produzidos movidos a gasolina, foram fabricados apenas 0,5\% de carros movidos a etanol. Em 1986 houve a maior produção de carros movidos a etanol, $72,6 \%$ da frota, enquanto que para a produção de carros movidos a gasolina foi de apenas $22,8 \%$. Com o aumento da oferta e a redução do preço do petróleo houve uma queda acentuada no preço do etanol, e os produtores passaram a utilizar a cana-de-açúcar apenas para a produção de açúcar, levando o setor a sofrer uma grave crise de abastecimento que gerou uma redução na produção de carros movidos a etanol combustível e, em consequência, a uma drástica diminuição no consumo do combustível. Sem as vantagens e incentivos de antes, tais como a redução do valor do Imposto sobre Produtos Industrializados (IPI), a produção entrou em declínio até atingir 3,3\%, em 2002.

Em movimento de adaptação perante as tendências do mercado de energia, a indústria automotiva brasileira passou a fabricar em grande escala os carros bicombustíveis, os modelos flex, que garantem o escoamento da produção de etanol e ampliam a liberdade de escolha dos consumidores. Atualmente, quase toda a frota de carros novos produzidos no Brasil possui esta tecnologia.

A mistura de etanol à gasolina aumenta as propriedades número de octano motor (MON - Motor octane number), número de octano pesquisa (RON - Research octane number) e antidetonantes. Existe também um incremento nos valores de massa específica e condutividade elétrica. [63,64].

Muitos países, como a China, Estados Unidos, Austrália e Japão, têm mostrado interesse em misturar etanol à gasolina para reduzir a emissão de gases poluentes. No Brasil, o uso do etanol restringiu a emissão de poluentes da crescente frota de veículos, principalmente de monóxido de carbono, óxidos de enxofre, compostos de chumbo e compostos orgânicos tóxicos como o benzeno $[65,66,67]$. 


\subsubsection{1 - Principais adulterações do etanol combustível}

As principais causas das fraudes praticadas no etanol combustível são oriundas do fato do álcool etílico anidro possuir tributação e alíquotas do ICMS diferenciadas em relação ao álcool etílico hidratado, sendo inferiores às deste [68 $\left.{ }^{69}\right]$. Contudo, uma adulteração bastante comum é o "álcool molhado", que consiste na venda de álcool etílico anidro com a adição irregular de água, como se fosse álcool etílico hidratado, obtendo-se maior lucro, por meio da sonegação de tributos, notadamente o ICMS. Para combater tais fraudes a ANP estabeleceu, por meio da Resolução no 36/2005, a obrigatoriedade de adição de corante de cor laranja ao etanol anidro. Como o etanol hidratado é incolor, o corante denuncia se houver presença do anidro irregularmente misturado. Com a medida, o índice de não conformidade no etanol caiu de 3,8\% em 2006 para 2,3\% em 2008 [58].

Outra adulteração frequente é a adição indevida de mais água ao álcool etílico hidratado (que contém normalmente entre 6,2 e 7,4 \% de água) visando ao aumento do volume. O teor alcoólico deverá estar entre 92,6ำ 93,8은 INPM e, se os valores obtidos forem diversos, isto indicará que o álcool etílico hidratado foi adulterado pela adição de água [58].

Em setembro de 2009, das análises que verificaram as não conformidades para o etanol, 45,5\% foram em relação ao ensaio de Massa Específica/Teor Alcoólico, seguido pelo ensaio de $\mathrm{pH} 36,4 \%$, condutividade $9,1 \%$ e outros $9,1 \%$ [58].

As especificações do álcool etílico anidro e do álcool etílico hidratado pela ANP estão presentes no anexo A.

\subsection{2 - Gasolina}

A gasolina é o carburante mais utilizado atualmente no mundo. Ela é constituída quimicamente por uma mistura complexa de mais de 400 hidrocarbonetos obtidos do petróleo bruto, por intermédio de vários processos como o cracking, destilação e outros. A gasolina comercializada no Brasil é oriunda do 
petróleo nacional e internacional, além de existir uma grande quantidade de refinarias e distribuidoras deste produto, gerando uma grande variação na sua composição do produto final. As características e especificações dos componentes da gasolina, bem como a sua comercialização são regulamentadas pela Agência Nacional de Petróleo (ANP) [58]. Através do Programa de Monitoramento da Qualidade de Combustíveis (PMQC) a ANP realiza o mapeamento e fiscalização permanente em postos, distribuidoras e refinarias de todas as regiões brasileiras. Buscando o controle da qualidade da gasolina no País, são coletadas amostras de combustíveis de modo aleatório em postos e através de testes físico-químicos é verificado se os mesmos atendem as especificações da ANP

Dentre as não conformidades mapeadas pelo Programa a variação do teor de álcool etílico e da octanagem são as mais relevantes. O octano é um dos hidrocarbonetos presentes em qualquer tipo de gasolina e sua importância está relacionada com uma das principais propriedades do combustível: o poder antidetonante.

Atualmente, encontram-se no comércio brasileiro vários tipos de gasolina $[56,58]$, sendo:

- Gasolina do tipo A (73 octanas - gasolina amarela);

- Gasolina do tipo B (82 octanas - gasolina azul);

- Gasolina do tipo C (76 octanas - gasolina + álcool etílico anidro), e;

- Gasolina Verde (de 110 a 130 octanas - somente utilizada na aeronáutica).

A gasolina do tipo A é produzida pelas refinarias de petróleo e entregue diretamente às companhias distribuidoras. Esta gasolina constitui-se basicamente de uma mistura de naftas numa proporção tal que enquadre o produto na especificação prevista. Este produto é a base da gasolina do tipo C.

A gasolina do tipo C é preparada pelas companhias distribuidoras que adicionam um percentual de álcool etílico anidro à gasolina do tipo $\mathrm{A}$. O conteúdo de álcool etílico anidro determinado por lei para mistura com a gasolina "A" está entre 20 a 25\%. A proporção entre ambos combustíveis é indicada pela porcentagem de álcool etílico anidro precedido pela letra E maiúscula. Desta maneira, a mistura E20 é composta de $20 \%$ de etanol anidro e $80 \%$ de gasolina, porcentagem estabelecida para o ano de 2005, passando para E23 em 2006. Desde Julho de 2007, a partir da 
publicação da Portaria no 143 do Ministério da Agricultura, Pecuária e Abastecimento, a mistura utilizada é E25, contando que não haja falta do produto. Em 2009, o consumo deste biocombustível ultrapassou o da gasolina [58].

\subsubsection{1 - Principais adulterações da gasolina}

O principal objetivo da adulteração da gasolina é o não pagamento de tributos, barateando o produto para a distribuição e comercialização ilícita, gerando, assim, prejuízos aos erários federal e estadual, além de danos aos veículos dos consumidores finais [68].

A refinaria recolhe sobre a gasolina, determinado valor a título de CIDE, no qual estão incluídos os valores do PIS e do COFINS.

Como a gasolina revendida pelos postos no Brasil recebe uma porcentagem de álcool etílico anidro, uma das principais fraudes praticadas na sua comercialização é a adição de álcool etílico anidro em porcentagem superior ao estabelecido de acordo com a lei. Em algumas fiscalizações, já foi constatada a presença de mais de $46 \%$ de álcool etílico anidro misturado na gasolina examinada.

Outra fraude muito comum, infelizmente, é a adição de solventes proibidos à gasolina, que não podem ser adicionados, pois alteram as suas características e a tornam imprópria para o consumo.

Alguns solventes utilizados de forma irregular provocam uma alteração na curva de destilação e na octanagem da gasolina. Já outros, a sua adição à gasolina é proibida em razão do tratamento tributário diferenciado que recebem, e a sua indevida adição, além de torná-la imprópria para o consumo, acaba por resultar em grande sonegação de tributos estaduais e federais. Para os solventes que pouco alteram a composição química da gasolina, a lei determina que eles recebam um marcador químico, cuja presença pode ser verificada por meio de um teste de análise cromatográfica gasosa.

As principais causas de não conformidade de gasolina, no mês de setembro de 2009, para diferentes regiões do Brasil, foram relativas ao teor de etanol anidro $(52,4 \%)$ destilação $(34,3 \%)$, octanagem $(4,8 \%)$ e outros $(8,6 \%)$. Para o estado de 
São Paulo, no mesmo período foram: etanol (34\%), destilação (24\%), octanagem (4\%) e outros $9 \%$.

Frente a tantas fraudes, torna-se amplamente desejável o desenvolvimento de novas tecnologias dedicadas ao controle da qualidade do combustível comercializado no Brasil.

Contudo, foram desenvolvidos neste trabalho conjuntos não específicos de sensores de paladar e de aroma, "línguas e narizes eletrônicos", bem como integrações destes sistemas, constituindo ferramentas de extrema sensibilidade, que de forma simples e barata, são capazes de identificar adulterações em alcoóis e gasolinas comercializados no Brasil.

\section{2 - LÍNGUAS E NARIZES ELETRÔNICOS}

Os sentidos fundamentais do corpo humano, visão, audição, tato, olfato e paladar, são importantes porque constituem as funções que propiciam o nosso relacionamento com 0 ambiente. Existem determinados receptores, altamente especializados, capazes de captar estímulos diversos. Tais receptores, chamados de receptores sensoriais, são formados por células nervosas capazes de traduzir ou converter esses estímulos em impulsos elétricos ou nervosos que serão processados e analisados em centros específicos do sistema nervoso central, onde será produzida uma resposta voluntária ou involuntária.

A função de um sensor artificial é reproduzir os sentidos do corpo humano ou superá-los. A figura 1 mostra a correspondência entre o sistema sensorial biológico e artificial no processo de recepção de um estímulo seguido de reação. 


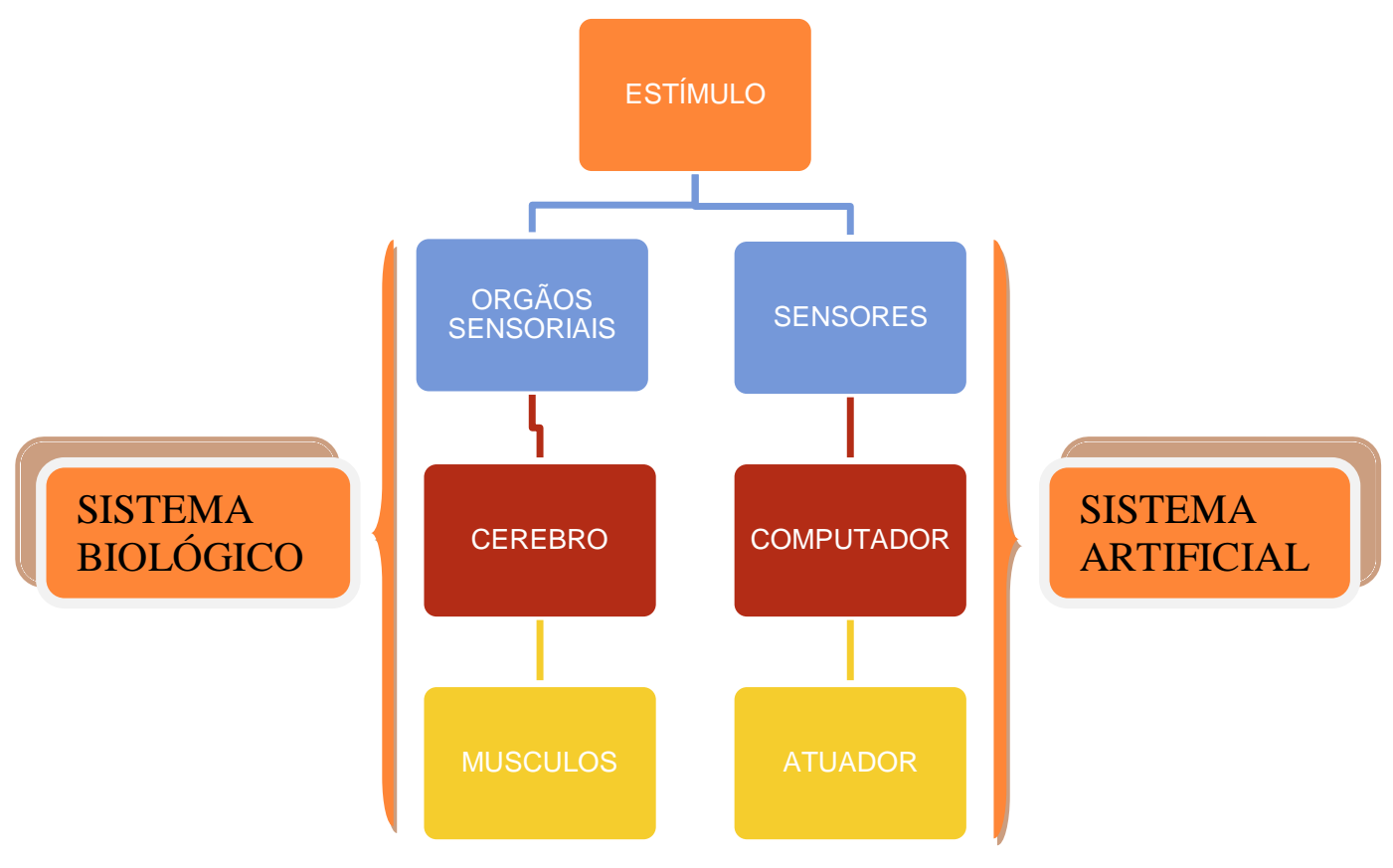

Figura 1 - Comparação entre o sistema sensorial biológico e o sistema sensorial artificial a partir da recepção de um estímulo, seguido de reação a este [20].

Sensores químicos são dispositivos que transformam informações químicas em um sinal analiticamente mensurável. A avaliação de sabores e odores pode ser feita através de sensores químicos aplicados em líquidos e gases. Conjuntos destes sensores atuam de maneira similar ao sistema gustativo e olfativo humano, uma vez que possuem estágios de deteç̧ão, reconhecimento e tradução semelhantes, e por esta razão são denominados Línguas e Narizes eletrônicos. A literatura mostra um grande potencial de aplicação de línguas e narizes eletrônicos em diversas áreas $[20,23,25,26,29,34,39]$ e devido à praticidade, rapidez e simplicidade, alguns destes sistemas sensores já estão sendo comercializados e usados em diversas indústrias para o controle da qualidade e rastreabilidade de diversos produtos.

O sistema gustativo e olfativo humano não é capaz de distinguir separadamente cada uma das substâncias responsáveis pelo estímulo do sabor e do odor. Portanto, uma língua eletrônica e um nariz eletrônico devem estar baseados no reconhecimento do sabor e do odor, e não na identificação em separado de cada substância química que compõem determinado líquido ou gás. Esse conceito é denominado de seletividade global e implica na habilidade de classificar grandes quantidades de substâncias em diferentes grupos, como o realizado pelos sistemas biológicos [20]. 
Diversos tipos de línguas e narizes eletrônicos são encontrados na literatura, diferenciando-se quanto aos seus princípios de operação. Dentre as línguas eletrônicas, basicamente quatro tipos são encontrados, sendo estes baseados em potenciometria, condutiviometria, amperometria e voltametria.

A primeira língua eletrônica descrita [70] é formada por sensores compostos por um conjunto de eletrodos modificados com membranas de PVC contendo lipídios (seletivos a íons), de diferentes composições e utiliza potenciometria como o método de detecção. Em alguns casos, um eletrodo convencional de $\mathrm{Ag} / \mathrm{AgCl}$ é utilizado como eletrodo de referência. Padrões distintos de sabor foram identificados por esta "língua", que é capaz de distinguir diferentes tipos de cervejas, café, água mineral, leite, vinho e outras bebidas. Responde ainda a efeitos de supressão, como a mistura de uma substância amarga em algo doce tornando o paladar doce amargo. Porém, este sistema apresenta algumas desvantagens como a necessidade de um sensor de referência, o que dificulta a fabricação de um sistema compacto, e principalmente quanto à baixa reprodutibilidade das respostas elétricas das membranas e pouca sensibilidade para não eletrólitos.

O segundo tipo de língua eletrônica utiliza vidros calcogênicos como materiais sensoativos (ou transdutores) e eletrodos do tipo íon-seletivo, empregando a potenciometria como método de detecção [25]. O princípio de funcionamento deste sistema é baseado na utilização de um conjunto de vários sensores e medidas de potencial elétrico em relação a um eletrodo de referência de $\mathrm{Ag} / \mathrm{AgCl}$. Este sistema sensor tem sido utilizado para análise de água mineral, vinho, análises qualitativas de diferentes tipos de bebidas e na determinação quantitativa de diferentes tipos de componentes em líquidos complexos, com ênfase a determinação de metais pesados. A análise dos dados é auxiliada pela utilização de métodos estatísticos, como análise de componentes principais (PCA) e através de bancos de dados interpretados por redes neurais artificiais. A desvantagem desta língua é o fato da potenciometria necessitar de um eletrodo de referência, o que dificultaria a miniaturização de um dispositivo e a dificuldade de entendimento do mecanismo de resposta dos diferentes sensores.

Um terceiro tipo de sistema sensor baseado em voltametria, é composto de um arranjo de eletrodos de diferentes metais nobres (ouro, platina, irídio, paládio, ródio) atuando como eletrodos de trabalho [23]. Os valores de corrente medidos são usados para o reconhecimento de líquidos e para a calibração do sensor. Tal 
sistema tem sido empregado na análise de sucos naturais, de leite [71], de chá, de líquidos contendo íons complexos e também da qualidade de água potável em estações de tratamento. A desvantagem deste sistema está associada à necessidade de equipamentos sofisticados e à difícil interpretação dos espectros de voltametria.

O quarto tipo de língua eletrônica, o estudado neste trabalho, é baseado em filmes ultrafinos de polímeros condutores depositados sobre microeletrodos interdigitados de ouro, formando os sensores. Esta língua distingue líquidos de acordo com diferenças de sabor [19,34,35,72], e utiliza medidas de impedância como método de operação. A identificação e a discriminação de sabores é auxiliada pela utilização de ferramentas de computacionais, como PCA e Redes Neurais artificiais. As vantagens deste sistema são a alta sensibilidade e a ausência de um eletrodo de referência, o que facilita a miniaturização do sistema.

A literatura mostra várias aplicações da língua eletrônica à base de polímeros condutores. Riul et al [19] demonstraram que uma língua eletrônica composta pela combinação de filmes de polímeros condutores, complexo de rutênio e filmes de um azopolímero possui alta sensibilidade e reprodutibilidade, sendo capaz de: distinguir os quatro tipos básicos de paladar (em alguns casos abaixo do limite de detecção humano); de detectar baixas concentrações de metais pesados em água ultra pura; de distinguir bebidas de mesmo paladar e também de detectar a supressão de paladares.

Outros trabalhos também evidenciam a sensibilidade da língua eletrônica feita com filmes de polímeros condutores, mostrando a sua capacidade em identificar sacarose, quinino, $\mathrm{NaCl}$ e $\mathrm{HCl}$ em partes por bilhão (ppb) (em alguns casos três ordens de grandeza abaixo do sistema gustativo humano), bem como a sua competência na distinção de águas [33,34].

Foram também realizados experimentos utilizando sensores compostos por filmes finos feitos a partir de misturas de polímeros condutores com membranas lipídicas, imitando a língua humana [35], os quais mostraram-se, como nos outros casos, eficientes para a detecção nas análises dos padrões básicos de paladares e nos efeitos de supressão de paladares, sendo também estudados na análise de bebidas comerciais. $O$ trabalho mostra que este sistema sensor distingue soluções de $\mathrm{NaCl}, \mathrm{HCl}$ e sacarose a $5 \mathrm{mM}$ e de quinino a $0,1 \mathrm{mM}$, além de separar diferentes 
tipos de bebidas comerciais, dentre elas o café, água mineral, água destilada, canade-açúcar e água de coco.

Outra aplicação desta língua eletrônica consiste na análise de vinhos, bem como de paladares, onde neste caso os filmes finos são compostos por quitosana alternada com poliestireno sulfonato de sódio (PSS) [73]. Esta língua eletrônica mostra-se sensível, podendo detectar $\mathrm{NaCl}$ a $5 \mathrm{mM}$, sacarose a $5 \mathrm{mM}$, quinino a 5 $\mathrm{mM}$ e $\mathrm{HCl}$ a $1 \mathrm{mM}$ e ainda distinguir vinhos tintos conforme a safra e o produtor.

Foram também fabricados filmes finos dos polímeros condutores, polipirrol e polianilina, formando diferentes sensores compondo uma língua eletrônica capaz de distinguir os padrões básicos de paladares, diversos tipos de águas minerais, chás e cafés comerciais [35]. Esta língua foi capaz de detectar $\mathrm{KCl}, \mathrm{HCl}, \mathrm{NaCl}$ e sacarose a $5 \mathrm{mM}$, separar dois tipos de águas minerais, dois tipos de chá e dois tipos de café existentes no mercado.

Finalizando, recentemente foi apresentada uma língua eletrônica composta por polímeros condutores e lipídeos, sendo eficientemente empregada na classificação de vinhos, distinguindo-os quanto à safra, o local onde foi produzido e os tipos de uvas [37].

Narizes eletrônicos formados por diferentes tipos de sensores, como piezoelétrico, óptico, transistores por efeito de campo (FET), condutométricos, também têm sido empregados em uma extensa gama de aplicações, tanto no meio acadêmico quanto na indústria, que vão desde aplicações alimentícias, médicas até monitoramento ambiental e controle de processos [39,40,43,44,45,46,47,48,74,75].

NEs são capazes de detectar não somente substâncias odorantes, mas também substâncias voláteis capazes de interagir com a camada sensoativa dos sensores [74,75]. Esta tecnologia também pode ser usada como um método complementar para avaliação psicofísica, onde pessoas treinadas avaliam odores.

A primeira discussão em torno das propriedades de sensoriamento de gases por polímeros condutores foi realizada, em 1982, por Persaud e colaboradores. Sequencialmente, em 1983, sensores fabricados a partir de filmes finos de polipirrol foram investigados [76,77]. Resultados demonstraram significativas respostas elétricas destes filmes quando expostos ao vapor de etanol bem como reversibilidade do sinal após vários ciclos de exposição. A polianilina, proposta no início da década de 90, e seus derivados também se apresentam como bons materiais sensoativos para aplicações em sensores de gases [75,77]. 
Os sensores baseados em polímeros condutores depositados sobre microeletrodos interdigitados se apresentam como bons materiais para esse tipo de aplicação [78,79,80,81,82,83,84]. Da mesma forma que a língua eletrônica, neste sistema sensor a impedância dos sensores é medida quando estes são expostos a um gás. A grande variedade de polímeros disponíveis, baixo custo e utilização em temperatura ambiente fazem a eficácia da aplicação desta tecnologia de sistemas sensores.

Existem disponíveis no mercado sensores de gases fabricados com semicondutores inorgânicos, como óxido de estanho e titanato de bário, que são de alto custo e pouco seletivos [85], exigindo ainda elevadas temperaturas de trabalho, levando a um consumo extra de energia elétrica.

NEs baseados em metaloporfirinas depositadas sobre microbalanças de quartzo estão entre os dispositivos não seletivos mais frequentes na literatura $[26,45,47,86,87,88]$. Neste sistema a frequência de oscilação do cristal piezoelétrico de quartzo, recoberto com a camada sensitiva, varia linearmente a partir da interação com moléculas voláteis quando expostos a determinadas substâncias. Como aplicações mais específicas destes dispositivos pode-se citar inúmeras, como: análise de alimentos, como peixe, vegetais, carne bonina e vinho [45], aplicações médicas em prevenções para câncer de pulmão, próstata, bexiga, melanoma e esquizofrenia, bem como para a detecção de outras doenças [89], fragrâncias [75], aplicação de nariz eletrônico na caracterização das criações olfativas como perfumes, a fim de proteger suas propriedades intelectuais [76], entre outras. Estes sensores possibilitam a realização de medidas diretas com poucos refinamentos e facilidade de implementação [15,75].

Dentre os diversos tipos de línguas e narizes eletrônicos descritos anteriormente, uma aplicação relevante e potencial de alguns destes sistemas particularmente interessante neste estudo consiste na análise de combustíveis. Alguns trabalhos são encontrados na literatura para este fim, que relatam:

1) $O$ desenvolvimento e aplicação de dois tipos de narizes eletrônicos, um baseado em sensores piezoelétricos e outro baseado em sensores capacitivos, com polímeros condutores e metaloporfirinas como materiais sensoativos, utilizados simultaneamente para análise de combustíveis. Este trabalho foi publicado como fruto deste estudo, e será detalhado nos capítulos posteriores [51]; 
2) Uso de narizes eletrônicos constituídos por conjuntos de sensores de gases baseados em óxido de metal semicondutor, usados para classificar diferentes tipos de combustíveis, identificar níveis excedentes de um ou mais compostos orgânicos voláteis presentes nestes, bem como para classificar biocombustíveis em gasolinas [90].

3) Desenvolvimento de narizes eletrônicos baseados em fibra ótica para a avaliação de compostos voláteis e combustíveis [91].

Outros estudos baseados no desenvolvimento de sensores de gases e líquidos para combustíveis são particularmente importantes para possíveis futuras aplicações como unidades sensoriais de narizes e línguas eletrônicos, como: um sensor baseado em um polímero condutor capaz de determinar álcool e combustíveis automotivos [92]; um sensor de impedância para líquido aplicado para determinar quantidade de etanol em gasolina [93]; bem como, um sensor baseado em nanocompósitos de porfirinas [94], entre outros.

Neste trabalho foram desenvolvidos diferentes tipos de sensores de gases e líquidos para a análise de combustíveis, os quais constituíram narizes e línguas eletrônicas para detectar adulterações em gasolina e etanol combustível.

\section{3 - SISTEMAS HÍBRIDOS DE SENSORES}

Como ocorre nos sistemas gustativos e olfativos humanos, combinados com a visão e os sentidos táteis produzem uma impressão digital do alimento, a utilização simultânea de diferentes tecnologias de sensores é um método eficiente para aumentar o desempenho dos sistemas de sensores químicos.

A relação entre transdutores e interações químicas é o principal fator de importância para o desenvolvimento de sensores eficientes. Como consequência, uma vez que cada transdutor é diferentemente influenciado por interações químicas, espera-se que a aplicação de múltiplos transdutores para a mesma camada sensoativa aumente a seletividade total com evidentes vantagens em múltiplas aplicações quanto diferentes moléculas são apresentadas ao mesmo tempo. 
O acréscimo de informação obtido a partir do uso de múltiplas tecnologias de sensores tem sido demonstrado na literatura $[15,50,51,75,95,96,97,98]$. Para este tipo de combinações de diferentes tecnologias de sensores foi adotado o termo "conjunto híbrido de sensores" [99].

Aplicações simultâneas de conjuntos de sensores de gás baseados em porfirinas, sensores piezoelétricos e eletrodos potenciométricos foram demonstradas por Di Natale et al, onde a cooperação entre nariz e língua eletrônicos tem se mostrado eficiente para melhorar a desempenho de classificação em análises clínicas e alimentícias [100].

Sensores híbridos formados por eletrodos voltamétricos modificados quimicamente por três famílias de substâncias eletroativas, polímeros condutores, complexos de ftalocianinas e perilenos foram desenvolvidos e usados para classificar vinhos a partir de diferentes variedades de uvas [101].

Outra aplicação destes sistemas descreve uma língua eletrônica hibrida baseada na combinação entre potenciometria, voltametria e condutimetria usada para classificar diferentes tipos de leite fermentado [99].

Neste trabalho, as propriedades de dois conjuntos híbridos de sensores é discutida em uma aplicação onde se busca a caracterização da qualidade de gasolinas, em particular para detectar a presença de adulterantes em combustíveis comerciais [51].

\section{4 - PORFIRINAS E METALOPORFIRINAS}

A estrutura da porfirina foi inicialmente proposta por Kuster em 1912 e sequencialmente sugerida, com estruturas mais estáveis e totalmente sintéticas, por Fischer e Willstaller [102,103,104] em 1926. Assim sendo, a estrutura da porfirina consiste em um macrociclo tetrapirrólico (constituído por quatro anéis pirrol), ligados por quatro pontes metílicas, que possui no seu centro um espaço apropriado para acomodar um íon metálico, figura 2. 


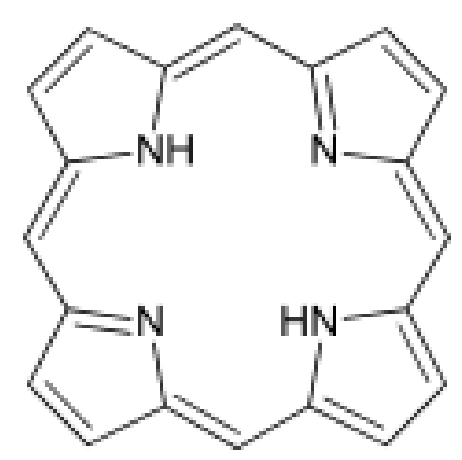

Figura 2 - Estrutura química de uma porfirina.

Este íon pode se ligar aos átomos de nitrogênio presentes na parte central da estrutura. $O$ macrociclo porfírico é um sistema aromático contendo 22 elétrons $\pi$ e obedece a regra de Huckel de aromaticidade $(4 n+2$ elétrons $\pi$, onde $n=4)$.

Os representantes mais comuns desta classe de compostos são o grupo hemo, que contém ferro, a clorofila, que contem magnésio e pigmentos biliares. Porfirinas e seus derivados são amplamente encontrados na natureza, desempenhando uma enorme variedade de funções nos sistemas biológicos. No corpo humano, o principal local de síntese de porfirinas é o fígado, nos hepatócitos.

A capacidade das porfirinas em mimetizar atividades biológicas as faz interessante em aplicações de detecção e, em particular para a detecção de compostos em fase gasosa.

As porfirinas também possuem a capacidade de serem metalizadas e desmetalizadas com o tratamento de ácidos de várias intensidades. Alterando-se o íon metálico pode se alterar a seletividade sensorial da porfirina. Grande parte dos metais presentes na Tabela Periódica já foram introduzidos em porfirinas.

Os derivados de porfirinas formados pela ligação de pelo menos um dos átomos dos nitrogênios centrais com um átomo de metal são denominados metaloporfirinas. O íon metálico ligado ao nitrogênio pode ter capacidade de ligar a mais um grupo químico no eixo perpendicular ao plano do anel da porfirina, produzindo compostos com diferentes geometrias de coordenação.

Compostos similares também podem ser obtidos modificando o macrociclo em si, como exemplo, um macrociclo corrol é obtido alterando um dos grupos metil com uma ligação simples. Este aspecto pode ser expandido, alterando a estrutura periférica padrão de substituição da porfirina. Desta forma, é possível influenciar a distribuição eletrônica no sistema aromático do macrociclo, assim influenciando a 
interação das metaloporfirinas com os ligantes axiais. Ou seja, o elétron retirado vai aumentar a carga positiva sobre o metal coordenado, o que conduzirá às interações fortes. Também é importante notar que a coordenação não é uma interação exclusiva que pode ocorrer entre metaloporfirinas e analitos. Interações fracas, como ligações de hidrogênio ou forças de van der Waals, devem ser levadas em conta e considerado o aumento do peso molecular dos analito com as variações do padrão de substituição de periféricos das porfirinas, podendo modular a importância destas interações fracas, acrescentando outra abordagem para influenciar sensibilidade e seletividade das metaloporfirinas.

Um grande número de sensores, com seletividades diferentes, pode ser preparado com o mesmo macrociclo mudando o átomo central. Conforme a quantidade de elétrons no metal central a porfirina pode ser caracterizada como um doador forte ou fraco de elelétrons. Essas propriedades podem ser previstas pelo princípio de Hard-Soft Acid-Base (HSAB). Esta regra estabelece que os ácidos fortes (íons metálicos) preferem vincular bases fortes (analito) e vice-versa.

Sistemas supramoleculares contendo porfirinas e metaloporfirinas e sua exploração como materiais quimicamente interativos em sensores químicos, fotosensores, entre outras, têm sido amplamente encontrados na literatura, numa vasta gama de estudos, com inúmeras possibilidades de aplicações [105,106,107].

\section{5 - POLÍMEROS CONDUTORES}

Os polímeros condutores podem também ser denominados de metais sintéticos por possuírem a capacidade de combinar as propriedades mecânicas e processabilidade de polímeros convencionais com um comportamento elétrico, óptico e magnético semelhante ao dos semicondutores inorgânicos e dos metais. Este conjunto de características faz com que os polímeros condutores possuam alto potencial tecnológico, em diversas aplicações como, por exemplo: em baterias recarregáveis, em dispositivos eletrônicos, em sensores químicos e térmicos, em biosensores, em janelas inteligentes, em diodos emissores de luz, em eliminação de 
cargas estáticas em microeletrônica, na proteção contra corrosão, no recobrimento de materiais, entre outras.

Os polímeros condutores provem de polímeros conjugados, os quais recebem esse nome por possuírem na sua estrutura química ligações simples e duplas alternadas ao longo da sua cadeia principal, que depois de dopados tornam-se condutores [108]. Com a dopagem podem se formar portadores de carga positiva, conhecidos como pólarons e bipólarons [108], o que possibilita que alguns destes polímeros possam atingir níveis de condutividade elétrica elevados, em alguns casos da ordem de milhares de $\mathrm{S} / \mathrm{cm}$.

Historicamente, o primeiro polímero condutor foi obtido em 1977 [109], pela exposição do poliacetileno na forma isolante (condutividade, $\sigma=10^{-5} \mathrm{~S} / \mathrm{cm}$ ), a agentes dopantes, oxidantes ou redutores, tornando-o condutor elétrico $(\sigma=102$ $\mathrm{S} / \mathrm{cm})$. No entanto, pela instabilidade térmica e ambiental, improcessabilidade (insolubilidade e infusibilidade) do mesmo, outros polímeros condutores foram investigados com o objetivo de superar estas dificuldades [110].

Dentre os polímeros orgânicos sintéticos, a polianilina, provavelmente é o mais antigo, tendo sido preparada pela primeira vez em 1862 [111]. Junto como os seus derivados, poli(o-metoxianilina)-POMA e poli(o-etoxianilina)-POEA, estão entre os polímeros condutores mais investigados, pois são facilmente sintetizados, possuem excelente estabilidade química e podem ser dopados de maneira controlada [112]. Acrescentando-se ainda que a POEA é um polímero solúvel em água.

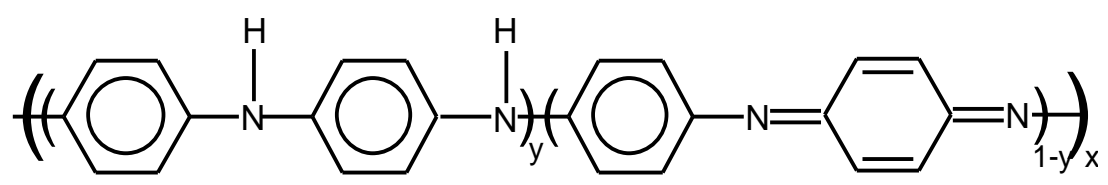

Figura 3 - Estrutura química da polianilina.

A polianilina, figura 3 , é formada por y e (1-y) unidades repetitivas das espécies reduzidas e oxidadas. O valor de y pode variar continuamente entre 1, para o polímero completamente reduzido (contendo somente nitrogênios do tipo amina), e 0 , no caso do polímero completamente oxidado (contendo somente nitrogênios do tipo imina) [113]. Os diferentes graus de oxidação da PANI são designados pelos 
termos leucoesmeraldina, protoesmeraldina, esmeraldina, nigranilina e pernigranilina, quando se assume os valores de $1 ; 0,75 ; 0,5 ; 0,25$ e 0 , respectivamente.

A polianilina pode ser dopada por protonação dos átomos de hidrogênio sem que ocorra mudança no grau de oxidação do polímero [113]. A dopagem química da polianilina no estado esmeraldina é feita por protonação em solução ácida aquosa, aumentando a condutividade até cerca de 10 ordens de grandeza em relação à polianilina não dopada e atingindo valores de condutividade entre 1 e 5 S/cm [113]. Os átomos de nitrogênio são protonados através de uma reação do tipo ácido-base. A figura 4 mostra o processo de dopagem da polianilina no estado esmeraldina.

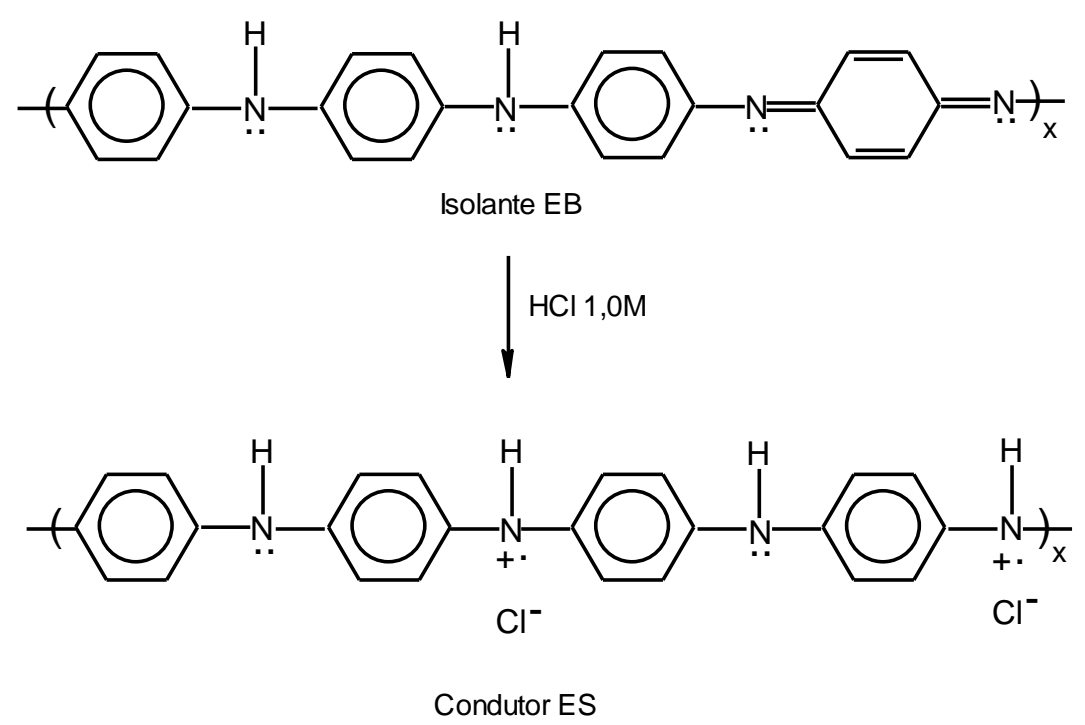

Figura 4 - Dopagem da polianilina no estado esmeraldina. EB=base esmeraldina; $E S=$ forma dopada de sal de esmeraldina.

Existe uma grande quantidade de aplicação de polianilinas como materiais sensíveis e/ou transdutores em sistemas sensores [114,115,116,117,118]. Polianilinas dopadas com ácidos orgânicos podem detectar compostos orgânicos voláteis como acetona, éter, clorofórmio [111]. Assim como também, filmes de POEA podem ser utilizados reversivelmente na detecção de etileno [119], gás liberado por frutas durante o processo de amadurecimento.

Outro material condutor, o polipirrol, foi descrito em 1968 que poderia ser polimerizado eletroquimicamente, e em 1973 [111] a sua polimerização química foi anunciada. Na década de oitenta, um grande avanço no estudo da polianilina e do 
polipirrol consistiu na habilidade de reproduzir a síntese de polímeros puros com peso molecular, estado de oxidação e grau de dopagem controlados [111].

Os polímeros condutores possuem a desvantagem de serem materiais de difícil processamento, por serem infusíveis e apresentarem baixa solubilidade em solventes comuns. Entretanto, técnicas de fabricação de filmes ultrafinos, como a de Langmuir-Blodgett (LB) e automontagem (AM), são promissoras com relação ao processamento de polímeros condutores [119]. Em aplicações para sensores, a aplicação de filmes ultrafinos é de grande importância, devido ao aumento significativo da sensibilidade dos dispositivos pela redução da espessura até a escala nanométrica.

A técnica de deposição de automontagem (AM) consiste na adsorção eletrostática (química ou física) de camadas ultrafinas (10-100 Å) de materiais sobre a superfície de um suporte sólido [119] e apresenta algumas vantagens quando comparada à técnica LB [120]. Na técnica de deposição de automontagem, os suportes sólidos onde será depositado o filme podem ter qualquer forma. O tempo de deposição independe da área a ser recoberta e o método pode ser utilizado no laboratório sem a necessidade de equipamentos especiais.

A fabricação de um filme nanoestruturado pela técnica de deposição por automontagem consiste primeiramente na imersão de um suporte sólido, cuja superfície (neste caso) é carregada negativamente [119], figura 5 (a), numa solução contendo um polieletrólito com cargas positivas (policátion), durante um tempo previamente determinado, ocorrendo então, através de atração eletrostática, adsorção física de uma camada do material, figura 5 (b). Com isso, a carga da superfície do suporte torna-se a mesma do policátion, finalizando o processo de adsorção. Para que seja removido o excesso de material, o suporte é imerso numa solução de lavagem e depois seco com ar comprimido ou nitrogênio. Finalizando é realizada a adsorção de uma nova camada, agora de um poliânion, figura 5 (c), da mesma maneira que para o policátion, formando uma bicamada, como mostra a figura 5. 


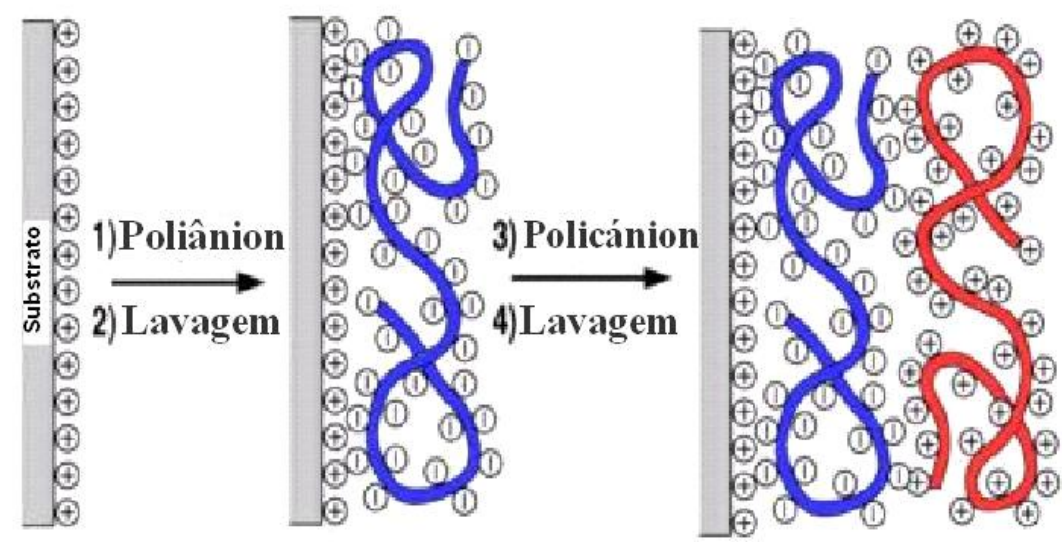

(a)

(b)

(c)

Figura 5 - Representação esquemática do processo de deposição automontagem: (a) Suporte sólido com superfície carregada negativamente. (b) Adsorção de um policátion. (c) Adsorção de um poliânion e formação de uma bicamada.

A repetição sucessiva dessas etapas forma filmes multicamadas, cuja espessura pode ser controlada pelo número de camadas depositadas (número de imersões) e a espessura de cada camada pode ser controlada através das condições das soluções dos materiais depositados [119], relacionadas com o pH, concentração de material, força iônica, etc. Alguns derivados de polianilina (policátions) são bastante solúveis em água quando estão dopados e podem, portanto, serem adsorvidos com poliânions comerciais, como o poliestireno sulfonato de sódio (PSS), através de atração eletrostática.

\section{6 - MEDIDAS DE IMPEDÂNCIA}

As propriedades elétricas de um filme de polímero condutor podem ser alteradas irreversivelmente pelo deslocamento de espécies ionizadas para o seu interior, bem como por polarização permanente do filme, quando este é submetido à corrente contínua. Medidas em corrente alternada impedem esses efeitos. Além disso, a flexibilidade de operar sensores feitos de polímeros condutores, em diferentes frequências, permite que estes possam ser sensíveis e seletivos a certas substâncias, o que normalmente não ocorreria com medidas em corrente contínua. 
A literatura tem mostrado que a sensibilidade e a seletividade de sensores de gás são melhoradas quando estes são operados em corrente alternada, permitindo inclusive a redução do número de sensores utilizados [121].

Dentre as técnicas de medidas em regime de corrente alternada, a espectroscopia de impedância tem se mostrado bastante promissora com respeito à caracterização das propriedades elétricas de filmes poliméricos, como membranas, hidrogéis, e polímeros condutores. Os dados experimentais obtidos com essa técnica podem ser modelados por meio de um circuito equivalente que permite identificar variações na solução eletrolítica, no filme depositado sobre um arranjo predeterminado de eletrodos e na dupla camada elétrica formada na interface filme/eletrólito [122].

\subsection{1 - Teoria envolvida na análise por espectroscopia de impedância}

Na figura 6 está esquematizado um circuito equivalente que descreve as características elétricas de um metal coberto com um filme não muito condutor, imerso em uma solução eletrolítica [122].

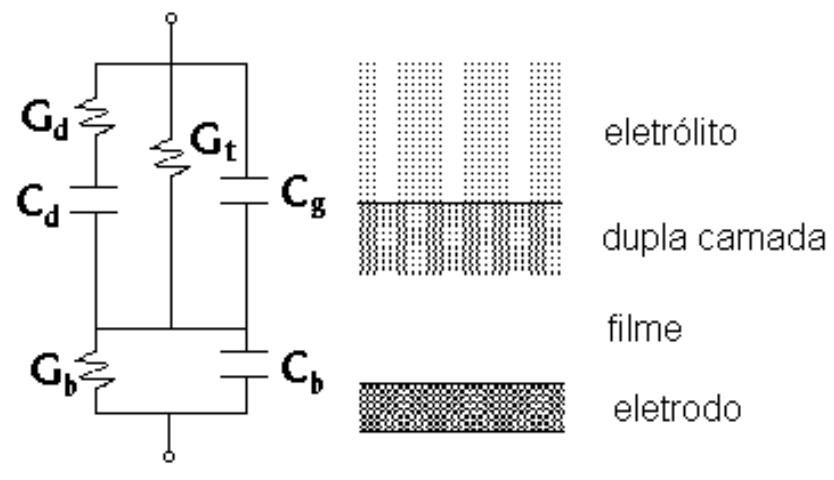

Figura 6 - Circuito equivalente para um sistema representando um eletrodo metálico coberto com um filme semicondutor, imerso em uma solução eletrolítica.

Um circuito desse tipo é formado levando-se em conta todos os processos que contribuem para a impedância do sistema. Cg é a capacitância geométrica do conjunto de eletrodos interdigitados imerso em uma solução eletrolítica, e uma maneira simples e alternativa de calculá-la está descrita na referência [123] e 
apresentada no item 3.2.3.1 deste trabalho. Gt representa uma condutância que permite a transferência de carga através da interface filme/eletrólito. A dupla camada formada pela adsorção de íons na superfície do eletrodo é representada pela capacitância $\mathrm{Cd}$, que é carregada pela condutância eletrolítica $\mathrm{Gd}$. A condutância total do eletrólito é $(G d+G t)$, mas devido à natureza pouco condutora do filme que cobre os eletrodos $\mathrm{Gt}<<\mathrm{Gd}$, de forma que $\mathrm{Gd}$ acaba representando efetivamente a condutância da solução eletrolítica. O filme que cobre os eletrodos é representado pela associação em paralelo de $\mathrm{Cb}$ e Gb, em série com a impedância da solução.

A admitância do circuito equivalente da figura 7 é dada por [124]:

$Y_{T}=G_{T}+i \cdot \omega \cdot C_{T}$

na qual

$$
\begin{aligned}
& C_{T}=\frac{\left[\left(C_{b} \cdot G^{2}+C \cdot G_{b}^{2}\right)+\omega^{2} \cdot\left(C_{b} \cdot C^{2}+C_{b}^{2} \cdot C\right)\right]}{\left[\left(G_{b}+G\right)^{2}+\omega^{2}\left(C_{b}+C\right)^{2}\right]} \\
& G_{T}=\frac{\left[\left(G_{b}^{2} \cdot G+G_{b} \cdot G^{2}\right)+\omega^{2}\left(C_{b}^{2} \cdot G+C^{2} \cdot G_{b}\right)\right]}{\left[\left(G_{b}+G\right)^{2}+\omega^{2}\left(C_{b}+C\right)^{2}\right]}
\end{aligned}
$$

sendo $\mathrm{C}$ e $\mathrm{G}$ expressos por:

$$
\begin{gathered}
C=C_{g}+\frac{C_{d} G_{d}^{2}}{G_{d}^{2}+\omega^{2} C_{d}^{2}} \\
G=G_{t}+\frac{\omega^{2} \cdot C_{d}^{2} \cdot G_{d}}{G_{d}^{2}+\omega^{2} \cdot C_{d}^{2}}
\end{gathered}
$$

A figura 7 indica a predição teórica do sistema acima. 


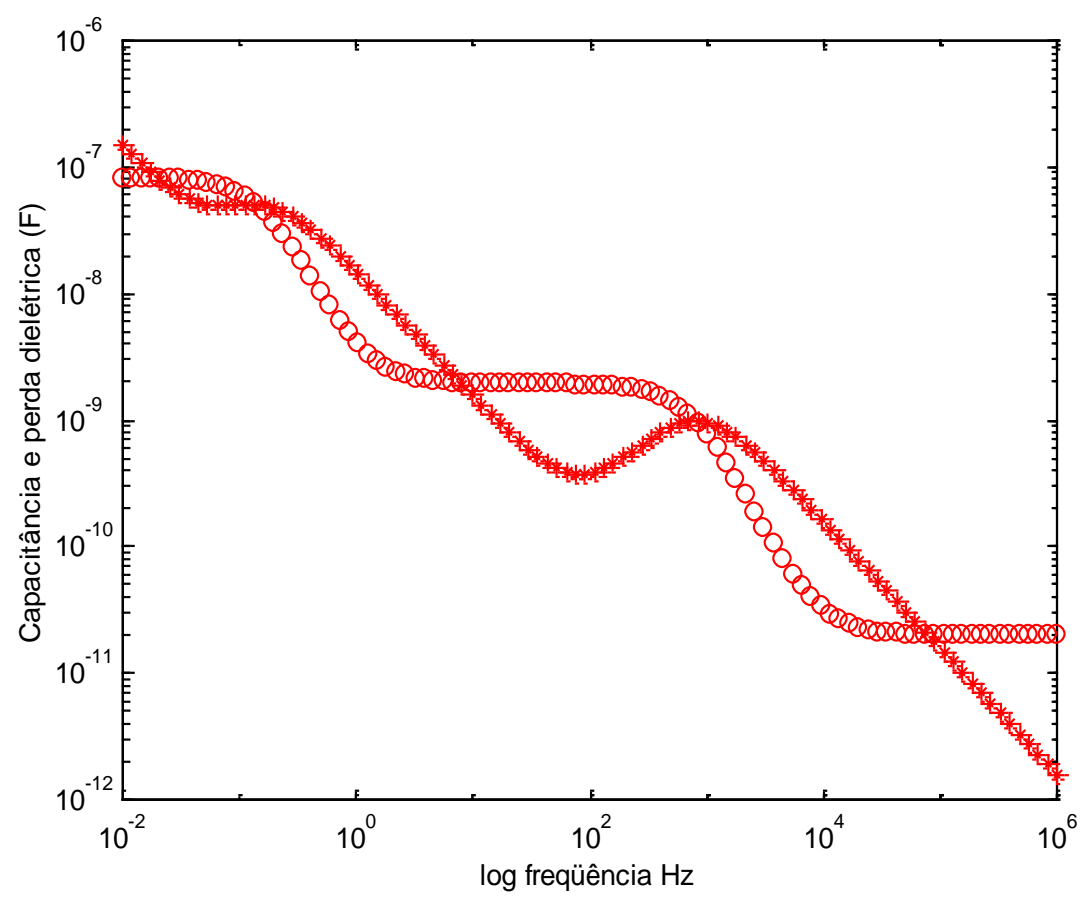

Figura 7 - Curvas teóricas de capacitância (o) e perda dielétrica $\left(\varepsilon^{*}\right)$ para 0 circuito equivalente descrito na figura 6 . Os valores utilizados para gerar as curvas de capacitância e perda dielétrica foram: $\mathrm{Cg}=20 \mathrm{pF} ; \mathrm{Cb}=2 \mathrm{nF} ; \mathrm{Cd}=100 \mathrm{nF} ; \mathrm{Gt}=10^{-8}$ $\mathrm{S} ; \mathrm{Gb}=10^{-7} \mathrm{~S} ; \mathrm{Gd}=10^{-5} \mathrm{~S}$.

De uma maneira geral, pode-se dizer que na região de baixas frequências a capacitância é dominada por efeitos de dupla camada, sendo que na região de 10 $\mathrm{Hz}$ a $10^{4} \mathrm{~Hz}$ aparecem os efeitos devido à presença do filme sobre os eletrodos. Em frequências muito altas, acima de $10^{5} \mathrm{~Hz}$, a impedância do sistema é dominada pela capacitância geométrica dos eletrodos.

\section{7 - MEDIDAS PIEZOELÉTRICAS E TRANSDUTORES DE MASSA}

A piezoeletricidade foi descoberta pelos irmãos Pierre e Jacques Curie [125], em 1880, verificando que determinados materiais cristalinos, se submetidos a uma tensão mecânica produzem um potencial elétrico entre as superfícies deformadas, e que a aplicação de uma voltagem produz deformações dimensionais, com o mesmo coeficiente de proporcionalidade do fenômeno anterior.

A propriedade piezoelétrica é possível somente para sólidos iônicos cristalinos que se cristalizam em estruturas carentes de centro de inversão [126]. 
Quando uma força, de compressão ou tensão é aplicada as suas superfícies, cargas, devidas à presença de íons e ligações polares, são separadas, produzindo um momento dipolo induzido e consequentemente uma polarização é gerada. Estes efeitos se acumulam pela regularidade na estrutura cristalina, surgindo um potencial na superfície do material.

Por outro lado, a aplicação de uma tensão elétrica provoca um deslocamento de cargas, por forças eletrostáticas, causando uma deformação nas células unitárias do cristal e, consequentemente, em todo material.

Se o potencial aplicado for alternado, o material piezoelétrico vibra com a mesma frequência da tensão de excitação. Entretanto, a amplitude dessa vibração é máxima quando a frequência da tensão elétrica coincidir com uma das frequências de ressonância do cristal. Como a piezoeletricidade é o efeito que liga estresse mecânico a deslocamento de carga, gerando um campo elétrico, bem como a aplicação de uma força mecânica sobre um material piezoelétrico induz um campo elétrico no cristal, devido a perda de carga, a aplicação de uma força constante produz apenas tensão transitória, que pode chegar a $20.000 \mathrm{~V}$. Por este motivo, piezeletricidade é basicamente estudada e utilizada no modo AC. Esse fato é, porém, muito benéfico do ponto de vista da medição, pois a frequência é umas das quantidades mais precisamente mensuráveis.

Dentre os diversos materiais piezoelétricos podemos citar como exemplo entre os mais conhecidos e aplicados, o quartzo, a turmalina, o tartarato de sódio e de potássio, o titanato zirconato de chumbo, o zirconato de bário, o polifluoreto de viniledeno e materiais compósitos envolvendo polímeros e cerâmicas piezoelétricas.

Materiais piezoelétricos têm sido extremamente utilizados como transdutores eletromecânicos e como osciladores altamente estáveis para controle de frequência, com diversas aplicações em circuitos eletrônicos (base de tempo e filtros seletivos), dispositivos eletroacústicos (microfones e alto-falantes), atuadores eletromecânicos (microbombas, microposicionadores), bem como transdutores de sensores físicos e químicos [127,128]. Os transdutores fabricados a partir de cristais piezoelétricos foram sugeridos por Saurbrey em 1959 e mais tarde, em 1964, demonstrados por King [129]. Por ser econômico e por haver um coeficiente piezoelétrico relativamente grande, o quartzo é o material escolhido para a maior parte das aplicações em sensores, tendo estrutura cristalográfica hexagonal sem centro de simetria $[74,75]$. Tanto a intensidade do coeficiente piezoelétrico como a extensão da sua 
dependência da temperatura são influenciados pela orientação do corte do cristal em respeito ao eixo cristalográfico principal, figura 8 . O corte mais aplicado é o AT, detalhado na figura 9.

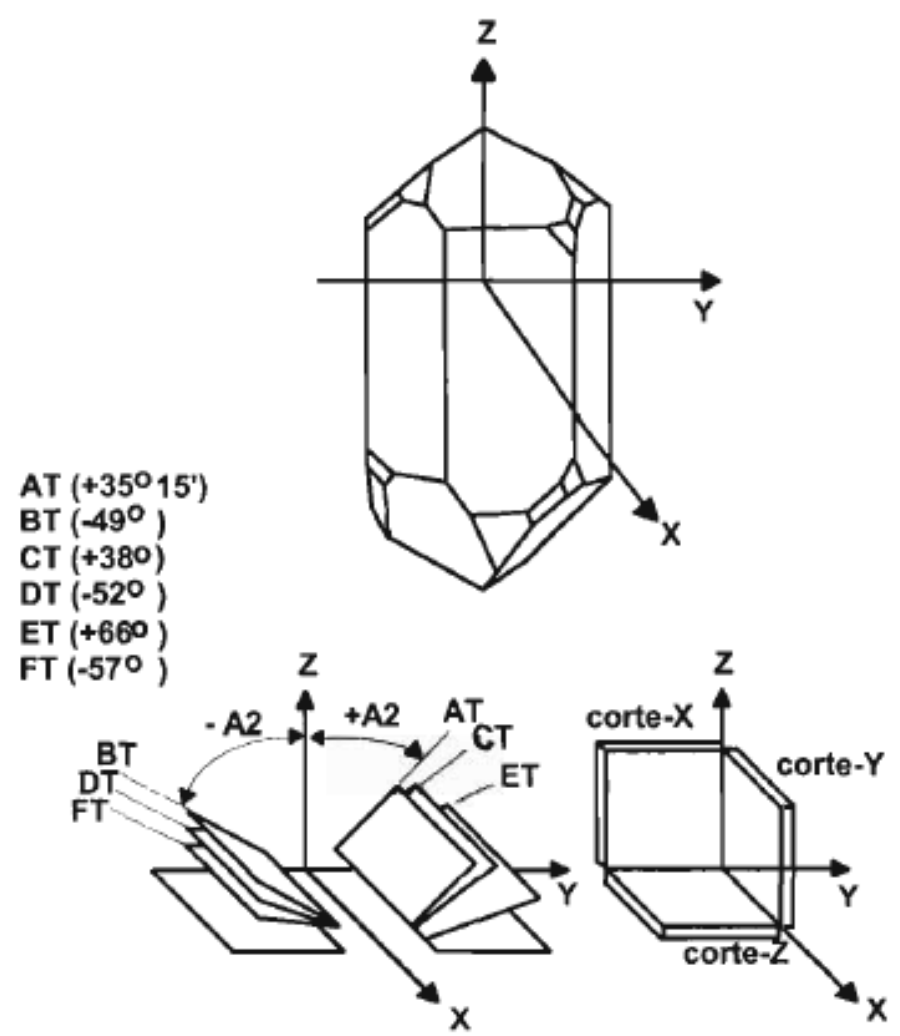

Figura 8 - Cortes do cristal de quartzo.

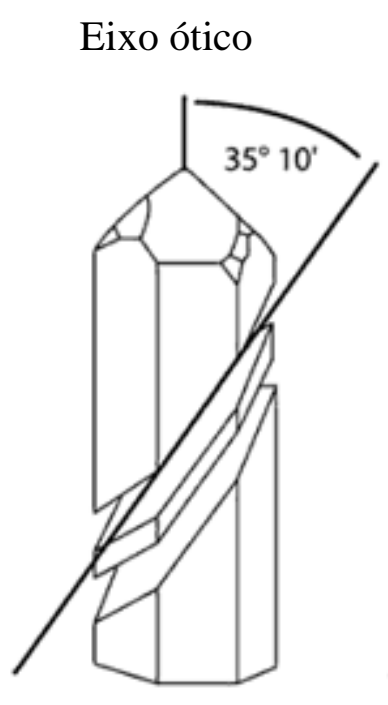

(a)

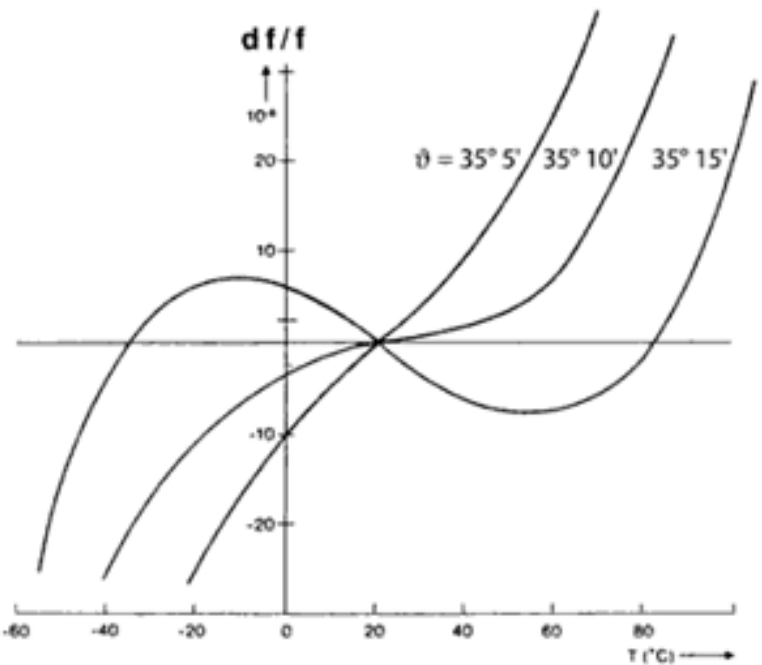

(b)

Figura 9 - a) Orientação do corte AT do cristal de quartzo. b) Relação da frequência relativa do cristal da microbalança de quartzo em relação a temperatura. 
Por razões práticas, a orientação ideal é escolhida de forma que o cristal tenha uma mínima dependência da temperatura dentro da faixa de temperatura de funcionamento previsto. Muitas aplicações usam o corte AT com inclinação em $35^{\circ} 15^{\prime \prime}$ no plano yz, exibindo o mínimo coeficiente de temperatura entre $50-70^{\circ} \mathrm{C}$. A temperatura ambiente encontrada nas aplicações de sensoriamento está entre 25 e $45^{\circ} \mathrm{C}$, portanto o corte $35^{\circ} 10^{\prime \prime}$ é o escolhido para este fim.

Microbalanças de quartzo (MBQ), figura 10, utilizam cristais piezoelétricos devidamente seccionados ao longo do eixo cristalino, em corte AT, onde a ressonância mecânica do cristal de quartzo é associada com uma ressonância elétrica. Uma vez que a ressonância mecânica do cristal é extremamente estável, a ressonância elétrica é caracterizada por um grande fator de qualidade.

As microbalanças de quartzo (MBQ) oscilam na frequência entre 5 e $50 \mathrm{MHz}$ aproximadamente. A oscilação do cristal de quartzo decorre do campo elétrico AC aplicado sobre o cristal a partir dos eletrodos metálicos. Os eletrodos são depositados diretamente sobre o cristal de quartzo, embora, a princípio, a ativação sem contato com o cristal também é possível. Um dos eletrodos é menor que o outro, a fim de eliminar o efeito de borda do campo elétrico. Esta geometria é necessária para tornar o campo o mais cilíndrico possível, figura 10.

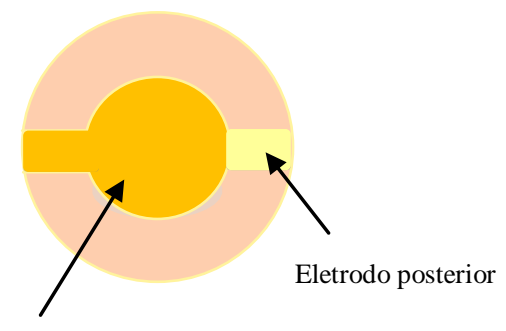

Eletrodo anterior

Figura 10 - Microbalança de quartzo.

A frequência fundamental do cristal depende da sua espessura. A espessura do eletrodo também desempenha um papel importante, pois não há deslocamento piezoelétrico fora do campo elétrico, isto significa que, na borda entre o metal e a região sem metal, a energia é refletida, resultando na formação de uma onda estacionária na parte excitada do cristal, sob os eletrodos metálicos. Este efeito ocorre quando a espessura do metal é menor que $50 \mu \mathrm{m}$. Por outro lado, se o metal 
é muito espesso o cristal deixa de oscilar. Existem dois modos de excitação pelo campo AC, longitudinal e transversal.

A relação quantitativa que rege o funcionamento desses sensores portanto, relacionam massa com variação de frequência. Esta propriedade é explorada para sensoriamento químico, onde a frequência das oscilações mecânicas diminuem quase linearmente com a massa sobre a superfície de quartzo. O mecanismo de funcionamento de sensores químicos formados a partir de microbalanças de quartzo baseia-se no revestimento do cristal piezoelétrico de quartzo com um filme sensoativo, como esquematizado na figura 11. A frequência de vibração fundamental varia linearmente com as interações de moléculas voláteis sobre superfície do revestimento, que é diretamente relacionada à massa do composto incorporado, de acordo com a lei de Sauerbrey:

$$
\Delta \mathrm{f}=-\mathrm{Kq} \times \Delta \mathrm{m}
$$

Onde, $\mathrm{Kq}$ é uma constante do quartzo, enquanto $\Delta \mathrm{m}$ é a variação de massa, quanto maior é a massa incorporada ao quartzo, menor é a frequência de oscilação

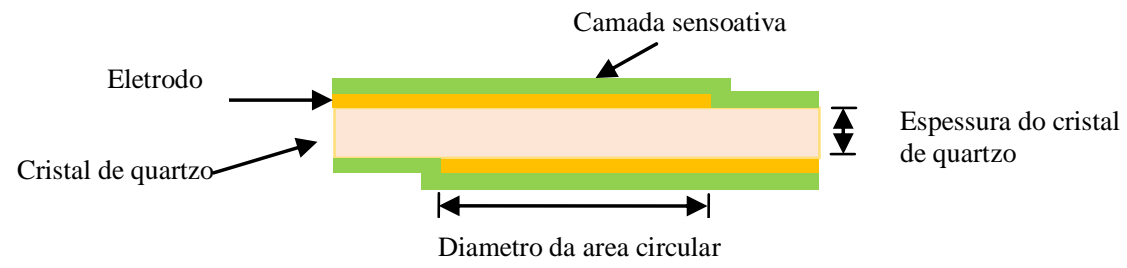

Figura 11 - Detalhe de uma microbalança de quartzo. Cristal de quartzo, eletrodos e camada sensoativa.

A baixa seletividade de sensores baseados em QMB leva a sua exploração em conjuntos de sensores, como narizes eletrônicos, onde cada QMB é revestida com diferentes materiais sensoativos, formando diferentes unidades sensoriais. 


\section{8 - MÉTODOS DE ANÁLISE DE DADOS}

Uma língua e um nariz eletrônico são compostos por diversos sensores diferentes entre si. Para a análise de quaisquer substâncias devem ser realizadas diversas medidas com cada um dos sensores com o intuito de se montar uma matriz, onde cada coluna apresenta os resultados de um mesmo sensor e as linhas apresentam o resultado de cada uma das medidas. Os sensores são medidos sequencialmente de maneira que cada linha representa uma destas sequências. A manipulação dessa grande quantidade de dados torna-se complicada para o operador do sistema, sendo necessário o desenvolvimento de programas computacionais para facilitar esta análise. $\mathrm{Na}$ literatura são encontrados trabalhos envolvendo narizes e línguas eletrônicas com interpretação de dados através de programas computacionais como PCA [130,131,132], Redes Neurais [131,133,134], e Redes Neuro Fuzzy $[131,135]$.

\subsection{1 - PCA (Principal component analysis - Análise da componente principal)}

A PCA [130] é uma ferramenta computacional utilizada para correlacionar dados estatisticamente. Esta ferramenta é aplicada ao sistema com a finalidade de indicar se uma determinada amostra é semelhante ou não a outra, qual variável contribui mais para essa diferenciação e se as variáveis estão correlacionadas ou são independentes umas das outras.

A PCA reduz praticamente a dimensão do problema para duas componentes principais, através da combinação linear das variáveis iniciais que mais contribuem para tornar as amostras diferentes umas das outras. Em outras palavras, o objetivo principal da análise de componentes principais é a obtenção de um pequeno número de combinações lineares (componentes principais) de um conjunto de variáveis, que retenham o máximo possível da informação contida nas variáveis originais. 
Os componentes são extraídos na ordem do mais explicativo para o menos explicativo. Teoricamente o número de componentes é sempre igual ao número de variáveis. Entretanto, poucos componentes são responsáveis por grande parte da explicação total.

Neste trabalho a PCA foi utilizada para correlacionar estatisticamente os dados obtidos pelos sensores, com a finalidade de indicar se uma determinada substância é semelhante ou não a outra.

\subsection{2 - PLS ( Partial Least Square - Mínimos Quadrados Parciais)}

O método da regressão por mínimos quadrados parciais (PLS), como a PCA, é uma ferramenta computacional utilizada para correlacionar dados estatisticamente. O PLS combina as características da análise de componentes principais com a regressão linear. No PLS também existe a função de redução da dimensionalidade de dados, porém requer uma matriz de variáveis dependentes, além dos dados iniciais, sendo um método de regressão que busca encontrar fatores que consigam capturar a variância dos dados originais e também obter correlação com a variável dependente.

Este método vem ganhando destaque nos últimos anos e representa um dos métodos mais avançados para resolver problemas de regressão linear múltipla e se torna muito útil quando é necessário predizer um conjunto de variáveis dependentes partindo de um número elevado de variáveis independentes.

Os algoritmos PLS utilizam técnicas de decomposição espectral, onde a decomposição é realizada considerando a informação de concentrações das amostras de calibração, o que resulta em pesos maiores para espectros com concentrações do analito mais altas e dois conjuntos de vetores e scores, um para os dados espectrais e outro para as concentrações.

No PLS as componentes são denominadas variáveis latentes e não necessariamente coincidem com as componentes principais.

A quantidade adequada de componentes principais ou fatores pode ser analisada pelo cálculo do PRESS ( Prediction Residual Error Sum of Squares- soma 
dos quadrados dos resíduos dos erros de predição) para cada fator possível. O PRESS é calculado a partir da construção de um modelo de calibração com um determinado número de fatores. O modelo elaborado é usado para a determinação da concentração em amostras conhecidas.

A qualidade do modelo obtido com a PLS pode ser validada através do cálculo do erro quadrático médio, obtido durante a fase de calibração (Root Mean Square of Calibration: RMSEC) e durante a fase de validação (Root Mean Square Error of Cross Validation: RMSECV).

As vantagens do PLS são que ele associa a cobertura espectral com a predição e as calibrações são em geral robustas podendo ser utilizado em misturas complexas. Como desvantagem pode-se citar a necessidade de uma adequada seleção das amostras de calibração, pois estas não devem apresentar colinearidade em suas propriedades. 


\section{3 - OBJETIVOS}

O objetivo deste trabalho foi desenvolver sistemas multissensoriais híbridos, eficientes para análise de combustíveis, buscando, através do desenvolvimento de língua e narizes eletrônicos, ferramentas úteis para identificar adulterações destes.

Para tanto foram focalizados, conforme o desenvolvimento natural do trabalho, os seguintes objetivos específicos:

- Estudo de geometrias de microeletrodos eficientes para análise em combustíveis;

- Estudo da estabilidade de filmes nanoestruturados na presença de combustível;

- Desenvolvimento de sistemas multissensoriais, língua e narizes eletrônicos para avaliação de combustíveis;

- Desenvolvimento do sistema de medidas para língua e narizes eletrônicos;

- Análise de combustíveis com língua e narizes eletrônicos;

- Desenvolvimento de dois sistemas multissensoriais híbridos a partir da combinação língua - nariz e de dois tipos de narizes eletrônicos diferentes;

- Desenvolvimento dos sistemas de medidas para conjuntos híbridos de sensores;

- Análise da adulteração de combustíveis com os sistemas híbridos;

- Avaliação de diferentes ferramentas de análise multivariada de dados para sistemas híbridos de multissensores. 


\section{4 - MATERIAIS E MÉTODOS}

\section{1 - MATERIAIS}

\subsection{1 - Materiais Sensoativos}

Os polímeros polianilina-PANI e poli(o-etoxianilina)-POEA foram obtidos por síntese química segundo método descrito por Mattoso et al. [112].

Poli(3-metiltiofeno)-P3MTh foi obtido por síntese eletroquímica segundo método descrito por Forner [136]. Polipirrol-PPy e poli(estireno sulfonado)-PSS foram adquiridos da Aldrich, enquanto que poli(3,4-etilenodioxi tiofeno)-PEDOT (Baytron P) foi obtido da Bayer. Lignina sulfonada-LS foi adquirida da Melbar Produtos de Lignina S/A.

Tetrafenilporfirinas funcionalizadas com metal, ferro (FeTPP), zinco (ZnTPP), manganês (MnTPP) e cobalto (CoTPP), bem como manganês-octoetilcorrol (MnOEC) foram sintetizados pelo departamento de química da Università Degli Studi Di Roma, Tor Vergata. As propriedades sensíveis destas porfirinas foram amplamente caracterizadas no passado [105,107,137,141]. Ftalocianina tetrasulfonada de níquel (FtTsNi) foi adquirida da Aldrich.

$\mathrm{Na}$ Tabela 1 estão apresentadas as estruturas químicas dos materiais sensoativos utilizadas na fabricação dos sensores.

Tabela 1- Fórmula estrutural dos materiais sensoativos utilizados na fabricação dos sensores.

\begin{tabular}{|c|c|}
\hline Nomenclatura & Estrutura Química \\
\hline PANI &
\end{tabular}




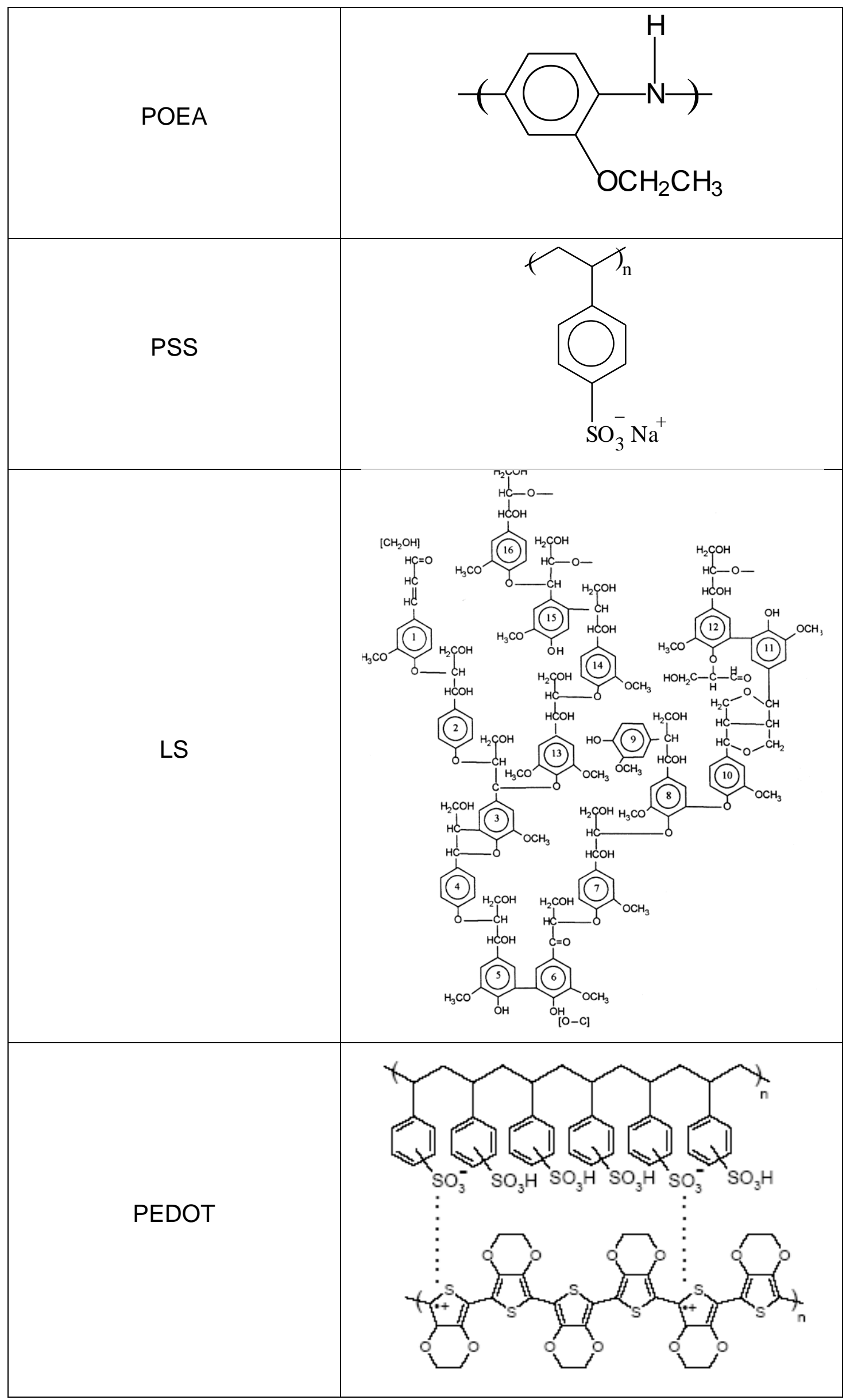




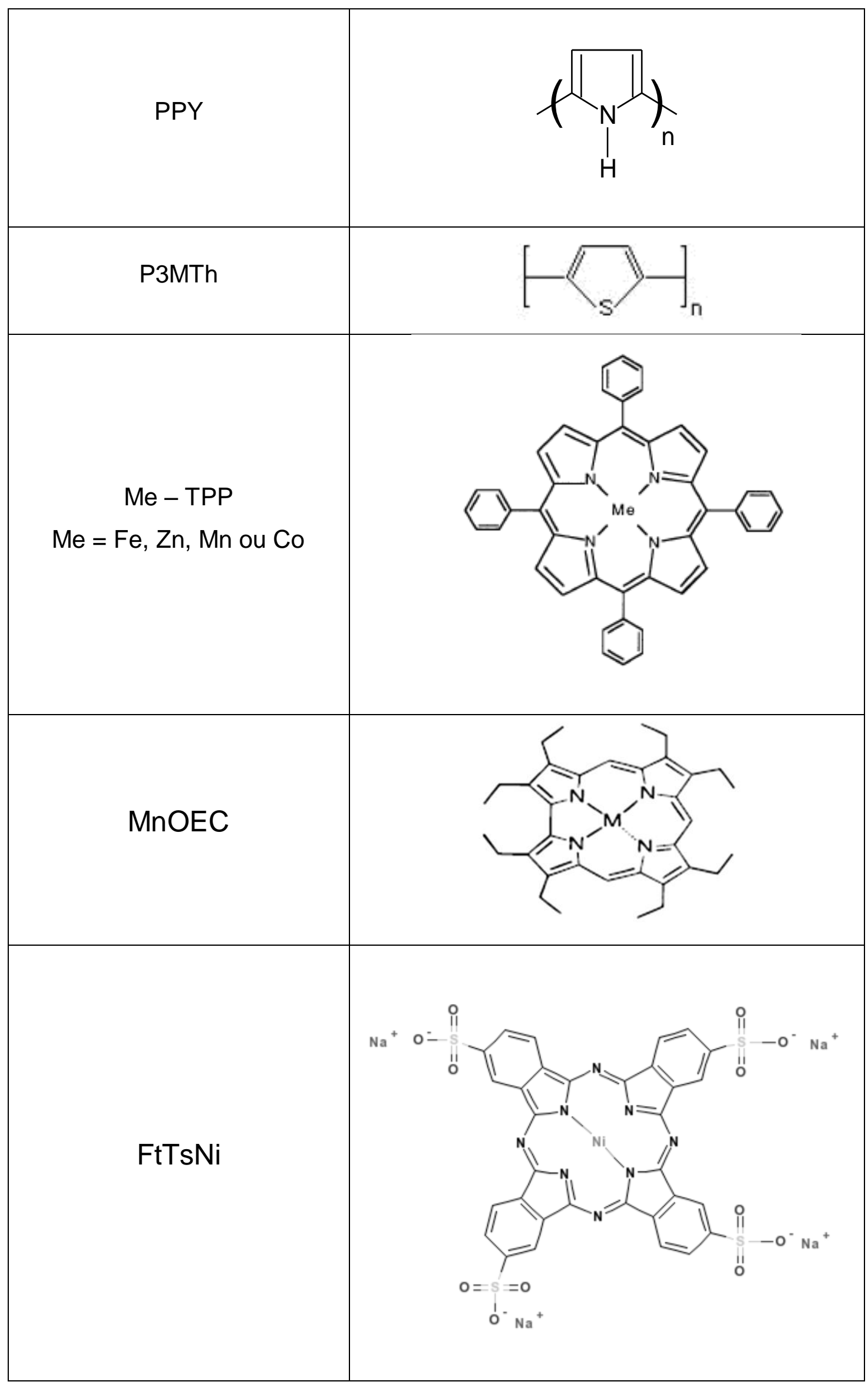




\subsection{2 - Substratos para estudo do filme}

Foram usadas placas de vidro óptico padronizadas - BK/ Superwrite da Opto Eletrônica S.A. (30x10x1 mm), divididas ao meio e apropriadas para medidas em espectrômetro UV-Vis.

\subsection{3 - Microeletrodos}

Microeletrodos foram usados para a fabricação das unidades sensoriais da LE e de um dos NEs desenvolvidos neste trabalho. Detalhes da fabricação deste dispositivo estão no Apêndice A. Estes dispositivos atuam como transdutores, gerando um valor de capacitância para cada substância analisada. A figura 12 mostra uma ilustração simplificada do microeletrodo interdigitado e suas dimensões.

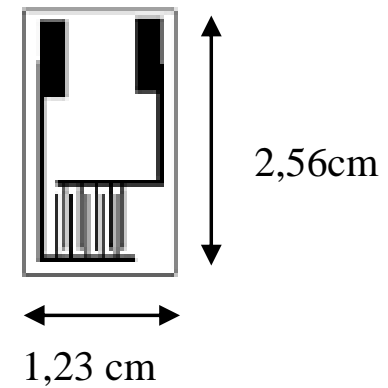

Figura 12 - Ilustração de um microeletrodo interdigitado e suas dimensões.

Os microeletrodos foram produzidos no Laboratório de Microeletrônica da EPUSP (conforme metodologia apresentada no Apêndice A) e o desempenho elétrico de diferentes geometrias de microeletrodos foi avaliado expondo-os a solventes e combustíveis.

A variação na geometria do microeletrodo pode inferir novas capacidades aos sistemas sensores desenvolvidos, como maior sensibilidade, facilidade de fabricação e redução de custo [36]. Nesse sentido, sete tipos de geometrias de microeletrodos foram utilizados neste trabalho, diferenciando umas das outras em relação ao comprimento, largura e números de dígitos, bem como o espaçamento entre dígitos, como mostra a tabela 2. Nas figuras 13 e 14 são apresentadas 
fotografias dos eletrodos fabricados segundo as geometrias descritas na tabela 2.

Tabela 2 - Tipos de geometrias de microeletrodos e suas dimensões

\begin{tabular}{|c|c|c|c|}
\hline $\begin{array}{c}\text { Tipos de } \\
\text { microeletrodos }\end{array}$ & $\begin{array}{c}\text { Número de } \\
\text { dígitos }\end{array}$ & $\begin{array}{c}\text { Largura do } \\
\text { digito }\end{array}$ & $\begin{array}{c}\text { Espaçamento } \\
\text { entre dígitos }\end{array}$ \\
\hline T-10 & 50 pares & $10 \mu \mathrm{m}$ & $10 \mu \mathrm{m}$ \\
\hline $\mathrm{T}-50$ & 50 pares & $10 \mu \mathrm{m}$ & $50 \mu \mathrm{m}$ \\
\hline $\mathrm{N}-10$ & 1 par & $550 \mu \mathrm{m}$ & $10 \mu \mathrm{m}$ \\
\hline $\mathrm{NF}-12$ & 1 par & $550 \mu \mathrm{m}$ & $12 \mu \mathrm{m}$ \\
\hline $\mathrm{NF}-120$ & 1 par & $550 \mu \mathrm{m}$ & $120 \mu \mathrm{m}$ \\
\hline $\mathrm{NF}-225$ & 1 par & $550 \mu \mathrm{m}$ & $225 \mu \mathrm{m}$ \\
\hline NF-440 & 1 par & $550 \mu \mathrm{m}$ & $440 \mu \mathrm{m}$ \\
\hline
\end{tabular}

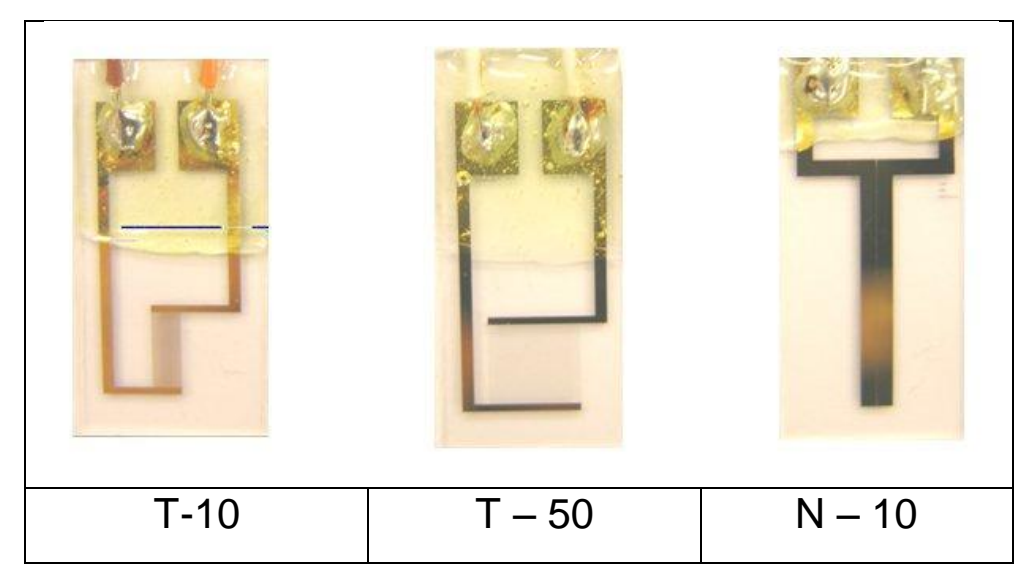

Figura 13 - Microeletrodos de diferentes geometrias.

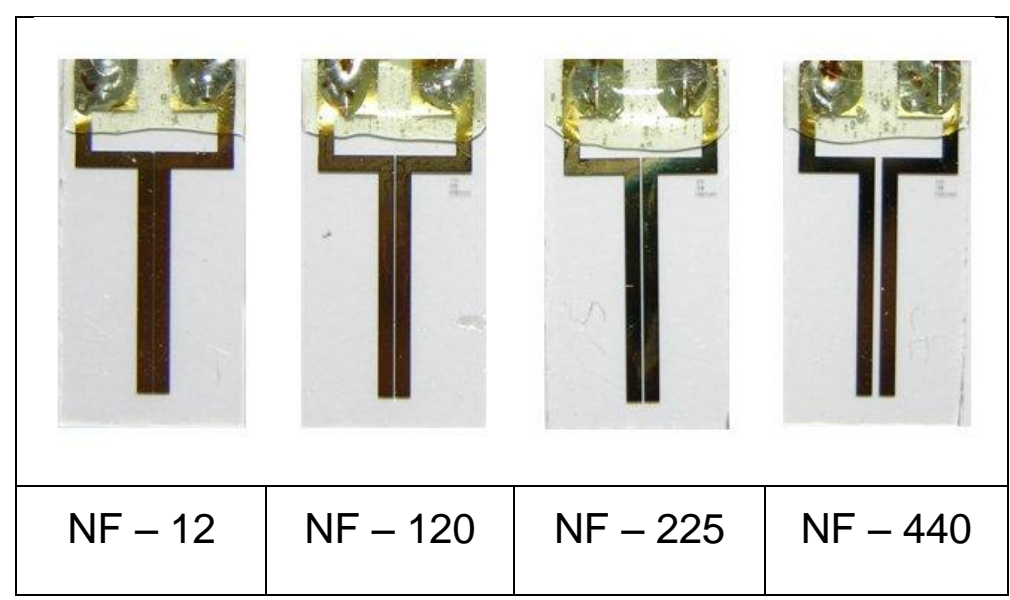

Figura 14 - Microeletrodos com geometrias do tipo NF 


\subsection{4 - Microbalança de quartzo}

As microbalanças de quartzo utilizadas neste trabalho, obtidas a partir de corte em placas de quartzo na direção AT, foram adquiridas comercialmente e fabricadas na espessura de cisalhamento onde a frequência de ressonância é de 20 $\mathrm{MHz}$, figura 15.

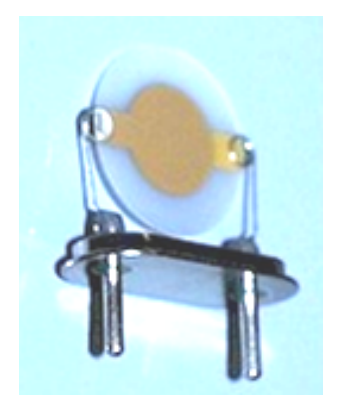

Figura 15 - Microbalança de Quartzo.

As microbalanças de quartzo, recobertas com filmes de diferentes materiais sensoativos, ao interagirem com as substâncias de interesse geram variação de massa e consequentemente variação na frequência de oscilação do quartzo [131].

\subsection{5 - Matriz capacitiva}

A matriz comercial de capacitores utilizada neste trabalho foi produzida pela Fujitsu (MBF 200) e fabricada visando a detecção biométrica da impressão digital. Este detector consiste em um conjunto de 256 × 300 capacitores protegidos e recobertos por uma camada uniforme de $\mathrm{Si}_{3} \mathrm{~N}_{4}$, figura 16. O revestimento oferece uma superfície disponível para a deposição de camadas sensoativas. 


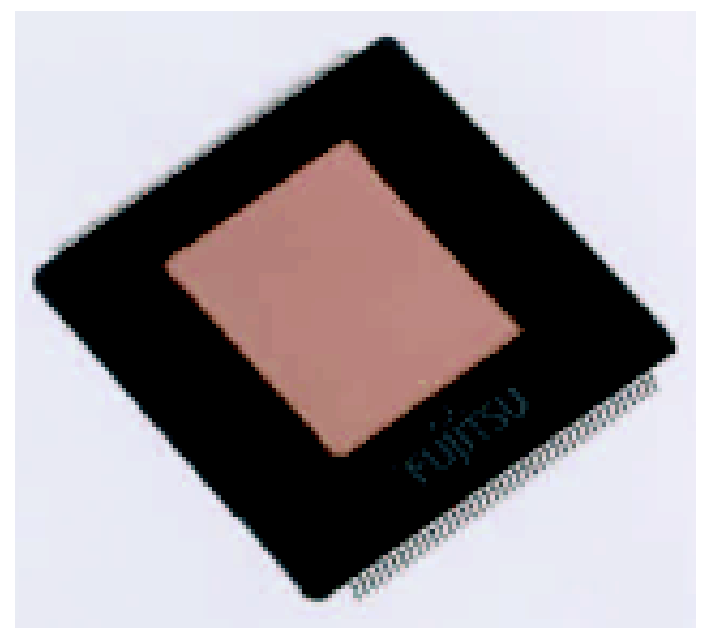

Figura 16 - Matriz capacitiva, conjunto de 256 × 300 capacitores, Fujitsu [43].

São usados hardware e Software dedicados para o controle e aquisição de dados do conjunto de capacitores. Um importante parâmetro desta matriz de capacitores é a sensibilidade, que pode ser ajustada alterando a descarga de corrente e tempo de descarga das células capacitivas, figura 17.

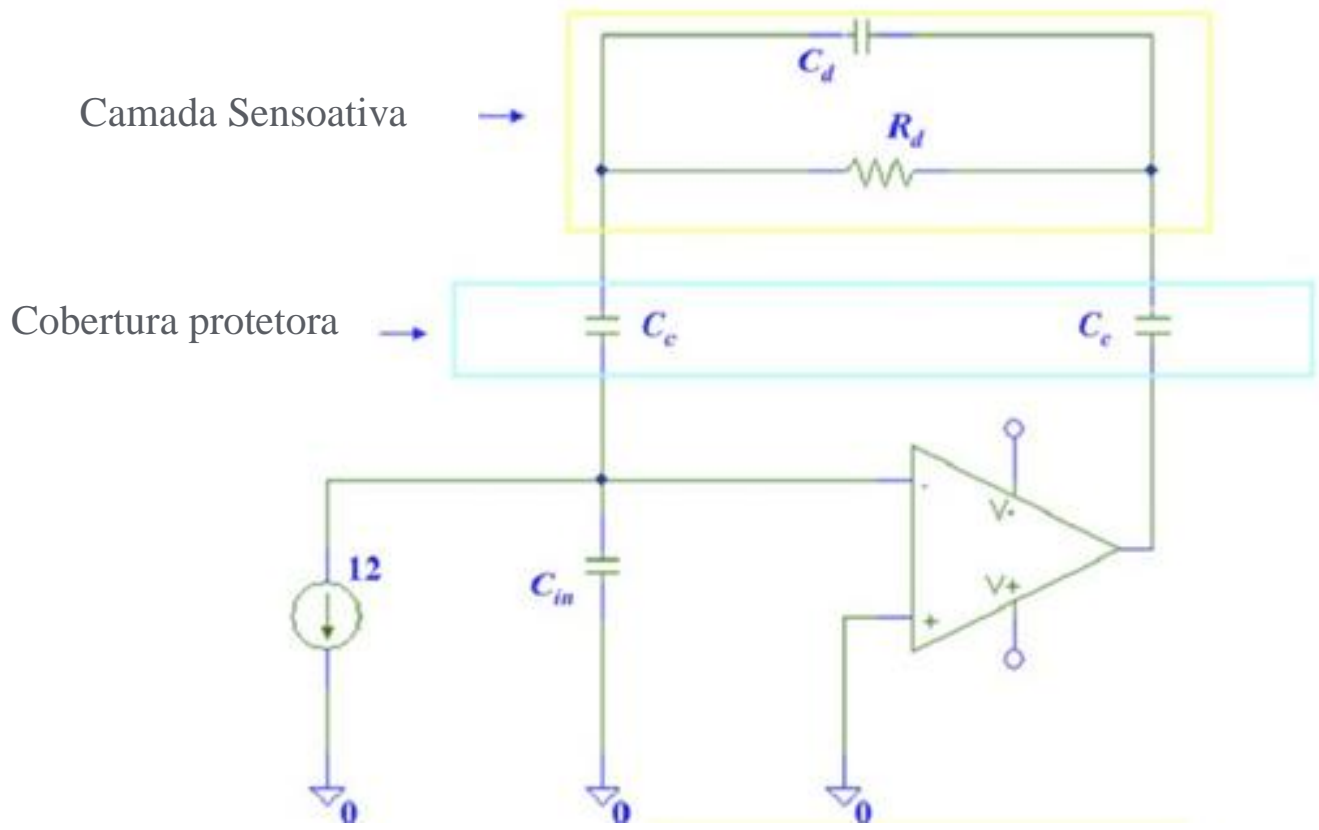

Figura 17 - Célula capacitiva.

Nesta figura, a camada sensoativa é representada como uma combinação de resistência $(\mathrm{Rd})$ e capacitância $(\mathrm{Cd})$. A variação destes parâmetros é dependente do 
processo de adsorção de moléculas sobre a camada sensoativa, alterando o deslocamento de carga no interior do material, e, consequentemente, modificando os parâmetros do modelo equivalente [43].

\subsection{6 - Analitos}

Os sensores foram testados em substâncias puras, como solventes, típicos constituintes e adulterantes de combustíveis automotivos, bem como em combustíveis, gasolina e etanol, e em misturas destes em diversas proporções.

\subsubsection{1 - Solventes}

A fim de avaliar a resposta dos sensores em relação às constantes dielétricas, bem como a sensibilidade em relação a compostos puros encontrados em combustíveis, foram ensaiados solventes de constantes dielétricas conhecidas, listados na tabela 3.

Tabela 3 - Constantes dielétricas de solventes

\begin{tabular}{|c|c|}
\hline Solventes & Constantes dielétricas [138] \\
\hline Água & 80 \\
\hline Acetona & 20,7 \\
\hline Clorofórmio & 4,8 \\
\hline Etanol & 25,3 \\
\hline Hexano & 2,02 \\
\hline Isopropanol & 18,3 \\
\hline THF (tetra hidrofurano) & 7,6 \\
\hline Tolueno & 2,38 \\
\hline
\end{tabular}




\subsubsection{2 - Combustíveis}

A capacidade dos sensores em detectar adulterações em combustíveis foi avaliada a partir da exposição destes a diferentes combustíveis. Os combustíveis avaliados neste trabalho foram:

- Etanol grau PA (99,9'INPM);

- Etanol anidro Combustível (99,3INPM);

- Gasolina A;

- Gasolinas C (Gasolina A + 20 a 25 \% de AEAC) comeciais da cidade de São Paulo;

- Etanóis comerciais da cidade de São Paulo (92,6 a 93,6INPM);

- Gasolinas comerciais da cidade de Roma, isentas de etanol;

- Misturas de gasolina com conteúdos de 10, 20, 25, 30, 50, 70 e 90\% de etanol;

- Diesel comercial da cidade de Roma. 


\section{2 - MÉTODOS}

\subsection{1 - Soluções químicas}

As soluções de PANI, POEA, PEDOT, PPY, PSS, LS e FtTsNi foram obtidas separadamente pela dissolução destes materiais em água em concentração específica para cada material, conforme listado na tabela 4 . O ajuste do $\mathrm{pH}$ das soluções poliméricas, bem como da solução de lavagem foi realizado pela adição $\mathrm{HCl}$ 0,1M. As soluções de PPy e PEDOT foram obtidas pela diluição das formulações comerciais diretamente em água, na proporção de 1:10, v/v.

Tabela 4 - Descrição das soluções poliméricas

\begin{tabular}{|c|c|c|}
\hline Soluções Poliméricas & Concentração (g/L) & $\mathbf{p H}$ \\
\hline PANI & 1,5 & 2,7 \\
\hline POEA & 0,6 & 3,0 \\
\hline PSS & 0,2 & 2,7 e 3,0 \\
\hline LS & 0,3 & 2,7 e 3,0 \\
\hline FtTsNi & 0,4 & 2,7 e 3,0 \\
\hline
\end{tabular}

\subsection{2 - Fabricação das unidades sensoriais}

\subsubsection{1 - Fabricação de sensores pela técnica de automontagem}

A fabricação de sensores contendo filmes de polímeros, PANI/PSS, PANI/LS, PANI/PEDOT, PANI/PPY, POEA/PSS, POEA/LS, POEA/PEDOT e de POEA/PPY, sobre microeletrodos e microbalanças de quartzo foi realizada pela técnica de automontagem, descrita brevemente no exemplo a seguir. O microeletrodo, é primeiramente imerso na solução do policátion (PANI ou POEA) de pH controlado 
(pH 2,7 para PANI e pH 3 para POEA), por 3 minutos, lavado em solução aquosa de mesmo pH da solução do policátion e seco com fluxo de $\mathrm{N}_{2}$. Em seguida é imerso na solução do poliânion (no caso PEDOT, PPY, PSS ou LS com pH igual ao do policátion), lavado e seco da mesma maneira, resultando em uma bicamada, como ilustra a figura 18. Sensores com até 10 bicamadas foram fabricados repetindo-se sucessivamente as etapas descritas anteriormente. O mesmo procedimento foi realizado para as microbalanças de quartzo, porém estas foram recobertas com apenas três bicamadas de material.
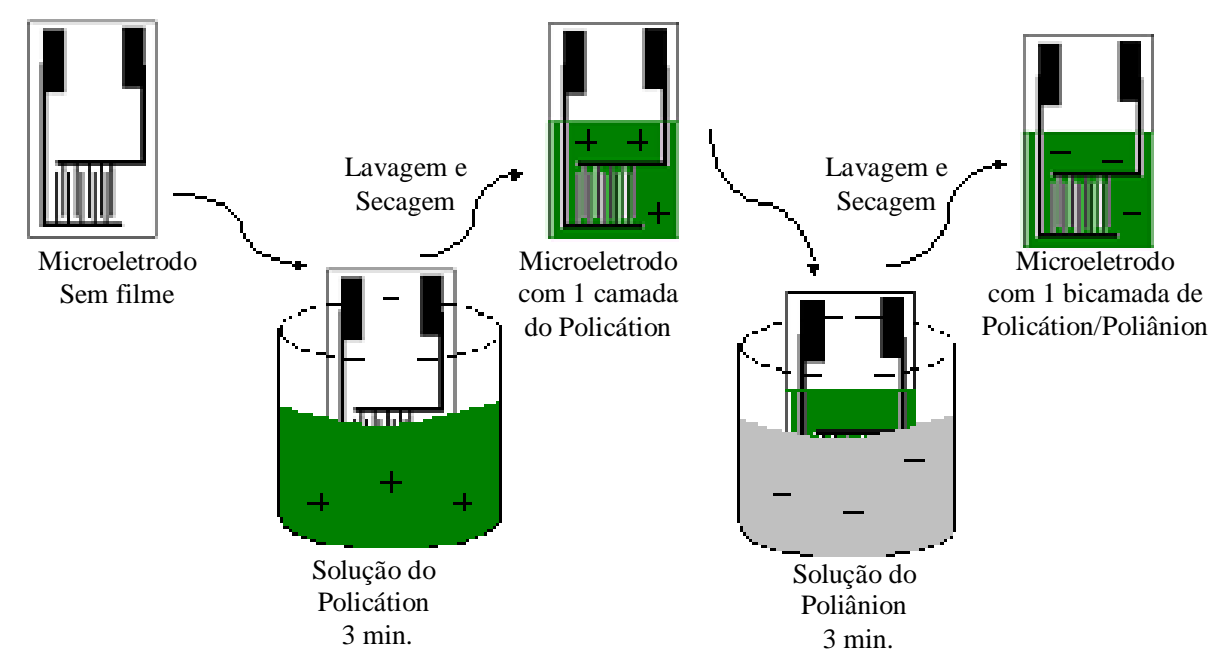

Figura 18 - Ilustração da fabricação de uma bicamada de Policátion/Poliânion pela técnica de automontagem.

\subsubsection{2 - Fabricação de sensores por eletrodeposição}

Os sensores contendo filmes de politiofeno foram fabricados por eletropolimerização conforme procedimento brevemente descrito a seguir.

A eletropolimerização foi realizada com o monômero 3-metiltiofeno $(0,1 \mathrm{~mol} / \mathrm{L}$, Aldrich), empregando-se as técnicas de cronoamperometria e cronopotenciometria. As sínteses foram realizadas em uma célula convencional com três eletrodos, em que o eletrodo de trabalho foi o microeletrodo do tipo T-10, acompanhado de um eletrodo de prata como referência e um eletrodo de platina como contra eletrodo. Os experimentos foram conduzidos com um potenciostato marca AUTOLAB PGSTAT 
30. Ao final, foram fabricados dois sensores diferentes partindo do monômero 3metiltiofeno $(0,1 \mathrm{~mol} / \mathrm{L})$ e duas técnicas de deposição eletroquímica diferentes, sendo estes, PMTh oxidado e PMTh reduzido.

\subsubsection{3 - Fabricação de sensores por spray casting}

Camadas sensoativas de metaloporfirinas foram depositadas sobre microbalanças de quartzo por spray casting. Para isto, as metaloporfirinas são dissolvidas em solvente e em seguida pulverizadas em ambas as faces de cada QMB. A fim de controlar a quantidade de depósito de metaloporfirinas sobre as QMB a frequência de ressonância é medida durante o processo de deposição [107].
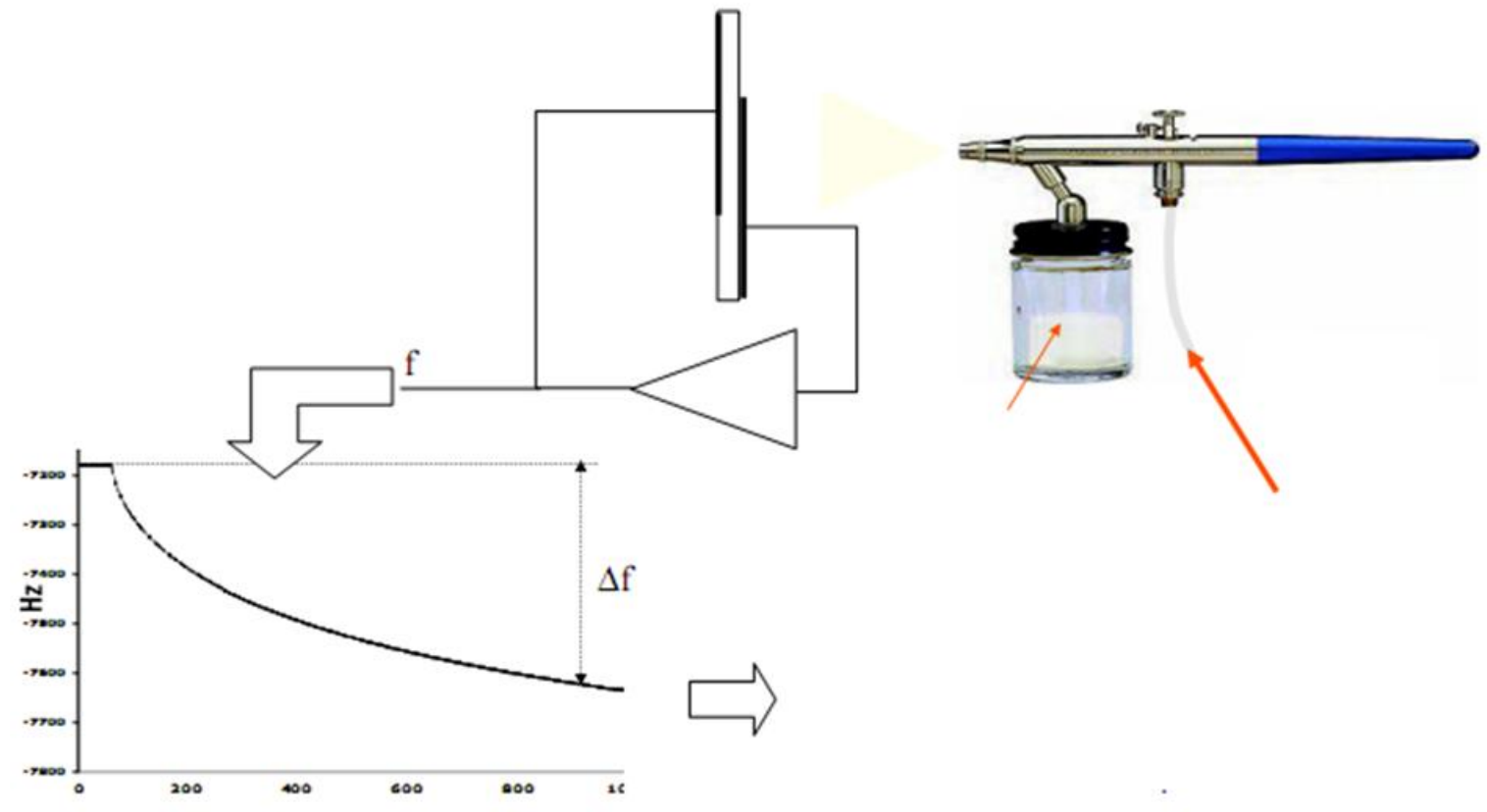

Figura 19 - llustração da deposição de filmes de metaloporfirinas sobre MBQ pela técnica de spray casting [107].

\subsubsection{4 - Fabricação de sensores por solvent casting}

A fabricação das camadas sensoativas sobre a superfície da matriz de capacitores foi realizada utilizando a técnica solvent casting que consiste na deposição de gotas de soluções de materiais sensoativos sobre a superfície em 
questão. Cada região da matriz de capacitores recoberta pelo mesmo material sensoativo foi definida como um sensor. Esta região da matriz de capacitores recoberta, dependendo da viscosidade do material sensoativo, pode variar em espessura.

\subsection{3 - Espectroscopia no ultravioleta e no visível (UV-Vis)}

A estabilidade dos filmes foi avaliada por meio de espectroscopia UV/VIS, usando um espectrofotômetro UV-VIS Shimadzu, modelo PC 1600, que permite a realização de medidas de absorção no intervalo entre 190 e 1100 nm.

Foram obtidos espectros dos filmes depositados sobre vidro, antes e após as sucessivas imersões no combustível de interesse e avaliadas as eventuais mudanças na intensidade de absorção e na forma das bandas dos espectros.

\subsection{4 - Cromatografia gasosa}

Amostras de combustíveis foram também analisadas por cromatografia gasosa (GC). A análise por headspace na fase de equilíbrio de vapor das amostras (2 $\mathrm{ml})$, contida em frascos $(20 \mathrm{ml})$, foi realizada usando uma fibra de polidimetilsiloxando 50/20 $\mu \mathrm{m}$ (Supelco, Sigma-Aldrich, St. Louis, USA). Esta, por sua vez, foi exposta por 20 minutos ao gás de análise. O Cromatógrafo usado foi o GC_MS QP 2010 Shimadzu do departamento de química da Università Degli Studi Di Roma, Tor Vergata. As condições cromatográficas foram as seguintes: temperatura de aquecimento inicial: $50{ }^{\circ} \mathrm{C}$; tempo de retenção $5 \mathrm{~min}$; variando de $10^{\circ} \mathrm{C} / \mathrm{min}$. até $300^{\circ} \mathrm{C}$, e, em seguida, mantida em $300^{\circ} \mathrm{C}$ por $2 \mathrm{~min}$. para um tempo total de execução de 32 min. A coluna usada foi uma coluna capilar equity-5 $(30 \mathrm{~mm}$ x 0,25 mm i.d.; com espessura de revestimento de 0,25 $\mu \mathrm{m})$. O gás transportador foi o Hélio em fluxo de 5,2 $\mathrm{ml} / \mathrm{min}$. 


\section{3 - SISTEMAS SENSORES}

\subsection{1 - Sistemas sensores Língua eletrônica e nariz eletrônico baseados em microeletrodos}

Primeiramente, o sistema sensor que compõe a língua eletrônica, desenvolvida neste trabalho (figura 20), foi fabricado conectando-se um conjunto de diferentes sensores desenvolvidos a partir de variadas geometrias de microeletrodos de ouro (figura 21), em uma cabeça sensora (figura 22 e 23), de modo que quando imersos no analito, em temperatura estabilizada, em $25^{\circ} \mathrm{C}$, por um banho termostático (figura 24), possam ser medidos sequencialmente. O sistema sensor para o nariz eletrônico baseado em microeletrodos, figura 25, segue este mesmo principio de fabricação da língua eletrônica, porém o microeletrodo é necessariamente coberto por uma camada de material sensoativo, dielétrico, e sua aplicação se dá em meio gasoso.
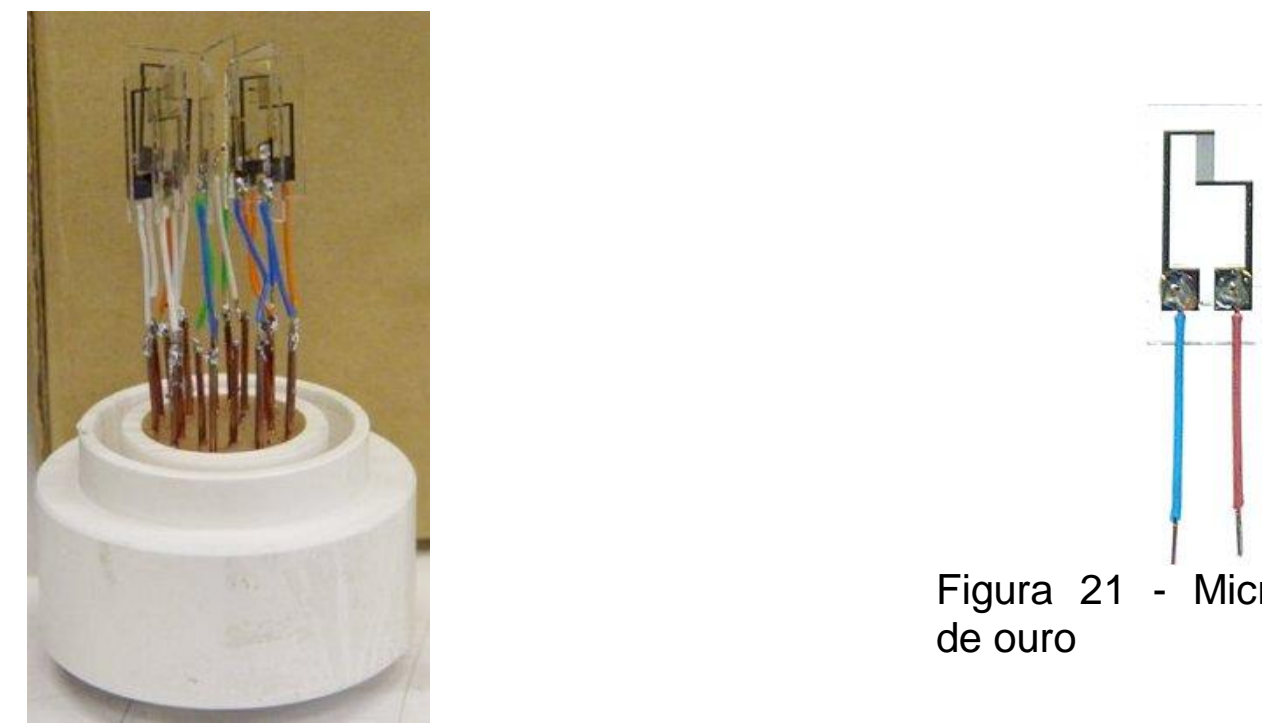

Figura 21 - Microeletrodo de ouro

Figura 20 - Língua Eletrônica baseada em microeletrodos. 


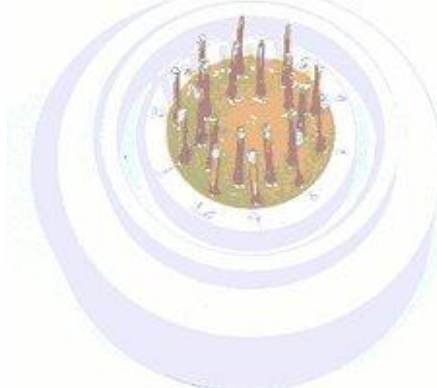

Figura 22 - Cabeça sensora -Terminais de entrada dos sensores.

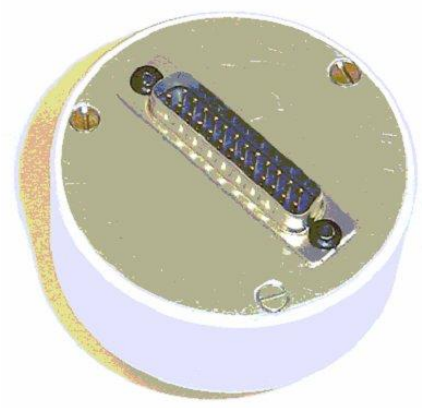

Figura 23 - Cabeça sensora Terminais de saída dos sensores.

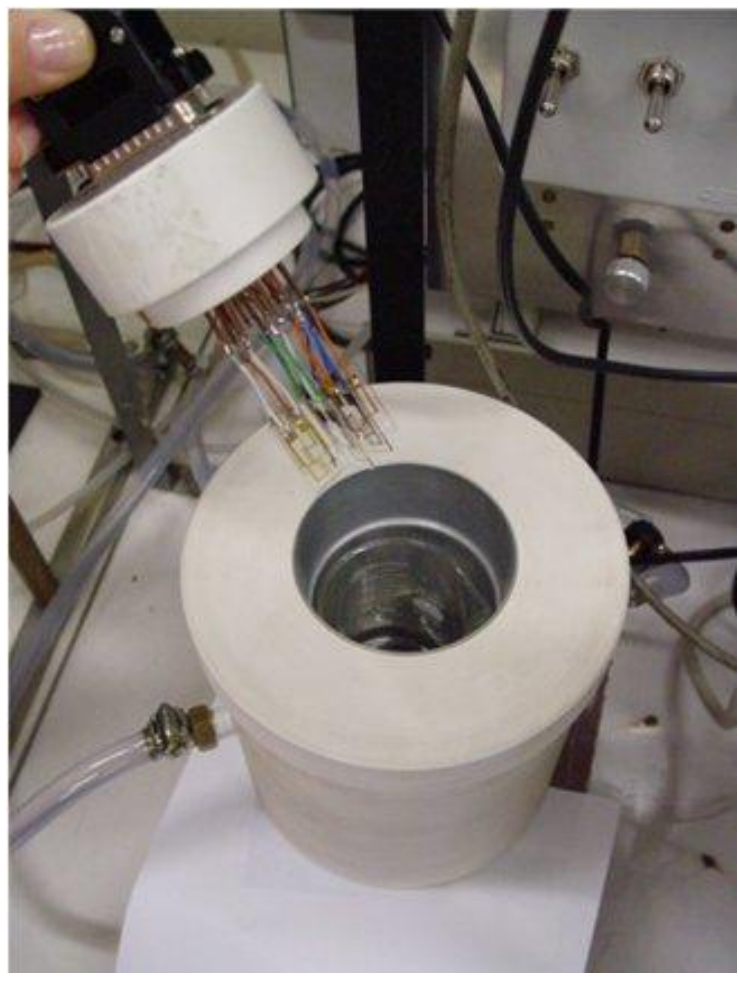

Figura 24 - Sistema de derivação de um banho termostático. 


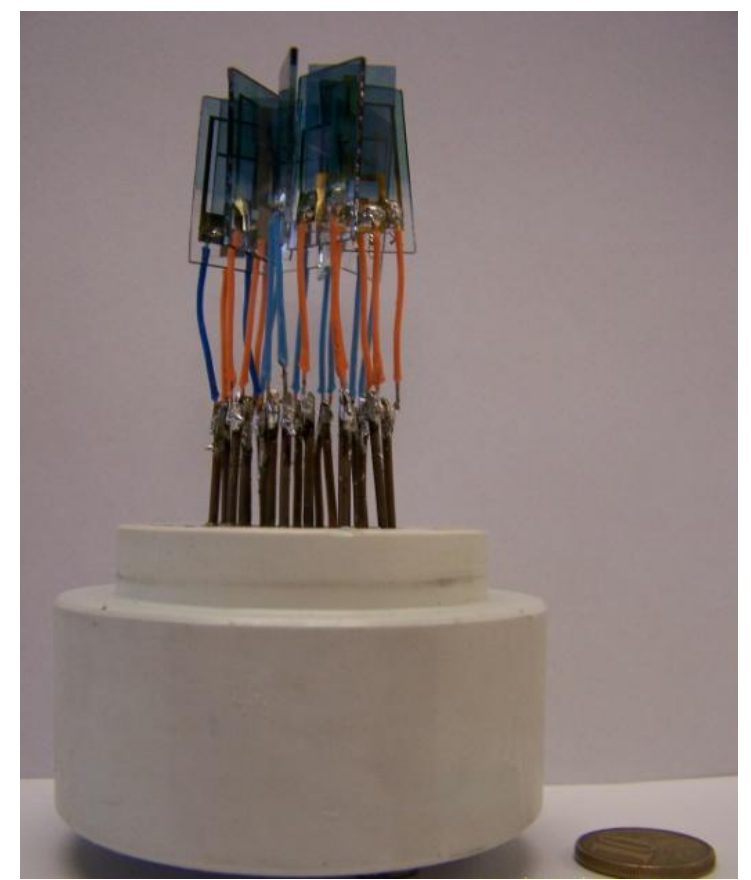

Figura 25 - Nariz Eletrônico baseado em microeletrodos.

4.3.1.1 - Sistema de medidas para línguas e narizes eletrônicos baseados em microeletrodos

Línguas e Narizes eletrônicos baseados em polímeros condutores compartilharam o mesmo sistema de operação. O sistema de medidas para estes sistemas sensores é composto por uma cabeça sensora, um multiplexador de 10 canais, um medidor de impedância (LCR ou um solartron interfaceado por GPIB) e um PC, exemplificado nas figuras 26 e 27. 


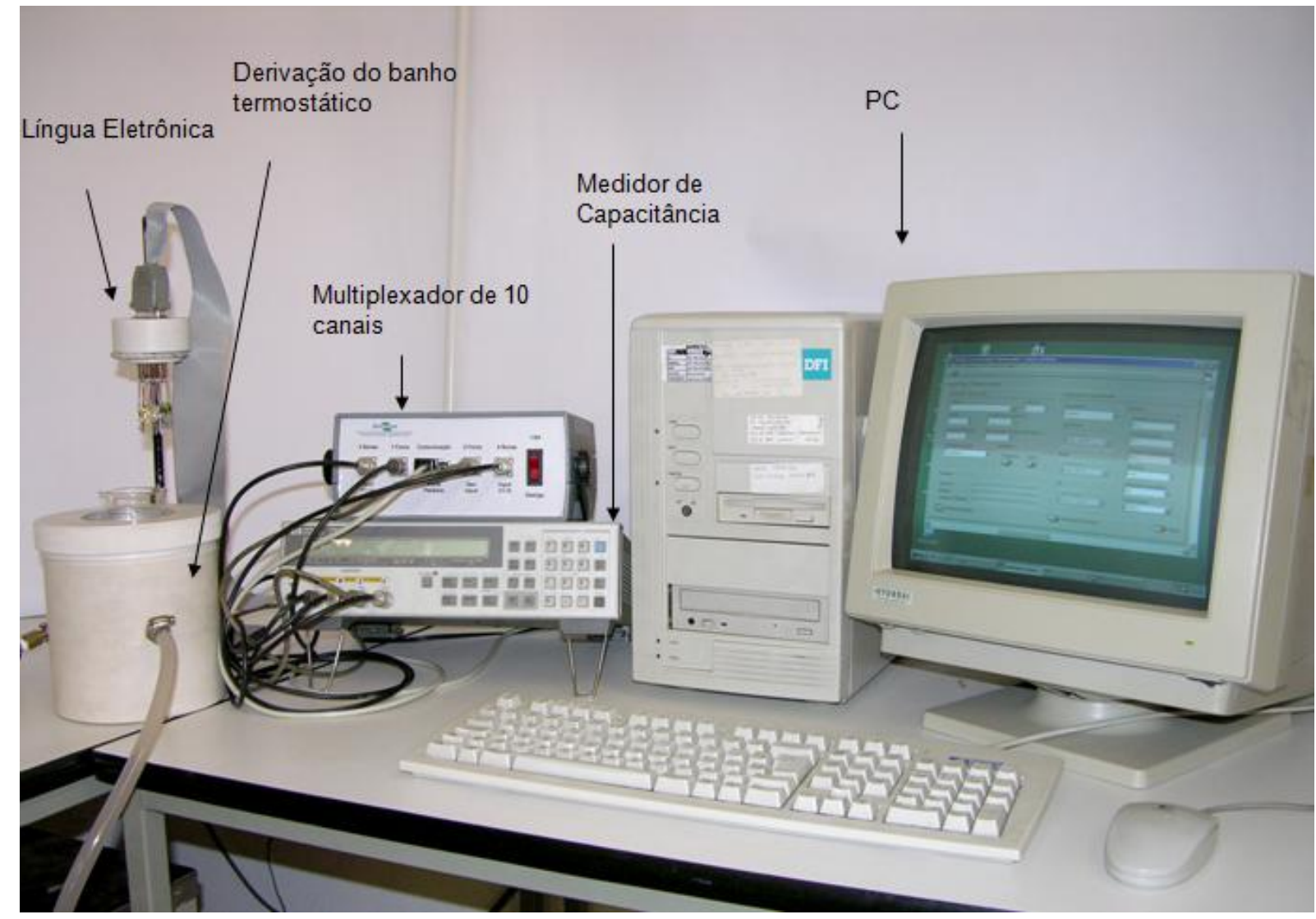

Figura 26 - Foto do sistema de medida para LE-NE, SH-1.

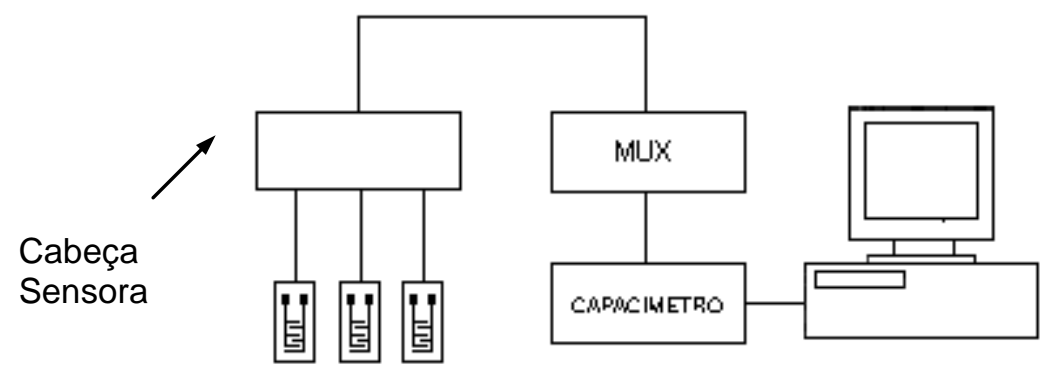

Figura 27 - Esquema do sistema de medida para LE-NE, SH-1.

A cabeça sensora é ligada ao multiplexador de canais o qual é conectado a um medidor de impedância controlado pelo PC através de um programa dedicado de computador. Os sensores conectados à cabeça sensora são colocados em contato com as soluções a serem analisadas, cuja temperatura é estabilizada por um sistema de derivação de um banho termostático. As medidas de capacitância são obtidas em uma frequência predeterminada e fixa. As capacitâncias medidas para 
cada substância geram um padrão de resposta elétrica específica obtida em cada um dos sensores, portanto, sequencialmente deve ser realizado o processamento dos dados através de algum método de análise multivariada. As medidas e a aquisição de dados são realizadas pelo computador através de um instrumento virtual dedicado criado em LabView.

\subsection{2 - Sistema sensor nariz eletrônico baseado em microbalanças de quartzo}

O nariz eletrônico utilizado neste estudo, figura 28, desenvolvido, projetado e montado pela Università degli Studi di Roma, Tor Vergata, baseia-se num conjunto de sensores formados por microbalanças de quartzo recobertas por filmes sensoativos. As camadas sensoativas que recobriram estes sensores basearam-se em metaloporfirinas e polímeros e foram depositados por spray casting ou layer-bylayer. As MBQs (ressonadores eletromecânicos, cuja frequência de ressonância varia proporcionalmente de acordo com a massa adsorvida sobre as superfícies do sensor) foram acopladas em uma câmara de medidas onde o fluxo de gás foi controlado. A reversível interação dos sensores com as substâncias voláteis gera uma variação da frequência de oscilação do quartzo gerando um padrão de resposta específica em cada um dos sensores.

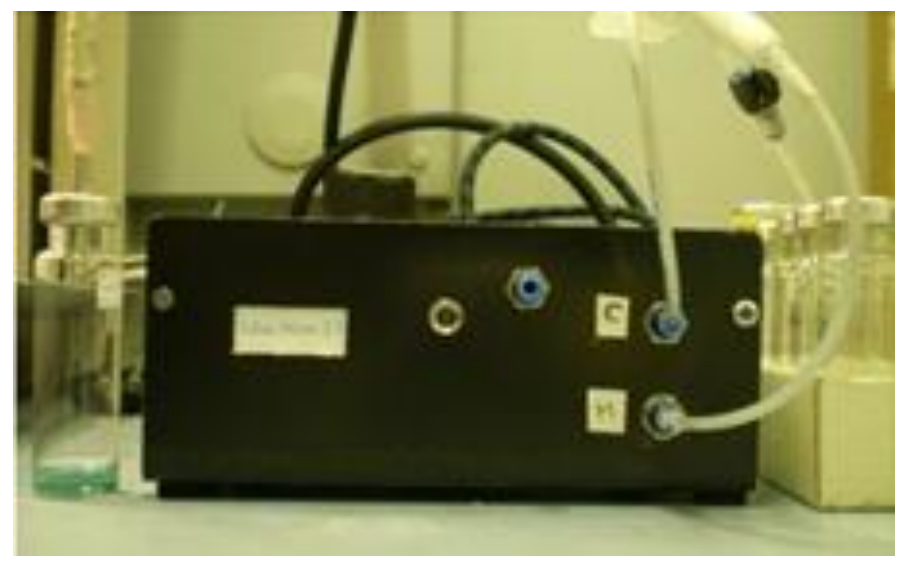

Figura 28 - Nariz eletrônico baseado em microbalança de quartzo. 


\subsubsection{1 - Sistema de medidas para o nariz eletrônico baseado em microbalança de quartzo}

O sistema de medidas para do nariz eletrônico baseado em microbalança de quartzo, E-nose - Tor Vergata, figura 29, é composto por uma câmara de medidas, uma microbomba interna, a parte eletrônica composta por multiplexador de canais, oscilador e contador de frequência e um PC, exemplificado na figura 29. Amostras líquidas foram vedadas em frascos em temperatura ambiente. Depois de equilibrado, o headspace dos frascos das amostras foi injetado com ar seco na câmara das microbalanças. O mesmo fluxo de ar foi usado para medida e para limpeza da superfície dos sensores. Uma bomba peristáltica manteve um fluxo constante de 300 sccm.

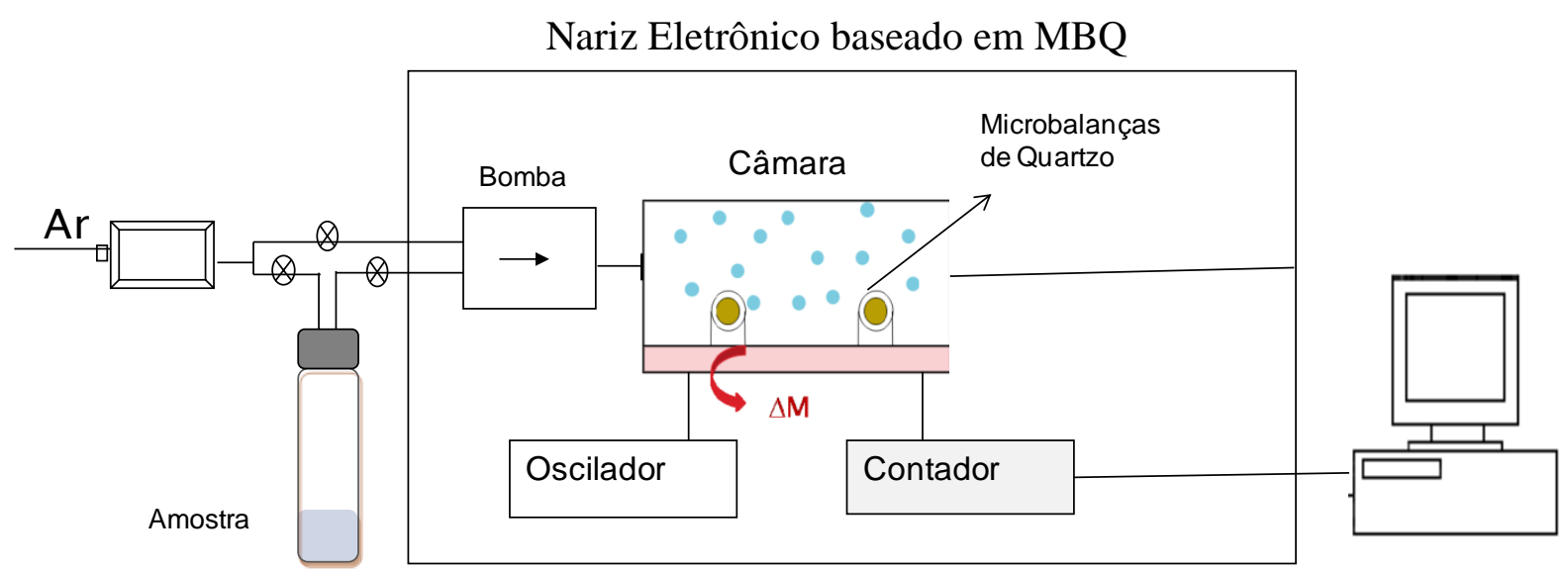

Figura 29 - Sistema de medidas para $\mathrm{MBQ}$.

A medida de variação de frequência do conjunto de sensores foi controlada por um software dedicado, onde os sinais dos sensores foram adquiridos e posteriormente formatados para tratamento e análise de dados. 


\subsection{3 - Sistema sensor nariz eletrônico baseado em matriz de capacitores}

Os sensores químicos que constituíram o sistema sensor nariz eletrônico baseado em uma matriz de capacitores comercial foram fabricados depositando pontos de materiais sensoativos sobre a superfície do dispositivo por solvent casting. Assim, a impressão digital da superfície da matriz de capacitores disponível foi apenas parcialmente explorada nas regiões da matriz contendo filmes, sensores, demonstrados em quatro pontos na matriz de capacitores da figura 30 .

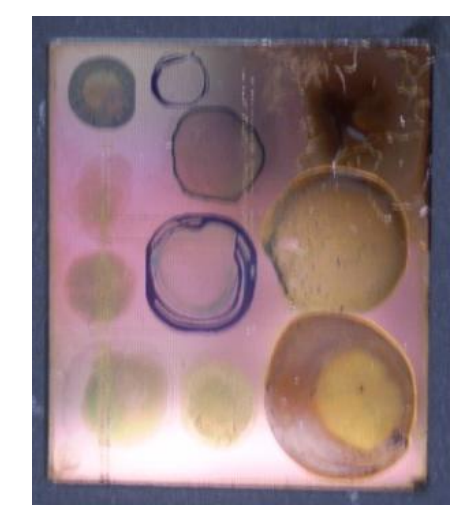

Figura 30 - Detector da matriz capacitiva recoberto com diferentes materiais sensoativos.

Os valores de capacitância foram obtidos em escala de imagem e processados como matrizes, seguindo o procedimento descrito na referencia 43 . A distribuição não uniforme das capacitâncias indica a não uniformidade do filme, um inconveniente típico deste tipo de deposição. A região de maior uniformidade do filme foi visualizada e selecionada via software. A média dos valores obtidos em escala de imagem desta região é calculada, obtendo um valor específico, denominado ponto sensorial. O mesmo procedimento foi realizado para os outros pontos sensoativos depositados sobre a matriz. 
4.3.3.1 - Sistema de medidas para o nariz eletrônico baseado em matriz de capacitores

O sistema de medidas para a matriz de capacitores foi baseado em uma câmara de medida (fabricada sobre a superfície o dispositivo de impressão digital), circuito eletrônico dedicado [43], uma bomba peristáltica e um PC, figura 31.

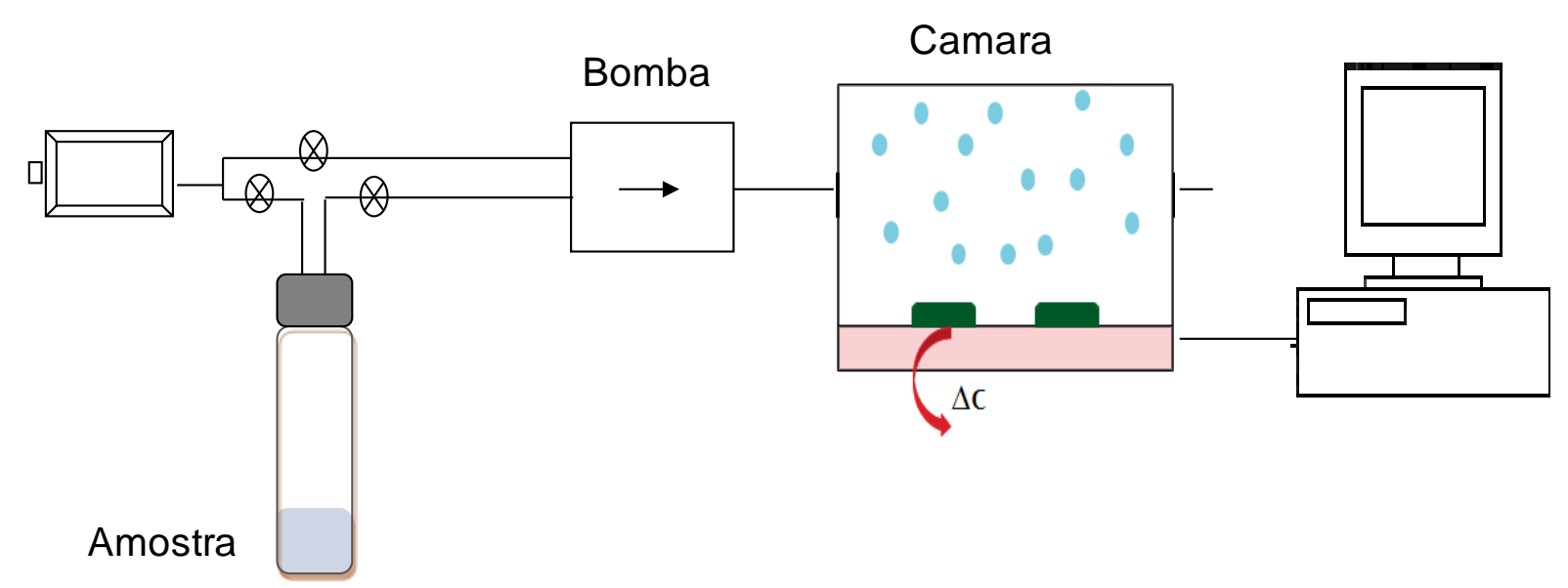

Figura 31 - Sistema de medidas nariz eletrônico baseado em matriz capacitiva.

Software e hardware dedicados foram desenvolvidos em outros estudos para alimentar o conjunto de capacitores e a aquisição de dados [43]. Os testes foram realizados expondo as regiões sensoativas do detector do dispositivo de impressão digital contido em uma placa com circuito eletrônico dedicado, figura 32, aos gases das substâncias de interesse que foram injetados em fluxo constante no interior da câmara de medida. 


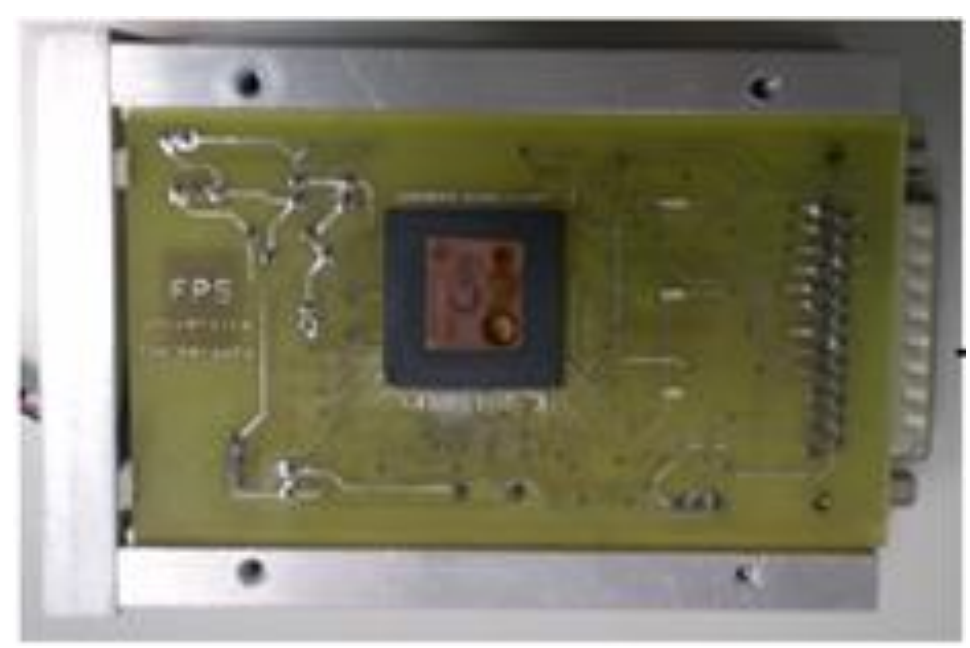

Figura 32 - Placa com o detector contendo as regiões sensoativas do nariz eletrônico baseado em matriz capacitiva

Os valores de capacitância da matriz capacitiva são obtidos em escala de imagem da região contendo filme sensoativo e diferenciam-se do restante da matriz conforme a exposição do dispositivo ao gás de interesse.

Os valores obtidos são processados como matrizes contendo valores em escala de imagens. Ferramentas computacionais de análise multivariada de dados foram usadas para avaliar a resposta do conjunto de dados dos sensores obtidos a partir das regiões sensoriais selecionadas.

\section{4 - SISTEMAS HÍBRIDOS DE SENSORES}

A relação entre transdutores e interações químicas é de grande importância no desenvolvimento de sensores químicos eficientes. Como conseqüência, sendo cada transdutor, particularmente, influenciado por interações químicas, espera-se que a aplicação de sistemas híbridos aumente a seletividade total do dispositivo, apresentando, simultaneamente, múltiplas aplicações de diferentes moléculas, acarretando em evidentes vantagens.

Contudo, os sistemas híbridos de sensores desenvolvidos nesse trabalho utilizam conjuntos de sensores químicos compostos por diferentes tipos transdutores e materiais sensoativos. Dentre os transdutores foram utilizados microeletrodos de ouro, uma matriz comercial de capacitores e microbalanças de quartzo. Polímeros 
condutores e metaloporfirinas constituíram os materiais sensoativos. Língua e narizes eletrônicos foram fabricados a partir destes materiais e a integração destes resultou em dois tipos de sistemas híbridos, denominados de $\mathrm{SH}-1$ e SH-2, onde o primeiro é formado por uma língua e um nariz baseados em microeletrodos e o segundo pela integração de dois tipos de narizes eletrônicos, um baseado em microbalança de quarto e outro em uma matriz de capacitores comercial. Os sistemas híbridos desenvolvidos são detalhados na figura 33.

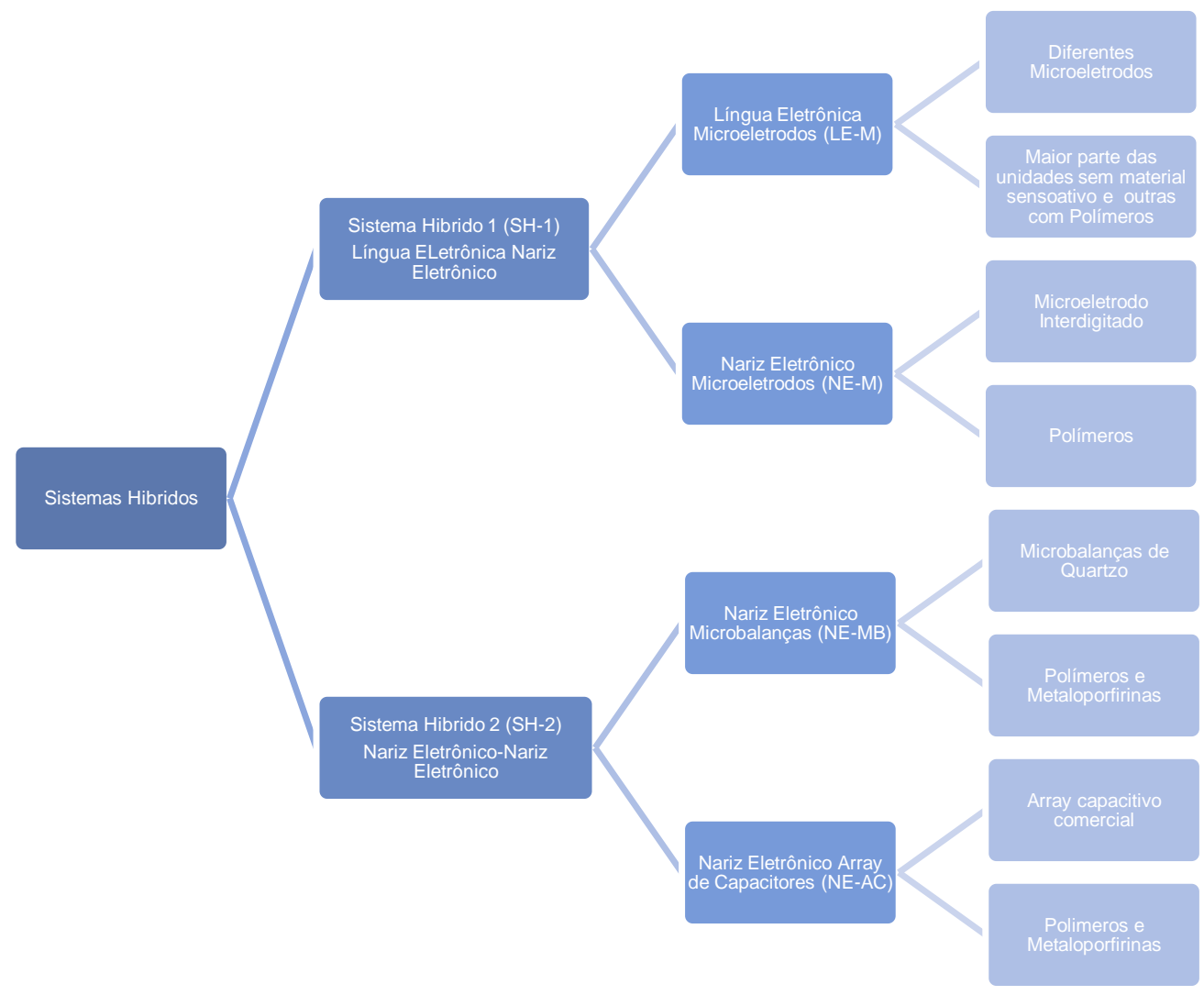

Figura 33 - Organograma detalhando os sistemas híbridos. 


\subsection{1 - Sistema híbrido nariz eletrônico e língua eletrônica baseados em ME (SH-1)}

O sistema híbrido 1, SH-1, foi fabricado acoplando os dois sistemas, língua eletrônica e nariz eletrônico baseados em microeletrodos, em uma única cabeça sensora, de modo que um conjunto de sensores fique imerso no líquido (língua) e outro conjunto fique fora deste (nariz), resultando em um sistema de medidas híbrido (língua-nariz), como mostrado na figura 34.

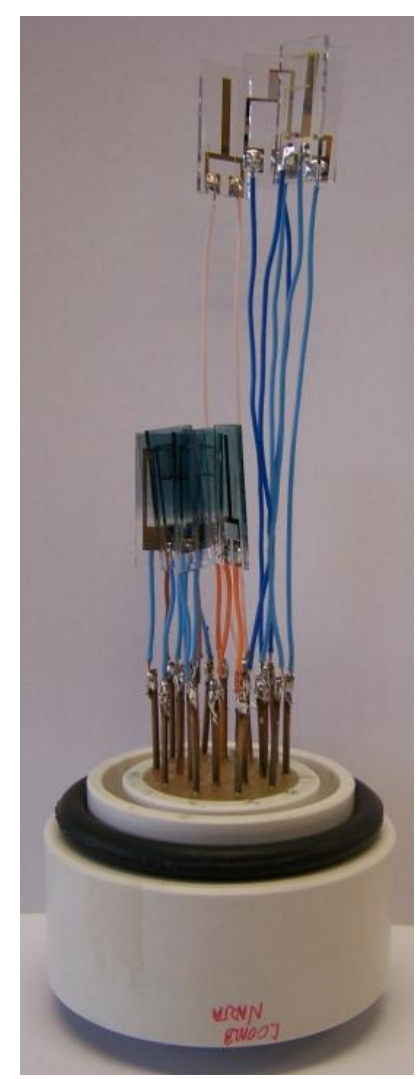

Figura 34 - Sistema Híbrido 1 (SH-1). 


\subsection{2 - Sistema híbrido de narizes eletrônico baseados em MBQ e matriz de capacitores comercial (SH-2)}

O sistema híbrido 2, $\mathrm{SH}-2$, foi desenvolvido a partir do uso de dois tipos de narizes eletrônicos. Um nariz eletrônico baseado em MBQ e outro nariz eletrônico baseado em matriz comercial de capacitores, em um mesmo aparato experimental, resultando em um sistema de medidas híbrido (nariz-nariz), como mostrado na figura 35. Amostras líquidas foram vedadas em frascos em temperatura ambiente. $O$ headspace dos frascos das amostras foi injetado com ar seco na câmara das microbalanças e do conjunto de capacitores, respectivamente. O mesmo fluxo de ar foi usado como referência e para limpeza da superfície dos sensores. Uma bomba peristáltica manteve um fluxo constante de $300 \mathrm{sccm}$.

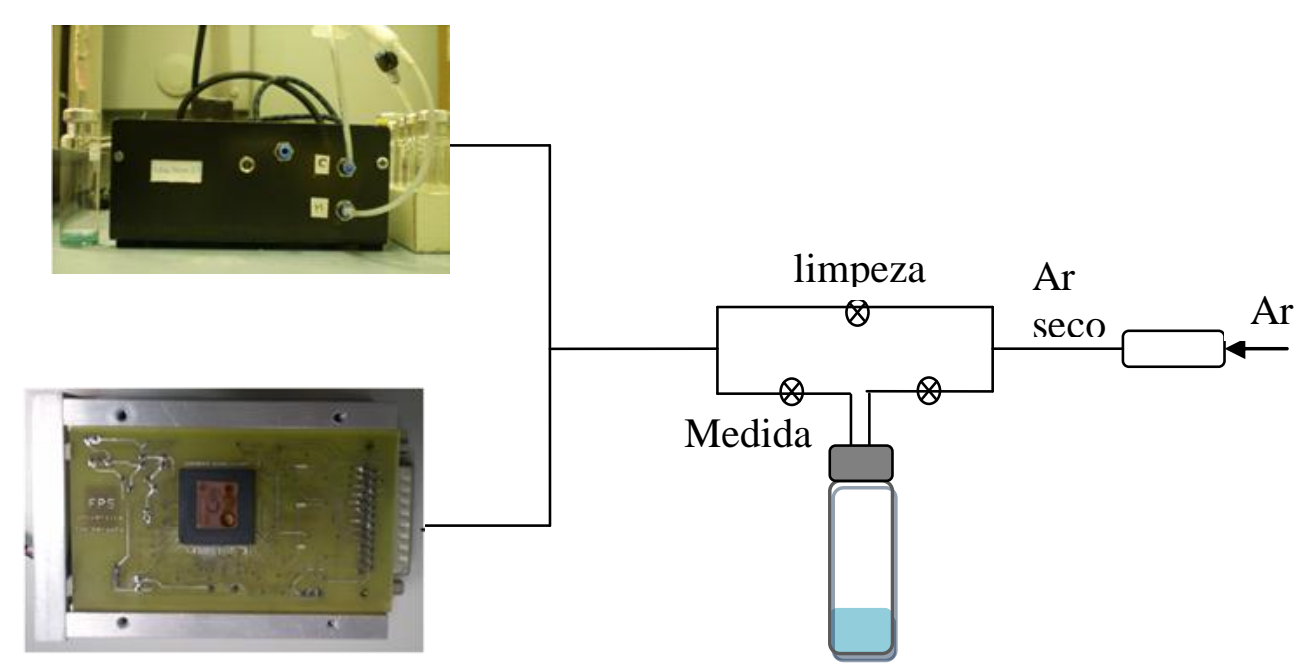

Figura 35 - Sistema de medidas NE-NE

Os dois conjuntos de dados foram analisados juntos a partir de ferramentas computacionais de análise multivariada, como a PCA e PLS. 


\section{5 - RESULTADOS E DISCUSSÃO}

Objetivando o desenvolvimento dos dois tipos de sistemas multissensoriais híbridos para a análise de combustíveis, $\mathrm{SH}-1$ e $\mathrm{SH}-2$, foram desenvolvidos neste trabalho uma língua eletrônica e três tipos diferentes de narizes eletrônicos. $\mathrm{O} \mathrm{SH}-1$ foi composto pela integração de uma Língua Eletrônica e um Nariz Eletrônico, ambos baseados em microeletrodos interdigitados, feitos a partir de microeletrodos de ouro. Já sistema híbrido SH-2 foi formado por dois Narizes Eletrônicos, baseados em dois tipos de transdutores diferentes. O primeiro Nariz Eletrônico foi baseado em microbalanças de quartzo e o segundo em uma matriz capacitiva comercial. $O$ desenvolvimento destes dispositivos e os resultados obtidos em análise de combustíveis são detalhados neste capítulo, e estão divididos basicamente em:

- Desenvolvimento e avaliação do desempenho dos sistemas sensores baseados em Microeletrodos;

- Desenvolvimento e avaliação do desempenho do sistema híbrido 1 (SH-1) para solventes e combustíveis;

- Desenvolvimento e avaliação do desempenho dos sistemas sensores baseados em MBQ;

- Desenvolvimento e avaliação do desempenho dos sistemas sensores baseados em Matriz Capacitiva;

- Desenvolvimento e avaliação do desempenho do sistema híbrido 2 (SH-2);

- Medidas Pulsadas. 


\section{1 - DESENVOLVIMENTO E AVALIAÇÃO DO DESEMPENHO DOS SISTEMAS SENSORES BASEADOS EM MICROELETRODOS}

\subsection{1 - Estudo da sensibilidade de diferentes microeletrodos na análise de combustíveis comerciais}

Em estudos anteriores [36] verificou-se o efeito de filmes finos e de geometrias de microeletrodos no desempenho de sensores químicos em análise de soluções de $\mathrm{NaCl}$. No presente capítulo foram avaliados os mesmos efeitos na análise de combustíveis. Em altas frequências, como $100 \mathrm{kHz}$, os valores de capacitância se tornam bastante reduzidos, já que a capacitância é uma grandeza inversamente proporcional à frequência. Porém, sabe-se que o efeito do microeletrodo (quando o mesmo contém filme polimérico) é melhor observado nessas frequências [122].

Dessa forma, microeletrodos diferenciados entre si pela geometria ou pelo espaçamento entre dígitos, tabela 2, foram imersos em AEAC e gasolina e realizadas medidas de capacitância na frequência de $100 \mathrm{kHz}$, com o resultado apresentado na figura 36. 


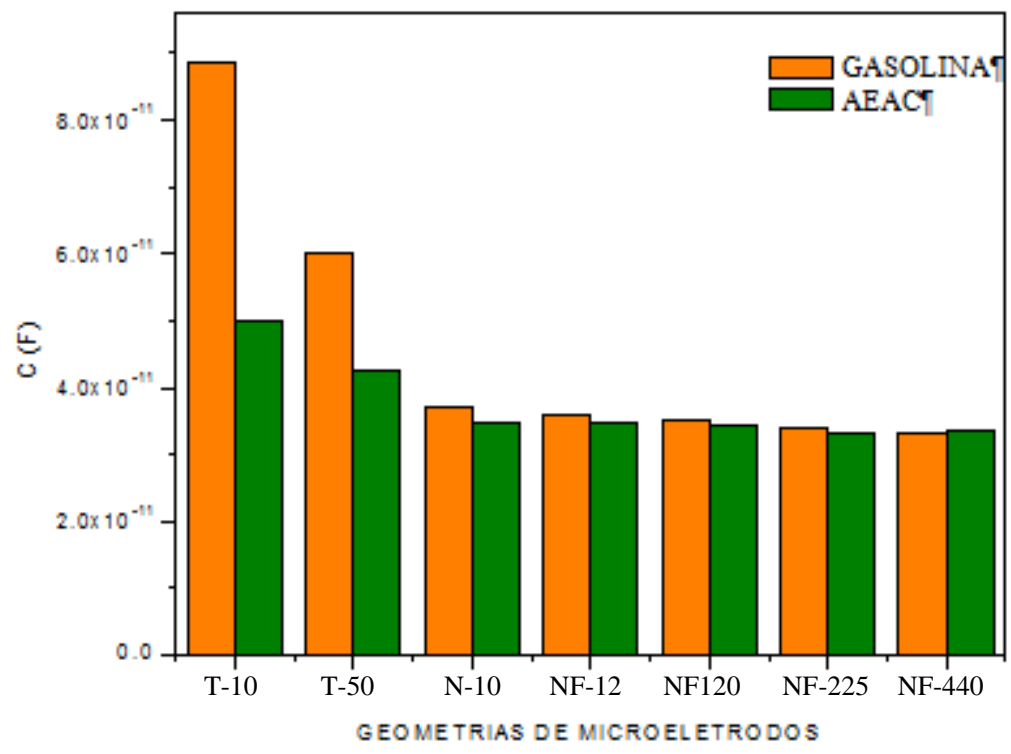

Figura 36 - Resposta de diferentes geometrias de microeletrodos no AEAC e na gasolina em $100 \mathrm{kHz}$.

$\mathrm{Na}$ figura 36 podemos observar que os microeletrodos do tipo T-10 e T-50 apresentaram maior resposta ao $A E A C$ e à gasolina em relação às outras geometrias. No entanto, em uma investigação prévia com soluções de $\mathrm{NaCl}$ foi constatado que quanto maior a área metálica do eletrodo, maior é a capacitância por ele medida. No presente caso, o contrário acontece. Esse resultado, provavelmente, está relacionado ao fato dos líquidos analisados aqui serem de constantes dielétricas inferiores as das soluções de $\mathrm{NaCl}$. Por conta disso, o líquido não é capaz de propagar as linhas de campo emanadas do topo dos eletrodos com a mesma eficiência.

A fim de se verificar a reprodutibilidade destes sensores foram avaliadas mais duas unidades replicadas de cada um dos tipos mais significativos de microeletrodos (T-10, T-50 e N-10), e os resultados são apresentados na figura 37. 


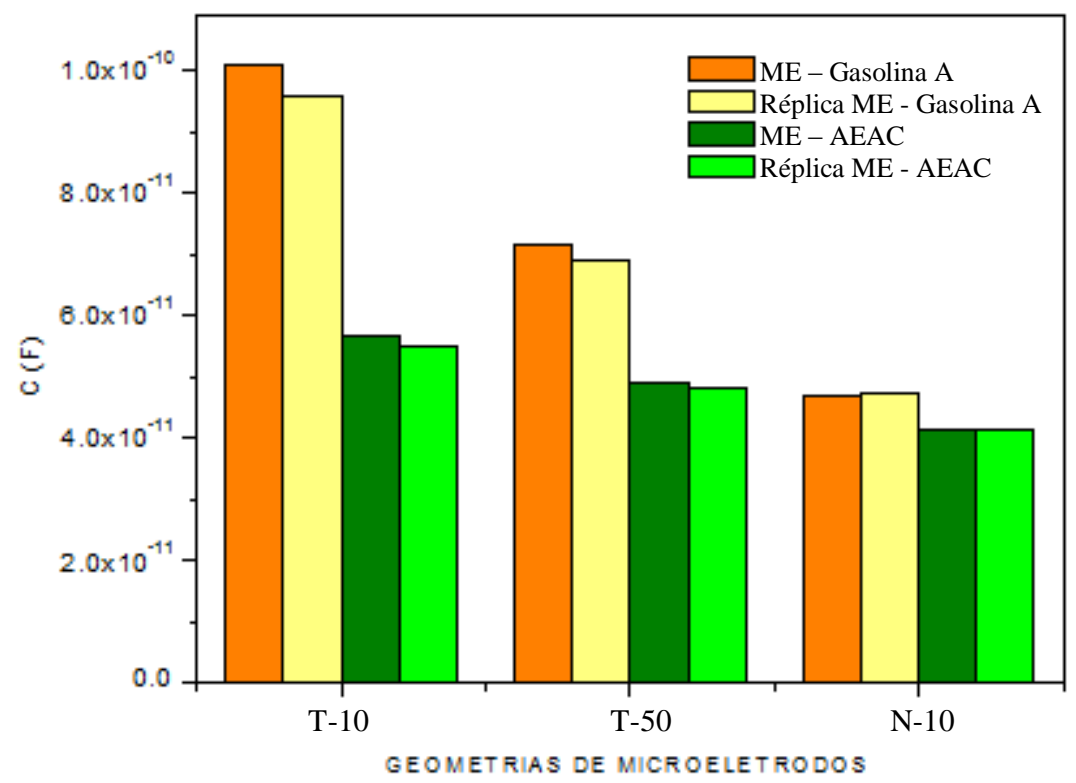

Figura 37 - Reprodutibilidade da resposta de microeletrodos de diferentes geometrias no álcool etílico e na gasolina em $100 \mathrm{kHz}$.

Podemos observar nesta figura a resposta em capacitância de duas unidades de cada tipo de geometria de microeletrodos em AEAC e gasolina A. Pode-se verificar que as unidades em duplicata responderam semelhantemente, ou seja, tiveram comportamentos semelhantes para o AEAC, como também para a gasolina A, mostrando-se reprodutivas, considerando que pequenas variações entre microeletrodos pode ocorrer durante o processo de fabricação. Exemplificando, as duas unidades do tipo T-10 apresentam valores de capacitância em torno de $10 \mathrm{nF}$ para a gasolina. Já para o álcool etílico as mesmas apresentam valores de capacitância em torno de 60 pF. 


\subsection{2 - Avaliação da estabilidade de filmes poliméricos para a análise de combustíveis em meio líquido}

Quando se pensa na utilização de filmes poliméricos em sensores para combustíveis, a grande dificuldade consiste na resistência dos mesmos a este analito, uma vez que poderão ser degradados ou até mesmo removidos. Diante disto, diferentes tipos de filmes poliméricos já estudados em diversos trabalhos utilizados em sensores da LE $[35,36,37,38,40]$ foram fabricados por automontagem para serem utilizados em análise de combustíveis, sendo eles: PANI/PEDOT, PANI/PPY, PANI/PSS, PANI/LS, POEA/PEDOT, POEA/PPY, POEA/PSS e POEA/LS.

Estes filmes foram imersos em álcool etílico anidro combustível por 14 vezes permanecendo durante 20 minutos em cada imersão. Na maioria dos filmes observa-se uma perda significativa de material, que pode ser qualitativamente observada, como mostrado na figura 38 .

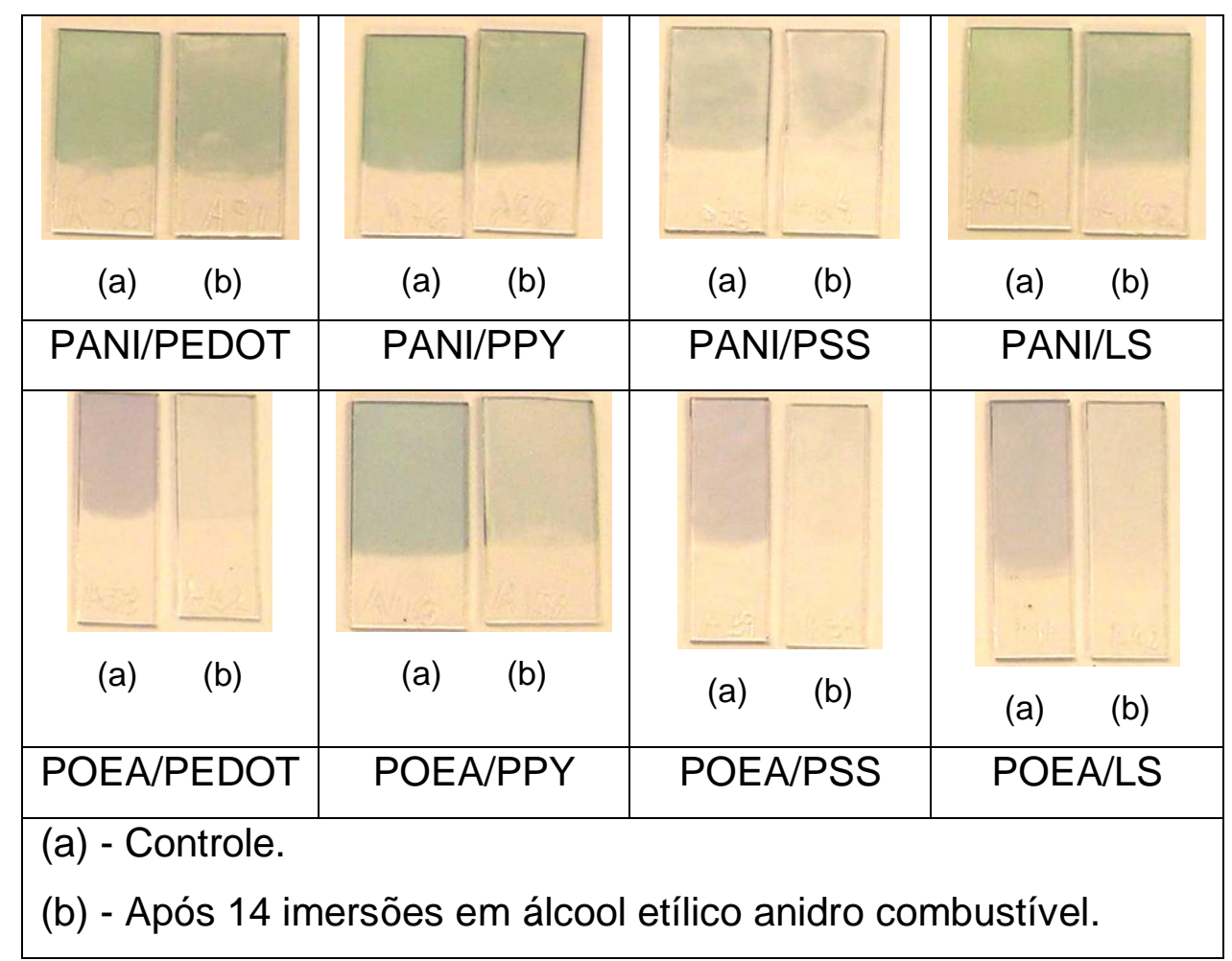

Figura 38 - Visualização para comparação de perda de filme sobre substrato de vidro, antes e após 14 imersões em álcool etílico anidro combustível. 
Para avaliar quantitativamente a perda de material devido à ação do álcool etílico, foram realizadas medidas de espectroscopia de UV-VIS após cada imersão. Os valores de absorbância em comprimentos de onda característicos da absorção do polímero (PANI ou POEA) foram obtidos em função do número de imersões no álcool etílico combustível, como mostra a figura 39.

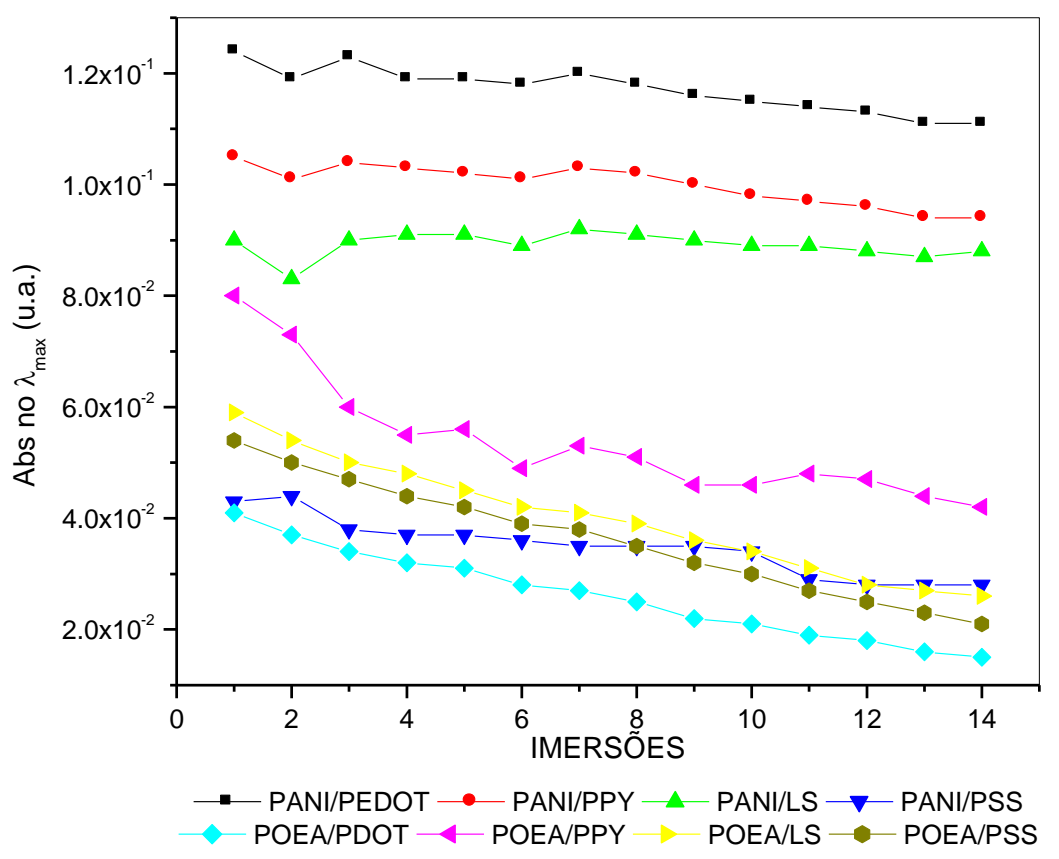

Figura 39 - Absorbância de diferentes filmes poliméricos em função do número de imersões em álcool etílico anidro combustível.

De modo geral, foi possível notar uma perda de massa de todos os filmes testados. Calculou-se esta perda em função do valor da absorbância máxima inicial, obtida antes de qualquer imersão, em relação ao valor da absorbância máxima final, obtida após 14 imersões. O resultado desta análise está apresentado na tabela 5.

Tabela 5 - Perda de massa de filmes após 14 imersões em Álcool etílico anidro combustível. 


\begin{tabular}{cc}
\hline Filmes & $\begin{array}{c}\text { Perda de } \\
\text { massa em } \%\end{array}$ \\
\hline PANI/LS & 16,2 \\
PANI/PPY & 21 \\
\hline PANI/PEDOT & 23,4 \\
PANI/PSS & 28,2 \\
POEA/PPY & 54,8 \\
POEA/LS & 63,4 \\
POEA/PSS & 67,2 \\
POEA/PEDOT & 72,2 \\
\hline
\end{tabular}

A partir deste estudo, pode-se observar que dos filmes poliméricos automontados analisados, os mais resistentes ao álcool etílico foram os que continham PANI, ou seja, PANI/LS, PANI/PPY, PANI/PEDOT e PANI/PSS. Este fato pode ser explicado pela insolubilidade da polianilina em álcool, diferentemente da POEA que é bastante solúvel em álcool etílico e até mesmo em água [139]. Entretanto, mesmo no caso de filmes de PANI, que tiveram menor perda de massa, a aplicação destes filmes para a análise de combustíveis em fase líquida torna-se impraticável. Portanto, é inviável o uso destes sensores com polímeros da tabela 5 em sistemas sensoriais do tipo línguas eletrônicas para análise de etanol combustível. A análise da gasolina comercial brasileira também fica inviabilizada porque esta possui por lei, na sua formulação, de 20 a $25 \%$ de etanol. Porém, para uma aplicação em meio gasoso, onde não há contato direto dos sensores com o líquido, o uso destes materiais sensoativos se justifica.

\subsection{3 - Avaliação do desempenho de filmes poliméricos depositados sobre microeletrodos na análise de vapor de combustíveis comerciais}

Nas aplicações em meios gasosos (como na análise com um Nariz Eletrônico) espera-se que não ocorra perda de massa da camada sensoativa, uma vez que a 
quantidade do analito é bem menor que em meio líquido. Para avaliar o desempenho de sensores de gases feitos a partir de filmes poliméricos na análise combustíveis, foram selecionados os filmes que apresentaram maior estabilidade no estudo sobre imersão em álcool etílico combustível (item 5.1.2). Estes filmes foram depositados sobre os microeletrodos que apresentaram as melhores respostas aos combustíveis, como identificado no item 5.1.1. Desse modo, foram utilizados microeletrodos do tipo T-10 (determinado anteriormente como o de maior resposta aos combustíveis) sobre os quais foram depositados os três filmes mais estáveis formando os seguintes sensores: T-10 PANI/PPY, T-10 PANI/PDOT e T10 PANI/LS. Como o filme de PANI/LS foi o mais estável dentre todos. Este filme foi depositado sobre as duas outras geometrias de microeletrodos restantes, formando os sensores T-50 PANI/LS e N-10 PANI/LS.

A fim de se observar o tempo, a intensidade de resposta e a retomada do sinal os sensores foram expostos aos vapores de álcool etílico anidro e gasolina $A$, durante 5 ciclos na frequência de $1 \mathrm{kHz}$. O resultado é apresentado na figura 40, onde são mostrados os resultados da variação da capacitância elétrica de todas as unidades sensoriais medidas durante 5 ciclos de ar e combustível. A título de comparação, as figura 40 (c) e 40 (d) apresentam os valores da capacitância elétrica em função do tempo de medida dos sensores menos sensíveis na presença de combustíveis. 


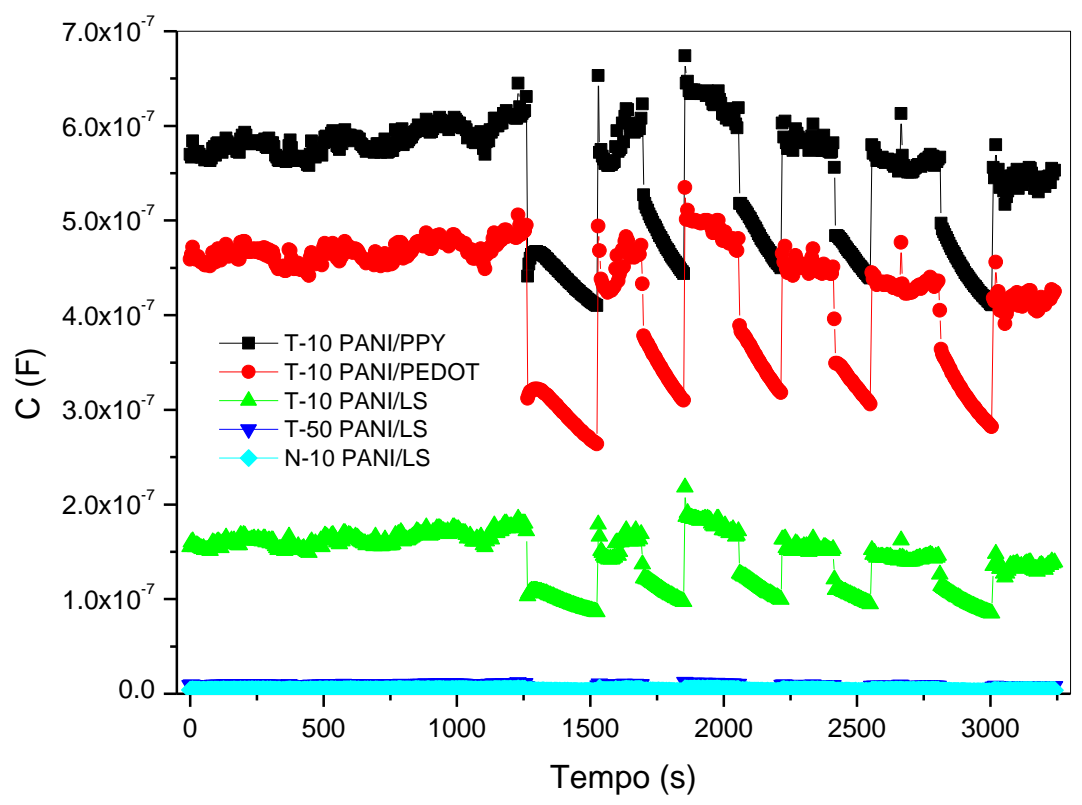

(a) Ciclos de medidas de capacitância no ar e no vapor de álcool etílico anidro combustível para microeletrodos do tipo T-10 com filmes de PANI/PPY, PANI/PEDOT e PANI/LS e do tipo T-50 e N-10 com filmes de PANI/LS.

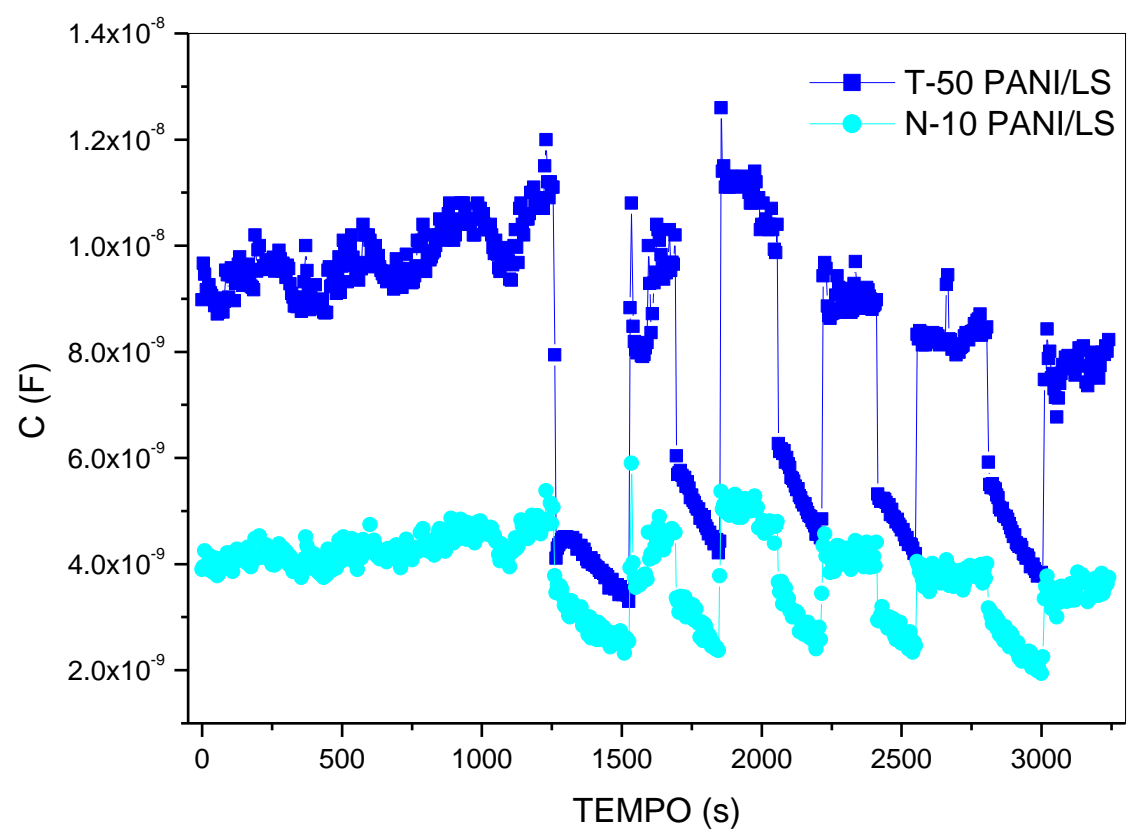

(b) Ciclos de medidas de capacitância no ar e no vapor de álcool etílico anidro combustível somente para microeletrodos do tipo T-50 e N-10 com filmes de PANI/LS da figura. 


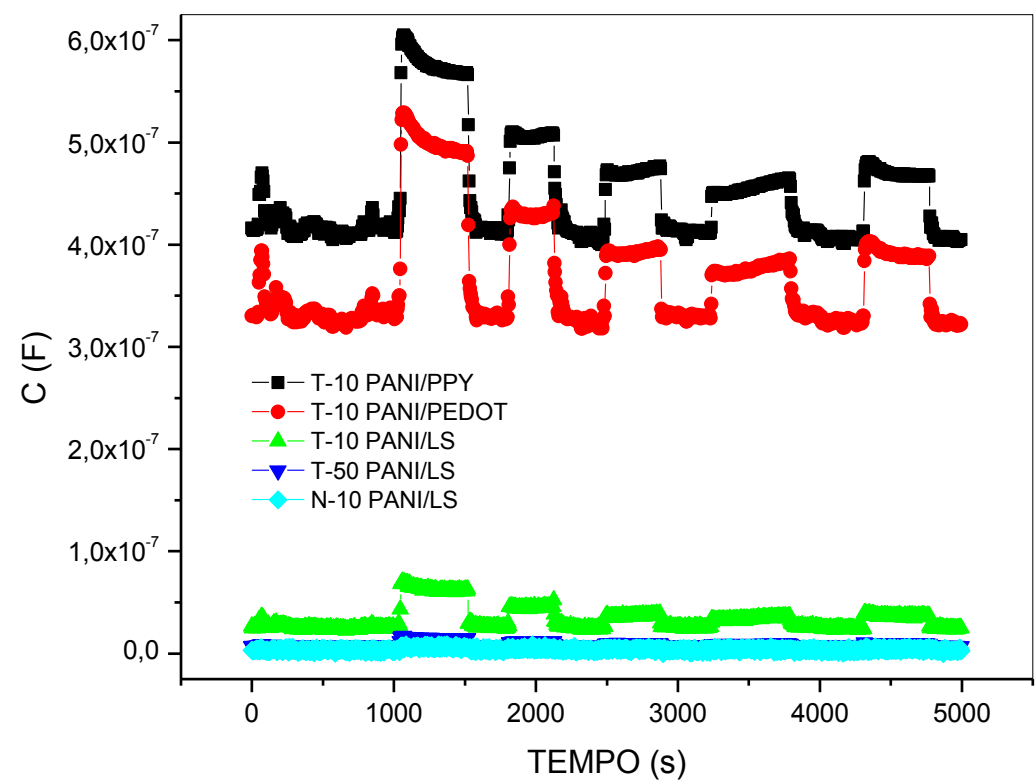

(c) Ciclos de medidas de capacitância no ar e no vapor de gasolina A para microeletrodos do tipo T-10 com filmes de PANI/PPY, PANI/PEDOT e PANI/LS e do tipo T-50 e N-10 com filmes de PANI/LS.

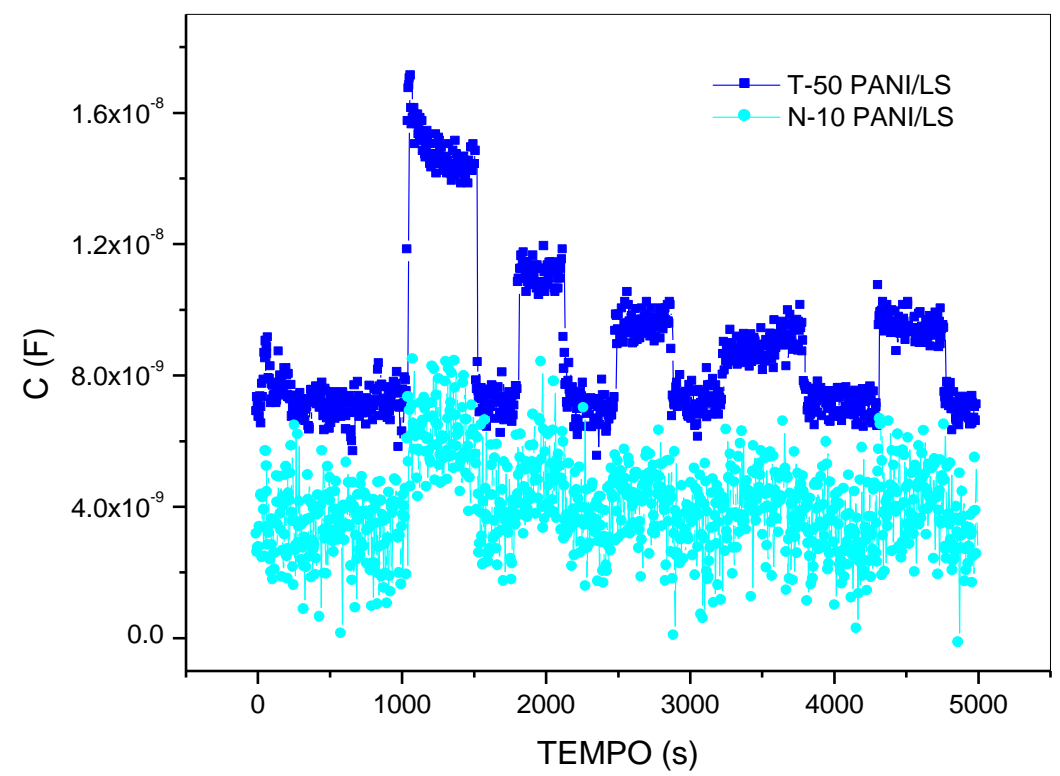

(d) Ciclos de medidas de capacitância no ar e no vapor de gasolina A somente para microeletrodos do tipo T-50 e N-10 com filmes de PANI/LS.

Figura 40 - (a) e (b) Medidas da capacitância de sensores com filmes poliméricos expostos ao ar e ao vapor de álcool etílico anidro combustível durante 5 ciclos em $1 \mathrm{kHz}$; (c) e (d) variação da capacitância de sensores com filmes poliméricos expostos ao ar e ao vapor de gasolina A durante 5 ciclos em $1 \mathrm{kHz}$. 
Nota-se, na comparação da figura 40 (a) com a figura 40 (c), que os sensores respondem de maneira oposta quando expostos aos vapores de etanol e gasolina. Quando em contato com o vapor de etanol a capacitância diminui em relação ao ar. No caso do vapor da gasolina, o valor de capacitância é superior a do ar. Além disso, pode-se observar a retomada dos sinais iniciais medidos no ar após os sensores terem sido expostos aos vapores de combustíveis. Isto significa que ocorreu o reset das unidades sensoriais. De fato, todos os ensaios realizados nesta etapa demonstraram que a resposta elétrica destes filmes é reversível, já que os experimentos foram repetidos durante cinco ciclos onde as unidades sensoriais foram "resetadas". É importante notar que os sensores de geometria tradicional (T10) apresentaram maiores valores de capacitância, embora os outros também tenham se mostrado sensíveis. Os sensores das figuras 40 (b) e 40 (d) também retomaram o sinal, exceto o sensor N-10 PANI/LS, cuja resposta em gasolina não foi estável.

Considerando apenas os sensores com geometria do tipo T-10 (figura 40 (a) e (c)) podemos notar a influência dos diferentes filmes sobre a resposta dos sensores aos combustíveis. O tipo de filme altera a resposta do sensor e a variação destes permite que possamos fabricar sensores diferentes. Esse resultado é bastante interessante e confirma a potencialidade da técnica de automontagem na obtenção de filmes com diferentes respostas, sendo isto fundamental para o desenvolvimento de um sistema multisensor.

O fato das respostas de um mesmo sensor ser diferente para o etanol e para a gasolina deve estar relacionado com a diferença na estrutura química dos analito e seu efeito sobre a interação com as moléculas de polímero dos filmes. É conhecido o fato que moléculas eletrofílicas quando em contato com polímeros condutores aumentam sua condutividade elétrica, uma vez que atraem os elétrons da cadeia polimérica e aumentam temporariamente o número de portadores positivos (os quais são responsáveis pela condução nesses polímeros). O oposto ocorre quando são expostos a moléculas nucleofílicas. Outros fatores também podem influenciar na resposta elétrica dos filmes, como polaridade do analito, disposição estereoquímica, etc.

A resposta de filmes em contato direto com o combustível, imersos, foi estudada com filmes eletrodepositados (melhor resistência ao analito) de PMTh, na forma reduzida e oxidada sobre microeletrodos interdigitados do tipo T-10. A 
variação da capacitância elétrica dos sensores contendo estes filmes foi avaliada no ar e imersos no álcool etílico anidro combustível e comparadas a um sensor de mesma geometria sem filme, como mostrado na figura 41 .

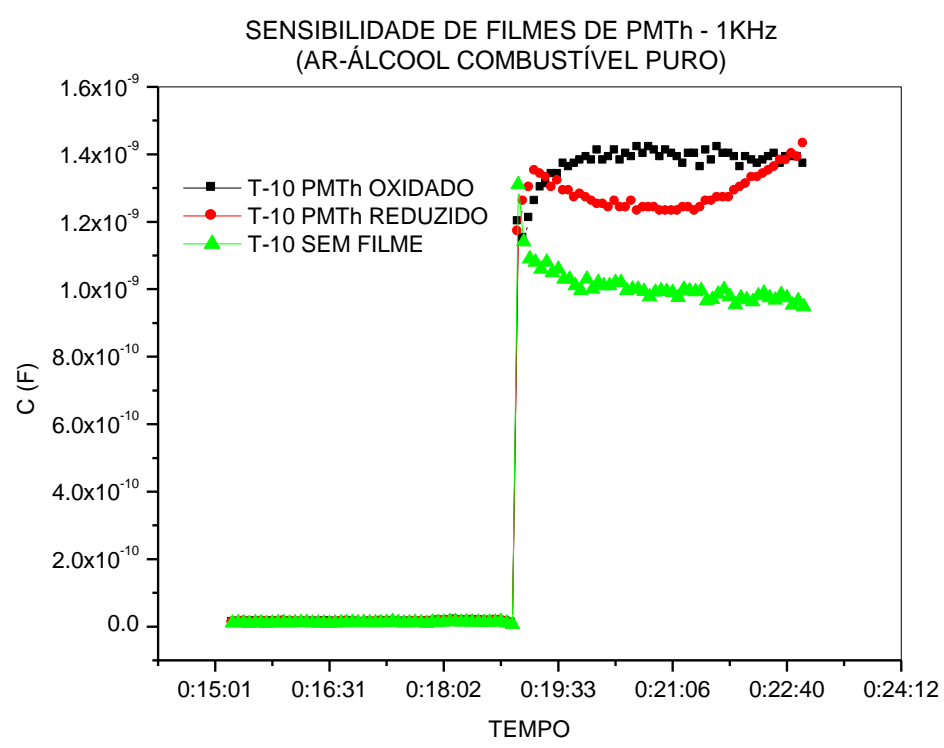

Figura 41 - Avaliação do desempenho de sensores contendo filmes de PMTh em álcool etílico anidro combustível.

Notamos que a intensidade da resposta dos sensores contendo filmes foi superior a do sensor sem filme, porém não muito. Podemos observar ainda que o comportamento inicial dos filmes oxidado e reduzido é diferente, sendo que o filme oxidado atinge a estabilização em um tempo inferior ao do sensor com filme de PMTh reduzido.

\subsection{4 - Desenvolvimento dos sistemas multissensores baseados em ME}

Após ter sido avaliado o desempenho dos sensores individualmente na análise de combustíveis, os combustíveis foram avaliados pelo uso de sistemas multissensores, língua e nariz eletrônicos. Como mencionado anteriormente, um sistema multisensor, língua eletrônica ou um nariz eletrônico, é composto por um arranjo de sensores feitos com materiais sensíveis que, no entanto, não apresentam qualquer especificidade ao analito de interesse. Sendo diferentes entre si (quimicamente ou fisicamente), os sensores respondem diferentemente uns dos 
outros para um mesmo analito ou substância. O conjunto de respostas gerado representa uma espécie de "impressão digital" do analito, uma vez que para analito diversos, diferentes conjuntos de resposta (ou impressões digitais) serão gerados. Dessa forma, dois sistemas multissensores foram fabricados para análise de combustíveis:

- Uma LE composta por sensores de diferentes geometrias e sem filme polimérico, denominada LC-1.

- Um sistema híbrido LE-NE composto por sensores diferentes entre si fisicamente através de diferentes geometrias de microeletrodos e quimicamente através de diferentes tipos de filmes poliméricos, denominado SI-1.

\subsection{5 - Desenvolvimento da LE baseada em ME e avaliação da sua capacidade de discriminação de solventes e combustíveis}

Inicialmente, foram realizados estudos do desempenho de uma língua eletrônica composta por sensores diferenciados entre si apenas pela geometria dos microeletrodos (sem a deposição de filmes poliméricos). Esta língua eletrônica é composta por 7 tipos de microeletrodos de diferentes geometrias e foi denominada como LC-1, tabela 6.

Tabela 6 - Sensores utilizados na Língua LC-1

\begin{tabular}{cc}
\hline Sensor & $\begin{array}{c}\text { Tipo de } \\
\text { Microeletrodo }\end{array}$ \\
$\mathbf{1}$ & $\mathrm{T}-10$ \\
$\mathbf{2}$ & $\mathrm{T}-50$ \\
$\mathbf{3}$ & $\mathrm{N}-10$ \\
$\mathbf{4}$ & $\mathrm{NF}-12$ \\
$\mathbf{5}$ & $\mathrm{NF}-120$ \\
$\mathbf{6}$ & $\mathrm{NF}-225$ \\
$\mathbf{7}$ & $\mathrm{NF}-440$ \\
\hline
\end{tabular}


Resultados preliminares com o sistema LC-1 demonstraram sua capacidade em discriminar gasolinas e alcoóis comerciais. Um primeiro estudo com este sistema foi realizado utilizando-se diversas amostras de combustíveis recolhidas em postos de gasolina da cidade de São Paulo e comparando-as à gasolina $\mathrm{A}$ e à gasolina com $20 \%$ de álcool etílico anidro combustível (porcentagem de AEAC estabelecida por lei no período de realização da análise) preparada em laboratório. Para tanto, as medidas de impedância foram analisadas, estatisticamente, através do método de análise de componentes principais (PCA), descrito anteriormente neste trabalho e os resultados são apresentados na figura 42.

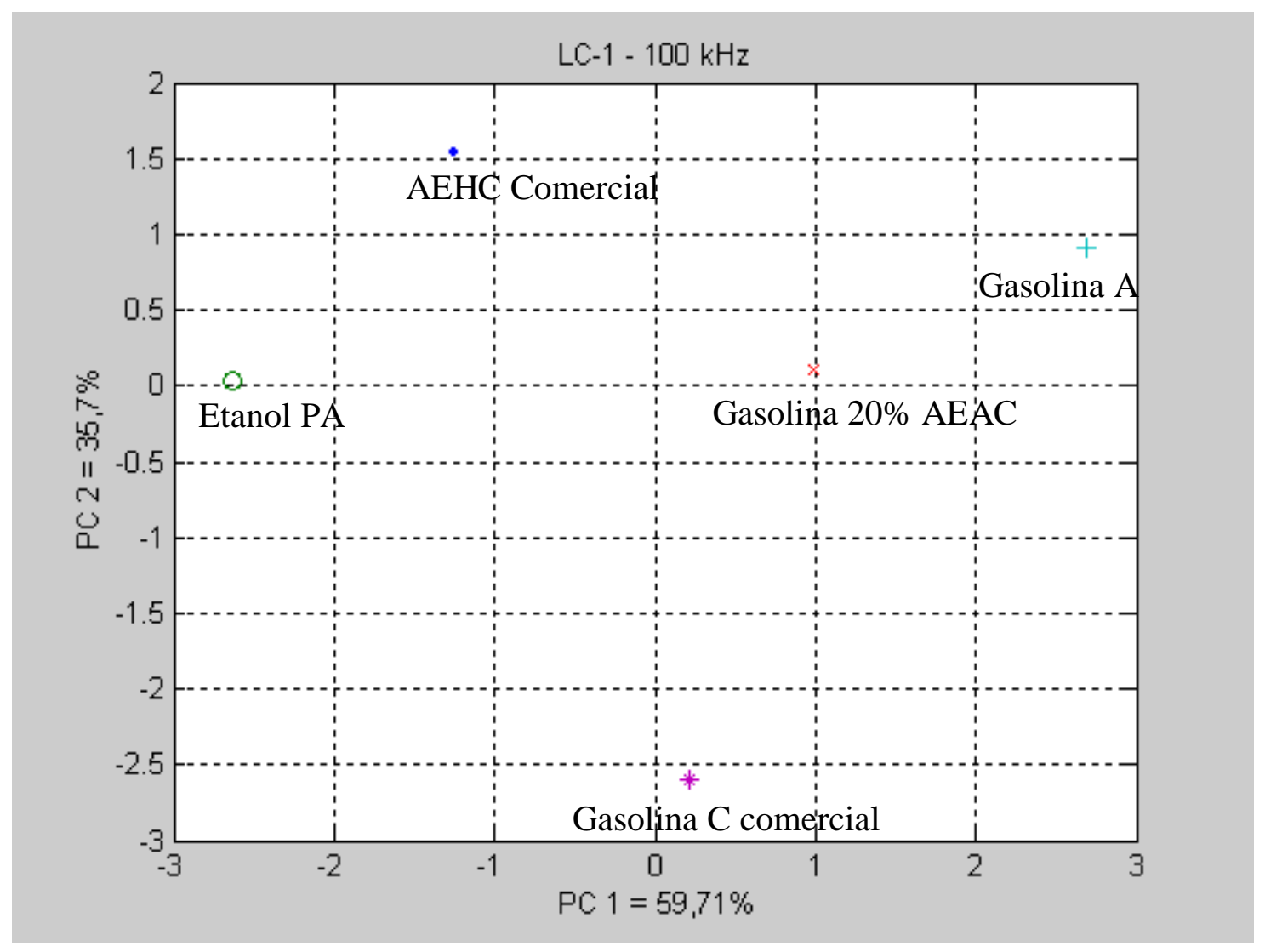

Figura 42 - Gráfico PCA comparando combustíveis comerciais da cidade de São Paulo com gasolina A e gasolina com $20 \%$ de AEAC preparada em laboratório.

O gráfico da PCA obtido para diferentes combustíveis na frequência de 100 $\mathrm{kHz}$ mostra que a primeira componente principal PC1 (eixo X) contém a maioria das informações importantes relacionadas a cada combustível $(59,71 \%)$ e a segunda componente, PC2 (eixo Y), contém a segunda maior quantidade de informações $(35,7 \%)$. Pode-se observar que os líquidos são discriminados pelo sistema sensor, 
uma vez que cada um deles ocupa uma região distinta do gráfico. Além disso, notase que a LC-1 é capaz de discriminar a gasolina $\mathrm{C}$ comercial em relação à gasolina A e à gasolina com $20 \%$ de AEAC. O mesmo é valido para a discriminação entre o álcool etílico hidratado combustível comercial e álcool etílico PA. Observa-se também, que a gasolina com $20 \%$ de AEAC apresenta-se no gráfico entre a gasolina C comercial e a gasolina $A$.

Sabe-se que quanto mais polar é uma substância, maior é a sua constante dielétrica. Sabe-se também que a gasolina é uma substância apolar e o álcool polar, logo o álcool etílico possui uma constante dielétrica muito maior que a gasolina. A constante dielétrica do álcool etílico PA é de 25,3, já a da gasolina é em torno de 2,2. Alguns solventes comerciais de constantes dielétricas conhecidas, tabela 3 , (pag. 60) foram avaliados pela LC-1 e comparados com alguns combustíveis comerciais, figura 43.

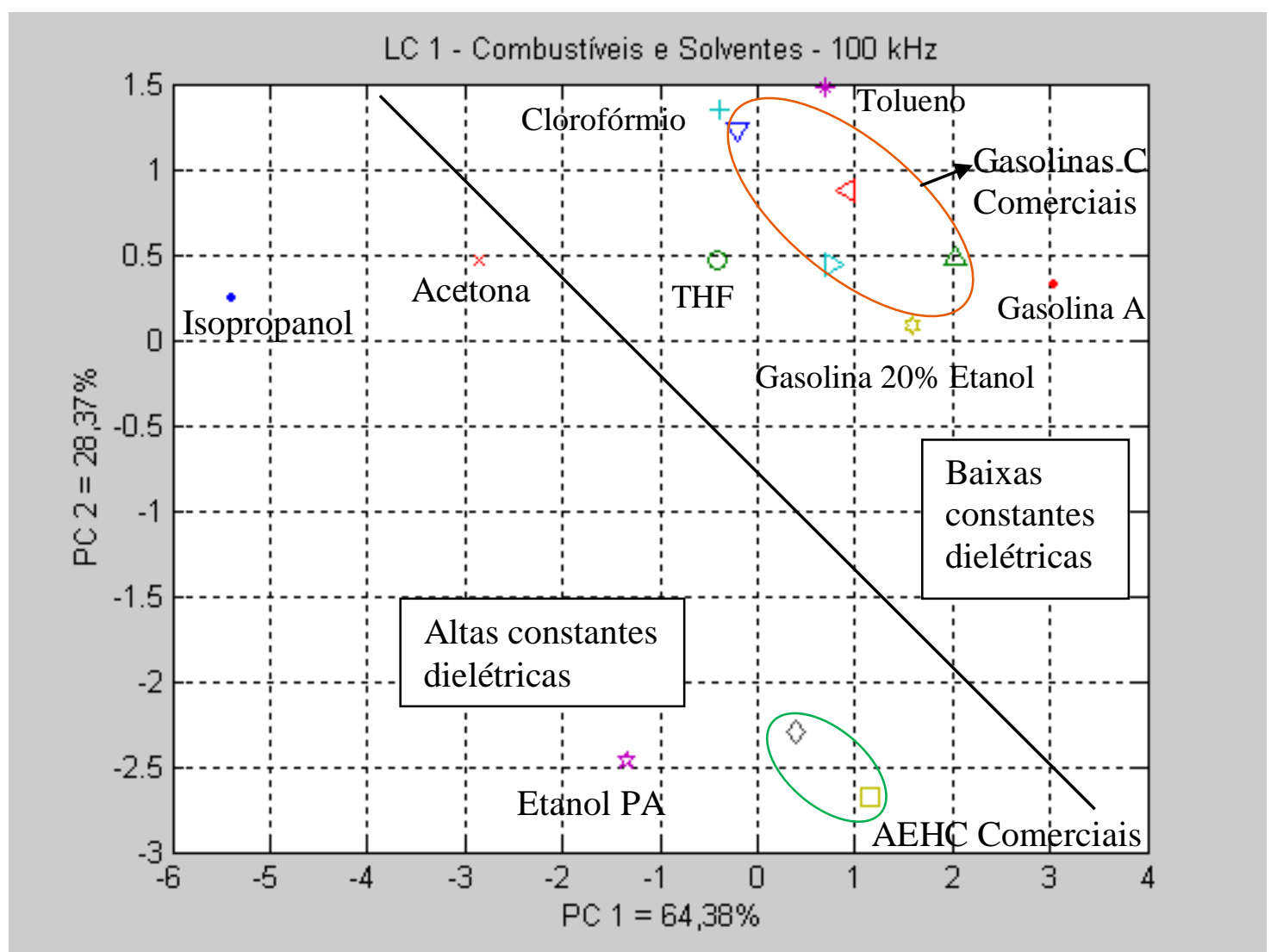

Figura 43 - PCA de combustíveis e solventes com diferentes constantes dielétricas.

Com este estudo observou-se que é possível avaliar a resposta dos sensores em relação a constantes dielétricas, já que as gasolinas $C$ comerciais juntamente com a que contém $20 \%$ de AEAC e a gasolina A encontram-se no gráfico da PCA 
próximas aos solventes de menores constantes dielétricas (Tolueno, Clorofórmio e THF) enquanto que os AEHC comerciais encontram-se próximos ao etanol PA (constante dielétrica igual a 25,3). A partir deste estudo inicial pode-se avaliar a capacidade do sistema LC-1 em discriminar líquidos de acordo com sua constante dielétrica.

\section{2 - DESENVOLVIMENTO E AVALIAÇÃO DO DESEMPENHO DO SISTEMA HÍBRIDO 1 (SH-1) PARA SOLVENTES E COMBUSTÍVEIS}

Buscando um sistema de extrema sensibilidade e capaz de determinar adulteração em combustíveis comercializados no Brasil, como a gasolina e o etanol, foi desenvolvido neste trabalho o sistema híbrido LE-NE (Língua Eletrônica - Nariz Eletrônico). Este sistema une na mesma cabeça sensora um nariz (possibilitando o uso de filmes poliméricos) e uma língua eletrônica. A parte LE deste sistema é composta por dois sensores de geometria $\mathrm{T}-10$ com a deposição de filmes de PMTH por eletrodeposição no estado oxidado e reduzido, respectivamente, e por mais três sensores diferenciados em relação à geometria dos microeletrodos (T-10, T-50 e N10) e sem filme. Já a parte NE do sistema é composta por três microeletrodos de mesma geometria ( $\mathrm{T}-10)$ contendo os três filmes anteriormente demonstrados como de maior estabilidade (PANI/PPY, PANI/PDOT e PANI/LS) e mais dois microeletrodos de geometrias diferentes entre si ( $\mathrm{T}-50$ e $\mathrm{N}-10)$ contendo o filme mais estável (PANI/LS). Este sistema foi denominado de SI-1 e está detalhado na tabela 7. 
Tabela 7 - Sistema híbrido LE-NE

\begin{tabular}{|c|c|c|c|c|}
\hline \multicolumn{5}{|c|}{ SISTEMA HÍBRIDO LE-NE (SH-1) } \\
\hline \multicolumn{2}{|c|}{ SENSOR } & \multirow{2}{*}{\begin{tabular}{|c|} 
TIPO DE \\
MICROELETRODO \\
T-10
\end{tabular}} & \multirow{2}{*}{$\begin{array}{l}\text { POLÍMERO } \\
\text { PANI/PPY }\end{array}$} & \multirow{2}{*}{$\begin{array}{c}\begin{array}{c}\text { № DE } \\
\text { CAMADAS }\end{array} \\
10\end{array}$} \\
\hline \multirow{5}{*}{ NARIZ } & 1 & & & \\
\hline & 2 & $\mathrm{~T}-10$ & PANI/PEDOT & 10 \\
\hline & 3 & $\mathrm{~T}-10$ & PANI/LS & 10 \\
\hline & 4 & $\mathrm{~T}-50$ & $\mathrm{PANI} / \mathrm{LS}$ & 10 \\
\hline & 5 & $\mathrm{~N}-10$ & PANI/LS & 10 \\
\hline \multirow{5}{*}{ LÍNGUA } & 6 & $\mathrm{~T}-10$ & PMTH-OXIDADO & - \\
\hline & 7 & $\mathrm{~T}-10$ & $\begin{array}{c}\text { PMTH- } \\
\text { REDUZIDO }\end{array}$ & - \\
\hline & 8 & $\mathrm{~T}-10$ & - & - \\
\hline & 9 & $\mathrm{~T}-50$ & - & - \\
\hline & 10 & $\mathrm{~N}-10$ & - & - \\
\hline
\end{tabular}

A capacitância elétrica destes sensores foi medida em função da exposição aos combustíveis, tanto em fase líquida quanto na gasosa, simultaneamente. $A$ análise do Nariz Eletrônico foi feita submetendo-se os sensores aos vapores dos combustíveis (headspace), sem a utilização de câmara de gás especial para este fim. A figura 44 mostra o gráfico de PCA obtido para os combustíveis utilizando-se o sistema híbrido. 


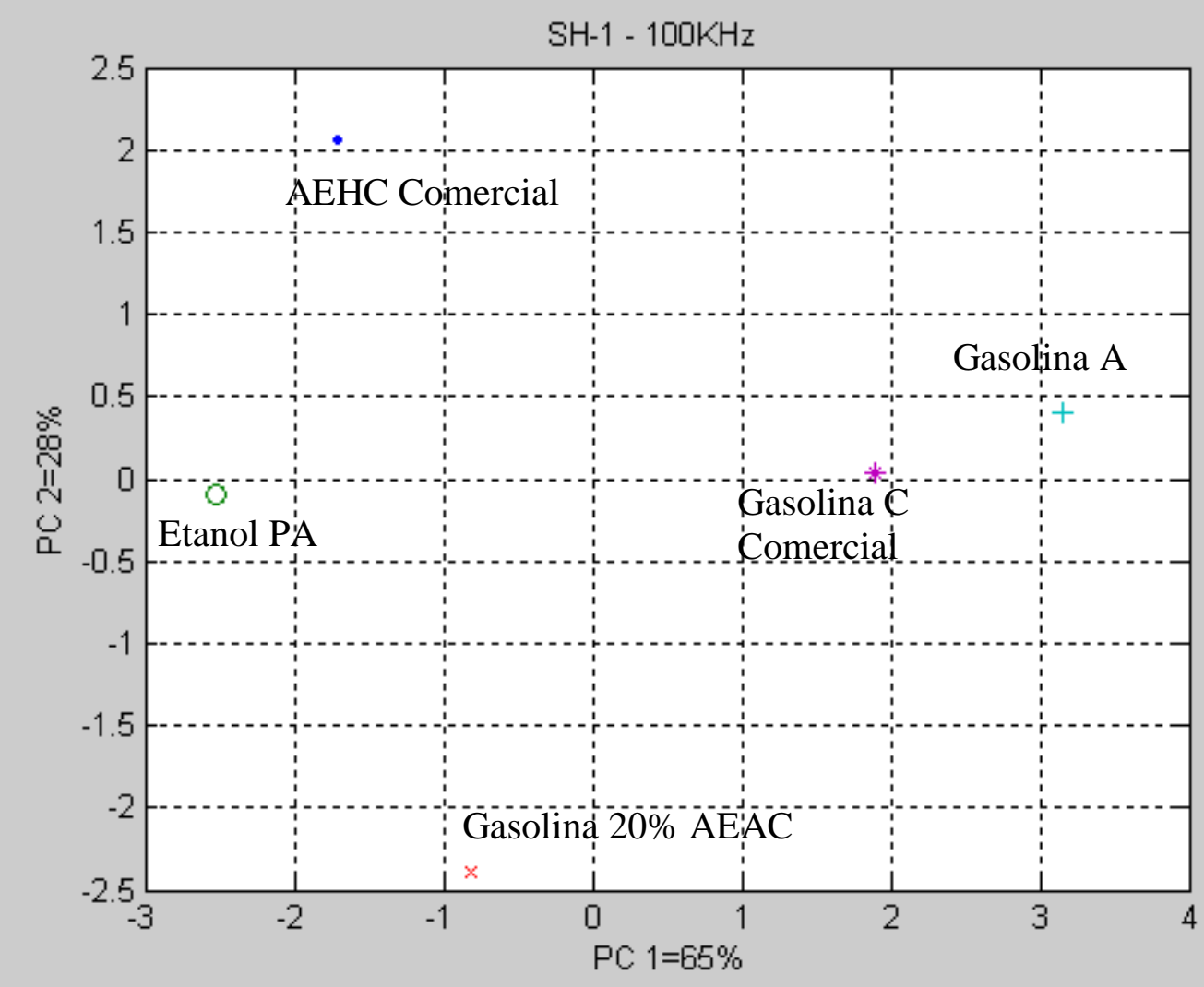

Figura 44 - Gráfico PCA comparando AEHC e gasolina comerciais com álcool etílico PA, gasolina A e gasolina com $20 \%$ de AEAC.

Podemos observar que o $\mathrm{SH}-1$ foi capaz de discriminar a gasolina $\mathrm{C}$ comercial em relação à gasolina $A$ e à gasolina com $20 \%$ de $A E A C$, bem como AEHC comercial das mesmas e este do álcool etílico PA, uma vez que estes ocupam regiões distintas no gráfico. Este estudo foi anteriormente realizado com a LC-1, que também conseguiu distinguir os combustíveis, porém na análise com 0 sistema LE-NE (SH-1) a primeira componente principal PC1 (eixo X), foi maior que na análise com a LC-1, passando de 59,71\% para $65 \%$.

A fim de se comprovar esta informação o experimento realizado com solventes e combustíveis na LC-1 foi repetido para o $\mathrm{SH}-1$, e os resultados de PCA são mostrados na figura 45. 


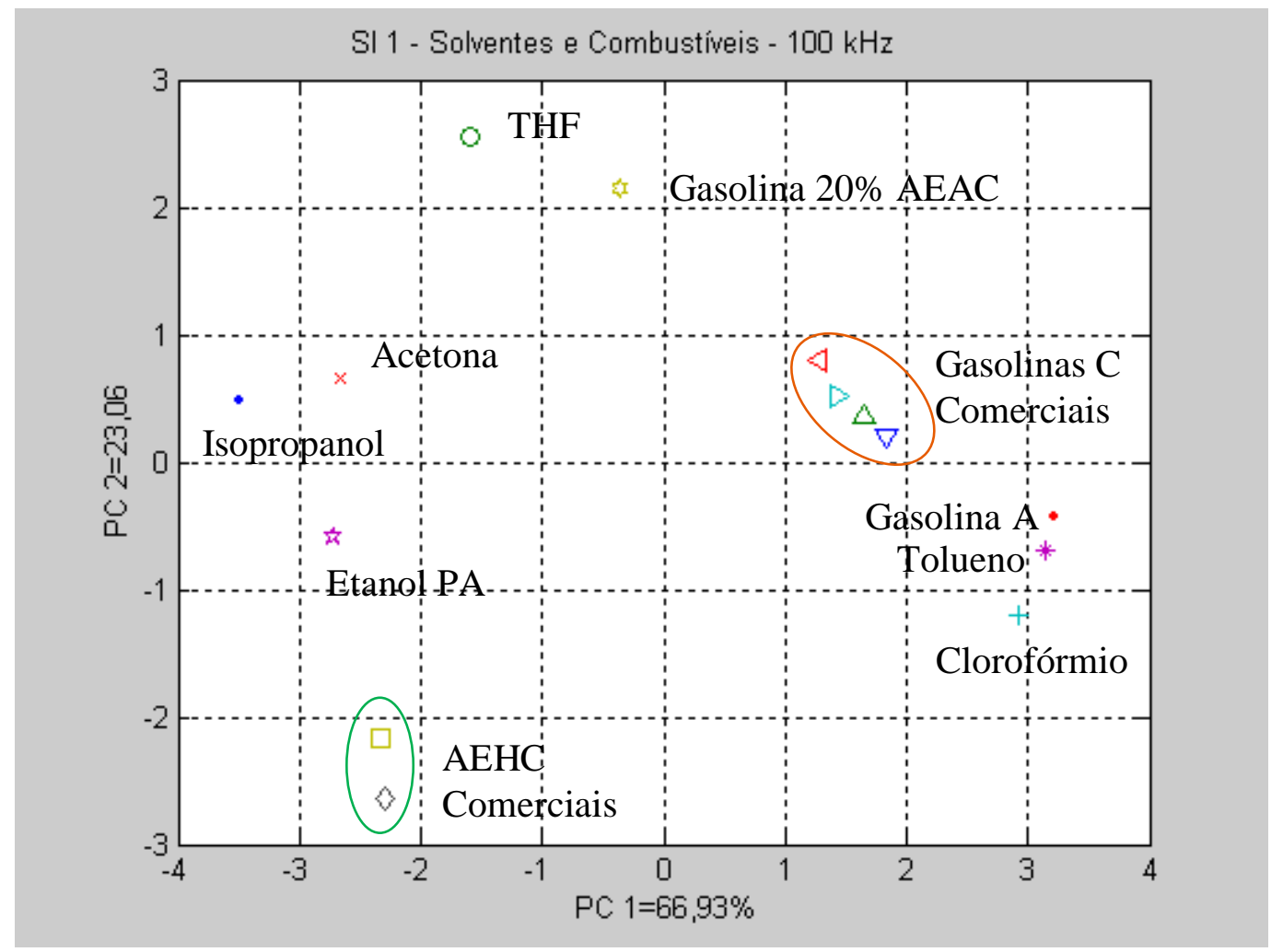

Figura 45 - Gráfico PCA comparando combustíveis comerciais da cidade de São Paulo com solventes, gasolina A e gasolina com $20 \%$ de AEAC, medidos com o sistema híbrido LE-NE.

É possível observar que o sistema híbrido conseguiu separar de forma mais eficiente as gasolinas $\mathrm{C}$ comerciais dos solventes, clorofórmio e tolueno. Observouse também que os solventes de maiores constantes dielétricas (isopropanol, acetona e etanol PA) permaneceram próximos uns aos outros no lado esquerdo do gráfico e próximo aos AEHC comerciais. Os solventes de menores constantes dielétricas (tolueno e clorofórmio) apresentam-se no lado oposto do gráfico (direito) juntamente com a gasolina $A$, indicando mais uma vez que é possível discriminar líquidos a partir de sua constante dielétrica usando-se o sistema híbrido. Comparando-se os resultados da figura $43 \mathrm{com}$ a figura 45 podemos notar que o $\mathrm{SH}-1$ possui maior capacidade de discriminação dos líquidos analisados em relação ao sistema LC-1.

A determinação de uma frequência ideal de uso dos sensores é uma fase importante quando se pensa na otimização de um sistema de análise multivariada, permitindo a simplificação do hardware e software do sistema de medidas.

Portanto, para que os sistemas multissensoriais (SM) possam trabalhar em condições otimizadas, foi estudado o comportamento do $\mathrm{SH}-1$, bem como de suas partes LE e NE separadamente, nas frequências de $100 \mathrm{~Hz}$ e $1 \mathrm{kHz}$, evidenciando a 
relevância de cada sistema multissensorial nestas condições. Além dos combustíveis e solventes de diferentes constantes dielétricas, a água, líquido com alto valor de constante dielétrica e principal adulterante do $A E H C$, também foi considerada neste estudo. As figuras 46 e 47 mostram os gráficos da PCA, biplot e scores plot, dos resultados obtidos com o NE, a LE e com o SH-1, em $100 \mathrm{~Hz}, 1$ $\mathrm{kHz}$, respectivamente. No gráfico biplot, os símbolos (+) numerados são os loadings, indicados na tabela 7. Os Scores são agrupados e denominados de acordo com a amostra medida. 


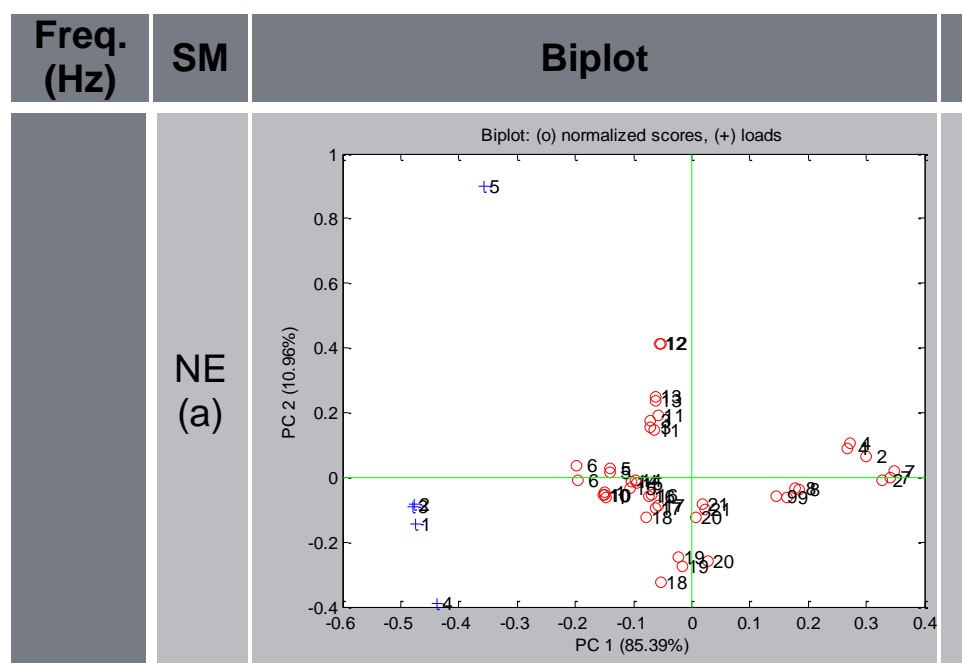

(1)
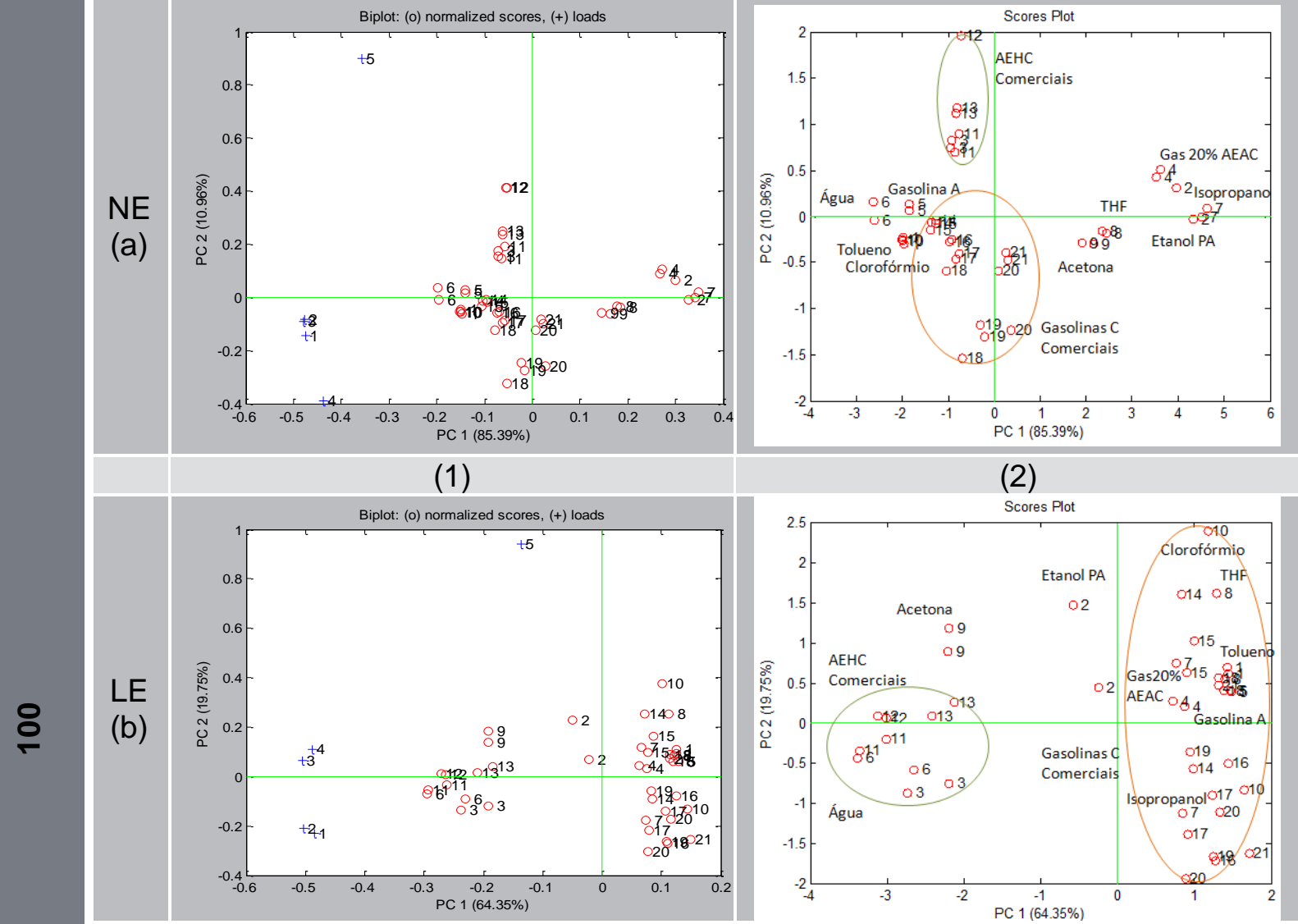

(1)

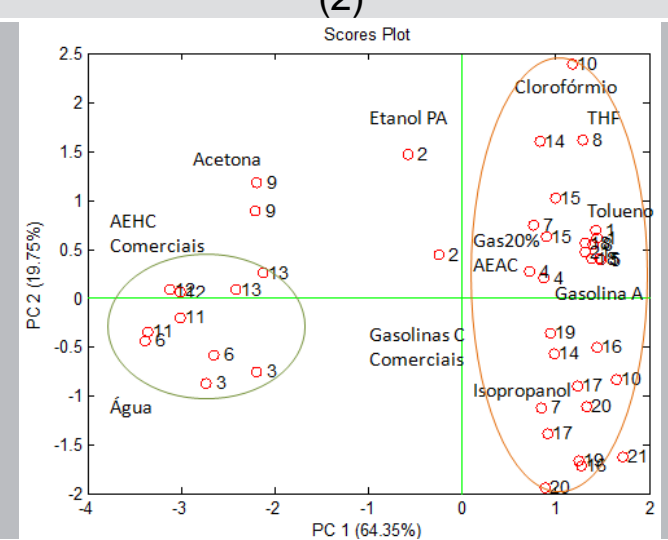

(2)

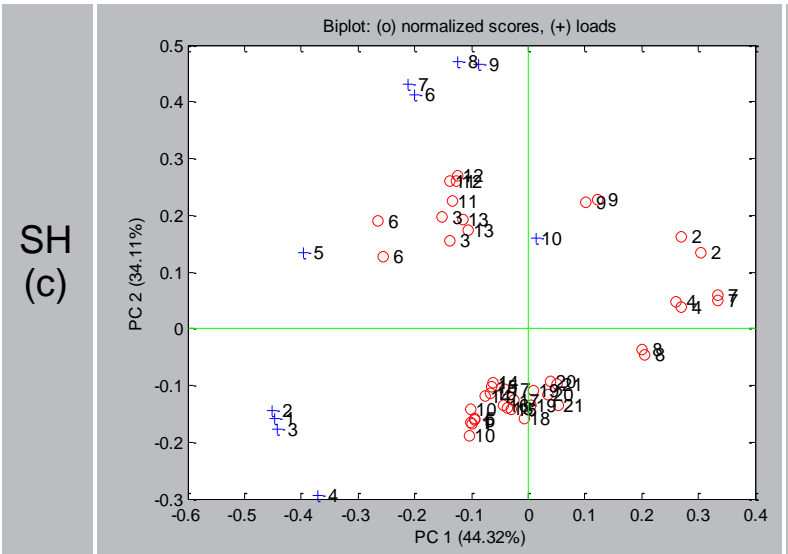

(1)

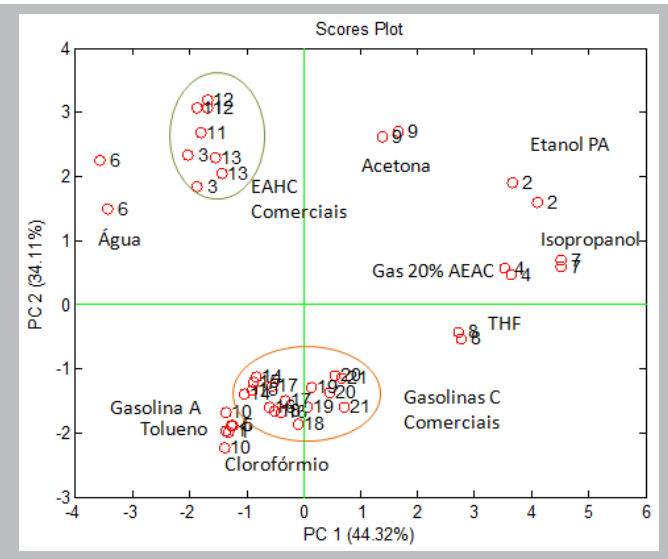

(2)

Figura 46 - Gráficos biplot e scores da PCA obtidos em medidas diferentes solventes e combustíveis com a LE, NE e SH, na frequência de $100 \mathrm{~Hz}$.

Nesta frequência, considerando o gráfico scores ptot do NE, figura 46 (a-2) observa-se que os AEHC não foram separados das gasolinas $A$ e $C$ ao longo da primeira componente principal. Tolueno puro, usado como amostras de referência para gasolina, aparece entre a água e as gasolinas A e C comerciais. Nenhuma 
separação entre o tolueno e o clorofórmio foi obtida. Os compostos puros de alta constante dielétrica, excluindo a água, estão concentrados na parte direita do gráfico. Na figura 46 (a-1), duas direções principais de loadings podem ser identificadas, relativas aos sensores de geometria T-10 com PANI/PPY, PANI/PEDOT e PANI/LS e ao sensor de geometria T-50 com filme de PANI/LS (loadings 1, 2, 3 e 4) orientados para a água, gasolinas e tolueno, e outra relativa ao sensor de geometria N-10 com filme de PANI/LS (loading 5) que é orientado para os $\mathrm{AEHC}$ comerciais e água.

Considerando a LE, figura 46 (b-2), a água, o AEHC e a acetona foram separados dos outros compostos e aparecem na parte esquerda do gráfico; o restante das substâncias aparecem na parte da direita e não houve separação eficiente entre a maioria destas. Vale ressaltar que não houve separação entre os AEHC comerciais e a água. Duas direções significativas de loadings são observadas na figura 46 (b-1), relativas aos sensores de geometrias $\mathrm{T}-10$ contendo filmes de PMTh oxidado e reduzido e T-10 e T-50 sem filme (loadings 1, 2, 3 e 4) orientados para a água e para os AEHC comerciais, e relativas ao sensor N-10 (loading 5) orientado para o etanol PA e a acetona.

Em relação ao $\mathrm{SH}-1$, figura 46 (c-2), é possível observar que houve uma melhora na resposta do sistema híbrido em relação aos sistemas NE e LE, onde a água e os $\mathrm{AEHC}$ aparecem próximos, na parte superior esquerda do gráfico. Os compostos puros de baixa constante dielétrica, tolueno e clorofórmio, aparecem na região inferior esquerda do gráfico, próximos a gasolina $A$ e as gasolinas $C$ comerciais. Já os compostos puros de alta constante dielétrica são identificados na região superior direita. Praticamente todos os compostos foram discriminados, havendo somente uma sobreposição do clorofórmio sobre a gasolina A e o tolueno.

Quatro direções principais de loadings são identificadas na figura 46 (c-1), relativas aos sensores do NE de geometria T-10 com PANI/PPY, PANI/PEDOT e PANI/LS e ao sensor de geometria T-50 com filme de PANI / LS (loadings 1, 2, 3 e 4) orientados para o tolueno, clorofórmio e gasolinas. Relativa ao sensor de geometria N-10 com filme de PANI/LS (loading 5), também contido no NE, orientado para a água. A terceira direção de loadings é relativa aos sensores da LE, sendo que os sensores de geometria T-10, com filme de PMTh oxidado, reduzido e sem filme, bem como de geometria T-50 sem filme (loadings 6, 7, 8 e 9) estão orientados para a água e para os AEHC comerciais. Já a quarta direção é relativa ao sensor N- 
10 (loading 5) que está orientado para a acetona. O biplot da figura 46 (c-1) ilustra a complementaridade entre os sensores da LE e do NE.

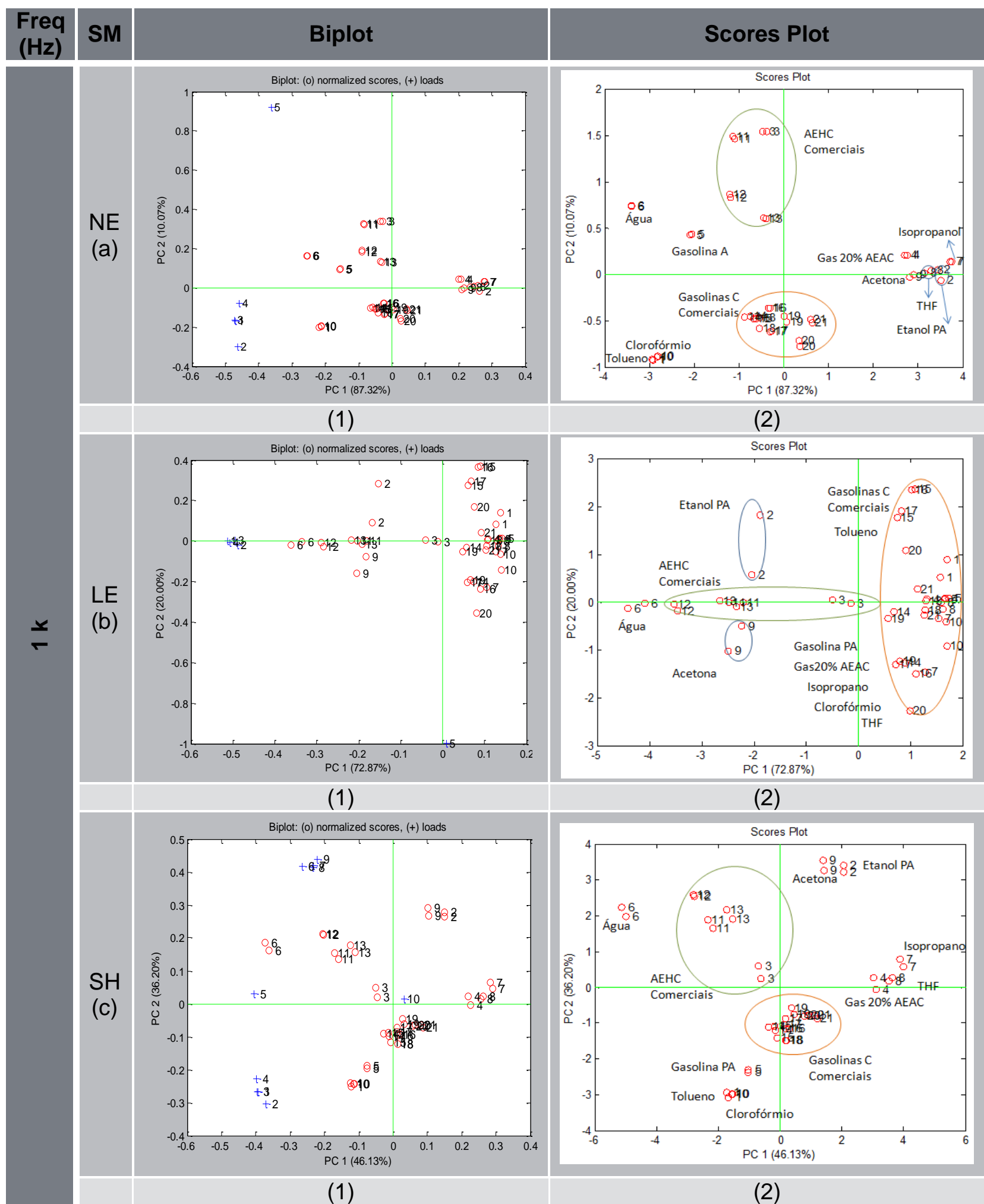

Figura 47 - Gráficos biplot e scores da PCA obtidos em medidas diferentes solventes e combustíveis com a LE, NE e SH, na frequência de $1 \mathrm{kHz}$. 
Em $1 \mathrm{kHz}$ é possível observar que com o NE, figura 47 (a-2), os compostos de alta constante dielétrica não foram claramente separados entre si. O Tolueno e o clorofórmio aparecem na mesma região das gasolinas $\mathrm{C}$ comerciais, porém a gasolina $A$ na região esquerda superior, próxima a água e aos AEHC comerciais. Duas direções principais de loadings podem ser identificadas na figura $47(a-1)$, relativas aos sensores de geometria T-10 com PANI/PPY, PANI/PEDOT e PANI/LS e ao sensor de geometria T-50 com filme de PANI / LS (loadings 1, 2, 3 e 4) orientados para o tolueno, clorofórmio e gasolinas $\mathrm{C}$ comerciais e relativa ao sensor de geometria N-10 com filme de PANI/LS (loading 5), orientado para a água e para os AEHC comerciais.

Observa-se que para a LE em $1 \mathrm{kHz}$, figura 47 (b), a água, os etanóis e a acetona foram, como em $100 \mathrm{~Hz}$, separados do restante das substâncias, que aparecem na parte da direita do gráfico, entre as quais não se obteve boa discriminação. Duas direções significativas de loadings são observadas na figura 47 (b-1), relativas aos sensores de geometrias T-10 contendo filmes de PMTh oxidado e reduzido, T-10 e T-50 sem filme (loadings 1, 2, 3 e 4) orientados para a água e AEHC comerciais, e relativas ao sensor $\mathrm{N}-10$ (loading 5 ) orientado basicamente para a acetona, gasolinas $\mathrm{C}$ comerciais e solventes de baixa constante dielétrica.

Considerando o SH-1, figura 47 (c), novamente é possível observar uma melhora na eficiência da resposta do sistema híbrido em relação aos sistemas LE e NE isoladamente, onde a água e os AEHC comerciais aparecem na parte superior esquerda do gráfico. Os compostos puros de baixa constante dielétrica aparecem na região inferior esquerda próximos das gasolinas. Os compostos puros de alta constante dielétrica aparecem na região superior direita e central, havendo, neste caso, uma separação do etanol PA e da acetona em relação aos demais compostos puros, permanecendo mais próximos dos AEHC comerciais. Praticamente todos os compostos foram discriminados, e nesta freqüência não houve mais a sobreposição do tolueno e clorofórmio sobre a gasolina $A$, porem estes dois compostos ainda aparecem bem próximos.

Três direções principais de loadings são identificadas na figura 47 (c-1), relativas aos sensores de geometria T-10 com PANI/PPY, PANI/PEDOT e PANI/LS e ao sensor de geometria T-50 com filme de PANI / LS (loadings 1, 2, 3 e 4) 
orientados para o tolueno, clorofórmio e gasolinas, relativa ao sensor de geometria N-10 com filme de PANI/LS (loading 5) que neste caso é orientado para a água e relativa aos sensores da LE, T-10 contendo filmes de PMTh oxidado e reduzido, T10 e T-50 sem filme (loadings 6, 7, 8 e 9) orientados para a água e AEHC comerciais, e relativas ao sensor $\mathrm{N}-10$ (loading 5) que neste caso aparece praticamente no centro do gráfico.

Os resultados baseados nas figuras 46 e 47 justificam o uso do sistema híbrido por evidenciar a separação entre os combustíveis e solventes analisados. $O$ sistema híbrido melhora os resultados se for comparado à utilização isolada da Língua Eletrônica e do Nariz Eletrônico de polímeros condutores. Quanto à frequência utilizada nas medidas existem poucas diferenças que pudessem diferenciar os resultados. A tendência em escolher a frequência de $1 \mathrm{kHz}$ é devido à facilidade de fabricação de sistemas de medidas de impedância nesta frequência, além de evitar possíveis ruídos decorrentes da segunda harmônica da rede de energia elétrica.

O uso deste sistema híbrido para análise de combustíveis comerciais brasileiros se justifica, principalmente, quando se pensa no sistema flex de combustíveis, onde o consumidor pode abastecer diferentes combustíveis: etanol combustível (etanol com aproximadamente $7 \%$ de água) e gasolina C (gasolina + $20-25 \%$ de etanol anidro).

\section{3 - DESENVOLVIMENTO E AVALIAÇÃO DO DESEMPENHO DOS SISTEMAS SENSORES BASEADOS EM MICROBALANÇAS DE QUARTZO}

Para compor o sistema multissensorial NE baseado em microbalanças de quartzo foram desenvolvidos oito sensores, onde quatro $\mathrm{MBQ}$ foram recobertas por filmes de tetrafenilporfirinas (TPP), funcionalizadas com ferro (FeTPP), zinco (ZnTPP), manganês (MnTPP) e cobalto (CoTPP), depositados por spray casting. A seletividade dos sensores depende do tipo de metal central e da substituição dos radicais externos dos macrociclos. A seleção dos filmes a serem depositados sobre 
as microbalanças de quartzo foi baseada em estudos anteriores de aplicações destes materiais [26]. As propriedades sensíveis destas porfirinas foram amplamente caracterizadas no passado [26,88]. Multicamadas de polímeros depositados pela técnica de automontagem recobriram as outras quatro microbalanças. Todos os filmes poliméricos foram baseados em camadas de PANI. A segunda camada foi formada por PEDOT:PSS, lignina sulfonada (LS), poliestireno sulfonado (PSS), e (FtTsNi) [36].

A deposição dos materiais por automontagem foi realizada pela imersão das microbalanças de quartzo, previamente funcionalizadas com mercaptana, alternadamente em soluções de cada material. Os sensores baseados em MBQ foram recobertos por três bicamadas poliméricas. A frequência de ressonância das microbalanças de quartzo foi avaliada após cada bicamada de material depositada, os valores obtidos estão detalhados na tabela 8 e ilustrados na figura 48 .

Tabela 8 - Avaliação da deposição de filmes em MBQ.

\begin{tabular}{|c|c|c|c|c|c|}
\hline $\begin{array}{c}\text { Filme } \\
\text { depositado } \\
\text { sobre QMB }\end{array}$ & $\begin{array}{c}\mathbf{F}(\mathbf{H z}) \\
\text { Inicial }\end{array}$ & $\begin{array}{c}\mathbf{F}(\mathbf{H z}) \text { Apos } \\
\text { Mercaptana }\end{array}$ & $\begin{array}{c}\mathbf{F}(\mathbf{H z}) \mathbf{1} \\
\text { bicamada }\end{array}$ & $\begin{array}{c}\mathbf{F}(\mathbf{H z}) \mathbf{2} \\
\text { bicamadas }\end{array}$ & $\begin{array}{c}\mathbf{F}(\mathbf{H z}) \mathbf{3} \\
\text { bicamadas }\end{array}$ \\
\hline PANI/PEDOT & 19.90885 & 19.90793 & 19.90799 & 19.9111 & 19.9105 \\
\hline PANI/LS & 19.99827 & 19.99 & 19.99544 & 19.99553 & 19.99337 \\
\hline PANI/PSS & 19.99175 & 19.9843 & 19.9918 & 19.99127 & 19.99033 \\
\hline PANI/ FtTsNi & 20.00058 & 19.9953 & 19.99981 & 19.99945 & 19.9983 \\
\hline
\end{tabular}




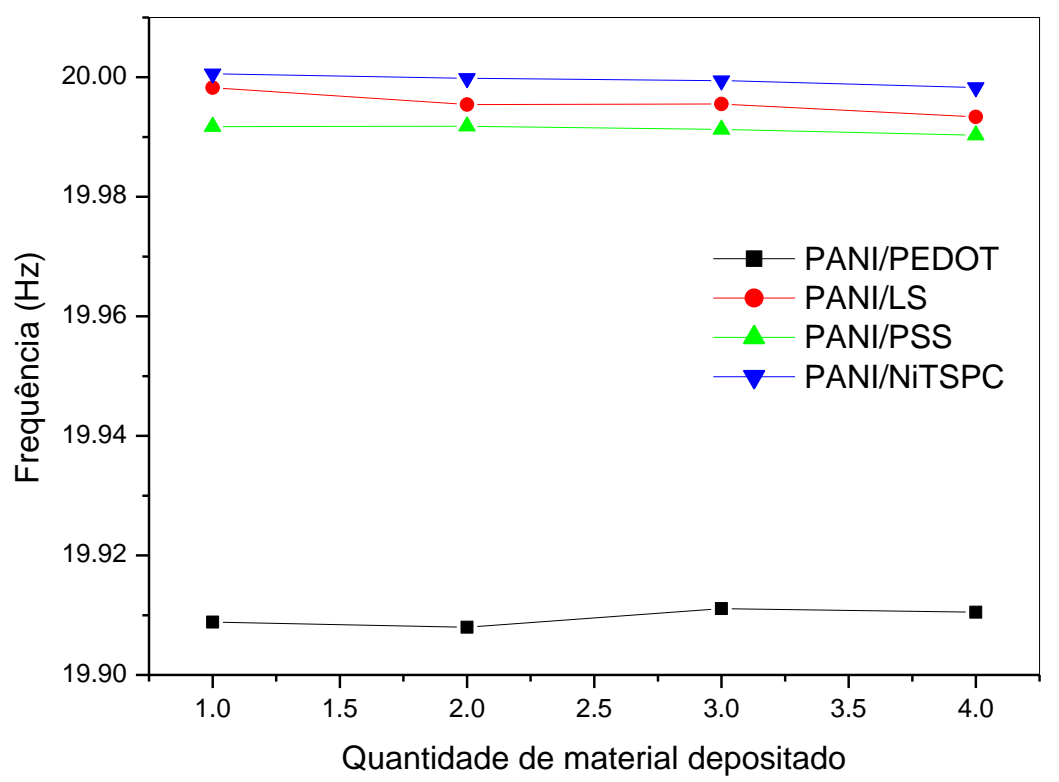

Figura 48 - Variação de frequência com a deposição de material sensoativo.

A variação na frequência de oscilação das microbalanças após a deposição das camadas sensoativas poliméricas foi praticamente inexistente, o que era esperado, já que o filme depositado é nanoestruturado e o número de bicamadas foi pequeno.

O mesmo estudo foi realizado para a deposição das metaloporfirinas por spray casting, onde uma variação de frequência de aproximadamente $60 \mathrm{kHz}$ foi obtida entre todas as camadas depositadas [87,88,89,105].

\subsection{1 - Desenvolvimento dos sistemas multissensoriais baseados em MBQ}

O sistema multissensorial Nariz Eletrônico baseado em MBQ foi desenvolvido a partir de sensores feitos com microbalanças de quartzo funcionalizadas com polímeros e metaloporfirinas, tabela 9. 
Tabela 9 - Sensores utilizados no NE-MBQ

\begin{tabular}{ll}
\hline Sensor & $\begin{array}{l}\text { Camada } \\
\text { Sensoativa }\end{array}$ \\
\hline S-1 & Fe-TPP \\
S-2 & Zn-TPP \\
S-3 & PANI/PEDOT \\
S-4 & Mn-TPP \\
S-5 & Co-TPP \\
S-6 & PANI/PSS \\
S-7 & PANI/LS \\
S-8 & PANI/FtTsNi \\
\hline
\end{tabular}

As unidades sensoriais foram acopladas na câmara de gás do sistema de medidas do nariz eletrônico desenvolvido pela Università Degli Studi di Roma, Tor Vergata.

\subsection{2 - Avaliação da capacidade de discriminação de solventes e combustíveis com o NE-MBQ}

Antes de testar o sistema sensor com amostras de combustíveis reais, a aptidão para identificar tanto compostos puros contidos na gasolina, como compostos naturais ou adulterantes, foi estudada. A Figura 49 mostra o gráfico biplot das duas primeiras componentes principais dos dados do sistema sensor de microbalanças quando expostos em dois dias diferentes a vapores de água, hexano, tolueno, etanol PA, bem como a diesel e gasolinas (sem etanol) comerciais italianos. O biplot é um método usado para mostrar, ao mesmo tempo, os scores e os loadings de uma análise de componente principal [16]. 


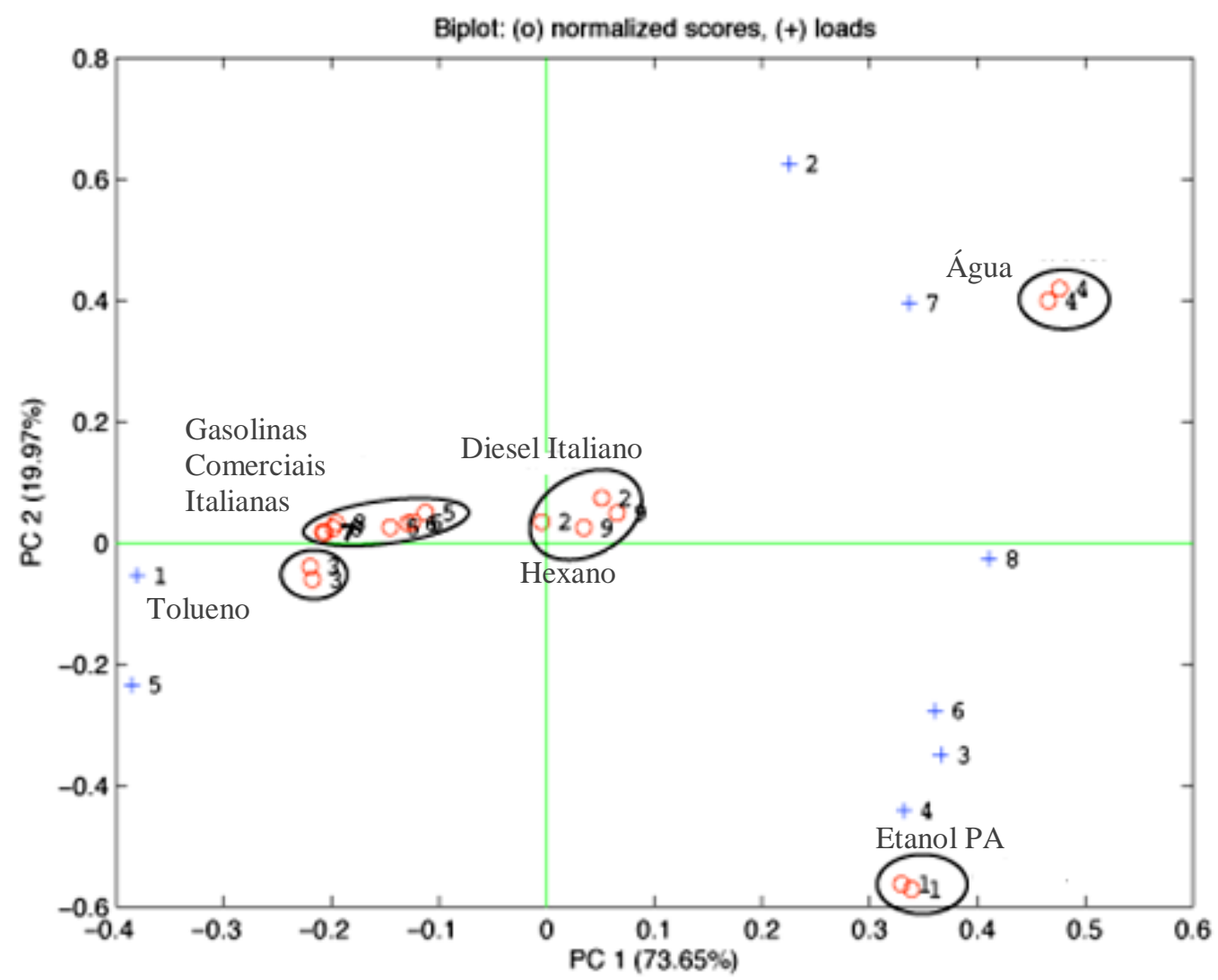

Figura 49 - Gráfico biplot da PCA dos dados do conjunto de sensores de MBQ. Scores são mostrados como círculos numerados.

No gráfico biplot, os símbolos (+) numerados são os loadings, indicados na tabela 9. Os Scores são agrupados e denominados de acordo com a amostra medida. O gráfico apresentado na figura 50 exprime $92 \%$ da variância total dos dados. Observa-se que os compostos polares (etanol e água) foram separados dos outros compostos ao longo da primeira componente principal. Tolueno e hexano puros, usados como amostras de referência para gasolina e diesel, são agrupados no centro do gráfico, e nenhuma separação entre o hexano e óleo diesel foi obtida. $\mathrm{O}$ biplot ilustra a complementaridade entre os sensores. Três direções principais de loadings podem ser identificadas, relativas ao FeTPP e ao CoTPP (loadings 1 e 5) orientadas para tolueno e gasolinas, ao ZnTPP e a PANI / LS (loadings 2 e 7) orientadas para a água, e relativa aos demais sensores (loadings $3,4,6$ e 8 ) que são essencialmente orientadas para etanol.

É interessante observar que, exceto FeTPP e CoTPP, todos os sensores são mais eficientes na detecção de compostos polares, tais como água e etanol. 
Este comportamento pode ser explicado considerando o conhecimento prévio da sensibilidade dos polímeros utilizados para o etanol e a água [140,114] e com a coordenação de moléculas incorporadas ao metal no centro do núcleo interno da porfirina. Para este último aspecto o conceito de "ácidos e bases duros e moles" Hard-Soft-ácido-base (HSAB) ou princípio de Pearson tem sido usado para explicar a sensibilidade de sensores baseados em metaloporfirinas [141].

\section{4 - DESENVOLVIMENTO E AVALIAÇÃO DO DESEMPENHO DOS SISTEMAS SENSORES BASEADOS EM MATRIZ CAPACITIVA}

Para este sistema, multissensorial, os sensores químicos foram fabricados depositando materiais sensoativos, metaloporfirinas e polímeros condutores, sobre a superfície da matriz capacitiva por solvent casting, figura 30.

Os sinais sensoriais foram avaliados individualmente seguindo 0 procedimento descrito na ref. 42. Para tanto, a média dos sinais medidos, relacionados às células capacitivas contidas nas regiões de deposição dos materiais sensoativos foi realizada, obtendo-se, assim, um conjunto de valores, sendo um para cada região sensível selecionada, figura 50 . 

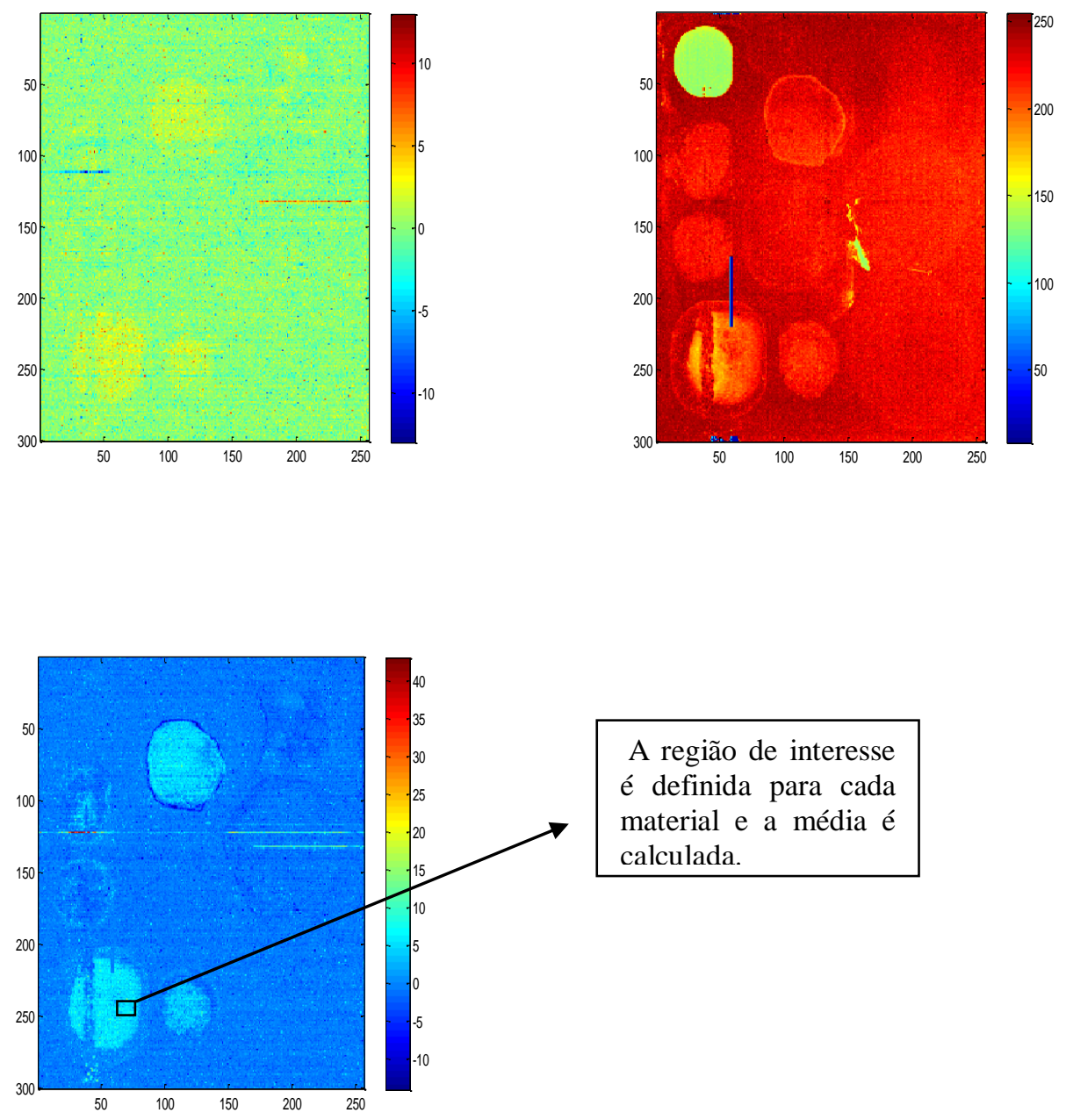

Figura 50 - Representação da matriz em contato com gases de análise

Desse modo, a partir da matriz capacitiva da figura 30, foram selecionadas apenas oito regiões sensoativas de interesse, contendo diferentes materiais depositados, obtendo-se assim oito sensores diferentes entre si, sendo estes recobertos por: FeTPP, CoTPP, MnTPP, FtTsNi, MnOEC, PEDOT:PSS, PANI e POMA. Os sensores estão detalhados na tabela 10. 
Tabela 10 - Sensores utilizados no NE - Matriz Capacitiva

\begin{tabular}{ll}
\hline Matriz Capacitiva \\
\hline Sensor & $\begin{array}{l}\text { Camada } \\
\text { sensoativa }\end{array}$ \\
$\mathbf{1}$ & POMA \\
$\mathbf{2}$ & PANI \\
$\mathbf{3}$ & PEDOT-PSS \\
$\mathbf{4}$ & MnOEC \\
$\mathbf{5}$ & MnTPP \\
$\mathbf{6}$ & FtTsNi \\
$\mathbf{7}$ & FeTPP \\
$\mathbf{8}$ & CoTPP \\
\hline
\end{tabular}

\subsection{1 - Avaliação da capacidade de discriminação de solventes e combustíveis com a Matriz capacitiva}

Um mapeamento dos mesmos compostos, testados anteriormente com 0 sistema multissensorial de $M B Q$, foi realizado analisando os dados obtidos a partir da matriz de capacitores exposta a vapores de água, hexano, tolueno, etanol PA, diesel italiano e gasolina italiana. As medidas foram repetidas durante dois dias. A figura 51 mostra o gráfico biplot da PCA calculada com os dados da matriz de capacitores. 


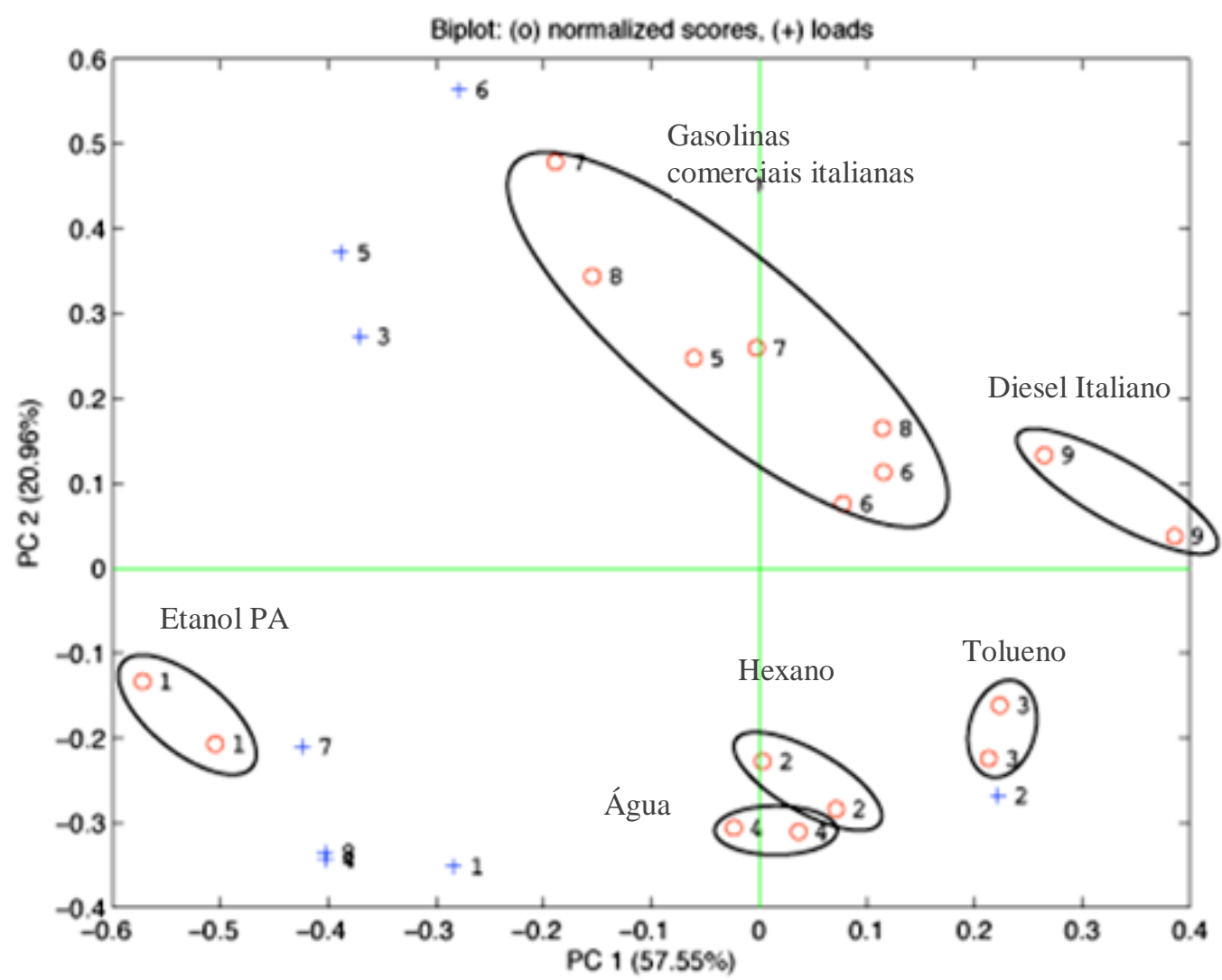

Figura 51 - Gráfico biplot da PCA dos dados do conjunto de sensores capacitivos. Scores e loadings são mostrados como círculos e cruzes numerados respectivamente. Os scores são agrupados e denominados na figura de acordo com a amostra medida. Os loadings estão detalhados na tabela 10.

Observa-se no gráfico biplot da PCA calculada com os dados da matriz de capacitores, que, neste caso, $77 \%$ do total da variância é explicada pelas duas primeiras componentes principais. As amostras de combustíveis e os compostos puros foram bem separados ao longo da segunda componente principal, e houve, ao longo da primeira componente principal, uma separação parcial dos compostos puros, com uma sobreposição parcial do hexano nas amostras de água. O etanol PA foi considerado como um composto puro.

Do ponto de vista da contribuição de cada material sensoativo, os loadings indicam três direções principais, que são formadas por: PEDOT-PSS, MnTPP, e FtTsNi (loadings 3, 5 e 6) orientados para as gasolinas; POMA, MnOEC, FeTPP, CoTPP (loadings 1, 4, 7 e 8) orientados para os compostos polares e, por fim, a PANI (loading 2) que está orientada para o tolueno. 
Este comportamento pode ser justificado considerando que para porfirinas a variação de capacitância é, provavelmente, devida às variações do vetor de polarização, onde, o dipolo elétrico das porfirinas com moléculas adsorvidas possui um efeito bastante semelhante ao que ocorre com a funcionalização de porfirinas em transistores de efeito de campo [21]. No caso do polímero, o aumento de volume das camadas poliméricas é, provavelmente, o efeito dominante [6]; compostos como os hidrocarbonetos, em que interações de sorção são dominantes, podem ser detectadas eficientemente por este tipo de sensores.

\section{5 - DESENVOLVIMENTO E AVALIAÇÃO DA CAPACIDADE DE DISCRIMINAÇÃO DE SOLVENTES COM O SISTEMA HÍBRIDO 2}

A cooperação entre o sistema unificado dos dois conjuntos de sensores, microbalanças e matriz capacitiva, foi demonstrada pela fusão de seus dados, tabela 11.

Tabela 11 - Sensores utilizados no SH-2

\begin{tabular}{|c|c|c|c|}
\hline \multicolumn{2}{|c|}{ Matriz Capacitiva } & \multicolumn{2}{|c|}{ Conjunto de MBQ } \\
\hline Sensor & $\begin{array}{l}\text { Camada } \\
\text { sensoativa }\end{array}$ & Sensor & $\begin{array}{l}\text { Camada } \\
\text { sensoativa }\end{array}$ \\
\hline 1 & POMA & 9 & FeTPP \\
\hline 2 & PANI & 10 & ZnTPP \\
\hline 3 & PEDOT-PSS & 11 & PANI/PEDOT-PSS \\
\hline 4 & MnOEC & 12 & MnTPP \\
\hline 5 & MnTPP & 13 & CoTPP \\
\hline 6 & FtTsNi & 14 & PANI/PSS \\
\hline 7 & FeTPP & 15 & PANI/LS \\
\hline 8 & CoTPP & 16 & PANI/ FtTsNi \\
\hline
\end{tabular}

A fusão metodológica aqui utilizada é bastante simples e baseia-se na criação de um aumento na matriz de dados que é obtido unindo as colunas das duas 
matrizes individuais de dados dos dois sistemas multissensoriais, este método foi adotado no passado para combinar dados de diferentes narizes eletrônicos $[49,100]$. A matriz aumentada foi analisada novamente com a PCA, figura 52, onde o gráfico biplot das duas primeiras componentes principais é mostrado.

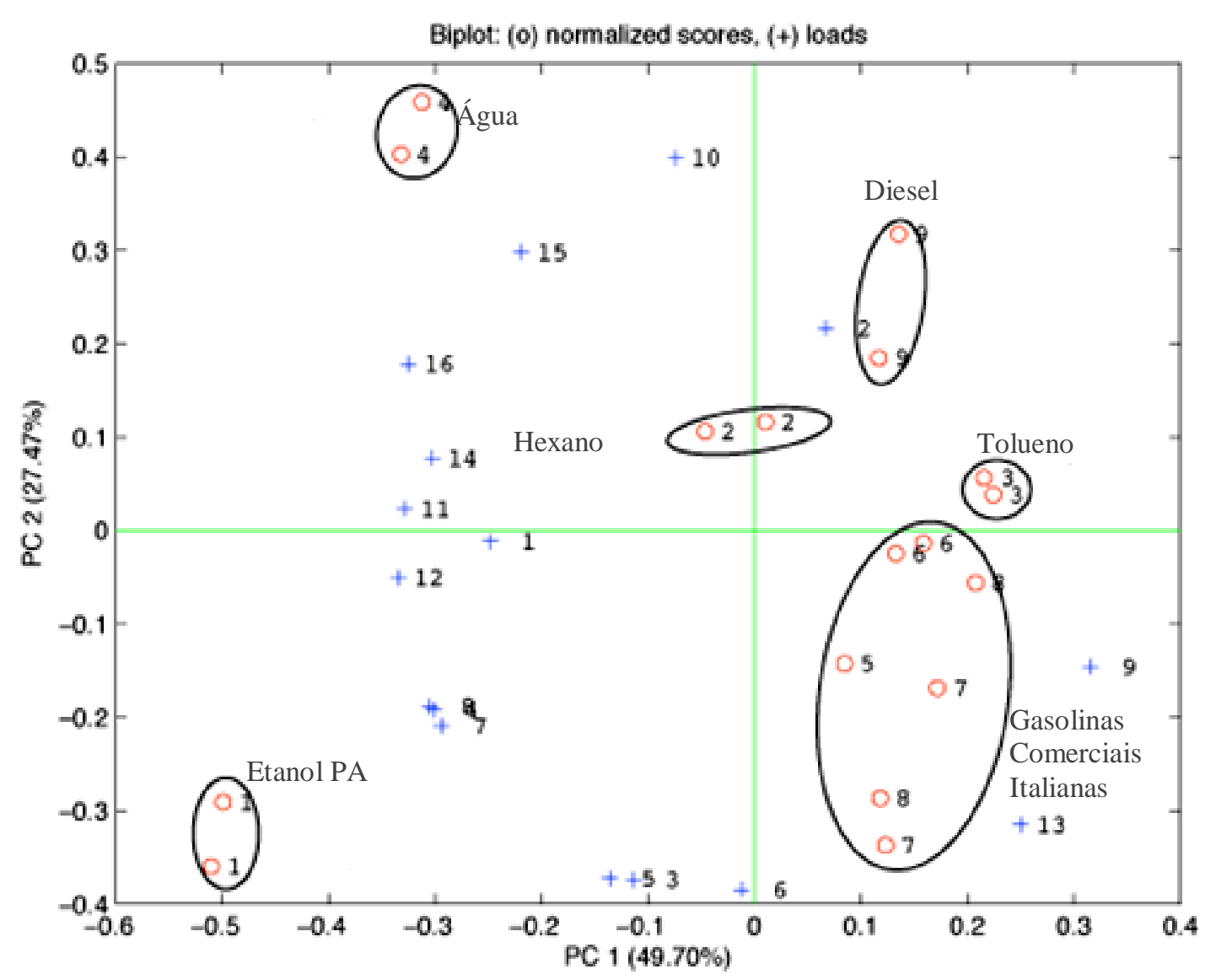

Figura 52 - Gráfico biplot da PCA do conjunto de dados do SH-2. Scores são mostrados como círculos e loadings como símbolos (+) numerados. Os scores são agrupados e denominados na figura de acordo com a amostra medida. Loadings de 1 a 8 representam o conjunto de sensores capacitores e de 9 a 16 o os sensores da $\mathrm{MBQ}$, listados na tabela 11.

Aproximadamente $76 \%$ da variância total dos dados é explicada neste gráfico. $E$ interessante notar que as sobreposições entre as amostras, que ocorreram nos gráficos obtidos com os dados de um único conjunto de sensor, são removidas pela fusão de dados. Os compostos puros estão alinhados ao longo da primeira componente principal e os dois tipos de combustíveis são separados ao longo da segunda componente principal. Como se observa, também no conjunto individual de sensores o etanol é claramente separado dos outros grupos de dados. Este 
comportamento sugere o uso da combinação destas matrizes para a detecção da presença de etanol em gasolinas. A análise dos loadings confirma o comportamento apresentado nas figuras 49 e 51 . Os sensores capacitivos recobertos por PEDOT/PSS, MnTPP, e FtTsNi (loadings 3, 5 e 6) e de QMB recobertos por FeTPP e CoTPP (loadings 9 e 13) na configuração do conjunto híbrido também mantém sua orientação principal na direção das amostras de gasolinas.

\subsection{1 - Avaliação da capacidade de discriminação de concentrações de etanol em gasolina com o SH-2}

Neste estudo, a sensibilidade dos conjuntos de sensores para concentrações de etanol em gasolina foi investigada. Para tanto, misturas de gasolina-etanol, em concentrações de: $0,20,25,30,50,70,90$ e $100 \%$ de etanol PA, foram preparadas a partir de gasolinas comerciais italianas isentas de etanol. A fim de quantificar o conteúdo de etanol nas amostras de gasolina, modelos de regressão de mínimos quadrados parciais, PLS, foram calculados a partir dos dados coletados.

O desempenho do modelo de regressão foi avaliado através do erro quadrático médio, root mean square error (RMSEC), obtido durante a fase de calibração, e em validações cruzadas, cross-validation, (RMSECV). O modo de Leave-one-out cross-validation foi realizado para estimar o erro de (generalização) treinamento do modelo [23]. Os modelos foram calculados em todo o conjunto de dados para quantificar a concentração de etanol em cada gasolina comercial. $\mathrm{Na}$ tabela 12 são apresentados os RMSEC e RMSECV relativos a cada modelo calculado. 
Tabela 12 - Erro quadrático médio de calibração (RMSEC) e de validação (RMSECV) obtidos para os quatro modelos de regressão PLS. Cada modelo pertence a uma única formulação de gasolina, exceto o último modelo, onde os dados são relativos as medidas de todas gasolina.

\begin{tabular}{lll}
\hline Modelo & RMSEC (\% de etanol) & RMSECV (\% de etanol) \\
\hline Gasolina 1 & 0,9 & 2,4 \\
Gasolina 2 & 2,1 & 3,1 \\
Gasolina 3 & 1,9 & 2,7 \\
Gasolina 1, 2 e 3 & 2,7 & 4,1 \\
\hline
\end{tabular}

Os erros de regressão de todo o conjunto de dados são cerca de duas vezes superior em relação à estimativa de etanol diluído em uma única gasolina. Os resultados da regressão são mostrados na figura 53, onde as concentrações reais e estimadas de etanol são apresentados por validações cruzadas. Cada figura corresponde a um dos modelos PLS, cujos resultados estão ilustrados na Tabela 12.

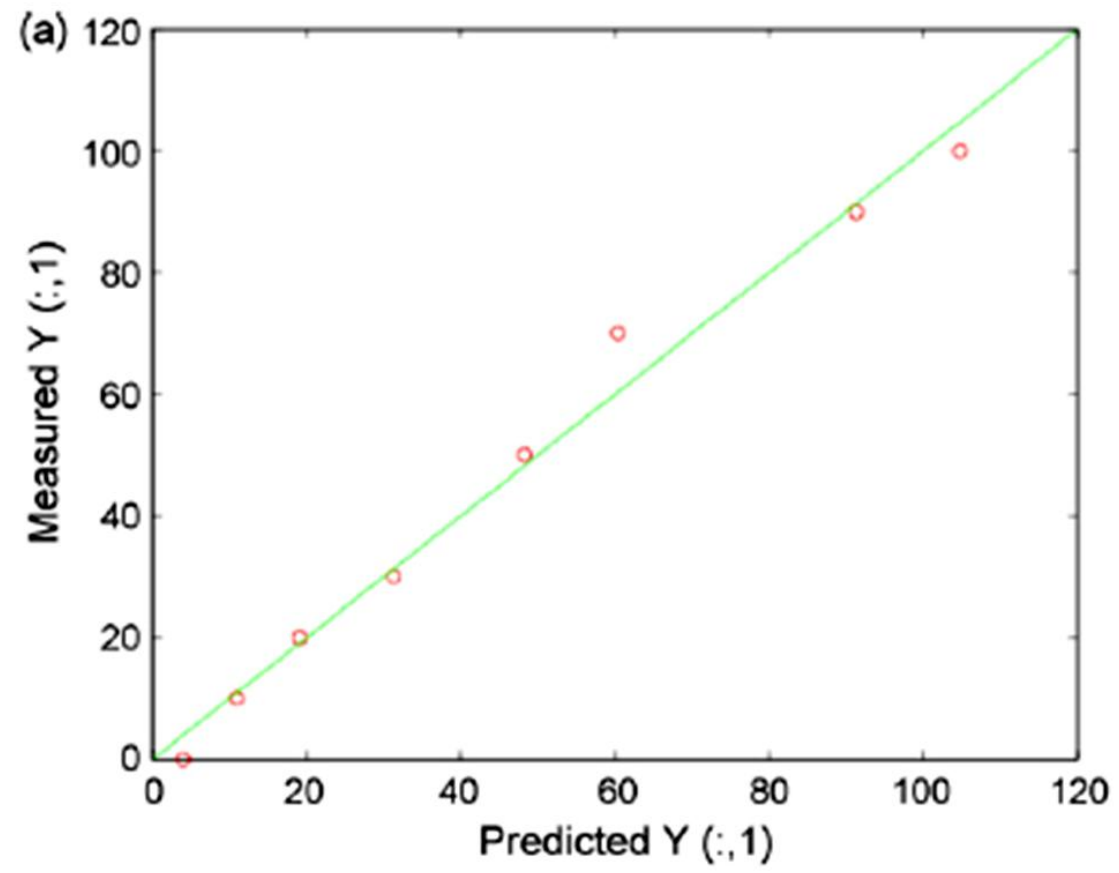



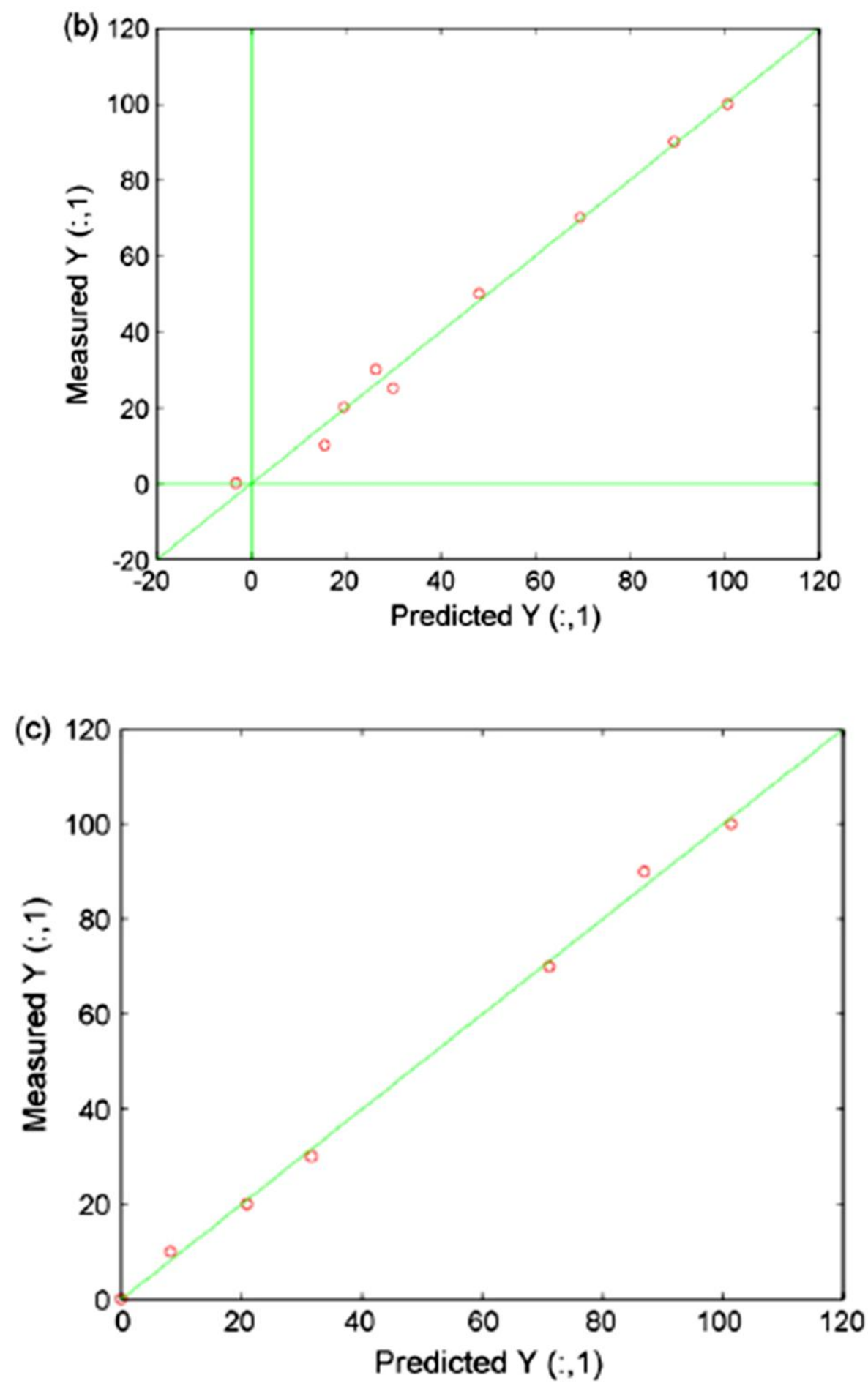


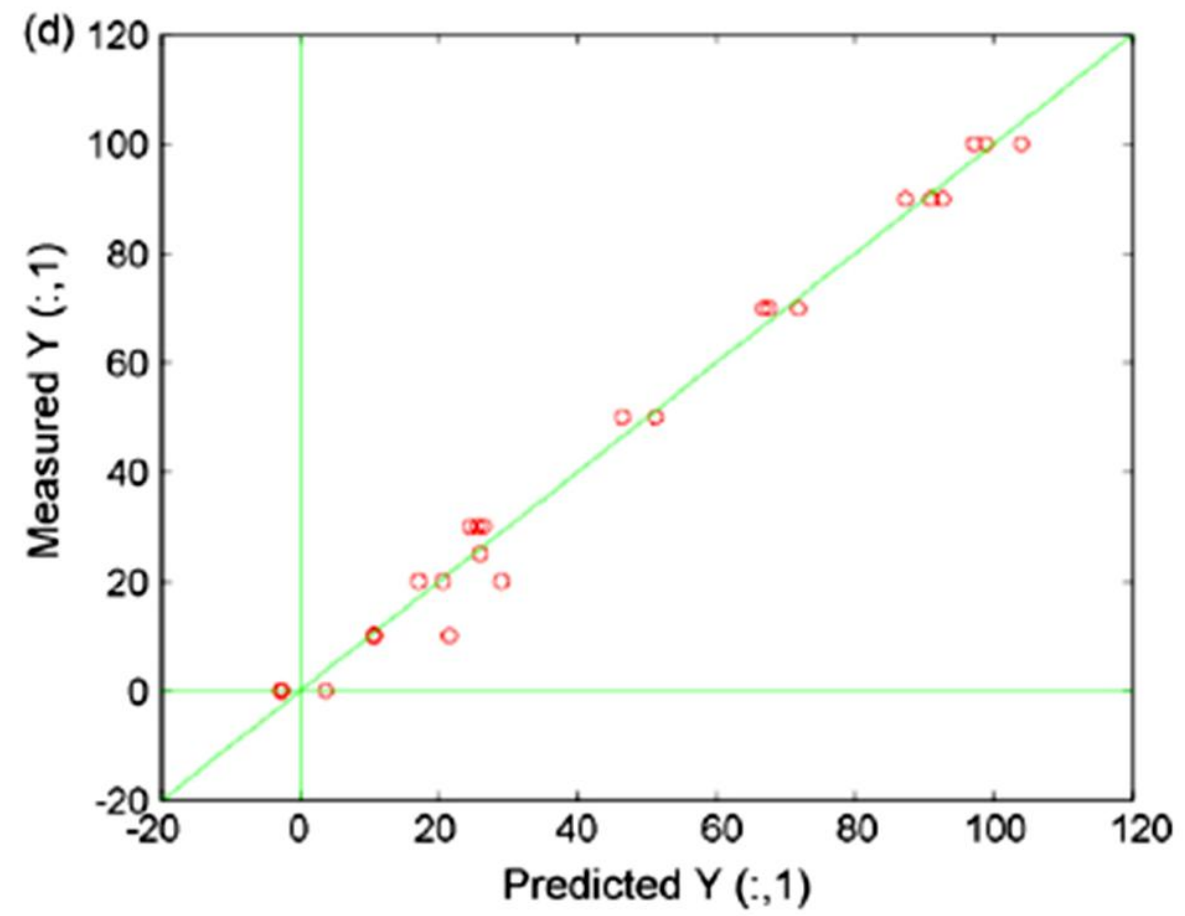

Figura 53- Modelo PLS para concentrações de etanol em gasolina, figura a, b e c são relativas aos dados de gasolinas individuais enquanto a figura d representa os dados de todas as gasolinas

Estes resultados indicam que o conjunto híbrido de sensores também é, suficientemente, sensível ao etanol dissolvido em gasolinas, bem como bastante sensível à composição da gasolina. Os erros relacionados ao modelo PLS, figura 53, formados a partir dos dados das três marcas de gasolinas italianas, são maiores em pequenas concentrações de etanol, onde a influência da composição da gasolina é de maior importância. Isto indica que a quantificação do teor de etanol é fortemente influenciada pela formulação base da gasolina. Este aspecto foi explorado analisando com cromatografia gasosa, GC-MS, o headspace de etanol PA misturado em gasolina comercial italiana. A figura 54 mostra o cromatograma de um dos combustíveis, antes e após a adição de $23 \%$ de etanol (Porcentagem de etanol acrescentada à gasolina $A$ brasileira para formar a gasolina $C$ no período em que foi realizado este experimento), ambos realizados no mesmo dia. 


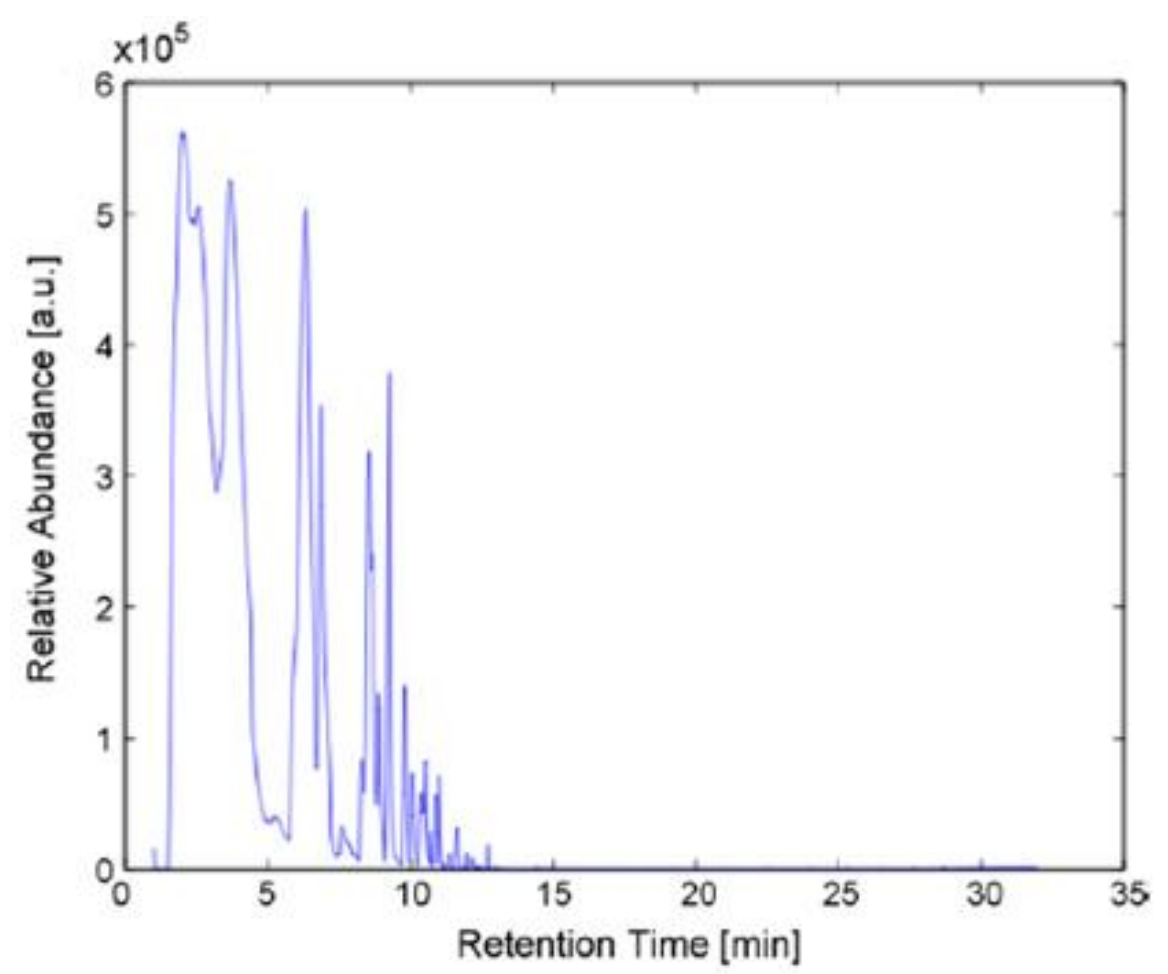

(a) Cromatograma gasoso de uma gasolina comercial Italiana

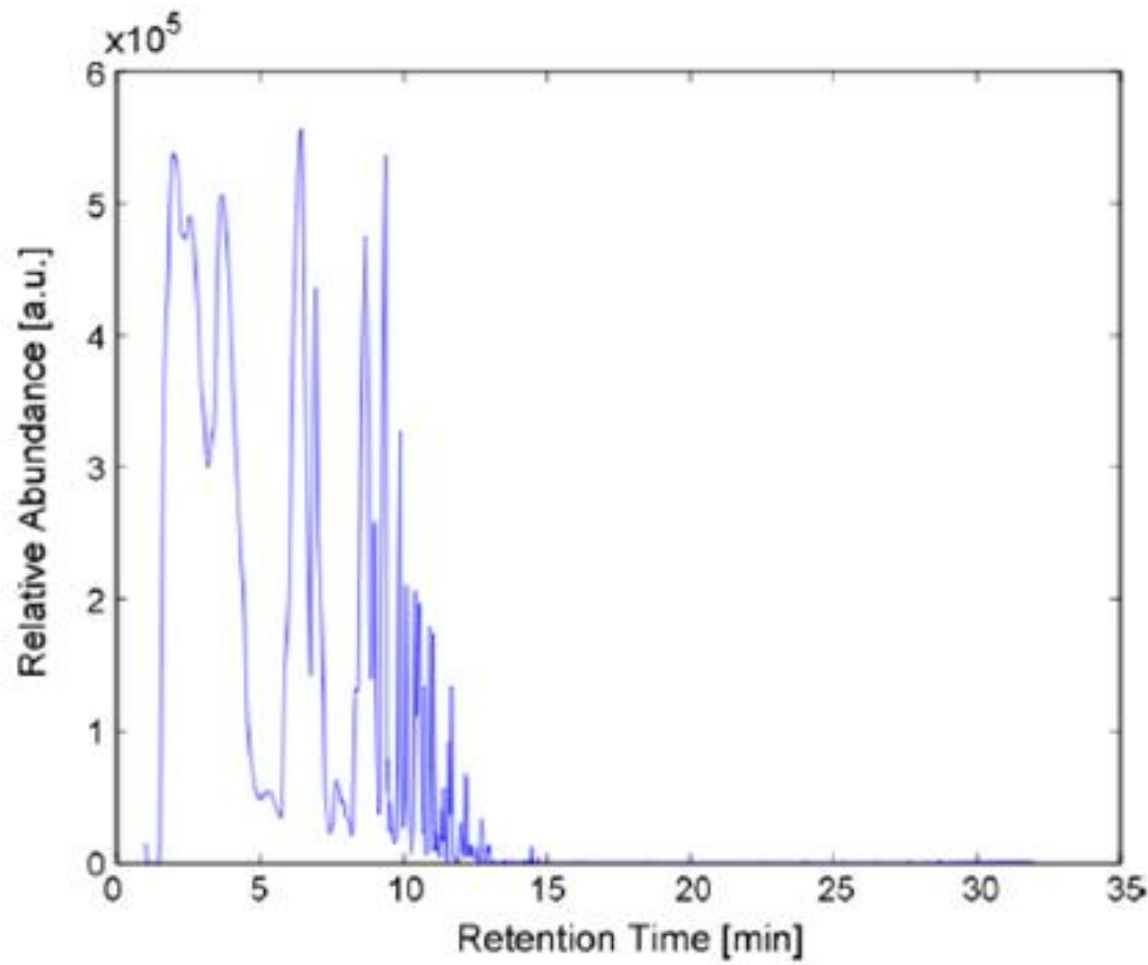

(b) Cromatograma gasoso de gasolina comercial italiana com $23 \%$ de etanol

Figura 54 - Cromatogramas de uma gasolina: (a) gasolina A, (b) gasolina com 23\% de etanol.

O tempo de retenção do etanol PA foi medido ha cerca de 3,2 min. No entanto, os cromatogramas não evidenciam o pico esperado do etanol, o qual está 
bastante escondido por outros compostos voláteis. Além disso, a composição do headspace da mistura etanol-gasolina é diferente do headspace de combustível puro, indicando que a adição de etanol tem um efeito complexo sobre a fase de equilíbrio de muitos componentes da gasolina. Este efeito, observado anteriormente, confirma a complexidade de detecção do etanol na gasolina.

Visando verificar a reprodutibilidade do $\mathrm{SH}-2$ foram realizadas medidas variando as concentrações de etanol nas três marcas distintas de gasolina, durante três dias consecutivos, figura 55.

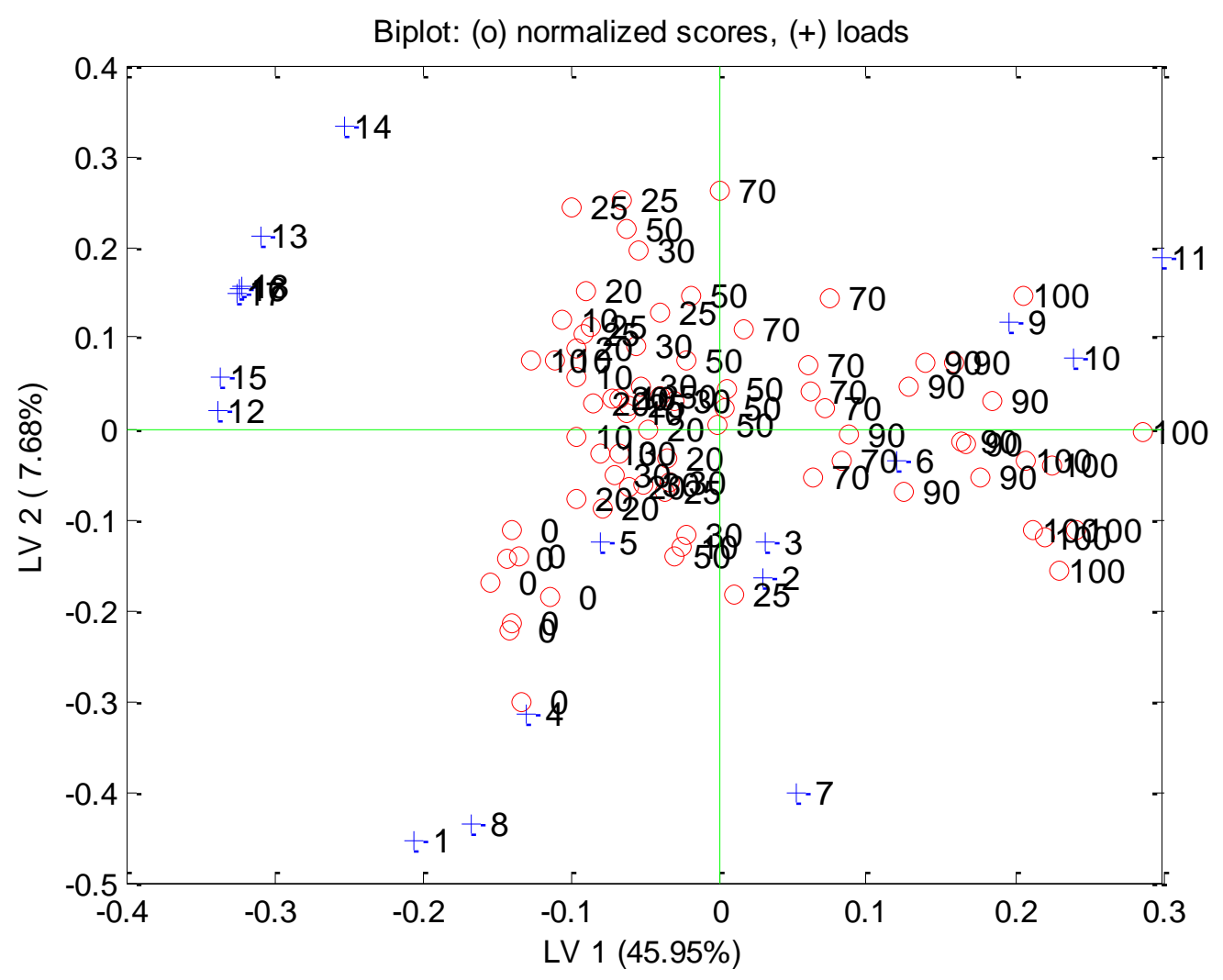

Figura 55 - Gráfico biplot da PLS dos dados do SH-2 para concentrações de etanol em gasolinas durante três dias consecutivos. Scores e loadings são mostrados como círculos e cruzes numerados respectivamente.

O gráfico biplot da figura 55 indica uma tendência da esquerda para a direita para o aumento da concentração de etanol nas gasolinas. O desempenho do modelo de regressão foi avaliado através do RMSEC e RMSECV. Na tabela 13 são apresentados os RMSEC e RMSECV relativos ao modelo calculado para as três gasolinas comerciais medidas durante três diferentes dias em comparação com o modelo do item anterior, calculado para um único dia. 
Tabela 13 - Erro quadrático médio de calibração (RMSEC) e de validação (RMSECV) obtidos para os quatro modelos de regressão PLS. O primeiro modelo pertence a três formulações de gasolina, contendo de $0-100 \%$ de etanol, medidas em um único dia. No último modelo, os dados são relativos às três formulações de gasolina medidas em três diferentes dias.

\begin{tabular}{|l|l|l|}
\hline Modelo & RMSEC (\% de etanol) & RMSECV (\% de etanol) \\
\hline Gasolinas 1, 2 e 3 & 2,7 & 4,1 \\
\hline $\begin{array}{l}\text { Gasolinas 1, 2 e 3 } \\
\text { em três dias } \\
\text { diferentes }\end{array}$ & 5,3 & 7,2 \\
\hline
\end{tabular}

Os resultados da regressão dos três últimos dias são mostrados na figura 56, onde as concentrações reais e estimadas de etanol são apresentadas por validações cruzadas.

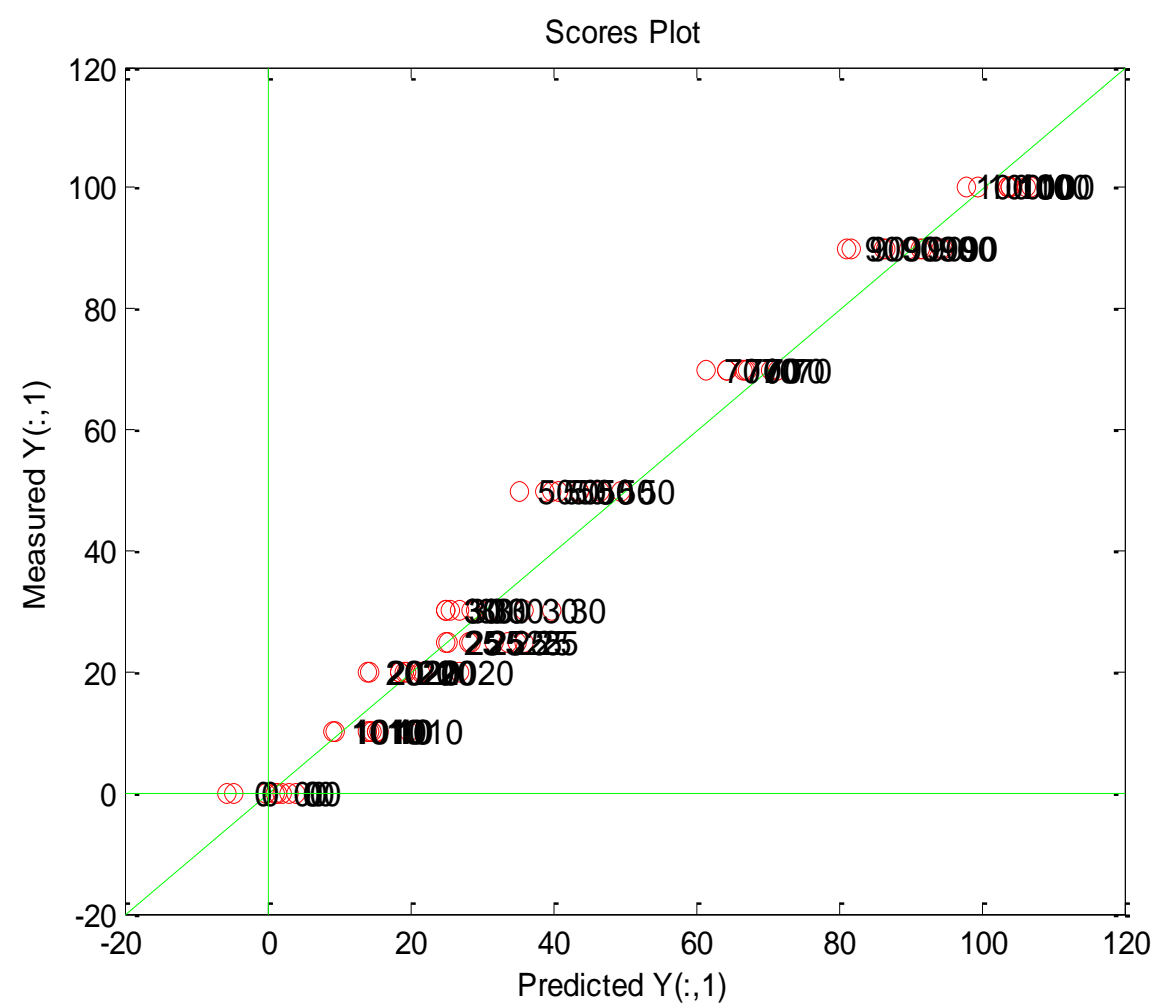

Figura 56 - Modelo PLS para concentrações de 0 a $100 \%$ de etanol em diferentes gasolinas comerciais italianas durante três dias.

Estes resultados indicam que os erros de regressão das medidas de todo o conjunto de dados realizadas em três dias diferentes são cerca de duas vezes superiores em relação à estimativa de etanol em um único dia. Atribuímos este efeito à influência do efeito de deriva de resultados (drift) e às alterações na gasolina de um dia para o outro. 


\section{6 - MEDIDAS PULSADAS}

Com a intenção de melhorar a qualidade das medidas e aumentar a reprodutibilidade dos sensores químicos foi realizado o estudo da Injeção Pulsada de Gás [142].

Em muitos casos, a baixa reprodutibilidade dos sensores químicos está relacionada a um tipo de efeito memória, ou seja, a resposta a um estímulo ocasionado por um determinado produto químico é parcialmente relacionada às exposições anteriores destes sensores. A injeção pulsada de gás é um método aplicado com o intuito de reduzir a quantidade de material adsorvido sobre um sensor, além de ser um método rápido de condicionamento do sensor, ou seja, de remover a influência da experiência passada. Este método foi realizado com microbalanças de quartzo recobertas com metaloporfirinas em um conjunto de medidas objetivando quantificar etanol em gasolinas.

Muitos sensores químicos são baseados em processos de adsorção e dessorção. Durante a exposição ao gás da amostra ocorre o processo de adsorção, enquanto que a dessorção ocorre durante a exposição ao gás de limpeza, exemplificado na figura 57. Esta última fase é crucial, porque somente quando o material sensível é completamente livre pela molécula adsorvida a medição sucessiva é realmente independente da anterior. 


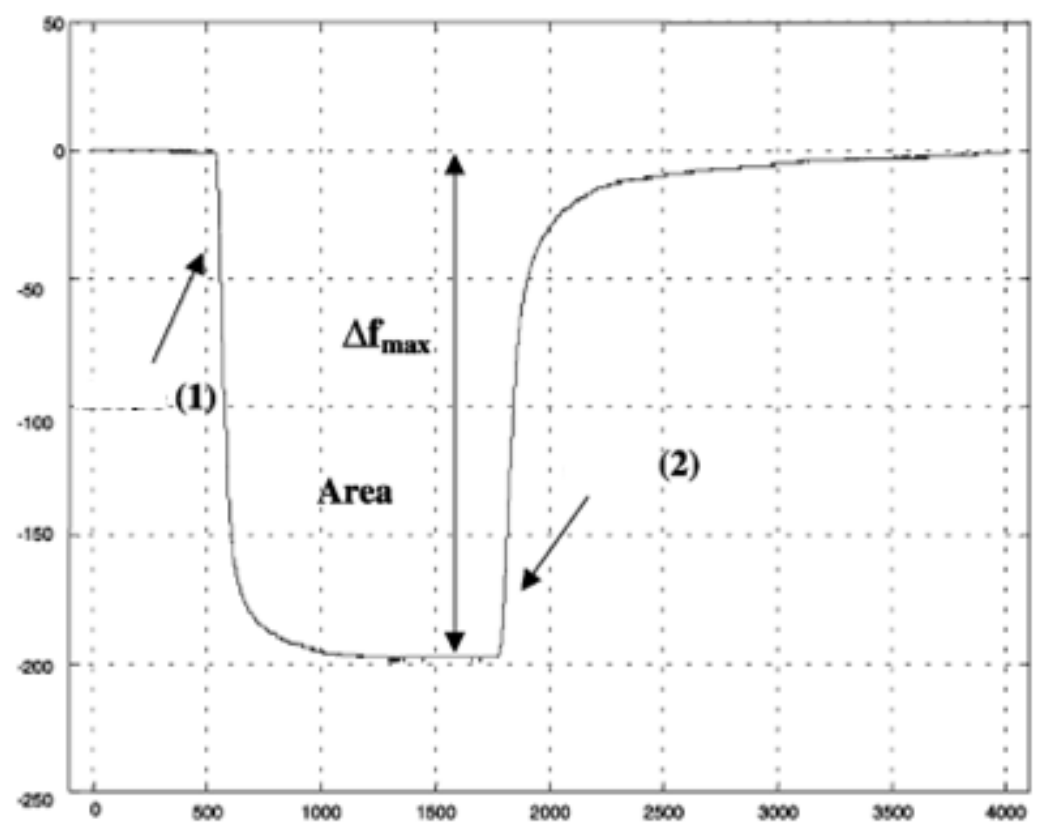

Figura 57 - Exemplo do processo de adsorção e dessorção durante a exposição de um sensor químico de microbalança de quartzo a um gás de amostra e sequencialmente a um gás de limpeza. (1) adsorção, (2) dessorção

Em aplicações práticas, seja porque o tempo de medição é limitado ou as constantes de ligação são grandes, a fase de restabelecimento raramente atinge a condição estável. O acúmulo de moléculas leva a uma redução progressiva do desempenho dos sensores. Este processo é uma das fontes mais prováveis de deriva (drift) em sensores químicos.

A fim de reduzir esse fenômeno foi realizada uma injeção pulsada de gás baseada em pelo menos duas exposições de gás em curta duração. Com a aplicação de uma sequência de pulsos supõem-se reduzir a quantidade de material sobre a superfície, pois a exposição ao gás é feita durante um curto período. Durante a aplicação do primeiro pulso de gás as moléculas adsorvidas em experiências anteriores competirão com as novas moléculas deste fluxo, caso não haja tempo suficiente para terminar a recuperação anterior. Após o primeiro pulso a superfície deve conter apenas as moléculas do gás em teste. Portanto, o sinal do sensor obtido durante o primeiro pulso é menos significativo para a medida do gás em questão.

Contudo, este método foi aplicado a um conjunto de medidas realizadas para quantificar o teor de etanol em amostras de gasolina, onde diferentes concentrações de etanol PA foram adicionadas a diferentes gasolinas. O headspace da mistura de 
gasolina-etanol foi medido com o conjunto de sensores de MBQ. Para cada medida três pulsos sucessivos de gás foram injetados nos sensores, sendo o primeiro com duração de um minuto, o segundo de dois minutos e o terceiro de um minuto. As três sequências de pulsos aplicados a um sensor estão ilustradas na figura 58.

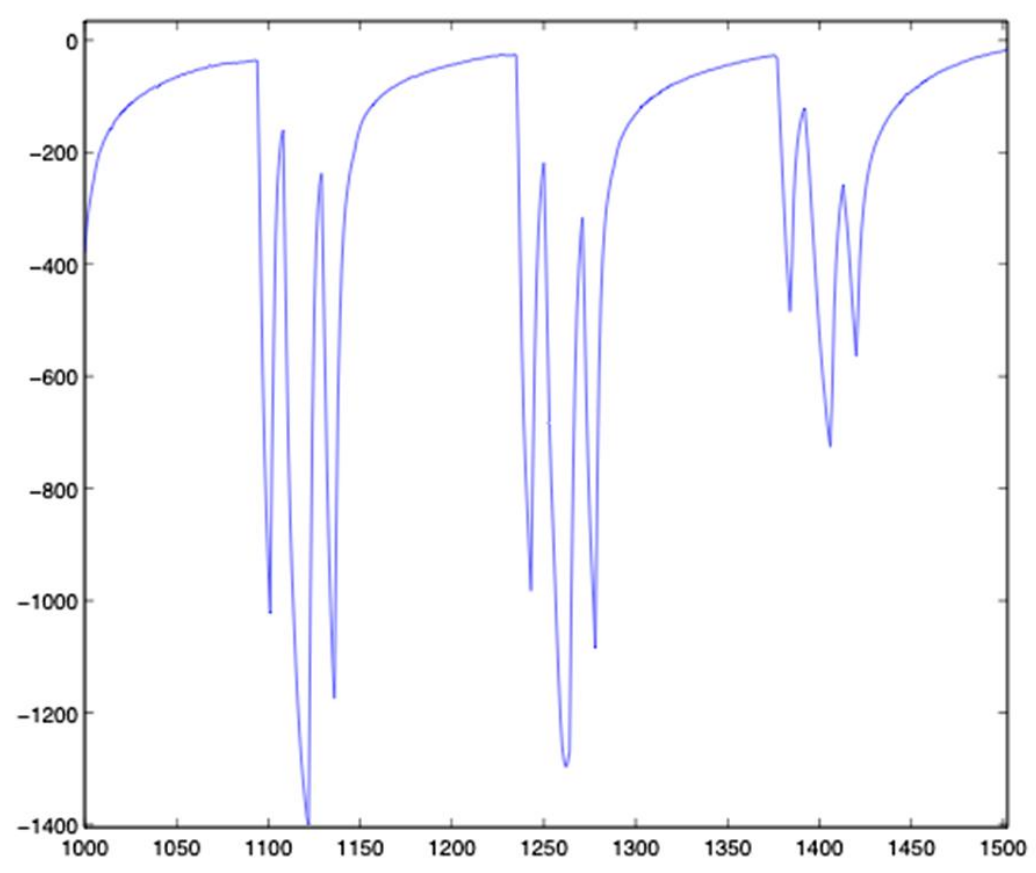

Figura 58 - Exemplo de três sequências de pulsos aplicadas a um sensor.

Foram realizadas medidas nos três pulsos para as amostras de diferentes concentrações de etanol em gasolina, sendo 0, 20, 25, 30, 50, 70, 90 e $100 \%$ de etanol as concentrações utilizadas, com medidas realizadas durante 5 dias diferentes e de forma aleatória, figura 59. 


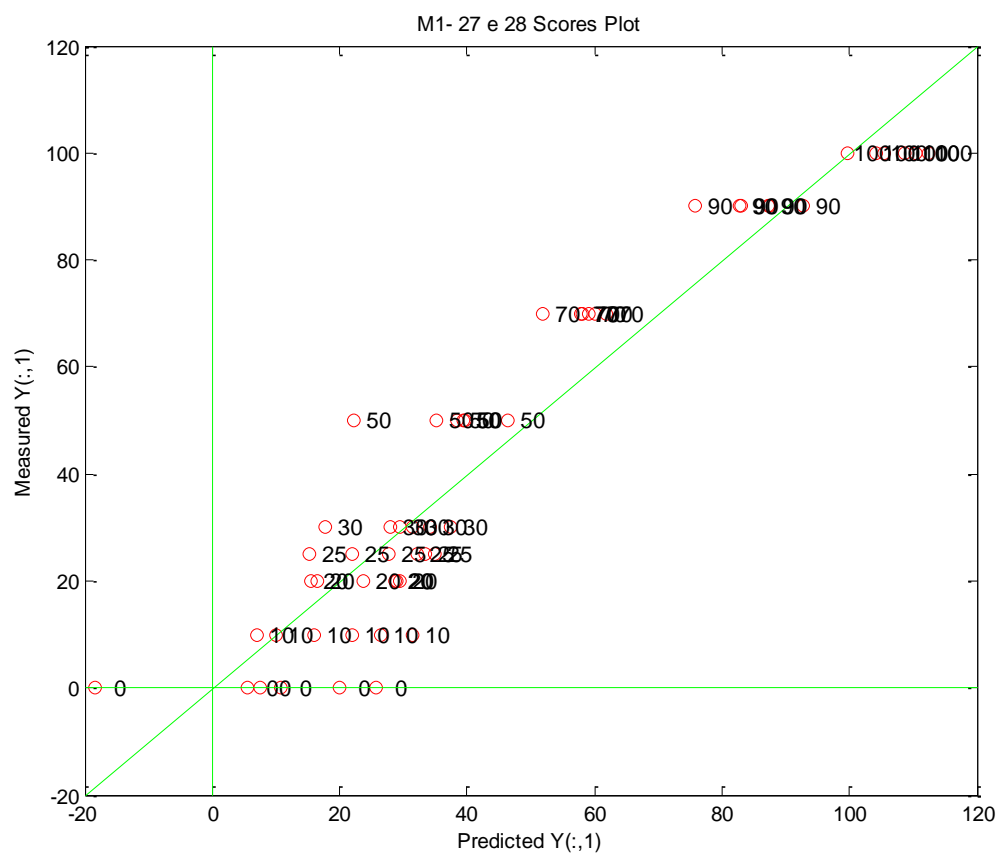

(a)

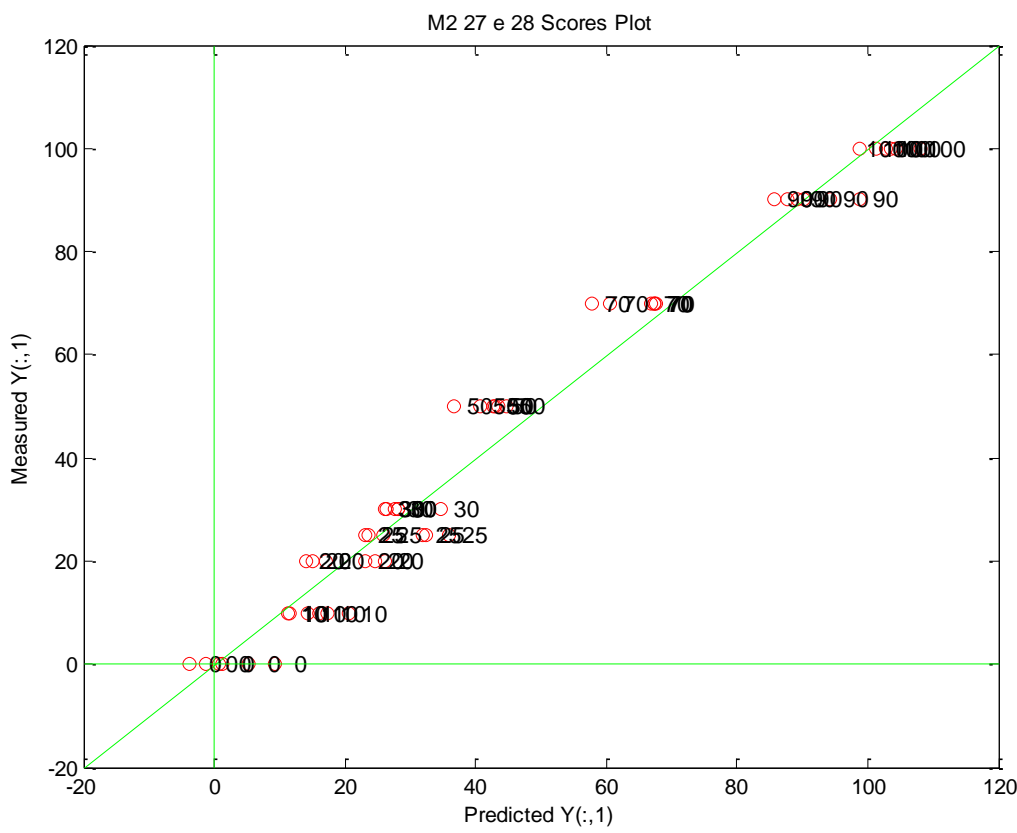

(b) 


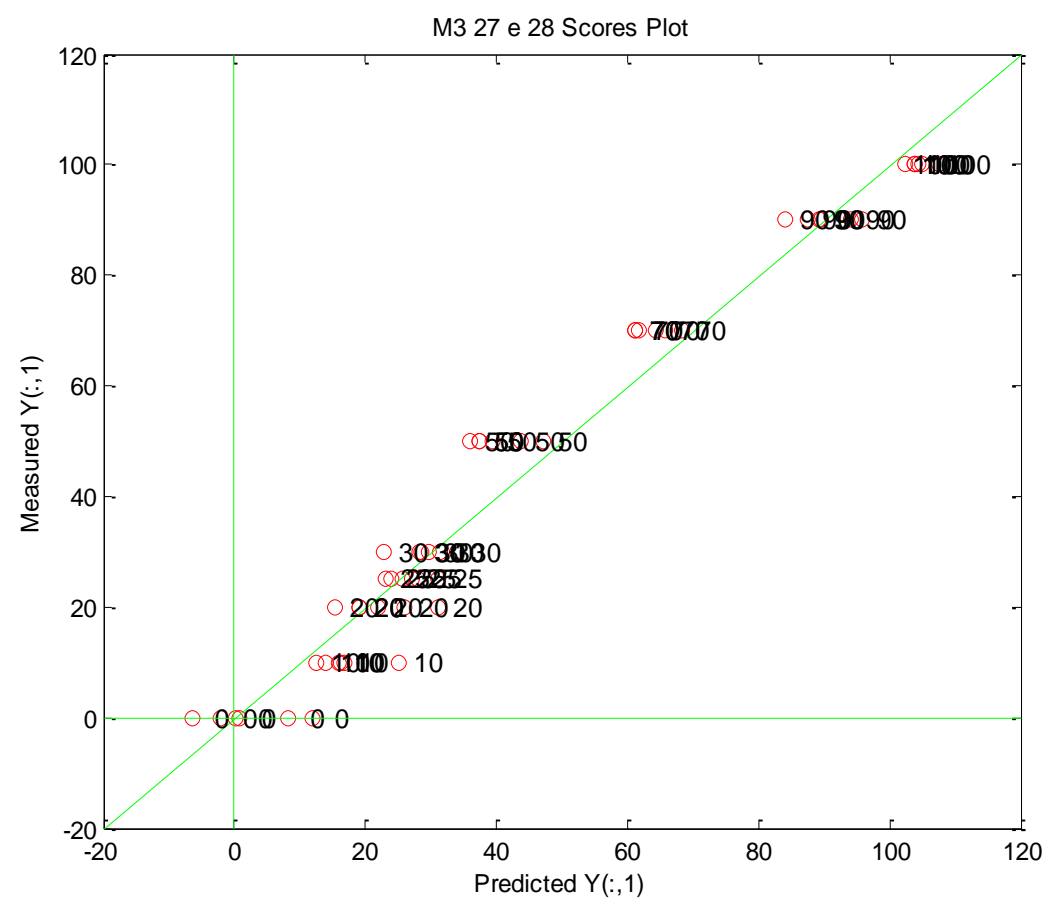

(c)

Figura 59 - Modelo PLS para medidas pulsadas em dois dias. Onde: (a) Primeiro pulso, (b) segundo pulso e (c) terceiro pulso.

O desempenho dos três modelos é resumido na tabela 14.

Tabela 14 - Quantidade de erros obtidos a partir dos modelos PLS baseados nos sinais relacionados ao primeiro, segundo e terceiro pulso para medidas de gasolina contendo concentração de $0-100 \%$ de etanol. RMSEC e RMSECV são os erros de treinamento e validação cruzada respectivamente. As quantidades dos erros são relatadas no percentual total de unidades.

\begin{tabular}{llll}
\hline Erros & $\mathbf{1}^{\circ}$ pulso & $\mathbf{2}^{\circ}$ pulso & $\mathbf{3}^{\circ}$ pulso \\
\hline RMSEC & 11,8 & 5,64 & 6,2 \\
RMSECV & 12,1 & 6,4 & 7,2 \\
\hline
\end{tabular}

Os modelos baseados no segundo e terceiro pulso possuem melhor desempenho que o baseado no primeiro pulso. Esse resultado confirma 0 pressuposto de que o primeiro pulso é menos significativo sobre a amostra em teste e que a aplicação do primeiro pulso prepara a superfície do sensor para interação mais eficiente e reprodutível com as moléculas do gás. 


\section{6 - CONCLUSÕES}

No presente trabalho estudou-se sistemas multissensoriais híbridos, baseados em língua e nariz eletrônicos, com vistas à aplicação tecnológica futura destes dispositivos como ferramenta para detecção de adulterações em combustíveis. Assim sendo, considerando as alterações de massa e constante dielétrica de camadas de compostos orgânicos sensíveis, foram desenvolvidos dois tipos de sistemas híbridos para a avaliação de combustíveis. O primeiro denominado $\mathrm{SH}-1$, foi formado pela combinação LE-NE, baseado em microeletrodos interdigitados. O segundo, denominado $\mathrm{SH}-2$, foi composto por dois tipos diferentes de NEs integrando sensores de microbalanças de quartzo e de uma matriz comercial de capacitores.

Através da utilização de diferentes materiais (polímeros e metaloporfirinas), processos de obtenção de filmes finos sensoativos (solvent casting, spray casting, automontagem e eletrodeposição) e transdutores (de massa e capacitivo) foram geradas diferentes unidades sensoriais que compuseram a língua e os narizes eletrônicos que formaram os dois sistemas multissensoriais híbridos. Sendo assim, obteve-se, os seguintes resultados:

A resposta dos sensores depende do tipo de transdutor, da camada sensoativa e do analito, ou seja, a resposta depende da combinação de elementos sensoativos com o analito;

Os sensores formados por microeletrodos utilizando filmes baseados em polímeros condutores depositados por automontagem são ineficientes em aplicações em fase líquida, uma vez que ocorre grande perda de massa e contaminação destes filmes quando imersos em combustíveis. Dentre os diversos filmes automontados avaliados neste estudo o de PANI/LS foi o mais estável na presença de etanol anidro combustível, seguido de PANI/PPY e PANI/PEDOT. Estes filmes apresentaram as menores perdas de massa após várias imersões neste combustível;

A simples utilização de microeletrodos sem filme foi suficiente para a resolução da problemática da exposição direta dos sensores aos combustíveis. $\mathrm{O}$ uso de diferentes geometrias de microeletrodos possibilitou a criação de diferentes unidades sensoriais para aplicação em análise de combustíveis em meio líquido; 
O sistema multissensorial Língua Eletrônica, LC-1, formado por sensores com diferentes geometrias de microeletrodos sem filme, foi capaz de discriminar diferentes combustíveis e solventes, de acordo com suas respectivas constantes dielétricas;

No meio gasoso a capacitância dos sensores baseados em microeletrodos contendo filmes automontados de PANI/LS, PANI/PPY e PANI/PEDOT aumenta quando são expostos ao vapor de gasolina e diminui quando os mesmos são expostos ao vapor de etanol anidro combustível;

Os sensores formados por filmes de polímeros condutores depositados por automontagem, apesar de não serem estáveis para a aplicação em LE, puderam ser usados em NE, na configuração headspace. Juntamente com sensores sem filme, usados em LE, estes sensores formaram um arranjo híbrido LE-NE baseado em microeletrodos interdigitados, denominado $\mathrm{SH}-1$. Este sistema foi capaz de discriminar solventes e combustíveis conforme as suas constantes dielétricas, apresentando uma melhora nos resultados quando comparada à utilização isolada da Língua Eletrônica e do Nariz Eletrônico baseados em microeletrodos;

Com relação à frequência utilizada nas medidas de impedância com o SH-1 existiram poucas variações que pudessem diferenciar os resultados. A frequência de $1 \mathrm{kHz}$ foi a escolhida (entre as freqüências de $100,1 \mathrm{k}$ e $100 \mathrm{kHz}$ testadas) devido à facilidade de fabricação de sistemas de medidas de impedância nesta frequência, além de evitar possíveis ruídos decorrentes da segunda harmônica da rede de energia elétrica;

Com o Nariz Eletrônico, baseado em microbalanças de quartzo contendo filmes de polímeros condutores e de metaloporfirinas, obteve-se uma grande separação de compostos polares, mas pouca eficiência na discriminação dos combustíveis e dos seus constituintes básicos (onde o hexano e o tolueno foram considerados);

O Nariz Eletrônico baseado na matriz de capacitores, onde os sensores foram fabricados depositando materiais sensoativos, metaloporfirinas e polímeros condutores, sobre a superfície do dispositivo, foi capaz de separar os compostos puros dos combustíveis, mas não foi capaz de separar completamente os compostos puros, hexano e água, entre si; 
Nas deposições por solvent casting, utilizada para formação das unidades sensoriais da matriz capacitiva, do ponto de vista morfológico mostrou-se que a espessura final dos filmes obedece a uma formação irregular que foi minimizada com a seleção (via software) da região da superfície de maior homogeneidade;

As propriedades peculiares dos sensores são conservadas interligando os conjuntos de dados tanto no $\mathrm{SH}-1$ quanto no $\mathrm{SH}-2$;

A análise da PCA com a matriz estendida de dados do $\mathrm{SH}-1$ demonstra a remoção das sobreposições que ocorrem quando se utiliza somente uma única tecnologia de sensor. O mesmo resultado foi obtido para o SH-2. A utilização simultânea de múltiplas tecnologias de sensores resulta em um aumento na capacidade de classificação dos combustíveis através de um sistema multissensorial;

As contribuições quase ortogonais das $M B Q$ e capacitores confirmam o fato de que a utilização simultânea de múltiplas tecnologias de sensores aumenta a capacidade de classificação dos sistemas estudados;

A quantificação do conteúdo de etanol em gasolina é altamente dependente da formulação desta, pois o erro na determinação da quantidade de etanol é menor quando se avalia concentrações diferentes deste combustível em uma única formulação de gasolina. Os desempenhos dos sistemas multissensoriais são piores quando se deseja obter a quantificação de etanol considerando amostras da mistura utilizando gasolinas de marcas diferentes;

Outra conclusão obtida nesse trabalho refere-se às medidas pulsadas, onde três ciclos de exposição ao gás são realizados durante um curto período. Com este procedimento, obteve-se a diminuição do efeito de deriva (drift - típico em sensores químicos) de um conjunto de medidas realizadas com microbalanças de quartzo para quantificar o teor de etanol em amostras de gasolinas durante cinco dias. Nestas medidas pulsadas, os modelos baseados no segundo e terceiro pulso possuíram melhor desempenho que o com base no primeiro pulso;

As análises de dados com PCA e PLS foram eficazes para análise do conjunto de dados dos sistemas híbridos e forneceram meios significativos para que as características de paladar e odor dos combustíveis analisados fossem comparadas entre si. Além disso, o uso destas técnicas possibilitou observar a contribuição de cada unidade sensorial dos sistemas híbridos na avaliação de combustíveis; 
De forma global, o estudo e a aplicação de diferentes tipos de transdutores e materiais sensoativos permitiram o desenvolvimento de arranjos de sensores otimizados, tanto para aplicações em meio gasoso quanto líquido, eficientes para a análise de combustíveis. Os resultados com os sistemas multissensoriais híbridos mostraram uma discriminação eficiente dos principais combustíveis usados nos motores flex, gasolina C (gasolina A com 20 a 25\% de etanol anidro) e etanol hidratado combustível, bem como a diversos solventes. Estes sistemas híbridos são ferramentas robustas, econômicas e promissoras para análise de adulterações em combustíveis comerciais brasileiros. 


\section{7 - SUGESTÕES PARA TRABALHOS FUTUROS}

- Analisar grandes quantidades de gasolinas comerciais com especificações da ANP.

- Desenvolver câmara de gás com bomba automatizada para análise pulsada dos gases.

- Aplicar medidas pulsadas.

- Desenvolver um fluxometro que permita avaliar concentrações de gases possibilitando o estudo quantitativo da sensibilidade dos sensores aos analitos gasosos.

- Aplicar os sistemas híbridos para outros analitos.

- Estudar profundamente o comportamento dos filmes de polímeros condutores utilizados e de metaloporfirinas na presença de combustíveis.

- Uso de metaloporfirinas no NE baseado em microeletrodos para análise de combustíveis.

- Aplicação do sistema híbrido baseado em microeletrodos e polímeros condutores $(\mathrm{SH}-1)$ para outros analitos.

- Uso de lógica fuzzy. 


\section{REFERÊNCIAS BIBLIOGRÁFICAS}

[1] ÉPOCA: revista semanal. São Paulo. Ed. Globo, no 456, 12 fev, ano p. 44-48, 2007.

[2] WIEDEMANN L.S.M. et al., "Adulteration detection of Brazilian gasoline samples by statistical analysis, Fuel, v. 84, p. 467-473, 2005.

[3] CORONADO C. R. et al. "Biodiesel $\mathrm{CO}_{2}$ emissions: A comparison with the main fuels in the Brazilian market" Fuel processing technology, v. 90, p. 204-211, 2009.

[4] PAVÓN J. L. P. et al "Determination of naphthalene and total methylnaphthalenes in gasoline using direct injection-mass spectrometry" Talanta, v.72, p. 256-262, 2007.

[5] FLUMIGNAN D.F, et al. "Multivariate calibrations in gas chromatographic profiles for prediction of several physicochemical parameters of Brazilian commercial gasoline" Chemometrics and Intelligent Laboratory Systems, v. 92 p. 53-60, 2008.

[6] RÉ-POPPI, N. et al., "Screening analysis of type C Brzilian gasoline by gas chromatography - Flame ionization detector" Fuel, v. 88, p. 418-423, 2009.

[7]ARAÑA, J. et al. "FTIR study of gas-phase alcohols photocatalytic degradation with $\mathrm{TiO} 2$ and AC-TiO2" Applied Catalysis B: Environmental, v.53, p. 221-232, 2004

[8] TEIXEIRA L. S. G. et al."Multivariate calibration in Fourier transform infrared spectrometry as a tool to detect adulterations in Brazilian gasoline", Fuel, v.87 p. 346-352, 2008

[9] FLUMIGNAN, D.L. et al. "Development, optimization and validation of gas chromatographic fingerprinting of Brazilian commercial gasoline for quality control" Journal of Chromatography A, v. 1202, p. 181-188, 2008.

[10] TAKESHITA E.V. et al. "Influence of solvent addition on the physicochemical properties of Brazilian gasoline" Fuel, v.87, p. 2168-2177, 2008. 
[11] FLUMIGNAN, D.L. et al. "Screening Brazilian C gasoline quality: Application of the SIMCA chemometric method to gas chromatographic data" Analytica Chimica Acta, v.595, p. 128-135, 2007.

[12] ALEME, H.G. et al. "Determination of ethanol and specific gravity in gasoline by distillation curves and multivariate analysis" Talanta, v. 78, p. 1422-1428, 2009.

[13] OLIVEIRA F. S. et al. "Screening analysis to detect adulterations in Brazilian gasoline samples using distillation curves" Fuel, v.83, p. 917-923, 2004.

[14] HONORATO F. A. et al. "Using principal component analysis to find the best calibration settings for simultaneous spectroscopic determination of several gasoline properties", Fuel, v.87, p. 3706-3709, 2008.

[15] D'AMICO et al. "Portraits of gasses and liquids by arrays of nonspecific chemical sensors: trends and perspectives" Sensors and Actuators B, v. 68 p.324-330, 2000.

[16] RIUL JR., A. et al. "Wine classification by taste sensors made from ultra-thin films and using neural networks" Sensors and Actuators B, v. 98, p. 77-82, 2004.

[17] CARMEL, L.; SEVER N.; HAREL, D. "On predicting responses to mixtures in quartz microbalance sensors" Sensors and Actuators B, v. 106, p. 128-135, 2005.

[18] ESCUDER-GILABERT, L.; PERIS, M. "Highlights in recent applications of electronic tongues in food analysis" Analytica Chimica Acta, 2010, in press.

[19] RIUL, A. et al. “Artificial taste sensor” Langmuir, v.18, p. 238-245, 2002.

[20] TOKO K.; “A Taste sensor” Meas. Sci. Technol., v.9, p.1919-1936, 1998.

[21] VLASOV Y.; LEGIN A.; RUDNITSKAYA A. "Eletronic tongue and their analytical application" Anal. Bioanal. Chem., v.373, p. 136-146, 2002.

[22] LEGIN, A. et al. "Electronic tongue for quality assessment of ethanol, vodka and eau-de-vie" Analytica Chimica Acta, v. 534, p. 129-135, 2005. 
[23] WINQUIST F.; WIDE P.; LUNDSTROM I. "An electronic tongue based on voltammetry" Anal Chim. Acta, v.357, p. 21-31, 1997.

[24] HOLMIN, H.; KRANTZ-RULCKER, C.; WINQUIST, F. " Multivariate optimisation of electrochemically pre-treated electrodes used in a voltammetric electronic tongue" Analytica Chimica Acta, v.519, p. 39-46, 2004.

[25] DI NATALE C. et al. "Multicomponent analysis on polluted waters by means of an electronic tongue" Sensors and Actuators B, v.44, p.423, 1997.

[26] DI NATALE, C. et al. "Application of metalloporphyrins-based gas and liquid sensor arrays to the analysis of red wine" Analytica Chimica Acta, v.513, p. 49-56, 2004.

[27] PERSAUD, K.; DODD. G.; "Analysis of discrimination mechanisms in the mammalian olfactory system using a model nose", Nature, v.299, n.23 p. 352-355, 1982.

[28] JAMES, D.; et al.; "Chemical Sensors for electronic nose systems", Microchemical Acta, v.149, p.1-17, 2005.

[29] ARRIETA, A. A. et al. "Voltammetric sensor array based on conducting polymermodified electrodes for the discrimination of liquids" Electrochimica, v. 49 p. 45434551, 2004.

[30] SI, P. et al. "Polymer coated quartz crystal microbalance sensors for detection of volatile organic compounds in gas mixtures" Analytica Chimica, v. 597 p. 223-230, 2007.

[31] LI, B. et al. "Inkjet printed chemical sensor array based on polythiophene conductive polymers" Sensors and Actuators B, v. 123, p. 651-660, 2007.

[32] KUMAR, B. et al. "Conductive bio-Polymer nano-Composites (CPC): Chitosancarbon nanotube transducers assembled via spray layer-by-layer for volatile organic compound sensing", Talanta, v. 81, p. 908-915, 2010.

[33] LEITE, F. L. et al. "Sensor arrays to detect humic substances and Cu(II) in waters" Synthetic Metals, v. 159, p. 2333-2337, 2009. 
[34]RIUL JR, A. et al.'Wine classification by taste sensors made from ultra-thin films and using neural networks" Sensors and Actuators B, v. 98, p. 77-82, 2004.

[35] RIUL JR, A. et al. "An artificial taste sensor based on conducting polymers, Biosensors and Bioelectronics, v. 18, p. 1365-1369, 2003.

[36] WIZIACK, N. K. L. et. al.; "Effect of film thickness and electrode geometry on the performance of taste sensors made of nanostructured conducting polymer films" Sensors and actuators B, v. 122, p 489-492, 2007.

[37] RIUL JR, A. et al. "An electronic tongue using polypyrrole and polyaniline" Synthetic Metals, v. 132, p. 109-116, 2003.

[38] BRUGNOLLO E. D. et al. "Fabrication and characterization of chemical sensors made from nanostructured films of poly(o-ethoxyaniline) prepared with different doping acids" Thin Solid Films, v. 516, p. 3274-3281, 2008.

[39] PATERNO, L. G. "Fabricação e caracterização de filmes ultrafinos de poli(oetoxianilina), visando a aplicação em sensores de gases" Dissertação (Mestrado em Engenharia de Materiais) Universidade Federal de São Carlos, São Carlos, 1999.

[40] HERMANN JUNIOR, P. S. P. et al. "Polyaniline-based sensor obtained by using line patterning techinique on plastic" Congresso Brasileiro de Engenharia e Ciências dos Materiais, Porto Alegre, 2004.

[41] MEDEIROS, E. S.de; "Desenvolvimento de sensors de polímeros condutores para avaliaçao de sucos de laranja" Tese (Doutorado em Engenharia de Materiais) Universidade Federal de São Carlos, 2006

[42] STETTER J, "A capacitance-based sensor array" Techn. Dig. Ninth International Symposium Olfaction and Electronic Nose, Rome, Italy, 2002.

[43] MARTINELLI, E. et al. "An array of capacitive sensors based on a commercial fingerprint detectors", Sensors and Actuators B, v. 130, p. 264-268, 2008.

[44] PIGHINI, M. et al. "A new application of capacitive sensors for the nucleic acids revelation”, Sens. Actuators B, v. 103, p. 325-330, 2004. 
[45] DI NATALE, C. et al. "An electronic nose for food analysis" Sensors and Actuators B, v. 44, p. 521-526, 1997

[46] SAEVELS, S. et al. "Electronic nose as a non-destructive tool to evaluate the optimal harvest date of apples" Biology and Technology, v 30, p. 3-14, 2003.

[47] PENNAZZAA G. et al. "Monitoring of melanoma released volatile compounds by a gas sensors array: From in vitro to in vivo experiments" Sensors and Actuators B, 2010, in press.

[48] BARTOLAZZIA, A. et al. "A sensor array and GC study about VOCs and cancer cells" Sensors and Actuators B, 2009, in press.

[49] WINQUIST, F.; LUNDSTROM, I.; WIDE, P. "The combination of an electronic tongue and an electronic nose"Sensors and Actuators B, v. 58, p. 512-517, 1999.

[50] APETREIA, C. et al. "Combination of an e-nose, an e-tongue and an e-eye for the characterisation of olive oils with different degree of bitterness" Analytica Chimica, v. 663, p. 91-97, 2010.

[51] WIZIACK, N. K. L. et al. "A sensor array based on mass and capacitance transducers for the detection of adulterated gasolines" Sensors and Actuators B, v. 140, p. 508-513, 2009.

[52] KRANTZ-RULCKER, C. et al.; "Electronic tongues for environmental monitoring based on sensor arrays and pattern recognition: a review" Anal Chim. Acta, v.426, 217-226, 2001.

[53] D'AMICO, A.; DI NATALE. C.; MARTINELLI, E. " Introduzione all'Analisi dei dati sperimentali, ed. Aracne, 2006.

[54] WOLD .S et al. "PLS-regression: a basic tool of chemometrics" Chemometrics and Intelligent Laboratory Systems v.58 p.109-130, 2001.

[55] BARKER M.; RAYENS W "Partial least squares for discrimination" Chemometrics, v. 17 p. 166-173, 2003. 
[56] PETROBRÁS Disponível em:

http://www2.petrobras.com.br/portugues/index.asp. Acesso em 15 de fev, 2007.

[57] TEIXEIRA L. S. G. et. al. "The influence of $\mathrm{Cu}, \mathrm{Fe}, \mathrm{Ni}, \mathrm{Pb}$ and $\mathrm{Zn}$ on gum formation in the Brazilian automotive gasoline" Fuel Processing Technology, v. 88, p. 73-76, 2007.

[58] AGÊNCIA NACIONAL DO PETRÓLEO, GÁS NATURAL E BIOCOMBUSTÍVEIS - ANP. Disponível em: http://www.anp.gov.br, acesso em 5 de mar, 2007.

[59] INOVAÇÃO UNICAMP. Campinas. Disponível em: www.inovacao.unicamp.br/report/le-combustível.shtml, acesso em 8 de nov, 2006.

[60] POUSA G. P.A.G, et. al. "History and policy of biodiesel in Brazil" Energy Policy, v. 35, p. 5393-5398, 2007.

[61] GOLDEMBERG, J.; MOREIRA, R. J. "The alcohol program" Energy Policy, v. 27, p. 229-245, 1999.

[62] ANOS DO PROALCOOL. Disponível em: < www.biodieselecooleo.com.br> Acesso em 31 out, 2006.

[63] DELGADO R. C. O. B. et. al., "Properties of Brazilian gasoline mixed with hydrated ethanol for flex-fuel technology", Fuel Processing Technology, v.88, $p$. 365-368 2007.

[64] CATALUÑA R.; et. al., "Specific consumption of liquid biofuels in gasoline fuelled engines" Fuel, v. 87, p. 3362-3368, 2008.

[65] COSTA R. C.; SODRÉ, J. R. "Hydrous ethanol vs. gasoline-ethanol blend: Engine performance and emissions" Fuel, v. 89, p. 287-293, 2010.

[66] RAVAGNANIA, M. A. S. S. et. al. "A mathematical model for the composition of Brazilian ethanol shares for exportation to be blended to gasoline", Energy Policy, v. 35, p. 5060-5063, 2007. 
[67] SMEETSA, E. et. al. "The sustainability of Brazilian ethanol-An assessment of the possibilities of certified production" Biomass and bioenergy, v. 32, p. $781-813$, 2008.

[68] CPI DOS COMBUSTÍVEIS. Disponível em: <www.camara.gov.br> Acessado em 31 de out, 2006

[69] MINISTÉRIO PÚBLICO FEDERAL. Disponível em: <www.prsp.mpf.gov.br> Acessado em 20 de agosto de 2008.

[70] HAYASHI K. et al. "Multichannel taste sensor using lipid-membranes" Sensors and Actuators B, v.2, p.205-213, 1990.

[71] WINQUIST F. et al. "Monitoring of freshness of milk by an electronic tongue on the basis of voltammetry" Meas. Sci. Tech., v.9, p.1937-1946, 1998.

[72] MEDEIROS, E. S. et al. "An artificial taste sensor made of conjugated polymer nanobibers for beverages quality assessment". International Symposium of

Olfaction and Electronic Nose, p. 180-183, Espanha, 2005.

[73] DOS SANTOS, D.S. et al. "A layer-by-layer film of chitosan in a taste sensor application" Macromol. Biosci., v.3, p.591-595, 2003.

[74] GRUNDLER, P. "Chemical Sensors - An Introduction for scientists and engineers” , Ed. Springer, 2007.

[75] JANATA J. "Principles of chemical sensors" Second edition, Ed. Springer, 2009.

[76] GUSTAFSSON, G. et al. "The interaction between ammonia and poly(pyrrole)" Synthetic Metals, v. 31, p.163-179,1989.

[77] LANGE, U.; ROZNYATOVSKAYA, N. V.; MIRSKY, V. M. "Review article Conducting polymers in chemical sensors and arrays" Analytica Chimica Acta, v. 614, p. 1-26, 2008. 
[78] STEFFENS, C. et al. "Low-cost sensors developed on paper by line patterning with graphite and polyaniline coating with supercritical CO2". Synthetic Metals, v. 159, p. 2329-2332, 2009.

[79] VENANCIO, E.C. et al. "Line patterning of graphite and the fabrication of cheap, inexpensive, throw-away sensors". Sensors and Actuators. B, Chemical, v. 130, p. 723-729, 2008.

[80] HERRMANN JUNIOR, P. S. P.; VENANCIO, E. C.; MATTOSO, L. H. C.; "Disposable sensor with line patterning tecnique of graphite and polyaniline (PANI), used to detected water vapor". Encontro Nacional de Física da Matéria Condensada, São Lourenço, 2006.

[81] STEFFENS, C. et al. "Polyaniline nanofibers obtained by pressurized fluid toward gas sensors construction. SBPMat - ICAM, Rio de Janeiro, 2009.

[82] MANZOLI, A. et al. "The substrate effect in the develop disposable sensor using line patterning technique of graphite". ICAM, Rio de Janeiro, 2009.

[83] HERRMANN JUNIOR, P. S. P.; FRANCO, H. J. A.;GARCIA, A. H. S.;TORRE NETO, A.; RABELLO, L. M.; CRUVINEL, P. E. Sistema eletrônico para leitura e aquisição de dados de sensores descartáveis, aplicados à detecção de voláteis, desenvolvidos com filmes ultrafinos de poli-anilinas condutoras. São Carlos, SP: Embrapa Instrumentação Agropecuária, 2007.

[84] HERRMANN JUNIOR, P. S. P.; VENANCIO, E. C.; MATTOSO, L. H. C.; MACDIARMID, A. G. Aplicação da técnica de formação de trilhas com grafite e polímeros, nanofibras e oligômeros condutores para obtenção de sensores descartáveis. São Carlos, SP: Embrapa Instrumentação Agropecuária, 2006.

[85] ROMAIN, A. C.; NICOLAS, J. "Long term stability of metal oxide-based gas sensors for e-nose environmental applications: an overview" Sensor and actuators $\mathbf{B}$, in press.

[86] D'AMICO, A. et al. "Technologies and tools for mimicking olfaction: status of the Rome "Tor Vergata" electronic nose, Biosensors \& Bioelectronics, v. 13, p. 711721, 1998.

[87] DI NATALE, C. et al. "Kelvin probe investigation of the thickness effects in 
Langmuir-Blodgett films of pyrrolic macrocycles sensitive to volatile compounds in gas phase", Sensors and Actuators B, v. 57, p. 183-187, 1999.

[88] PAOLESSE, R, et al. "Self-assembled monolayers of mercaptoporphyrins as sensing material for quartz crystal microbalance chemical sensors" Sensors and Actuators B, v. 47, p. 70-76, 1998.

[89] D'AMICO, A. et al "Olfactory systems for medical applications" Sensors and Actuators B, Sensors and Actuators B. v. 130, p. 458-465, 2008.

[90] SOBANSKI, T. et al. "Electronic nose applied to automotive fuel qualification" Sensors and Actuators B, v. 116, p. 207-212, 2006.

[91] AERNECKE, M. J. WALT, D. R. "Optical-fiber arrays for vapor sensing" Sensors and Actuators B, V. 142, p. 464-469, 2009.

[92] BENVENHO, A. R. V.; LI, R. W. C.; GRUBER, J. "Polymeric electronic gas sensor for determining alcohol content in automotive fuels" Sensors and Actuators B, v. 136, p. 173-176, 2009.

[93] ROCHA, M.S.; SIMOES-MOREIRA J. R. "A simple impedance method for determining ethanol and regular gasoline mixtures mass contents, Fuel, v. 84, p. 447-452, 2005.

[94] TIMMA, R. A. et al. "Vanadium oxide-porphyrin nanocomposites as gas sensor interfaces for probing low water content in ethanol" Sensors and Actuators B, V 146, p. 61-68, 2010.

[95] BURATTI, S. et al. "Prediction of Italian red wine sensorial descriptors from electronic nose, electronic tongue and spectrophotometric measurements by means of Genetic Algorithm regression models" Food Chemistry, v. 100, p. 211-218, 2007.

[96] BURATTI, S. et al." Characterization and classification of Italian Barbera wines by using an electronic nose and an amperometric electronic tongue" Analytica Chimica Acta, v. 525, p. 133-139, 2004.

[97] LAUREATI, M. et al. "Discrimination and characterisation of three cultivars of Perilla frutescens by means of sensory descriptors and electronic nose and tongue analysis" Food Research International, 2010, in press. 
[98] COSIO, M. S. et al.“Evaluation of different storage conditions of extra virgin olive oils with an innovative recognition tool built by means of electronic nose and electronic tongue" Food Chemistry, v. 101, p. 485-491, 2007.

[99] WINQUIST, F. et al "A hybrid electronic tongue" Analytica Chimica Acta, v. 406, p.147-157, 2000.

[100] DI NATALE, C. et al. "Electronic nose and electronic tongue integration for improved classification of clinical and food samples", Sensors and Actuators B, v. 64 , p. $15-21,2000$.

[101] PARRA, V. et al. "E-tongue based on a hybrid array of voltammetric sensors based on phthalocyanines, perylene derivatives and conducting polymers: Discrimination capability towards red wines elaborated with different varieties of grapes" Sensors and Actuators B, v. 115, p. 54-61, 2006.

[102] FISCHER, H.; WALLACH, B. , J. Ann. Chem., v. 98, p. 468, 1926.

[103] FALK, J. E. "Porphyrins and metalloporphyrins", 1964.

[104] SMITH, K. M. "Porphyrins and metalloporphyrins" - A new edition base on the original volume by J. E. Falk“, 1975.

[105] PAOLESSE, R. et al. "Porphyrin thin coated quartz crystal microbalances prepared by electropolymerization technique" Thin Solid Films, v. 354, p. 245-250, 1999.

[106] C. DI NATALE, C. et al. "An artificial olfaction system based on the optical imaging of a large array of chemical reporters" Sensors and Actuators B, v. 142, p. 412-417, 2009.

[107] DI NATALE, C. et al. Characterization and design of porphyrins-based broad selectivity chemical sensors for electronic nose applications, Sensors and Actuators B, v. 52, p. 162-168, 1998.

[108] DE PAOLI, M.A.; MENESCAL, R.K. " Polímeros orgânicos condutores de energia elétrica" Química Nova, v.09, p.133-140, 1986. 
[109] CHIANG, C.K. et al, " Effect of uniaxial stress on electrical conductivity of sulphur nitride polymer” Phys. Rev. Lett., v.60, p.375-377, 1977.

[110] MATTOSO, L.H.C., Química Nova, 19, v.4, p.388, 1996.

[111] MACDIARMID, A.G. "Polyaniline and polypyrrole Where are we headed?" Synth. Met., v.84, p.27-34, 1997.

[112] MATTOSO, L.H.C. et al. "Studies on the chemical syntheses and on the characteristics of polyaniline derivatives" Polym. Sci: Part A: Polym. Chem, v.33, p.1227-1234, 1995.

[113] HUANG, W.S.; HUMPHREY, B.D.; MACDIARMID, A.G. J. "Polyaniline, a novel conducting polymer - morphology and chemistry of its oxidation and reduction in aqueous-electrolytes" Chem. Soc. Faraday Trans., v.82, p.2385-2400, 1986.

[114] AGBOR, N.E. et al. "Langmuir-blodgett films of polyaniline" Synthetic Metals, v. 57, p. 3789-3794, 1993.

[115] AYAD M. M.; EL-HEFNAWEY, G.; TORAD, N. L. "A sensor of alcohol vapours based on thin polyaniline base film and quartz crystal microbalance" Journal of Hazardous Materials, v. 168, p. 85-88, 2009.

[116] M. M.; TORAD, N. L "Alcohol vapours sensor based on thin polyaniline salt film and quartz crystal microbalance" Talanta, v. 78, p. 1280-1285, 2009.

[117] XIE, G. et al. "Fabrication of methane gas sensor by layer-by-layer self assembly of polyaniline/PdO ultra thin films on quartz crystal microbalance" Sensors and Actuators B, v. 145, p. 373-377, 2010.

[118] JOUBERT, M. et al. "Conducting polyaniline composite: From syntheses in waterborne systems to chemical sensor devices" Polymer, v. 51, p. 1716-1722, 2010.

[119] PATERNO, L.G.; MATTOSO, L.H.C. J. "Influence of different dopants on the adsorption, morphology, and properties of self-assembled films of poly(oethoxyaniline)" Appl. Polym. Sci., v.83, p.1309, 2002. 
[120] BLODGETT, K.B. "Films built depositing successive monomolecular layers on a solid surface", J. Am. Chem. Soc., v.57, p.1007-1022, 1935.

[121] MUSIO, F.; FERRARA, M.C. "Low frequency a.c. response of polypyrrole gas sensors" Sensors and Actuators B, v.41, p.97, 1997.

[122] TAYLOR, D.M.; MACDONALD A.G., .G., " AC admittance of the metalinsulator-electrolyte interface" J. phys. d: Appl. Phys, v.20, p.1277, 1987

[123] HOFMANN, T. et al. " Fluid characterization using sensor elements based on interdigitated electrodes” Sensors and Actuators B, v.37, p.37, 1996.

[124] MACDONALD J.R., Impedance Spectroscopy: Emphasizing Solid Materials and Systems, ed. John Wiley and Sons, New York, 1987.

[125]http://nobelprize.org/nobel_prizes/physics/laureates/1903/pierre-curie-bio.html. Acessado em 10/05/2010.

[126] SCIENCE. Disponível em: http://www.physicspost.com/science-article-26.html. Acessado em 10/05/2010.

[127] White, R.M., et. al. "Plate-Mode Ultrasonic Oscillator Sensors" IEEE Trans. Ultrason. Dev. Ferroel. Freq. Contr. UFFC-34, 162,1987.

[128] DICKERT, F. L. et al. "SAW and QMB for chemical sensing" IEEE International Frequency Control Symposium, p. 120 - 123, Orlando, FL, 1997

[129] KING, W.H. "Piezoelectric Sorption Detector" Anal Chem, v. 36, 1735-1739, 1964.

[130] KRANTZ-RULCKER, C et al.; "Electronic tongues for environmental monitoring based on sensor arrays and pattern recognition: a review" Anal Chim. Acta, v.426, 217-226, 2001.

[131] RYAN, M. A. et al. "Computational methods for sensor material selection" (integrated Analytical Systems - Series Editor: Radislav A. Potyrailo, GE Global Reserch), Springer, 2009. 
[132] POTYRAILO R. A. MIRSKY, V. M. "Combinatorial methods for chemical and biological sensors", Integrated Analytical Systems - Series Editor: Radislav A.

Potyrailo, GE Global Reserch, Ed. Springer, 2009

[133] HAYKIN, S.; Neural Networks, $2^{a}$ edição, Upper Saddle River, N.J. Prentice Hall, 1999.

[134] BARATTO, G.; "Classificador de aromas com redes neurais artificiais para um nariz eletrônico" Tese de Doutorado, Universidade de São Paulo, Brasil,1999

[135] SHAW, I. S.; SIMÕES, M. G., Controle e Modelagem Fuzzy, 1a edição, ed. Edgard Blucher, São Paulo, 1999.

[136] FORNER, A. A. C "Magnetismo em Polímeros Derivados de Politiofeno Sintetizados Eletroquimicamente" Tese de doutorado defendida na Universidade Federal de São Carlos, São Carlos, 2003.

[137] LVOVA, L. et al. "Corrole-based ion-selective electrodes"J. Porphyrins Phthalocyanines, v. 13: 1168-1178, 2009.

[138] DAVID R. LIDE "Handbook of Chemistry and Physics" CRC Press, Boca Raton.

[139] DHAWAN; S.K.; TRIVEDI, D.C. Poly(o-phenetidine) - a soluble conducting polymer: syntheses, characterization and its uses. Synth. Met.; v.60, p.67-71, 1993.

[140] SLATER, M.; PAYNTER, J.; WATT, E. J. "Multi-layer conducting polymer gas sensor arrays for olfactory sensing" Analyst, v. 188, p. 379-384, 1993.

[141] BRUNINK, J. et al. "The application of metalloporphyrins as coating materials for quartz microbalance based chemical sensors", Anal. Chim. Acta, v. 325, p. 53641996.

[142] WIZIACK, N. K. L. et al.. Pulsed Gas Delivery as a Method for Reproducibility Enhancement in Chemical Sensors. In: EUROSENSORS XXII, Dresden, Alemanha, 2008. 


\section{APÊNDICE A: CONFECÇÃO DOS MICROELETRODOS}

Através das máscaras fabricadas a partir do layout gerado em AutoCad são fabricados os microeletrodos. A confecção dos microeletrodos foi feita na Sala Limpa do Laboratório de Microeletrônica da Escola Politécnica da USP.

Inicialmente foram depositados em seqüência $\mathrm{NiCr}$ e ouro pela técnica de sputtering sobre as placas de vidro utilizadas como substrato. Essa camada de ouro depositada sobre os vidros tem uma espessura de aproximadamente 2000 angstrons.

Com substratos cobertos por uma fina película de ouro, o processo de fotogravação é iniciado. Primeiro é aplicado o fotoresiste positivo através de spinner. O espalhamento do produto é uniforme e feito à rotação de 4000 rpm por 30 segundos. Após a aplicação do fotoresiste, o substrato de vidro é colocado numa estufa por 20 minutos, a $80^{\circ} \mathrm{C}$.

A fotogravação do microeletrodo no substrato de vidro é feita utilizando-se a fotomáscara descrita anteriormente. O substrato de vidro, juntamente com a fotomáscara, é exposto durante aproximadamente 5 segundos à radiação ultravioleta. Neste processo, a parte do fotoresiste que foi exposta à radiação ultravioleta será eliminada na etapa de revelação.

Em seguida, o substrato de vidro é colocado em um revelador. Após a revelação (ou seja, a remoção do fotoresiste que recebeu a radiação ultravioleta) é feita uma verificação no microscópio dos dígitos dos microeletrodos para detecção de eventuais falhas no momento da revelação. O sensor é colocado mais uma vez na estufa por 30 minutos a uma temperatura de $100^{\circ} \mathrm{C}$.

O substrato de vidro coberto de ouro possui o desenho do microeletrodo gravado em sua superfície. A partir disso é feita uma corrosão do microeletrodo, onde restará apenas a camada de ouro coberta pelo fotoresiste. No processo de corrosão, o primeiro passo é retirar a camada de ouro, utilizando a solução para corrosão de ouro. Em seguida é retirada a camada de níquel-cromo.

Após o processo de corrosão, é feita mais uma verificação dos microeletrodos através de um microscópio óptico, para a identificação de eventuais curtos entre os dígitos. Feita a verificação, o fotoresiste é removido com acetona. O microeletrodo está pronto. 


\section{APÊNDICE B: PUBLICAÇÕES E PARTICIPAÇÕES EM CONGRESSOS CIENTÍFICOS}

[1] Gregorut, C., Silva, J.B., Wiziack,N.K.L, Paterno, L.G., Panizzi, M.C.C., Fonseca, F.J. Appliction of electronic tongue in identification of soybeans. ISOEN 2009, Brescia, Italy. AIP Conference Procedings, v 1137, 2009.

[2] Ozaki, S.T.R., Wiziack,N.K.L, Paterno, L.G., Fonseca, F. J. Classification of fuels using multilayer perceptron neuralnetworks. Isoen 2009, Brescia, Italy. AIP Conference Procedings, v 1137, 2009.

[3] Wiziack, N. K. L.; Catini A. ; Santonico M.; D'Amico A..; Paolesse R.; Paterno L.G.; Fonseca F.J.; Di Natale, C. A sensor array based on mass and capacitance transducers for the detection of adulterated gasolines. Sensors and Actuators. B, Chemical, v. 140, p. 508-513, 2009.

[4] Wiziack, N. K. L.; Correa A.A.; Mattoso L.H.C.; Fonseca F.J., Fuel adulteration detection using a hybrid system: Electronic tongue and Electronic nose. In press: ISAMN, Santo André, Brazil, 2009.

[5] Wiziack, N. K. L.; Martinelli, E.; Santonico M.; Paolesse R.; D'Amico A.; Fonseca F.J.; Di Natale, C. Pulsed Gas Delivery as a Method for Reproducibility Enhancement in Chemical Sensors. In: EUROSENSORS XXII, Dresden, Germany, 2008.

[6] Wiziack, N. K. L.; Catini A. ; Santonico M.; Mantini G.; Paolesse R.; Paterno L.G.; D'Amico A.; Fonseca F.J.; Di Natale, C. A Hibrid Sensor Array for Adulterated Gasoline Detection. In: IMCS, Ohio, USA 2008.

[7] Wiziack, N. K. L.; Catini A. ; Santonico M.; Mantini G.; D'Amico A.; Paolesse R.; Fonseca F.J.; Di Natale, C. Detection of gasoline samples adulteration with a capacitances array and quartz microbalances. In: AISEM, Rome, Italy, 2008.

[8] WIZIACK, N. K. L. ; Paterno L.G. ; Fonseca, F. J. ; Mattoso, L. H. C. " Effect of film thickness and different electrode geometries on the performance of chemical sensors made of nanostructured conducting polymer films" Sensors and Actuators. B, Chemical, v. 1, p. 10-20, 2006.

[9]Garnica, L. A. ; WIZIACK, N. K. L. ; SANTOS, S. A. "Transferência de tecnologia por meio da criação de empresas de base tecnológica: um estudo multicaso de 
licenciamento de patentes da Embrapa e UFSCar" In: XXVI ENEGEP, 2006, Fortaleza. XXVI ENEGEP, 2006.

[10] WIZIACK N.K.L., PATERNO L.G., KANNO F.H., FONSECA F.J., NAIME J.M., MATTOSO L.H.C. "Fabrication of POEA/PSS films by the Self-Assembly technique nd their utilization in an eletronic tongue" In: BRASILIAN WORKSHOP ON SEMICONDUCTOR PHYSICS, 12, São José dos Campos, 2005.

[11] PATERNO L.G., WIZIACK N.K.L, KANNO F.H., FONSECA F.J., NAIME J.M., BRUGNOLLO E. D.; MATTOSO L.H.C.; "Evaluation of the performance of nanostructered films of poly(o-ethoxyaniline)/sulfonated polystyrene as sensing units in an electronic tongue" In: ENCONTRO DA REDE NANOBIOTEC, São Pedro, SP, 2005.

[12] WIZIACK N.K.L, KANNO F.H, FONSECA F.J, PATERNO L.G.; MATTOSO L.H.C."Interdigitated microelectrodes of different geometries for application in electronic tongue based on conducting polymers" In: INTERNATIONAL SYMPOSIUM ON ELECTRETS, 12, Salvador, BA, 2005.

[13] PATERNO L.G.; WIZIACK N.K.L.; KANNO F.H, FONSECA F.J, MATTOSO L.H.C."Nanostructered films of poly(o-ethoxyaniline) and sulfonated polysterene as sensing parts for taste sensor development" In: INTERNATIONAL SYMPOSIUM ON ELECTRETS, 12, Salvador, BA, 2005.

[14] PATERNO L. G., WIZIACK N. K. L , KANO F. H., NAIME J. M., FONSECA F. J. AND. MATTOSO L. H. C "Nanostructured films of poly(o-ethoxyaniline) for taste sensor application” In: EUROSENSORS, XVIII, Roma, Itália, 2004.

[15] WIZIACK N.K.L, KANNO F.H, FONSECA F.J, PATERNO L.G.; NAIME J.M; "MATTOSO L.H.C. "Evaluation of the electrical properties of POEA/PSS layerby-layer films and their utilization as sensing parts in an electronic tongue" III ENCONTRO DA SBPMAT, BRASILIAN MRS MEETING, 3, Fóz do Iguaçu, 2004

[16] WIZIACK N.K.L, PATERNO L.G., FONSECA F.J, "MATTOSO L.H.C. "Influence of different microelectrode geometry on the performance ofan electronic tongue based on nanostructured conducting polymer films" IMMP, Workshop Milenio, Atibaia, 2006. 


\section{ANEXO A}

REGULAMENTO TÉCNICO ANP № 7/2005

\section{Objetivo}

Este Regulamento Técnico aplica-se ao Álcool Etílico Anidro Combustível (AEAC) e ao Álcool Etílico Hidratado Combustível (AEHC), nacional ou importado, para uso como combustível e estabelece as suas especificações.

\section{Normas complementares}

A determinação das características do produto far-se-á médiante o emprego de Normas Brasileiras (NBR) da Associação Brasileira de Normas Técnicas (ABNT) ou das Normas da American Society for Testing and Materials (ASTM).

Os dados de exatidão, repetitividade e reprodutibilidade fornecidos nos métodos relacionados a seguir devem ser usados somente como guia para aceitação das determinações em duplicata do ensaio e não devem ser considerados como tolerância aplicada aos limites especificados neste Regulamento.

A análise do produto deverá ser realizada em amostra representativa do mesmo, coletada segundo as normas ASTM D4057 - Practice for Manual Sampling of Petroleum and Petroleum Products ou ASTM E300 - Practice for Sampling Industrial Chemicals.

3. As características constantes da Tabela das Especificações deverão ser determinadas de acordo com a publicação mais recente dos seguintes métodos de ensaio:

\begin{tabular}{|l|l|}
\hline MÉTODO & TíTULO \\
\hline NBR 5992 & $\begin{array}{l}\text { Determinação da massa específica e do teor alcoólico do } \\
\text { Álcool Etílico e suas misturas com água }\end{array}$ \\
\hline
\end{tabular}




\begin{tabular}{|c|c|}
\hline NBR 8644 & $\begin{array}{l}\text { Álcool Etílico Combustível - Determinação do resíduo por } \\
\text { evaporação }\end{array}$ \\
\hline NBR 9866 & $\begin{array}{l}\text { Álcool Etílico - Verificação da alcalinidade e determinação da } \\
\text { acidez total }\end{array}$ \\
\hline NBR 10422 & $\begin{array}{l}\text { Álcool Etílico - Determinação do teor de sódio por fotometria } \\
\text { de chama }\end{array}$ \\
\hline NBR 10547 & Álcool Etílico - Determinação da condutividade elétrica \\
\hline NBR 10891 & Álcool Etílico Hidratado - Determinação do pH \\
\hline NBR 10893 & $\begin{array}{l}\text { Álcool Etílico - Determinação do teor do cobre por } \\
\text { espectrofotometria de absorção atômica }\end{array}$ \\
\hline NBR 10894 & $\begin{array}{l}\text { Álcool Etílico - Determinação dos íons cloreto e sulfato por } \\
\text { cromatografia iônica }\end{array}$ \\
\hline NBR 10895 & $\begin{array}{l}\text { Álcool Etílico - Determinação do teor de íon cloreto por } \\
\text { técnica potenciométrica }\end{array}$ \\
\hline NBR 11331 & $\begin{array}{l}\text { Álcool Etílico - Determinação do teor de ferro por } \\
\text { espectrofotometria de absorção atômica }\end{array}$ \\
\hline NBR 12120 & $\begin{array}{l}\text { Álcool Etílico - Determinação do teor de sulfato por } \\
\text { volumetria }\end{array}$ \\
\hline NBR 13993 & Álcool Etílico - Determinação do teor de hidrocarbonetos \\
\hline ASTM D512 & Chloride Ion in Water \\
\hline ASTM D1125 & Electrical Conductivity and Resistivity of Water \\
\hline ASTM D1613 & $\begin{array}{l}\text { Acidity in Volatile Solvents and Chemical Intermédiates Used } \\
\text { in Paint, Varnish, Lacquer and Related Products }\end{array}$ \\
\hline
\end{tabular}




\begin{tabular}{|l|l|}
\hline ASTM D4052 & $\begin{array}{l}\text { Density and Relative Density of Liquids by Digital Density } \\
\text { Meter }\end{array}$ \\
\hline ASTM D5501 & $\begin{array}{l}\text { Determination of Ethanol Content of Denatured Fuel Ethanol } \\
\text { by Gas Chromatography }\end{array}$ \\
\hline
\end{tabular}

Tabela I - Especificações do AEAC e do AEHC

\begin{tabular}{|c|c|c|c|c|c|}
\hline \multirow{2}{*}{ CARACTERÍSTICA } & \multirow[t]{2}{*}{ UNIDADE } & \multicolumn{2}{|c|}{ ESPECIFICAÇÕES } & \multicolumn{2}{|l|}{ MÉTODO } \\
\hline & & AEAC & $\mathrm{AEHC}$ & ABNT/NBR & $\begin{array}{l}\text { ASTM } \\
\text { (1) }\end{array}$ \\
\hline Aspecto & - & (2) & (2) & \multicolumn{2}{|l|}{ Visual } \\
\hline Cor & - & (3) & (4) & \multicolumn{2}{|l|}{ Visual } \\
\hline $\begin{array}{l}\text { Acidez total (como } \\
\text { ácido acético), máx. }\end{array}$ & $\mathrm{mg} / \mathrm{L}$ & 30 & 30 & 9866 & $\begin{array}{l}D \\
1613\end{array}$ \\
\hline $\begin{array}{l}\text { Condutividade elétrica, } \\
\operatorname{Max}\end{array}$ & $\mu \mathrm{S} / \mathrm{m}$ & 500 & 500 & 10547 & $\begin{array}{l}D \\
1125\end{array}$ \\
\hline $\begin{array}{l}\text { Massa específica a } \\
20^{\circ} \mathrm{C}\end{array}$ & $\mathrm{kg} / \mathrm{m} 3$ & $\begin{array}{l}791,5 \\
\text { máx. }\end{array}$ & $\begin{array}{l}807,6 \quad a \\
811,0(5)\end{array}$ & 5992 & $\begin{array}{l}D \\
4052\end{array}$ \\
\hline Teor alcoólico & oINPM & $\begin{array}{l}99,3 \\
\text { mín. }\end{array}$ & $\begin{array}{l}92,6 \quad a \\
93,8(5)\end{array}$ & 5992 & - \\
\hline $\begin{array}{l}\text { Potencial } \\
\text { hidrogeniônico }(\mathrm{pH})\end{array}$ & - & - & 6,0 a 8,0 & 10891 & - \\
\hline
\end{tabular}




\begin{tabular}{|l|l|l|l|l|l|}
\hline $\begin{array}{l}\text { Resíduo por } \\
\text { evaporação, máx. (6) }\end{array}$ & $\mathrm{mg} / 100 \mathrm{Ml}$ & - & 5 & 8644 & - \\
\hline $\begin{array}{l}\text { Teor de } \\
\text { hidrocarbonetos, } \\
\text { máx.(6) }\end{array}$ & $\%$ vol. & 3,0 & 3,0 & 13993 & - \\
\hline Íon Cloreto, máx. (6) & $\mathrm{mg} / \mathrm{kg}$ & - & 1 & $10894 / 10895$ & $\begin{array}{l}\mathrm{D} \\
512(7)\end{array}$ \\
\hline Teor de etanol, mín. (8) & $\% \mathrm{vol}$. & 99,6 & 95,1 & - & $\begin{array}{l}\mathrm{D} \\
5501\end{array}$ \\
\hline Íon Sulfato, máx.(9) & $\mathrm{mg} / \mathrm{kg}$ & - & 4 & $10894 / 12120$ & - \\
\hline Ferro, máx. (9) & $\mathrm{mg} / \mathrm{kg}$ & - & 5 & 11331 & - \\
\hline Sódio, máx. (9) & $\mathrm{mg} / \mathrm{kg}$ & - & 2 & 10422 & - \\
\hline Cobre, máx. (9) (10) & $\mathrm{mg} / \mathrm{kg}$ & 0,07 & - & 10893 & - \\
\hline
\end{tabular}

(1) Poderão ser utilizados como métodos alternativos para avaliação das características nos casos de importação do álcool, com exceção do método ASTM D4052, que poderá ser sempre utilizado como método alternativo para a determinação da massa específica.

(2) Límpido e isento de impurezas.

(3) Incolor antes da adição de corante, segundo especificação constante da Tabela II deste Regulamento Técnico, que deverá ser adicionado no teor de $15 \mathrm{mg} / \mathrm{L}$ proporcionando ao produto a cor laranja.

(4) Incolor.

(5) Aplicam-se na Importação, Distribuição e Revenda os seguintes limites para massa específica e teor alcoólico do AEHC: 805,0 a 811,0 e 92,6 a 94,7 respectivamente. 
(6) Limite requerido na Importação, Distribuição e Revenda, não sendo exigida esta análise para emissão do Certificado da Qualidade pelos Produtores.

(7) Procedimento C e modificação constante na ASTM D4806.

(8) Requerido quando o álcool não for produzido por via fermentativa a partir da cana-de-açúcar ou em caso de dúvida quando da possibilidade de contaminação por outros tipos de álcool.

(9) O produtor deverá transcrever no Certificado da Qualidade o resultado obtido na última determinação quinzenal, conforme previsto no $\S 1^{\circ}$ do Art. $5^{\circ}$ da presente Resolução.

(10) Deverá ser determinado no AEAC que tiver sido transportado ou produzido em local que possua equipamentos ou linhas de cobre, ou ligas que contenham este metal.

Tabela II - Especificação do corante a ser adicionado ao álcool etílico anidro combustível (AEAC)

\begin{tabular}{|l|l|l|}
\hline Característica & Especificação & Método \\
\hline $\begin{array}{l}\text { Aspecto líquido visual } \\
\text { Família química ("Color } \\
\text { index") }\end{array}$ & Solvent Red 19 ou Solvent Red 164 & - \\
\cline { 2 - 3 } & Solvent Yellow 174 & - \\
\hline Cor & Laranja & visual \\
\hline Absorvância a $420 \mathrm{~nm}$ & 0,150 a 0,190 & $\left({ }^{*}\right)$ \\
\hline Absorvância a $530 \mathrm{~nm}$ & 0,100 a 0,135 & $\begin{array}{l}\text { visual } \\
(* *)\end{array}$ \\
\hline Solubilidade & solúvel em AEAC e insolúvel em água & \\
\hline
\end{tabular}


${ }^{*}$ *) A absorbância deve ser determinada em amostra contendo $15 \mathrm{mg} / \mathrm{L}$ do corante em AEAC, medida em célula de caminho ótico de $1 \mathrm{~cm}$, no valor especificado para o comprimento de onda.

$\left.{ }^{(* *}\right)$ A solubilidade deve ser avaliada em amostra contendo $15 \mathrm{mg} / \mathrm{L}$ do corante em AEAC. 


\section{ANEXO B}

\section{REGULAMENTO TÉCNICO ANP № 2/2009}

Objetivo

Este Regulamento Técnico aplica-se à gasolina de referência para utilização nos ensaios de avaliação de consumo de combustível e emissões veiculares para fins de homologação, segundo os critérios fixados para a etapa L-6 do PROCONVE, e estabelece sua especificação.

Normas aplicáveis

A determinação das características da gasolina de referência será realizada médiante o emprego das normas da Associação Brasileira de Normas Técnicas (ABNT) e da American Society for Testing and Materials (ASTM).

Os dados de precisão, repetitividade e reprodutibilidade, fornecidos nos métodos relacionados neste Regulamento, devem ser utilizados somente como guia para aceitação das determinações em duplicata do ensaio e não devem ser considerados como tolerância aplicada aos limites especificados.

A análise do produto deverá ser realizada em amostra representativa do mesmo, obtida segundo método NBR 14883 - Petróleo e produtos de petróleo - Amostragem manual ou ASTM D4057 - Practice for Manual Sampling of Petroleum and Petroleum Products.

As características incluídas na Tabela I deverão ser determinadas de acordo com a publicação mais recente dos seguintes métodos de ensaio: 
2.1. Métodos ABNT

\begin{tabular}{|c|c|}
\hline MÉTODO & TíTULO \\
\hline ABNT NBR 7148 & $\begin{array}{l}\text { Petróleo e produtos de petróleo - Determinação da massa } \\
\text { específica, densidade relativa e }{ }^{\circ} \mathrm{API} \text { - Método do } \\
\text { densímetro }\end{array}$ \\
\hline ABNT NBR 9619 & Produtos de petróleo - Destilação à pressão atmosférica \\
\hline ABNT NBR 13992 & $\begin{array}{l}\text { Gasolina automotiva - Determinação do teor de álcool } \\
\text { etílico anidro combustível AEAC }\end{array}$ \\
\hline ABNT NBR 14065 & $\begin{array}{l}\text { Destilados de petróleo e óleos viscosos - Determinação da } \\
\text { massa específica e da densidade relativa pelo densímetro } \\
\text { digital. }\end{array}$ \\
\hline ABNT NBR 14149 & $\begin{array}{l}\text { Gasolina e misturas de gasolina com produtos oxigenados - } \\
\text { Determinação da pressão de vapor pelo método seco }\end{array}$ \\
\hline ABNT NBR 14156 & $\begin{array}{l}\text { Produtos de petróleo - Determinação da pressão de vapor - } \\
\text { Minimétodo }\end{array}$ \\
\hline ABNT NBR 14359 & $\begin{array}{l}\text { Produtos de petróleo - Determinação da corrosividade - } \\
\text { Método da lâmina de cobre }\end{array}$ \\
\hline ABNT NBR 14478 & $\begin{array}{l}\text { Gasolina - Determinação da estabilidade à oxidação pelo } \\
\text { método do período de indução }\end{array}$ \\
\hline ABNT NBR 14525 & Combustíveis - Determinação de goma por evaporação \\
\hline ABNT NBR 14932 & $\begin{array}{l}\text { Produtos líquidos de petróleo - Determinação dos tipos de } \\
\text { hidrocarbonetos pelo indicador de absorção por } \\
\text { fluorescência }\end{array}$ \\
\hline
\end{tabular}




\begin{tabular}{|l|l|}
\hline ABNT NBR 14954 & Combustível destilado - Determinação da aparência \\
\hline ABNT NBR 15289 & $\begin{array}{l}\text { Determinação de benzeno e tolueno por cromatografia em } \\
\text { fase gasosa }\end{array}$ \\
\hline ABNT NBR 15441 & $\begin{array}{l}\text { Combustíveis de motores a explosão - Determinação de } \\
\text { benzeno por espectroscopia de infravermelho médio }\end{array}$ \\
\hline
\end{tabular}

2.2. Métodos ASTM

\begin{tabular}{|l|l|}
\hline MÉTODO & TíTULO \\
\hline ASTM D86 & Distillation of Petroleum Products at Atmospheric Pressure \\
\hline ASTM D130 & $\begin{array}{l}\text { Corrosiveness to Copper from Petroleum Products by Copper } \\
\text { Strip Test }\end{array}$ \\
\hline ASTM D381 & Gum Content in Fuels by Jet Evaporation \\
\hline ASTM D525 & Oxidation Stability of Gasoline (Induction Period Method) \\
\hline ASTM D1298 & $\begin{array}{l}\text { Density, Relative Density (Specific Gravity) or API Gravity of } \\
\text { Crude Petroleum and Liquid Petroleum Products by Hydrometer } \\
\text { Method }\end{array}$ \\
\hline ASTM D1319 & $\begin{array}{l}\text { Hydrocarbon Types in Liquid Petroleum Product by Fluorescent } \\
\text { Indicator Adsorption }\end{array}$ \\
\hline ASTM D2622 & $\begin{array}{l}\text { Sulfur in Petroleum Products by Wavelength Dispersive X-ray } \\
\text { Fluorescence Spectrometry }\end{array}$ \\
\hline ASTM D2699 & Research Octane Number of Spark-Ignition Engine Fuel \\
\hline ASTM D2700 & Motor Octane Number of Spark-lgnition Engine Fuel \\
\hline
\end{tabular}




\begin{tabular}{|c|c|}
\hline ASTM D3120 & $\begin{array}{l}\text { Trace Quantities of Sulfur in Light Liquid Petroleum } \\
\text { Hydrocarbons by Oxidative Microcoulometry }\end{array}$ \\
\hline ASTM D3231 & Phosphorus in Gasoline \\
\hline ASTM D3237 & Lead in Gasoline by Atomic Absorption Spectroscopy \\
\hline ASTM D3606 & $\begin{array}{l}\text { Determination of Benzene and Toluene in Finished Motor and } \\
\text { Aviation Gasoline by Gas Chromatography }\end{array}$ \\
\hline ASTM D4052 & Density and Relative Density of Liquids by Digital Density Meter \\
\hline ASTM D4176 & $\begin{array}{l}\text { Free Water and Particulate Contamination in Distillate Fuels } \\
\text { (Visual Inspection Procedures) }\end{array}$ \\
\hline ASTM D4953 & $\begin{array}{l}\text { Vapor Pressure of Gasoline and Gasoline-Oxygenate Blends } \\
\text { (Dry Method) }\end{array}$ \\
\hline ASTM D5190 & Vapor Pressure of Petroleum Products (Automatic Method) \\
\hline ASTM D5191 & Vapor Pressure of Petroleum Products (Mini Method) \\
\hline ASTM D5443 & $\begin{array}{l}\text { Paraffin, Naphthene, and Aromatic Hydrocarbon Type Analysis in } \\
\text { Petroleum Distillates Through } 200^{\circ} \mathrm{C} \text { by Multi-Dimensional Gas } \\
\text { Chromatography }\end{array}$ \\
\hline ASTM D5453 & $\begin{array}{l}\text { Determination of Total Sulfur in Light Hydrocarbons, Spark } \\
\text { Ignition Engine Fuel, Diesel Engine Fuel, and Engine Oil by } \\
\text { Ultraviolet Fluorescence }\end{array}$ \\
\hline ASTM D5482 & $\begin{array}{l}\text { Vapor Pressure of Petroleum Products (Mini Method - } \\
\text { Atmospheric) }\end{array}$ \\
\hline ASTM D6277 & $\begin{array}{l}\text { Determination of Benzene in Spark-Ignition Engine Fuels Using } \\
\text { Mid Infrared Spectroscopy }\end{array}$ \\
\hline
\end{tabular}


ASTM D7039

Sulfur in Gasoline and Diesel Fuel by Monochromatic Wavelength Dispersive X-ray Fluorescence Spectrometry

Tabela I - Especificação da Gasolina de Referência para Ensaios de Consumo e Emissões.

\begin{tabular}{|c|c|c|c|c|c|}
\hline \multirow{2}{*}{$\begin{array}{l}\text { CARACTERÍSTIC } \\
\text { A }\end{array}$} & \multirow{2}{*}{$\begin{array}{l}\text { UNIDA- } \\
\text { DE }\end{array}$} & \multicolumn{2}{|l|}{ LIMITE } & \multicolumn{2}{|l|}{ MÉTODO } \\
\hline & & $\begin{array}{l}\text { Gasoli- } \\
\text { na A }\end{array}$ & $\begin{array}{l}\text { Gasoli- } \\
\text { na C }\end{array}$ & $\begin{array}{l}\text { ABNT/NB } \\
\mathbf{R}\end{array}$ & ASTM \\
\hline Aspecto & & LIMS (1) & LIMS (1) & $14954(2)$ & $\begin{array}{l}\text { D4176 } \\
\text { (2) }\end{array}$ \\
\hline $\begin{array}{l}\text { Teor de Álcool } \\
\text { Etílico Anidro } \\
\text { Combustível - } \\
\text { AEAC (3) }\end{array}$ & $\begin{array}{l}\% \\
\text { volume }\end{array}$ & Isento & $22 \pm 1$ & 13992 & - \\
\hline $\begin{array}{l}\text { Massa específica } \\
\text { a } 20^{\circ} \mathrm{C}\end{array}$ & $\mathrm{kg} / \mathrm{m}^{3}$ & $\begin{array}{l}720,0 \text { a } \\
758,0\end{array}$ & $\begin{array}{l}735,0 \quad a \\
765,0\end{array}$ & $\begin{array}{l}7148 \\
14065\end{array}$ & $\begin{array}{l}\text { D1298 } \\
\text { D4052 }\end{array}$ \\
\hline \multicolumn{4}{|l|}{ Destilação } & 9619 & D86 \\
\hline $\begin{array}{l}\text { PIE (Ponto Inicial } \\
\text { de Ebulição) }\end{array}$ & $\stackrel{\circ}{C}$ & $\begin{array}{l}30,0 \quad a \\
40,0\end{array}$ & - & & \\
\hline $\begin{array}{ll}10 \% & \text { vol., } \\
\text { evaporados } & \end{array}$ & & $\begin{array}{ll}45,0 & a \\
60,0 & \end{array}$ & - & & \\
\hline $\begin{array}{ll}50 \% & \text { vol., } \\
\text { evaporados } & \end{array}$ & & $\begin{array}{l}90,0 \text { a } \\
110,0\end{array}$ & - & & \\
\hline
\end{tabular}




\begin{tabular}{|c|c|c|c|c|c|}
\hline $\begin{array}{ll}90 \% & \text { vol., } \\
\text { evaporados } & \end{array}$ & & $\begin{array}{l}149,0 \text { a } \\
170,0\end{array}$ & - & & \\
\hline $\begin{array}{l}\text { PFE (Ponto Final } \\
\text { de Ebulição) }\end{array}$ & & $\begin{array}{l}195,0 \text { a } \\
213,0\end{array}$ & - & & \\
\hline Resíduo, Max & $\%$ volume & 2,0 & - & & \\
\hline $\begin{array}{ll}\text { № de } & \text { Octano } \\
\text { Motor } & \text { (MON), } \\
\text { mín. } & \end{array}$ & - & - & 82,0 & - & D2700 \\
\hline $\begin{array}{ll}\text { No de } & \text { Octano } \\
\text { Pesquisa } & \text { (RON), } \\
\text { mín. } & \end{array}$ & - & - & 93,0 & - & D2699 \\
\hline $\begin{array}{l}\text { Pressão de vapor } \\
\text { a } 37,8^{\circ} \mathrm{C}\end{array}$ & $\mathrm{kPa}$ & - & $\begin{array}{l}54,0 \quad a \\
64,0\end{array}$ & $\begin{array}{l}14149 \\
- \\
14156 \\
-\end{array}$ & $\begin{array}{l}\text { D4953 } \\
\text { D5190 } \\
\text { D5191 } \\
\text { D5482 }\end{array}$ \\
\hline $\begin{array}{l}\text { Goma atual } \\
\text { lavada, máx. }\end{array}$ & $\begin{array}{l}\mathrm{mg} / 100 \mathrm{~m} \\
\mathrm{~L}\end{array}$ & 4,0 & 4,0 & 14525 & D381 \\
\hline $\begin{array}{l}\text { Período de } \\
\text { indução a } 100^{\circ} \mathrm{C} \text {, } \\
\text { mín. }\end{array}$ & minuto & - & 1000 & 14478 & D525 \\
\hline $\begin{array}{l}\text { Corrosividade ao } \\
\text { cobre, 3h } 50^{\circ} \mathrm{C} \text {, } \\
\text { máx. }\end{array}$ & - & 1 & 1 & 14359 & D130 \\
\hline
\end{tabular}




\begin{tabular}{|c|c|c|c|c|c|}
\hline Enxofre, máx. & $\mathrm{mg} / \mathrm{kg}$ & 50 & 50 & $\begin{array}{l}- \\
- \\
-\end{array}$ & $\begin{array}{l}\text { D2622 } \\
\text { D3120D5 } \\
453 \\
\text { D7039 }\end{array}$ \\
\hline $\begin{array}{l}\text { Chumbo, máx. } \\
\text { (4) }\end{array}$ & $g / L$ & 0,005 & 0,005 & - & D3237 \\
\hline Fósforo, máx. (4) & $g / L$ & 0,005 & 0,005 & - & D3231 \\
\hline Benzeno, máx. & $\%$ volume & 1,0 & 1,0 & $\begin{array}{l}15289 \\
- \\
15441\end{array}$ & $\begin{array}{l}\text { D3606 } \\
\text { D5443 } \\
\text { D6277 }\end{array}$ \\
\hline \multicolumn{4}{|l|}{ Hidrocarbonetos } & 14932 & D1319 \\
\hline $\begin{array}{l}\text { Aromáticos, } \\
\text { máx. (5) }\end{array}$ & $\%$ volume & 35,0 & - & & \\
\hline $\begin{array}{l}\text { Olefínicos, máx. } \\
\text { (5) }\end{array}$ & & 15,0 & - & & \\
\hline $\begin{array}{l}\text { Saturados, máx. } \\
\text { (5) }\end{array}$ & & Anotar & - & & \\
\hline
\end{tabular}

(1) Límpida e isenta de água ou material em suspensão, conforme condições determinadas nos métodos especificados para avaliação do Aspecto.

(2) Procedimento 1.

(3) AEAC deverá estar em conformidade com a especificação do álcool etílico anidro combustível de referência para ensaios de avaliação de consumo de combustível e emissões veiculares para homologação de veículos automotores, estabelecida pela legislação em vigor. 
(4) Proibida adição de qualquer composto contendo fósforo ou chumbo. Esta característica deverá ser analisada quando houver dúvida quanto à ocorrência de contaminação.

(5) Alternativamente é permitida a determinação dos hidrocarbonetos aromáticos, olefínicos e saturados por cromatografia gasosa. Em caso de desacordo entre resultados prevalecerão os valores determinados pelos ensaios ABNT NBR no 14932/ASTM D1319. 